University of Louisville

ThinkIR: The University of Louisville's Institutional Repository

Electronic Theses and Dissertations

$5-2021$

\title{
A translingual approach to the theory and practice of basic writing.
}

Rachel Rodriguez

University of Louisville

Follow this and additional works at: https://ir.library.louisville.edu/etd

Part of the Language and Literacy Education Commons

\section{Recommended Citation}

Rodriguez, Rachel, "A translingual approach to the theory and practice of basic writing." (2021). Electronic Theses and Dissertations. Paper 3610.

https://doi.org/10.18297/etd/3610

This Doctoral Dissertation is brought to you for free and open access by ThinkIR: The University of Louisville's Institutional Repository. It has been accepted for inclusion in Electronic Theses and Dissertations by an authorized administrator of ThinkIR: The University of Louisville's Institutional Repository. This title appears here courtesy of the author, who has retained all other copyrights. For more information, please contact thinkir@louisville.edu. 


\title{
A TRANSLINGUAL APPROACH TO THE THEORY AND PRACTICE OF BASIC WRITING
}

\author{
By \\ Rachel Rodriguez \\ B.A., McDaniel College, 2009 \\ M.A., University of Maine, 2011 \\ A Dissertation \\ Submitted to the Faculty of the \\ College of Arts and Sciences of the University of Louisville \\ in Partial Fulfillment of the Requirements \\ for the Degree of \\ Doctor of Philosophy \\ In English/Rhetoric and Composition \\ Department of English \\ University of Louisville \\ Louisville, KY
}

May 2021 
Copyright (C) 2021 by Rachel Rodriguez

All rights reserved 

A TRANSLINGUAL APPROACH TO THE THEORY AND PRACTICE OF BASIC

\author{
WRITING \\ By \\ Rachel Rodriguez \\ B.A., McDaniel College, 2009 \\ M.A., University of Maine, 2011 \\ A Dissertation Approved on
}

April 14, 2021

by the following Dissertation Committee:

Bruce Horner

Karen Kopelson

Frank Kelderman

John Trimbur 


\section{DEDICATION}

This dissertation is dedicated to my husband, Williams. You believed in me more than I believed in myself. Without you, I never would have had the courage to try. 


\section{ACKNOWLEDGEMENTS}

I extend my appreciation to my committee for their advice and encouragement throughout the writing and revision process. I especially thank my director Bruce Horner for his guidance. I am also grateful to the English graduate students at the University of Louisville, both former and present, for their mentorship, friendship, and support. I heartily thank all of my former students, especially the basic writers, for sharing their stories and their language with me. To my parents Tom and Beth Pyles, for instilling in me a lifelong love of reading and of languages, dziękuję. Lacy Kline, thank you for always being there to talk me through it. And to my son Joaquin, I will be forever grateful for the joy you brought me as I wrote this dissertation. Que crezcas en un mundo que valore todas las posibilidades de tu herencia lingüística. 


\begin{abstract}
A TRANSLINGUAL APPROACH TO THE THEORY AND PRACTICE OF BASIC WRITING

Rachel Rodriguez

April 14, 2021

Linguistic justice and the treatment of language difference are of great concern to the discipline of rhetoric and composition. Yet, basic writing, arguably the field's richest source of language variation, has not received the full benefit of what has been termed the "translingual turn" (Alvarez; Corcoran; Hall; Jackson; Kubota). This dissertation explores the role of language ideologies in the theory and practice of basic writing, culminating in a review and critique of current uptakes of translingualism in basic writing scholarship. Overall, I find that greater attention needs to be paid to the translingual potential of seemingly conventional language as well as classrooms comprised of so-called monolingual students. Chapter one investigates the field's changing perceptions of the basic writer, their languaging, and their place in the university. I argue that shifting language ideologies exert change upon approaches to basic writing; our field's ideological stance toward basic writers has been shaped by and has shaped our stance toward language difference. Chapter two explores the treatment of error and writing standards in basic writing scholarship of the past fifty years, and articulates how theoretical approaches to basic writing, including translingualism, respond to so-called
\end{abstract}


error. Chapter three focuses on basic writing pedagogy, examining translingual potential and missed opportunity in extant scholarship on language ideology and language difference. I find that latent translingualism is evident in basic writing scholarship published before the coinage of the term. In a similar vein, chapter four centers on basic writing placement practices and programmatic development, assessing the translinguality of models currently being enacted. Ultimately, this project works to expand disciplinary understanding of the histories of basic writing and ideologies of language difference, and sheds light on the relationship between these fields. Articulating this relationship allows us to better seize the opportunity that translingualism offers, in the basic writing classroom and beyond. 


\section{TABLE OF CONTENTS}

PAGE

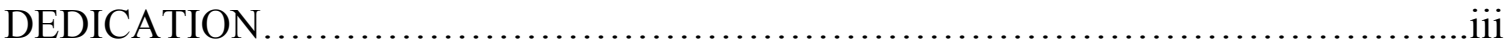

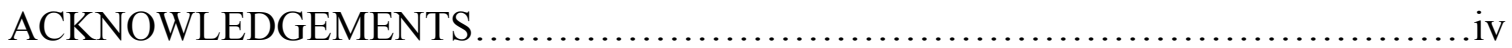

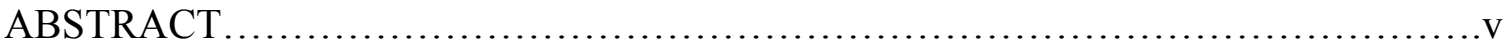

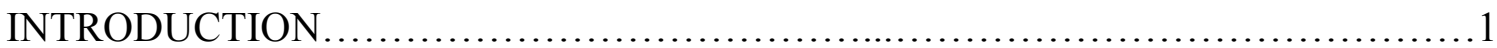

Basic Writing and Basic Writers......................................4

Basic Writing, Ideologies of Language Difference, and Linguistic Justice...........8

Translingual Basic Writing........................................... 13

CHAPTER ONE: MAPPING THE DUAL EVOLUTIONS OF BASIC WRITING AND

IDEOLOGIES OF LANGUAGE DIFFERENCE................................18

Understanding the Role of Language Ideologies in Basic Writing...............22

Language Difference as Deficit: The Basic Writer as Underdeveloped...........31

Language Difference as Natural: The Basic Writer as Initiate...................43

Language Difference as Opportunity: The Basic Writer as Conflicted.............52

Questioning Language "Difference”: The Basic Writer as Agent of Change..... 61

\section{CHAPTER TWO: QUESTIONING THE REIFICATION OF “ERROR” AND}

“STANDARDS” IN THE BASIC WRITING CLASSROOM......................68

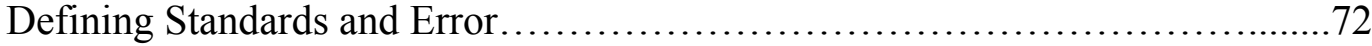

The Efficient Arbitrariness of Language Standards...........................85

Student Desire and the Lowering of the Bar................................ 95

The Teaching of Linguistic Control..................................... 105

The Damage of the Standard.......................................... 111

Translingualism's Relation to Error and Standards........................115 
CHAPTER THREE: TRANSLINGUAL BASIC WRITING PEDAGOGY 122

Principles of a Translingual Basic Writing Pedagogy.........................126

Scholarship on Translingual Basic Writing.................................129

Scholarship on Translingual Pedagogy in FYC............................. 146

Basic Writing Before “Translingualism” was Coined.........................163

CHAPTER FOUR: TRANSLINGUAL BASIC WRITING PLACEMENT AND

PROGRAMMING............................................................. 180

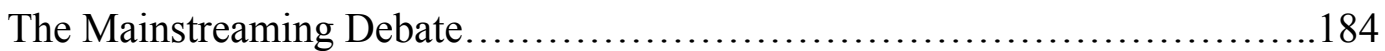

Principles of a Translingual Approach to Basic Writing Placement and

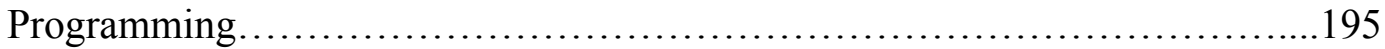

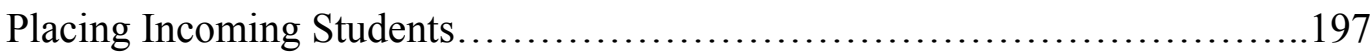

Designing the Basic Writing Course....................................207

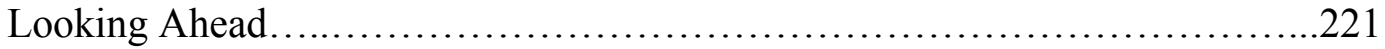

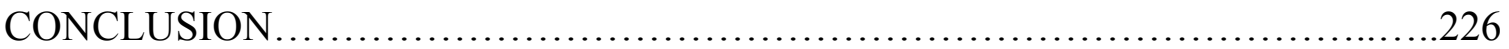

REFERENCES ............................................................. 237

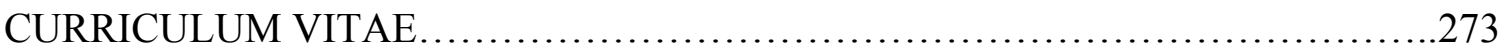




\section{INTRODUCTION}

About six years ago, at a developmental studies committee meeting at the community college where I worked as a writing tutoring coordinator, an academic vice president groaned at the sight of the latest retention numbers for our remedial non-credit math and writing courses, calling the developmental program the "hemorrhage point of the college." I remember imagining the college as a giant corporeal body, the classes in question a kind of severed artery, students as lifeblood pulsing and pooling like in a television crime show. Was he saying that too many students were being lost from the collegial body, or that the body itself was suffering, or both? His concern felt more for the university's loss than for the students we were failing (over half of those who attempted the basic writing course). At the time, I had taught basic writing at two institutions, but knew next to nothing about its history or theory, as is the case with so many basic writing instructors. ${ }^{1}$ In fact, I realized only after the semester had closed on my first basic writing course that it had been, in fact, a basic writing course. I only knew I was being paid more, the class carrying 4 credit hours due to an additional hour in the computer lab for what the department chair hiring me said was "extra time to write." Tellingly, my ignorance meant I mainstreamed the students without intending to: I taught my familiar FYC curriculum, they produced good work, we spent the lab hour

\footnotetext{
${ }^{1}$ I use the terms "basic writer" and "basic writing" in this dissertation to refer to students who are enrolled in college writing classes that fall below the FYC degree requirement. Though nomenclature varies between developmental writer, remedial writer, and basic writer, basic writer is the reigning term in scholarship. While I problematize this label, I choose to use recognizable vocabulary in order to effect that argument.
} 
conferencing, writing, and workshopping, and the majority earned As and Bs. Business as usual.

Years later, at the community college with the dramatic VP, I knew in advance that I was teaching basic writing, but that knowledge did not prepare me for the students I encountered. My story of a touchstone student will likely ring familiar to readers; many texts on basic writing open with a pedagogical moment of profound bewilderedness, what Chris Gallagher and Matt Noonan call a "Shaughnessy moment" (167), after the famous Mina Shaughnessy, who in 1977 wrote in Errors and Expectations of CUNY teachers feeling "stunned" and "unready in heart and mind" (3) to broach the "alien" (190) writing of open admissions students. For me, the student who changed everything was named Wilson. ${ }^{2}$ Even before knowing him, Wilson made an immediate impression. He was easily over six feet tall (imagine in comparison to my five foot frame). Wilson was also quiet, thoughtful, and deferential. When he turned in his first piece of writing, my eyes widened at the sight of his first and last name, both left uncapitalized, just as every first letter of every first word that started every sentence was left uncapitalized. Surely this was a mistake, I thought. Yet when I sat next to Wilson during in-class work and watched his fingers type on the aging computers provided in the classroom (a dilapidated room with exposed pipes in the oldest and farthest building from the campus quad), I began to understand the depths of his struggle to provide me with the kind of prose he knew I expected.

We worked together closely that semester, and I was continually mystified by his writing, often patchworked from the articles we read, but an intricate kind of patchwork,

\footnotetext{
${ }^{2}$ Wilson is a pseudonym, as are all student names used. Though I saved Wilson's writing, I did not obtain his consent to use his writing in my research, and have since been unable to contact him.
} 
words and phrases taken seemingly out of context and combined into a shockingly lurid quilted paragraph composed of a single sentence with no punctuation whatsoever. I agonized over his revisions, feeling increasingly doubtful of my ability to get him through the course. I wasn't going to contribute to the hemorrhage if I could help it. He strove to meet the bar I felt I was lowering each week; he met with writing tutors, enrolled in TRiO. ${ }^{3}$ I began to do some research in my desperation, finding to my shock that he had passed the 6-week intensive grammar boot camp that ran concurrent to my course, despite earning a 27 on the Accuplacer sentence skills test used to place him in these courses (a perfect score is a 120, and an 80 was needed to enter ENGL101). I hunted for possible ESL scores, finding none. I reached out for a lifeline in the department chair and developmental coordinator, trying to demonstrate the extent of the problem, writing that Wilson “doesn't understand how to take comments that I write in the margins and make changes to his text." I saved copies of everything he wrote, knowing even then that I would want to one day go back.

By the time the semester was nearing its end, I dreaded the blind reading of his final portfolio. I knew Wilson now as a person, the way novice teachers know those struggling students who, through sheer will, they are determined to help. It will likely come as no surprise that I made a Hail Mary defense when his portfolio was flagged for group review. I told the group I was sure he would not come back to school if we failed him, that he had already withdrawn from developmental math. He wanted to work in IT, I pleaded, he would just need one more English class. He was passed, and the next semester re-enrolled in developmental math (which he needed to complete before credit

\footnotetext{
${ }^{3} \mathrm{TRiO}$ is a federal student services program that provides academic and financial support services for students from disadvantaged backgrounds.
} 
coursework). I underestimated Wilson's resilience. He persevered through two more agonizing semesters of developmental math, diligently meeting with tutors and his TRiO coordinator, until his inability to progress and his vision of the long, long road ahead became too much. One of the last times I saw Wilson, he expressed his frustration with our institution and the gates he felt were keeping him out. "I just want to set up computers," he explained sadly. "Why do I need so much English, so much math?" I tried to explain the nature of an Associate's degree, encouraging him to persist. I remember his kindly smile at my hopefulness, knowing already, as he did at that point, that he would not be coming back.

My scenes with Wilson are still so vivid in my mind because he haunts me. That semester, my belief that Wilson needed to align to the standards of academic English was so strong that it clouded my vision to anything else. I was unable to ever step back and engage him in an honest conversation about his writing. I was encouraging, attentive, and available, but I was also ruthless, demanding, and afraid of what his failure meant to my own ethos. I still wonder what damage my good intentions may have unwittingly inflicted upon him and his attitude toward writing today. But I have Wilson to thank for the lingering questions that have dogged me ever since about language, power, and how certain types of students are othered even amidst the inclusivity of open access institutions of higher education. In graduate school, I was determined to set my own mind right, so that when I replayed the scenes in my head, I would be able to see a path I might've taken instead. A path for next time.

\section{Basic Writing and Basic Writers}


What is basic writing, and who are basic writers? In his 1997 landmark article “Our Apartheid: Writing Instruction \& Inequality,” Ira Shor calls basic writing "a containment track below freshman comp, a gate below the gate" (94). If freshman composition vets the writing ability of college novices, then basic writing asserts that ability is not yet present to vet. When students in remedial math and writing are prevented from enrolling in other coursework, basic writing becomes a kind of proving ground in which a student must demonstrate linguistic realignment to some central core in order to earn full college citizenship. This mirrors the segregation of ESL; in fact, the populations of basic writers and ESL writers are often mixed at institutions where no separate courses are offered (Friedrich; Matsuda, "Basic Writing," "Composition Studies," "The Myth"). The experience of basic writing is frequently a long, expensive, and frustrating one for students. Forty-one percent of students attempting developmental coursework at public 4-year institutions do not finish or pass, with fifty-one percent failing at the 2-year college (Chen and Simone 23).

Basic writing and the politics of higher education have always been intertwined. As George Otte and Rebecca Williams Mlynarczyk write in their 2010 Basic Writing, this subfield of composition has always been acutely aware of having been created to accomplish a specific mission: the widening of college admissions, especially in the 1960s and 1970s. Thus stripped of any intrinsic relationship to the fundamental work of writing studies, basic writing has maintained a vulnerable and peripheral status in the academy (Otte and Mlynarczyk xv). Basic writing has been buffeted by the storms of changing national sentiment, which at times calls for increased access, at other times, exclusivity. This instability has resulted in persistent funding, staffing, and status issues, 
leaving basic writing at the whim of larger forces. In a way, basic writing is a microcosm of the challenges faced by composition as a discipline. As sites of relegated remediation of language difference, the composition classroom's purview is wide, but the intensity of the basic writing classroom is deep and lasting, and there are millions of students in this liminal space.

Although the dismantling of basic writing programs at elite research institutions may lead some to wonder if basic writing has faded from the landscape of higher education, data tells a different story. According to a 2016 report by the National Center for Educational Statistics, ${ }^{4} 28.1 \%$ of students at public 2 -year institutions, and $10.8 \%$ of students at public 4-year institutions, take at least one "remedial English/reading" course (Chen and Simone 15). ${ }^{5}$ Placement is often based on timed, multiple-choice tests, such as ACT, SAT, TOEFL, COMPASS, or Accuplacer. ${ }^{6}$ While created to expand educational opportunities for underprepared students, basic writing as a field faces questions of ethics. Remedial coursework frequently carries fewer or no graduation credits despite commensurate or additional cost, delaying students' transfer or degree completion by sometimes years. As Figure 1 demonstrates, students of color and of lower socioeconomic status are funneled into these courses at a disproportionately higher rate than white, middle, and upper class students:

\footnotetext{
${ }^{4}$ The NCES is a branch of the U.S. Department of Education's Institute for Education Sciences, charged with collecting, analyzing, and publishing statistics on education.

${ }^{5}$ Since many bachelor-degree granting institutions have admissions standards in place that reject students who test below a certain bar, the number of students enrolled in basic writing is significantly lower at the 4year level. While profitable, basic writing brings with it a host of administrative issues, including questions of placement and the labor of tracking student success and retention.

${ }^{6}$ Recently, colleges are considering multiple measures for placement into credit level work, an initiative this dissertation explores in chapter 4. These measures can include but are not limited to GPA, HSA (High School Assessment), holistic measures like "grit" score (Duckworth), and directed self-placement (Royer and Gilles, "Introduction," "Directed Self Placement").
} 
Figure 1: Percentage of Beginning Postsecondary Students Taking Remedial Courses in Any Subject

\begin{tabular}{|l|c|c|c|c|c|}
\hline & Black & Hispanic & White & Low-Income & High-Income \\
\hline Public 2-year college & $78.3 \%$ & $74.9 \%$ & $63.6 \%$ & $75.5 \%$ & $59 \%$ \\
\hline Public 4-year college & $65.9 \%$ & $52.6 \%$ & $35.8 \%$ & $51.7 \%$ & $32.9 \%$ \\
\hline
\end{tabular}

The stage is set for a new wave of basic writers, as President Joe Biden's campaign platform includes "The Biden Plan for Education Beyond High School," committing to provide two years of community-college tuition free in addition to making all public colleges and universities tuition free for families earning $\$ 125,000$ or less (“The Biden Plan"). Currently 19 states, including Kentucky, ${ }^{7}$ have passed laws that waive tuition for at least the first 2 years of qualified students' college careers (Dickler). ${ }^{8}$ Participating states have seen a rise in the number of college students, thereby necessitating more basic writing sections, as students who were previously unable to afford college (statistically more likely to be placed in developmental coursework than their wealthier peers) are attempting the effort with the lure of free tuition. There are also more students in our writing classrooms who speak more than one named language than ever before. ${ }^{9}$ In addition to U.S. students whose home lives have taught them languages other than English, the number of international students enrolled in U.S. institutions of

\footnotetext{
${ }^{7}$ Kentucky's "last-dollar Work Ready Kentucky Scholarship helps Kentuckians who have not yet earned an associate's degree afford an industry-recognized certificate or diploma. Applicants must be accepted or enrolled in a qualifying program in health care, advanced manufacturing, transportation/logistics, business services/IT, or construction" ("KHEAA").

${ }^{8}$ This, of course, has fine print; students must be residents of that state, have recently graduated and/or have maintained a minimum GPA to qualify.

${ }^{9}$ The term "named language" comes from linguistics and fronts the idea that languages are social constructs rather than discrete linguistic objects (Heller 2007; Makoni and Pennycook 2010).
} 
higher education has grown almost every year since 1948, rising from 25,464 in 1948 , to 1,094,792 in 2017 (“Enrollment”). At best, higher education in the U.S. sees the language resources of non-native English speakers as detrimental to their learning here, while the native speaker's learning of any language other than English is a useful but hardly required skill. Neither mindset appreciates a diverse linguistic ecology as contributing toward a stronger institutional environment. Such appreciation is deep-seated in translingual theory, a theory I take up here in the reimagining of the linguistic assets that both multilingual and monolingual basic writers bring to not only the writing classroom, but to institutions of higher education (in their role as language hubs) at large.

\section{Basic Writing, Ideologies of Language Difference, and Linguistic Justice}

Although basic writing has always been about language, such scholarship has only rarely been about ideologies of language. Ideologies are more than beliefs, they are pervasive doctrines saturating belief systems and impacting perceptions of choice so deeply that the ideology behind one's actions or beliefs appears almost invisible and natural (Berlin; Bourdieu; Calvet). Ideologies of language range from the implicit monolingualism structuring much of U.S. education, attitudes toward bilingualism and multilingualism which celebrate language as tied to identity while at the same time insisting that languages other than standard English are appropriate only in certain contexts, and the ideology of translingualism I forward here. The effect of ideologies on everyday language practices is traditionally the purview of sociolinguists, with language difference (imagined primarily as the effect of languages other than English on English writing) the territory of fields like TESOL and L2. Paul Kei Matsuda writes of the 
disciplinary divide between composition studies and ESL writing, consciously born from growing workloads after WWII's influx of international students, the need for specialized teacher training, and the desire for disciplinary prestige ("Composition Studies" 710). Unfortunately, the benefits of disciplinary security have also resulted in a divide in teaching and scholarship, meaning the two fields rarely read or reference each other; scholars doing overlapping work participate in wholly distinct professionalization practices (organizations, conferences, etc.) (Matsuda, “Composition Studies"). One result of this undue separation is the undertheorization of the language ideologies informing and influencing basic writing as both a concept and a practice.

When professional organizations in the research and teaching of composition and English (namely, the Conference on College Composition and Communication (CCCC) and the National Council of Teachers of English (NCTE)) do speak out on language, it is in the form of position statements. A number of such statements have been released in the past fifty years that aim to articulate the discipline's stance toward language issues, the most famous of which is the 1974 CCC resolution on "Students' Right To Their Own Language, referred to as STROL. ${ }^{10}$ STROL championed students" "variant dialects" of English, reified English and its "variants" as bound to the identities of its speakers/writers, and attempted to address linguistic difference in a way that respected students while still ultimately advocating for the erasure of such difference in academic contexts. As a whole, these position statements speak out against English Only policies,

\footnotetext{
${ }^{10}$ For past relevant position statements, see Conference on College Composition and Communication's CCCC Guideline on the National Language Policy (1988, 1992), CCCC Statement on Second Language Writing and Writers (2001, 2009), National Council of Teachers of English's Position Statement Prepared by the NCTE Committee on Issues in ESL and Bilingual Education (1981,2008), Resolution on Developing and Maintaining Fluency in More Than One Language (1997, 2008), Resolution on English as a Second Language and Bilingual Education (1982, 2008), and Resolution on English as the 'Official Language' (1986, 2008).
} 
assert the legitimacy of mother tongues, dialects and variations, and support multilingual writers in college writing classrooms by advocating for rigorous teacher training. They do so, however, from a stance that assumes the value of "English" as both a national and international commodity, as well as a global lingua franca.

More recently, rhetoric and composition is part of a national movement grappling with linguistic racism and linguistic justice. The field's channeling of this zeitgeist is illustrated in a number of recent documents. The 2019 Conference on College Composition and Communication call for proposals, written by Vershawn Ashanti Young, was groundbreaking and first of its kind, written in a code-meshed style mixing standard English and Black English (“Call”). The Chair's Address of CCCC that year, by Asao Inoue, was entitled "How Do We Language So People Stop Killing Each Other, Or, What Do We Do About White Language Supremacy?” In July of 2020, on the heels of a national outcry following the murders of George Floyd and Breonna Taylor, a CCCC Special Committee released “This Ain’t Another Statement! This is a DEMAND for Black Linguistic Justice!" which included a list of demands such as putting an end to the teaching of code-switching as well as an end to the portrayal of standard English as the communicative norm (Baker-Bell et al.). Ideologies of language difference are experiencing a kairotic moment in rhetoric and composition, but the field's renewed commitment to linguistic justice needs application in basic writing, where much of our field's linguistic discrimination and erasure of difference takes place.

While my understanding of basic writing includes multilingual, international, and ESL writers, these students will not be my focus. As I will argue, too much scholarship already centers on this population as being the only imagined recipients of a translingual 
pedagogy. Instead, I write chiefly with the so-called monolingual basic writer in mind, the writer who would claim native fluency in English. There are deeper issues at play when an individual who has been speaking, reading, and writing English for twenty years is found incapable of participating in collegiate discourse, and these are the issues I explore. Therefore, I do not examine in-depth the relationship between the ESL student and the basic writer as she is conceived by the university, as such work has been undertaken (Matsuda, “The Myth," "Basic Writing”; Troyka). Instead, I separate the teaching of basic writing from the teaching of a new language, and I also separate the idea of translingualism from the mixing of two distinct languages. I take translingualism as concerned with reconfigurations within any and all language; thus my chief interest is in the benefits of translingualism for the so-called monolingual student or instructor, rather than translingualism's intersection with ESL.

The main language ideology of concern in this project is translingualism. As this term is much contested, I will briefly outline here my uptake, and each chapter explores more in-depth my relationship to and application of this theory of language. Monolingualism is a pervasive and subtle ideology that maintains languages like English, Spanish, or Urdu are stable and internally coherent systems. Speakers and writers who obtain these languages thoroughly can then participate in ongoing discourse. In this ideology, language differences, such as variant spelling, syntax, or words in other languages, are evidence of an impartial grasp of language, a grasp that must be tightened and secured through rigorous education (Horner and Lu, "Resisting Monolingualism"; Horner and Trimbur, "English-Only"). By contrast, translingualism as an ideology begins from the assumption that all speakers and writers have an expansive, capacious, and 
emerging linguistic, a repertoire that may or may not contain features of several named languages. All writers draw from this fund of knowledge in changing contextual situations, using what they have to meet whatever writing scenarios they are faced with, and the labor of drawing down changes the fund itself (Horner, "Language Difference"). This drawing down is not a matter of switching between languages, or mixing multiple languages, but rather strategic selection (Lorimer Leonard "Rhetorical Attunement”). One's linguistic repertoire is inevitably and repeatedly changed through the labor of usage, undergoing constant evolution. Academic writers (and this includes basic writers) who are cognizant and reflective of their ever-changing repertoires sometimes choose language that aligns with academic conventions, and sometimes choosing against this alignment, for strategic effect. Both choices are, therefore, enacted from a translingual mindset (Lu, "Professing Multiculturalism"). Choosing to sediment convention is neither a capitulation nor an evasion (Horner, "Relocating Basic Writing"). ${ }^{11}$

In this sea of choice, language from a translingual mindset is performative, morphous, permeable, and never the same from one moment or place to another (Pennycook, Language as a Local Practice). To teach from a translingual approach is to teach the nature of choosing. The goal is not the acquisition of language as if it is a bounded, static entity. If language is not fixed, then neither are language rules. Writing

\footnotetext{
${ }^{11}$ Often in my discussion of translingual writing, I will use the word "choice," arguing that translingualism teaches student writers to reflect on and consciously choose their utterances in a way that fulfills the exigencies of the given situation. I claim this act of choosing upholds a writer's agency, but it should be noted that the ideology of neoliberalism has taken up the concept of choice in a radically different and dangerous way. Neoliberalism centers competition at the heart of human activity, rendering society into a market, citizens into consumers, and individual actions as matters of buying and selling. In this framework choice is key; the more choices available to a consumer the more competition is driven. Only the strongest thrive, and those with less (such as those in poverty or the unemployed) are framed as struggling as a result of their own inferior choices. Neoliberalism has equally repurposed the idea of "freedom" as personal liberty at the expense of the common good. I want to consciously separate myself from the neoliberal connotations of choice and freedom. To me, agency is an understanding of the inherent self worth of every individual, not the unrestrained ability to buy and sell.
} 
conventions like grammar, style, and even citation undergo constant, dynamic change

(Hopper). Language conventions persist only insofar as they are enacted by writers. Rules that are seemingly clear-cut and permanent are merely the result of sedimented practice and are thus changeable (Lu and Horner). As every writer works on and with language in every act of writing, every writer is continually contributing to this sedimentation, in that "difference" and "more of the same" equally transform the nature of the existing landscape in any given moment.

As Horner and Alvarez point out, some scholars take up the term translingualism in ways that maintain the notion of languages as discrete, reinforce the idea that communication is transparent and untroubled, or reify the unchangeability of standards and conventions. Other adherents see translingualism as chiefly work done by writers moving between languages on the page, upholding the idea of code-meshing as part of or related to translanguaging (Li Wei; Gevers), meaning so-called monolingual students would be incapable of translingual work (Canagarajah, Translingual Practice). In contrast, I argue that a classroom of so-called monolingual students is fully equipped to become a translingual classroom; foreign languages and non-native speakers are not necessary ingredients for translingual connections or writing.

\section{Translingual Basic Writing}

My overall intervention is in bringing a translingual approach to the theory and practice of basic writing. I aim to demonstrate translingualism as always already part of basic writing. Translingual principles are interwoven in the very fabric of early basic writing, long before the term was coined. By making space for basic writing's subcurrent 
of translingual thought over the past fifty years, I hope to generate ongoing momentum, galvanizing the current interest in valuing and respecting language difference into the channel of basic writing specifically. This subfield of rhetoric and composition, I argue, has more to gain from recognizing translingual potential and opportunity than any other. Ironically, it is also the subfield that gleans the least amount of scholarly attention, and whose practitioners are given the least amount of time for reflective praxis. In these pages I first theorize a translingual approach to language, the basic writer, their error, and the standard by which they are measured, then pivot to evaluations of extant efforts to enact a translingual approach to basic writing pedagogy and programming. My theorization and evaluation promotes a future for basic writing that is agentive and inclusive, both for students and for teacher-scholars. My project begins with, and centralizes theory, in order to demonstrate that translingualism is a theory and a way of thinking that informs all practice. Translingualism cannot be encapsulated in a course text, activity, reading habit, programmatic structure, or placement mechanism. It emanates outward. When applied only superficially, it enacts only superficial change.

The body of theory in basic writing comes chiefly from its flagship journal, the Journal of Basic Writing. Scholarship on basic writing also appears in other journals, like College Composition and Communication, College English, and Writing Program Administration, but rarely. There are a good number of edited collections published on basic writing, as well as monographs both canonical (Shaughnessy's Errors and Expectations, Rose's Lives on the Boundary, Bartholomae's Writing on the Margins) and recent (Otte and Mlynarczyk's Basic Writing, Ritter's Before Shaughnessy). The majority of my archive on basic writing theory and practice is drawn from these sources. As 
aforementioned, translingualism is a cross-discipline phenomenon; therefore, I draw chiefly from its uptake in rhetoric and composition journals and books, but also, at times, from sociolinguistics and L2 scholarship. I acknowledge that relying entirely on textual analysis for my arguments and assertions regarding basic writing is limiting. Interviewing basic writing teachers, administrators, and students would have given rich dimension to my findings. Yet I chose to analyze a broad corpus of scholarship in order to take a long view of basic writing as it has been enacted since its conception. In so doing, I sacrifice for purposes of scope the depth that hearing from individuals would afford.

Chapter one investigates how rhetoric and composition's perception of the basic writer, their languaging, and their place in the university have changed over time, arguing that these shifts in perception align with evolutions in ideological approaches to language difference. Our field's historical approach to basic writers is a result of our changing ideological stance toward language difference. At the same time, national and global ideological change has shaped our understanding of basic writers. By marking the distinct evolutions in both basic writing and language ideologies from 1700 to the present, using terminology by Brian Street and Mary Lea to bridge this gap, I end by highlighting translingualism as prefigured in early basic writing and underexplored today.

From language ideologies, chapter two narrows to the specific treatment of error, and conceptions of writing standards, as considered in basic writing scholarship of the past fifty years. Understanding the history of error uncovers the motives behind pedagogies that work to eradicate or encourage language difference. These motives, once analyzed, carve out space for inquiry into an approach to error that would reflect the 
field's current desire to respect the agency of all writers, especially basic writers. ${ }^{12}$ Over the years "error" evolved from evidence of ignorance, to a clue to idiosyncratic logic, to ultimately, under translingualism, an opportunity for mutual negotiation and learning. This chapter features writing by two freshmen students, providing sample responses to their so-called errors that reflect each era's stance toward language difference.

Chapter three marks what may seem initially like a turn to the practical, focusing on current uptakes of translingualism in basic writing scholarship, translingual scholarship that concerns basic writers, and past basic writing scholarship (from before the coinage of "translingualism") that prefigures translingual principles. Chapter three holds pedagogical scholarship up to a framework of translingual principles, evaluating the adherence of said scholarship to the sentiments and assertions about language that define translingualism. Rather than proposing an entirely new approach, chapters three and four are assemblages of the strengths and weaknesses of current efforts, as well as a recognition of missed opportunities. While much of the scholarship at the nexus of translingual basic writing is promising, there remains an overreliance on visible codemeshing/code-switching in student texts and an overemphasis on the multilingual student as ideal recipient of a translingual pedagogy. Instead, I emphasize the importance of recognizing the sedimentation of the conventional as translingual, and the so-called monolingual student as equally receptive to a translingual approach to the teaching of writing.

In the same vein as chapter three, chapter four examines current placement measures and programmatic models for basic writing, evaluating these for their

\footnotetext{
${ }^{12}$ I define agency not as unrestrained freedom, but rather, an individual's strategic and tactical decisionmaking, often under conditions not of their choosing.
} 
translingual potential using a similar yet distinct set of translingual principles. Placement practices such as standardized testing, impromptu timed essay writing, multiple measures, portfolios, and directed self-placement are reviewed. Programmatic structures analyzed include traditional basic writing, mainstreaming (defined as a wholesale dismantling of basic writing programs), and intensive, stretch, accelerated, and studio models. I find overall that directed self-placement and studio hold the greatest translingual potential, with standardized testing and intensive basic writing the most problematic. Both chapters three and four ultimately argue that nascent translinguality can be identified in past basic writing scholarship, and should be revived and reexamined.

Ultimately, this project works to expand disciplinary understanding of the histories of basic writing and ideologies of language difference, and sheds light on their relationship. These intersections are important because they offer insight into our assumptions about the academy, the standards and conventions we claim to teach, and the people who deserve to obtain the power encapsulated in education. We live in a time of increased commitment to equity and justice; basic writers are an invisible population under our own purview, one that does not wholly benefit from our rhetorics of inclusion. I hope this project can trace the thread of language difference through the history of basic writing. Seeing this thread allows us to better seize the opportunity that translingualism offers, in the basic writing classroom and beyond. 


\section{CHAPTER ONE:}

\section{MAPPING THE DUAL EVOLUTIONS OF BASIC WRITING AND IDEOLOGIES OF}

\section{LANGUAGE DIFFERENCE}

Why is basic writing relegated to the shadows of rhetoric and composition? Ours is a field intent on studying marginalization, paying careful attention to issues like accessibility and indigenous land rights at our national conferences. It is ironic then, that we act as if basic writing has been all but eradicated, as if droves of students aren't placed in basic writing sections in college campuses across the nation. Despite the prevalence and endurance of "basic writer" as a label given to students, publication on basic writing is on the decline. ${ }^{13}$ The scholarship that is being forwarded on basic writing is chiefly pragmatic. Publications on the success of various programmatic approaches (whether accelerated learning, studio, or stretch) are those most widely cited among basic writing scholarship of the past two decades. Articles in the Journal of Basic Writing rarely linger in the realms of theory, often providing a theoretical lens upfront merely as a frame to situate concrete practices in the basic writing classroom. Examples of handouts, assignment sequences, and writing prompts are not uncommon in $J B W$. Yet is not basic writing deserving of theorizing? In "Sp(1)itting Images; Or, Back to the Future of (Rhetoric and?) Composition," Karen Kopelson outlines how our disciplinary birth was

\footnotetext{
${ }^{13}$ A JSTOR search for publications in $C C C$ featuring the keyword "basic" results in 455 hits between 1980-1990, 345 between 1990-2000, 261 between 2000-2010, and only 188 between 2010-2020.
} 
forged through remaking practice by developing new theory (751), arguing theory "performs the invaluable service of tracing, often in order to fracture, the very consensus around "reason" (765). The question we must ask then, is not how theory serves us in our basic writing teaching practices, "but what theory can do to us" (765, emphasis in original).

Yet in basic writing scholarship, questions of the work theory does to the minds of teacher-scholars are too often abandoned in favor of surface-level overgeneralization of theory, a move that Mike Rose in "Narrowing the Mind and Page" argues reduces the impact of theory to no more than a "diagnostic framework" (268). Many teachers of basic writing and writing program administrators see themselves as "in the trenches" and in need of immediate, directive advice. This urgency is rooted in several factors: not only is time of the essence (teachers may have only one semester to bring students up to a "college" level), success and retention rates of basic writing classes are usually highly scrutinized and tracked, and teachers are often underpaid and undertrained (i.e. adjuncts or graduate students). These factors are part of a larger issue within the field of writing studies at large: the rhetorical portrayal of remedial education as a temporary measure that will erase itself with persistence when the "literacy crisis is solved in other segments of the educational system" (Rose, "The Language of Exclusion" 341). Sustained investment in basic writing courses, therefore, is hard won and tenuous. Teachers of basic writing appeal most successfully to "efficiency-obsessed administrators and legislators" by "defending their work in utilitarian terms" (Rose, "The Language of Exclusion" 346), and have consequently internalized the conceptual ramifications of this utilitarianism. 
Insistence on the practicality of basic writing scholarship implies that basic writing, and basic writers, can still be "fixed" through knowable, translatable activities. These activities, centered as they often are in the so-called "givens" of writing - error reduction, grammar rules, etc. - are not seen as open to contestation or debate but rather clear-cut, elementary basics. Furthermore, the assumption is that any basic writing teacher, equipped with the latest tried and true pedagogies, can in the duration of a semester exert her/his newfound knowledge in the equal transformation of all their students, reducing basic writing to a matter of tools and effort. In "The Birth of Basic Writing," Bruce Horner theorizes that the field has neglected "the whys and wherefores of work in basic writing" (20) due to this "practical" bent. An emphasis on practicality narrows the scope of discursive possibility for teachers and administrators, "shaping the kind of statements possible and impossible for them to make" ("The Birth" 25). One cannot challenge the limits of working toward practicality, including material constraints and an emphasis on skill teaching ("The Birth" 21). This is in stark contrast to approaches to "regular" freshman composition that acknowledge the interplay of power, institution, background, and identity in the writing classroom. I provide here a piece of theoretical coherence for basic writing, arguing that the field's shifting understanding of the role of language difference directly affects its mode of maintaining or challenging the dominant, standard language ideology in the remediated writing classroom.

A teacher in the trenches might feel comforted by explicit instructions, especially when trained to believe they are not capable of agentive action in the field. ${ }^{14}$ This is the case of the cadre of basic writing teachers, who often face a lack of training, undercompensation, and exploitative labor practices (Taylor and Holberg). Even when

\footnotetext{
${ }^{14}$ If the pedagogues are the soldiers, are we then at war with our students? Our institutions?
} 
they want to, undervalued and unsupported pedagogues cannot possibly be asked to invest the time and energy needed to develop a theoretical framework for a course deemed unworthy of the expertise of more established faculty. Yet the moment the nature of the battle changes, whether it be a shift in weather, a road closure, or a weapon malfunction, a soldier reliant on explicit direction realizes her hapless underpreparedness. Had she been prepared in a different way, perhaps by strategic briefing, comprehensive maps, contingency plans, or a sense of how her mission fits into the puzzle of a larger engagement, the soldier's ability to adjust on the fly is drastically increased. These are the tools of theory. Theory, for basic writing, calls into question the importance of context and makes visible overarching, historical patterns that change for us what teaching and writing signify, i.e. a contingent and dynamic product of attempts and efforts. My mapping of the field's shifting construction of the basic writer and her language has implications for how rhetoricians and compositionists consider student ability, language difference, and academic writing. This is a map worth having for any teacher in the trenches of basic writing.

Theorizing the relationship between basic writing and ideologies of language difference reveals that the two are intrinsically intertwined and co-constituted. As over time, the definition changes of what "counts" as language difference, what this difference signifies, and what our role as compositionists is in addressing this difference in our writing classrooms (either by extinguishing, ignoring, or kindling it), so too have theories of basic writing adapted in kind. I argue that shifting ideologies surrounding language difference are inextricably interwoven in iterations of basic writing; our field's historical approach to basic writers has been shaped by and has shaped our ideological stance 
toward language difference. Mapping the history of language ideologies and basic writing reveals emergent translinguality in past approaches to basic writing.

\section{Understanding The Role of Language Ideologies in Basic Writing}

The concept of language ideologies is key to understanding how basic writing's emphasis on elimination of error and alignment to "Standard English" makes it a nexus of both social justice concerns and opportunities. Drawing on Göran Therborn, James Berlin defines ideology as that which provides us with the language we need to define ourselves in relation to others and determine what is real, valuable, and possible in the world ("Rhetoric" 479). Ideologies about language have to do with the kind and amount of value ascribed (or lack thereof) to certain named languages and linguistic purity, and the criteria by which we determine this value status. Rather than being consciously learned, French sociologist Pierre Bourdieu argues that ideologies are subconsciously inscribed through the "prolongued labour of inculcation" (Language 61) by those in power in credentialing institutions that comprise the "linguistic market" (Language 50), such as grammarians and teachers. In Towards an Ecology of World Languages, Louis-Jean Calvet untangles this felt sense of linguistic capital, claiming that our representations concerning the prestige of named languages like English "foster and reinforce the realities" (3) of its market value; it is our practices, and not anything inherent in the language itself, that empowers, solidifies, and globalizes English. Similarly, Bourdieu uses the term "symbolic power" (Language 170) to describe the very real effects that language ideologies produce without resorting to actual force, calling this power "an almost magical power" (Language 170) not because it is exercised in a vacuum devoid of 
agents, but because its authority is seamlessly recognized by both those in power and those who submit.

A "standard language ideology" (a term coined by Milroy and Milroy) is biased toward an idealized and homogenous language, and seeks to suppress variation (Milroy and Milroy, Authority). This suppression manifests in the form of language policies which, when invested with power as entities capable of inflicting change seemingly without human participation, falsely portray languages as always-existing and unchanging monoliths. Such language policies “express who belongs and who doesn't belong ... set the rules for entry and the conditions for staying ... [and] communicate clearly an absence of rights to those who do not conform to the codes of belonging" (Cummins ix). Despite the fact that the United States does not proclaim an official language policy, tacit language policies thrive nevertheless in the way we instruct language learners and circulate information. Language policies are effective because they mask reality: that the idea of language has been paradoxically invented by people; it does not exist apart from its users and yet seems to exist naturally in the eyes of every user. The utter saturation of language ideologies into our psyches aids in the efficaciousness of language policies.

Rooting their study in theories of the distribution of power (namely, Althusser, Marx, and Foucault), scholars in composition, cultural studies, and sociolinguistics such as James Berlin, Joseph Williams, Leslie Milroy, Nikolas Coupland, and Rosina LippiGreen have studied active ideological discourses operating in the language classroom, as the university is an apparatus for the dissemination of ideology as defined by Althusser. In the standard Western language ideology, virtually all citizens are indoctrinated to the 
"common sense" notion that languages exist in standardized forms; the canonical and pristine form exists outside of even the native speaker, housed instead in external documents like grammar handbooks whose mysteries can be deciphered only by educators (Milroy, "Language Ideologies" 537). Indoctrination comes at the hand of vetted individuals like teachers, whom Bourdieu calls the "agents of regulation and imposition" (Language 45); the educational system thereby can "produce the need for its own services and its own products; i.e. the labour and instruments of correction" (Language 61). Consequently, the "truth" of an unchanging English is taken for granted as self-evident; its reverse (that language is formless, shifting, and ephemeral) is practically unthinkable. Languages such as English may be defined more by the ideologies of their practitioners than by any internal structure, and academics are no exception; our field's preference for ever-expanding the boundaries of Standard English rather than questioning the concept of boundarying altogether continues to endorse a standard language ideology (Milroy, "Language Ideologies"; Coupland, "Sociolinguistic Prevarication”). Modern language theories like translingualism call our consciousness toward a reflective acknowledgement of these pervasive beliefs and ask us to recognize that rules are sedimentations of form resulting from repeated human practice and therefore constantly emergent and in motion. The creative remaking and reshaping of language is the true norm (Pennycook, Language as a Local Practice 41).

A logical consequence of language ideologies' work toward social regulation is their tendency to fallaciously use language as a cipher for class or race. After all, depending on the degree of their empowerment, individuals have varying abilities to both adapt to changing linguistic markets and market themselves as producers of language 
(Bourdieu). While this conflation plays out nationally in efforts like English-Only

legislation, it is also at work in university admissions, placement, and assessment

practices that take a student's identity as measurable through their languaging, as well as

field-specific language rights efforts, such as the 1974 CCCC Language Statement

entitled "Students' Right to Their Own Language." "False reification of language as

bound to identity both deflects the possibility that writers can and do write differently

depending on context and takes as given that writing is simply transcribed speech, rather

than itself a unique mediator of language (see Olson's “Oral Discourse”). Dangerous

examples of confusing language with class and race appear in the work of Thomas Farrell

and Basil Bernstein, both of whom utilized notions of IQ in their assessment of language

practices and whose projects will be outlined in Part One of my analysis. For better or

worse, higher education is a key mediator of language ideologies - both their maintenance

and their revision - thereby making basic writing a unique site of social justice concerns.

Basic writing is gatekeeping ${ }^{16}$ at its core, giving students only provisional and

partial access to academia and serving as arguably the most stringent enforcer of

language ideologies across all levels of higher education. This gatekeeping is

multifaceted. On the one hand, it is an enrollment management strategy deployed by the

institution itself. In The Politics of Remediation, Mary Soliday links the creation and

\footnotetext{
15 “Students' Right to their Own Language" reads: "We affirm the students' right to their own patterns and varieties of language -- the dialects of their nurture or whatever dialects in which they find their own identity and style. Language scholars long ago denied that the myth of a standard American dialect has any validity. The claim that any one dialect is unacceptable amounts to an attempt of one social group to exert its dominance over another. Such a claim leads to false advice for speakers and writers, and immoral advice for humans. A nation proud of its diverse heritage and its cultural and racial variety will preserve its heritage of dialects. We affirm strongly that teachers must have the experiences and training that will enable them to respect diversity and uphold the right of students to their own language."

16 "Gatekeeping" is controlling the rate at which students can progress in their course of study. For an argument in favor of gatekeeping, see Jeff Smith's "Students' Goals, Gatekeeping, and Some Questions of Ethics."
} 
expansion of basic writing with historical moments in which higher education was forced to manage unparalleled growth. Basic writing allows an institution to accept students widely, hold them indefinitely, and pass vetted students onward to FYC only after they have met a bar, upholding the institution's standards and thus its reputation. On the other hand, teachers themselves keep the gate, invested as many are in their role as linguistic proxies. In this sense, some basic writing teachers see themselves as guarding the gate, beyond which lies their beloved conception of "English," from potentially unworthy students.

Depending on the institution, students in basic writing may be prevented from enrolling in other coursework with developmental prerequisites, turning the basic writing classroom into a kind of linguistic quarantine, or incubation tank (one's metaphor depending on whether basic writers are deemed "remedial" or "developmental"). Students must demonstrate proof of "growth" and alignment in order to earn the status of a fully enrolled college student. As I will soon demonstrate in Part One, basic writing's history reinforces its role as a language remediator. Across the eras, from the birth of the land-grant university in the mid-nineteenth century as a new chance for rural students, to the "Awkward Squad" at Yale (Ritter), to the GI Bill's influx of so-called illiterate veterans in English classrooms, and the open admissions era at CUNY, the remediated English classroom has from the beginning been a designated space to assess, police, and control language. ${ }^{17}$ What Bronwyn Williams calls the "perpetual literacy crisis" in America has time and time again meant the field of composition has been tasked, by an anxious middle class, with reinforcing conventional language practices deemed markers

\footnotetext{
${ }^{17}$ The term "open admissions" refers to a categorization of college admissions under which the only required prerequisite for acceptance is proof of a high school diploma or GED. The majority of community colleges have an open admissions model.
} 
of cultural capital. Whether the approach to basic writers' linguistic difference was to cordon them off from the general population, study them as if newcomers from an alien world, or celebrate their diversity, each stance exemplifies an ideology toward language difference.

While taking a historical approach to examining the language ideologies of basic writing may on the surface seem at odds with the current needs of basic writing instructors and WPAs, I focus on this trajectory in order to situate basic writing within the gravitational force of language, so as to leverage the current energy regarding language difference, in particular translingualism, in a re-examination of an oft-neglected subfield. Until now, basic writing has not been predominantly seen as a study of language, rather a study of cognitive or cultural differences. Similarly, translingual theory has not been linked with so-called monolingual basic writers, and is often seen as applicable only to students who navigate between multiple named languages. While much work has been done on basic writing as social justice, little scholarship attempts to frame basic writing as affected by and affecting ideologies of language difference, and even less has been offered that positions translingualism and basic writing together. ${ }^{18}$ Publications that do attempt this joining are subject to the pedagogical imperative of teachers eager for ways to improve the conditions of the basic writing classroom, but with little time for reflection. As my introductory section suggests, I see this imperative, while understandable, as ultimately detrimental to the practice and reform of basic writing.

\footnotetext{
${ }^{18}$ Notable exceptions include chapters by Asao Inoue (on assessment), and Katie Malcolm (on a community college studio model) in Crossing Divides: Exploring Translingual Writing Pedagogies and Programs (2017), and articles published by the Journal of Basic Writing by Bruce Horner ("Relocating Basic Writing"), Rebecca Williams Mlynarczyk ("Storytelling”), Andrea Parmegiani ("Bridging Literacy Practices"), and Xiqiao Wang ("Developing Translingual Disposition"), and in College English by John Trimbur ("Translingualism").
} 
The remainder of this chapter outlines the evolutions of basic writing's construction of the writer and stance toward her/his language difference in four approaches to the teaching of basic writing. I link each approach with a language ideology, forging the links using Brian Street and Mary Lea and Street's models of literacy, as their vocabulary helps bridge the gap between the concreteness of basic writing practices and theoretical, ideological attitudes toward language. While my use of the term "evolution" here implies both chronology and perpetual forward development, the narrative of basic writing is hardly so clearly delineated. Thus I draw upon the metaphor of a map of basic writing rather than, say, a timeline. This metaphor permits a conceptualization of basic writing's history and future as a non-linear, non-directional topology, while acknowledging markers of a pathway trod by thinkers over the past fiftyplus years. As we shall see, the idea of language difference as cognitive deficit or lack has certainly not disappeared from the landscape of basic writing; in a similar vein, prefigurations of translingual approaches to basic writing can be seen in the 1970s. Nevertheless, as a whole, the field has evolved when it comes to writerly construction. Identifying these approaches, while risking an appearance of boundedness, still helps mark the cyclical adoption and rejection of various ways of thinking about language difference in the basic writing classroom.

I divide my analysis into the identification and explication of four approaches. First, "Language Difference as Deficit," which sees the minds of basic writers as underdeveloped and therefore less capable of abstract thought, ${ }^{19}$ and which includes the oral/literate divide, which has claimed to be able to trace the unpreparedness of basic

\footnotetext{
${ }^{19}$ D'Angelo; Flower and Hayes; Lunsford, "Cognitive Development”; Odell; Troyka, "Perspectives."
} 
writers to their "residually oral" cultural backgrounds. ${ }^{20}$ Second, "Language Difference as Natural," which sets as its goal the enculturation of basic writers into academic discourse without the loss of their home cultures. ${ }^{21}$ Third, "Language Difference as Opportunity" which proposes tension in the basic writing classroom as a space for productive, if painful, growth. ${ }^{22}$ And my final and fourth section is titled "Questioning Language 'Difference,"' which examines the current intersection between basic writing scholarship and translingualism. See Figure 2 on the following page for a visual overview of the chapter's breakdown. In closing each of these sections, I also offer an example response to a real piece of student writing, in illustration of each model's ideological approach. The sample I include is from one of my own past sections from the spring of 2019 , by a writer who I here call Ryan. ${ }^{23}$

Figure 2: Outline of the Chapter

\begin{tabular}{|l|l|l|l|}
\hline Part & Approach to Basic Writing & $\begin{array}{l}\text { Street/Lea and Street's } \\
\text { model of literacy }\end{array}$ & $\begin{array}{l}\text { Ideology of Language } \\
\text { Difference }\end{array}$ \\
\hline One & $\begin{array}{l}\text { Language Difference as Deficit: } \\
\text { The Basic Writer as Underdeveloped }\end{array}$ & $\begin{array}{l}\text { Study Skills Model \& } \\
\text { Autonomous Literacy }\end{array}$ & Monolingualism \\
\hline Two & $\begin{array}{l}\text { Language Difference as Natural: } \\
\text { The Basic Writer as Initiate }\end{array}$ & Academic Socialisation & Bi/Multi/Plurilingualism \\
\hline Three & $\begin{array}{l}\text { Language Difference as Opportunity: } \\
\text { The Basic Writer as Conflicted }\end{array}$ & Academic Literacies & Multilingualism \\
\hline Four & $\begin{array}{l}\text { Questioning Language 'Difference': The } \\
\text { Basic Writer as Agent of Change }\end{array}$ & $\begin{array}{l}\text { Academic Literacies \& } \\
\text { Ideological Literacy }\end{array}$ & Translingualism \\
\hline
\end{tabular}

\footnotetext{
${ }^{20}$ Farrell, "Developing Literacy"; also see Farrell "IQ," "Open Admissions," "Literacy," and the work of Walter Ong.

${ }^{21}$ Bartholomae, "Inventing the University"; Bizzell, "College Composition”, "Cognition," "What Happens"; Shaughnessy, Errors

${ }^{22}$ Lu, "Conflict," "Professing Multiculturalism," "Redefining the Legacy"; Gilyard; Rose, "Narrowing the Mind," Lives; Shor; Villanueva.

${ }^{23}$ I obtained Ryan's consent to use his writing for research purposes, as I did with all writers whose work is excerpted in this dissertation.
} 
A note before diving in on my use of Street and Lea and Street's models of literacy ideologies: while Street's earlier work in New Literacy Studies was taken up by ethnography and anthropology, his later work with Mary Lea was concerned with understanding literacy models as they work within local contexts of higher education, including the U.S. writing and reading classroom. Street's models herald changes in educational approaches to literacy; each model progressively diminishes the power held by a monolithic concept of literacy and grants increasing agentive choice to the student as changer of language rather than passive receiver (Literacy in Theory and Practice). Literacy ideologies align with language ideologies, and both jointly help illustrate the power and belief structures at work within higher education, specifically, the basic writing classroom. Utilizing Street and Lea and Street's models in this way is a new contribution to the conversation on literacy theories as they manifest in the basic writing classroom.

Overall, I provide an understanding of the way each approach to basic writing frames the student, their speech and writing practices, and the place of basic writing within the university at large. In identifying parallels with ideologies of language difference using Street and Lea and Street's models of literacy, I situate basic writing within the concurrent conversations about language happening in literacy studies, sociolinguistics, and rhetoric and composition. This exercise reveals that turns in basic writing theory are the results of shifts in perceptions of writers and their languaging, solidifying the impact that language ideologies have on the evolution of our field. 


\section{Part One: Language Difference as Deficit: The Basic Writer as Underdeveloped}

The narrative that students whose language and writing appears to deviate from a "norm" of standard correctness need remediation through intensive writing courses is what we might call the default narrative; it certainly reigned supreme from the creation of the designated freshman composition course at Harvard in the 1870's (when entering students of Harvard and Yale, almost all elite white males, were found lacking in the required Latin grammar) and continues in many arenas today (Arendale 60; Fleming 1). This narrative portrays language diversity, such as the mixing of languages in speech or writing, or writing that lacks the flow or style teachers might expect, as the understandable output of underdeveloped writers. In this construction, we live in a world where languages can be named, defined, and bounded; those whose writing does not conform to our expectations have simply not yet reached the level of linguistic sophistication and maturity of their more advanced peers. James Slevin calls this a "narrative of lack" in which any difficulty readers encounter in student writing signals a need for improvement. To Slevin, "narratives of lack" are pernicious because of their ability to skew student deficiencies as opportunities for growth:

This model is especially effective because it conceals the interpretation of difficulty as lack. As such, the construction of lack cannot be refused or even challenged because narratives of improvement based on lack conceptualize agency only within a teleology (and as part of a process) of improvement. Thus only improvement, not the construction of lack that is its precondition, can be refused; when refused, improvement gives us misbehaving, or uncivilizable, students. (15-6)

This narrative was assumed the natural and correct mission of writing courses in higher education for almost 100 years, carving out a designated space and time to improve and sophisticate students' language in preparation for college-level writing. 
Even if freshman composition had elite roots, in the late nineteenth century it truly flourished in the U.S. heartland, as the expansion of population-specific institutions of higher education, such as community or "junior" colleges, land-grant public universities, historically black colleges and universities (HBCUs), and women's colleges broadened access (Fleming 8; DeGenaro). Suddenly, composition was entangled in a national educational mission of producing a conscientious and literate citizenry, thereby bestowing legitimacy to those wishing to enter the growing middle class. The land-grant mission, founded on the Morrill Land Grant Act of 1862, was constructed on a "rhetoric of democracy and access" that aimed to provide practical, liberal education to all Americans regardless of economic status (Brown 327-8). Still, Danika Brown in "Hegemony and the Discourse of the Land Grant Movement" argues that this rhetoric is a false foil to the corporatization model of other universities, demonstrating how even landgrant universities operated within a "discourse of economic utility," shaping productive working class laborers through their ability to name (and thus redefine) the educational requirements needed for economic success (334).

The pressure to admit new populations into higher education in the nineteenth century necessitated widespread freshman composition courses for improving the handwriting, spelling, and grammar of the masses (Rose, "Language" 343). Yet this constant expansion was tested to its limits at the close of World War II, when the G.I. Bill provisioned a free college education for veterans, leading to a dramatic growth in enrollment and faculty hiring as well as an immediate need for curricular change (Otte and Mlynarczyk 4). Contemporary accounts highlight the dual feelings of promise and panic encapsulating the education of these men. In a 1945 issue of The English Journal, 
Paul Witty in "Teaching the 3 R's to the Army" writes of the intense training programs of the U.S. naval forces ("illiterate" men could gain the literacy skills needed for their positions in an 8-week program) that proved "the fundamental educability of the mass of American youth" (132). In the same issue, however, Samuel Adams Lynde faces head-on the impact this flood of veterans was having on the educational system. In his "Plea for the Under-Educated Veteran," he cites a startling statistic from the Army Office of Education: that $3 \%$ of enlisted men (by his estimate about a half a million individuals) had less than a fourth-grade education (153). Knowing that many of these veterans would seek the schooling offered them by the G.I. Bill, Lynde posed a challenging question:

What is to be done for this tremendous number of educationally deficient servicemen? They cannot go to college or high school unless present standards are radically revised. [Yet,] it is impossible to place them in the classroom with children of a comparable level of educational attainment ... Those charged with the responsibility of planning courses for veterans of all stages of academic attainment must consider this special group as a group requiring special assistance. (153)

The response then, as it was after each wave of students, was a remediated English classroom, a cordoned-off space meant to maintain the barrier to collegiate-level work while granting the appearance of access and inclusivity.

As the doors to higher education ever widened following the protests of the 1960 's, admitting "the immigrant poor, veterans, the racially segregated, [and] the disenfranchised" (Rose, "Language" 355), basic writing reached its acme in the 1970s with Mina Shaughnessy's 1977 Errors and Expectations, a text resulting from the City University of New York's open admissions program and reflective of that institution's response to a drastic influx of underprepared students. Suddenly, teachers encountered students whose writing was "almost certain to sound and feel alien" (Shaughnessy, 
Errors 190). ${ }^{24}$ Shaughnessy's book was ahead of its time, downplaying students' deficiencies and stressing the influence of the communities where they were schooled, prefiguring the approach we will see in Part Two: "Language Difference as Natural: the Basic Writer as Initiate." Shaughnessy asks teachers to "develop a fresh perspective on error" (121) and recognize that a student's "errors reflect upon his linguistic situation, not upon his educability" (121). Errors, she argues revolutionarily, "no matter how peculiar they may sound to a teacher, are the result not of carelessness or irrationality but of thinking" (105, emphasis in original). Rather than see students as incapable of grasping (or worse, unwilling to grasp) basic skills, scholars like Shaughnessy argue that these skills had never been presented to students in their educational histories, shifting blame from the individual to the culture at large (Ritter 29).

This social-constructivist bent to basic writing was novel, as in the 1970s, drawing primarily on Britton's cognitive-developmental psychology and Piaget's four stages of cognitive development in children, the majority of basic writing scholarship claimed that basic writers, though adults, had never reached Piaget's final, formal operational stage of logic, usually reached by children between $11-15$ years (The Language and Thought of the Child). Therefore, basic writers were less capable of forming abstractions, conceptualizing, and transferring what they learned from one context to another in their writing. To these so-called cognitivists, writing was a direct expression of thought; therefore, basic writers' struggle to describe their thinking processes (Kroll), identify errors in their own writing (Laurence), and distance

\footnotetext{
${ }^{24}$ There are numerous references in Errors and Expectations to the language of basic writers as being strange and foreign, including "students whose difficulties with the written word seemed ... as if they had come, you might say, from a different country" (2), teachers feeling "stunned" (3) "unready in mind and heart" (3), the book's intention to serve as a "frontier map ... to this pedagogical West" (4), and injunctions that teachers "must try to decipher the individual student's code ... as a scientist might" (40).
} 
themselves from an essay prompt (Lunsford, "The Content") all serve as evidence of their inability to decenter from a narrow, egocentric worldview in which they "merge" (Lunsford, "The Content" 281) with the writing and reading tasks assigned. Pedagogies derived from this cognitivist perspective included activities meant to foster deduction, such as sentence combination and pattern identification. This approach aligns with Lea and Street's first literacy model, called the "study skills" model, which sees literacy as a cognitive, individually obtained, transferable skill. Identifying literacy deficits as a kind of pathology, the study skills model focuses on surface level language skills by placing student abilities within a series of tiers, such as Piaget's stages of cognitive development (Lea and Street, "The 'Academic Literacies' Model”).

The narrative that basic writers are in some way cognitively stunted continues in another vein with scholarship that draws on Walter Ong's work on the divide between "oral" and "literate" cultures. When literacy is positioned opposed to orality, Ong's 1982 Orality and Literacy (a historical study of the ostensible impact of the introduction of literacy on the human consciousness, centering on classical epic poetry and rural tribesmen) is often invoked, framing orality as a kind of fundamental incompleteness that can only be made whole by literacy education. A protégée of Ong, Thomas Farrell brought his mentor's work into the realm of remedial college writers. Farrell reasoned that basic writers come from oral cultures; their "oral cast of mind carries with it profound restrictions on both the apprehension and the conceptualization of the external world" ("Open Admissions" 249) and limits "their degree of conscious control of what they are doing" ("Developing Literacy" 38). Literacy, specifically reading and writing, 
would infuse students' minds with the capacity to reach new levels of perception and logic (Farrell, "IQ"), even helping them become "more fully human" ("Literacy" 447).

The classic basic writing example of the theory of an "oral/literate" divide is Farrell's 1983 article "IQ and Standard English" on the "oral" home cultures of inner-city black youths. Farrell claims, citing Ong, that poor IQ scores by black children could be explained by their "functionally oral cultural environment" (472) that inhibited them from developing the abstract, analytic thinking required by the test; Farrell hypothesizes that "master[ing] the grammar of Standard English" (479) would improve their scores. This prompted a counterstatement response by Greenberg, Hartwell, Himley, and Stratton in the 1984 issue of $C C C$ that unleashed heavy criticism that Farrell's claims revived "racist myths" (455). Farrell's article and its ensuing response mirror larger concerns the field of rhetoric and composition had with the eager uptake of Ong (and others') work. Mike Rose summarizes the critique when he writes that the field's application of anthropological studies on orality and literacy to modern, urban Americans dangerously generalized the fictional linear evolution of literacy, relied too heavily on bipolar dichotomies, and was "historically, culturally, and economically reductive - and politically naive" ("Narrowing the Mind" 289).

Another example of the conflation of speech practices with intellectual/social maturity can be seen in the work of Basil Bernstein, a linguist, who spent the majority of his career conducting research claiming differences in language use could be traced to differences in social class ("Social Class"; Bernstein and Henderson, "Social Class Differences"). In studying the language patterns of working class youths and mothers, Bernstein concludes that these speakers relied solely on a "restricted code" of meaning 
making, one that was context-dependent and particularistic; working-class speakers could only reproduce speech, not produce it like the middle-class speaker who could access more "elaborated codes" ("Social Class" 233). Many of Bernstein's critics latched onto the implicit argument that the language of the working class was deficient (Danzig). ${ }^{25}$ Bernstein's hierarchy resonates with Farrell's work; Farrell argues that "the oral person is involved and committed to a given. . . 'received' ... position on matters, whereas the fully literate person, precisely because of being literate, is capable of being detached and looking at matters from different points of view" ("Developing Literacy" 32). The crux of these assertions is the ideological assumption that a subject's language patterns reflect their identity and environment; moreover, linguistic analysis can predict social success.

Both the oral/literate divide and cognitivism rely heavily on formulaic dichotomies: either you are oral or you are literate; either you are in Piaget's concrete operational stage, or the formal operational stage. Not only do both these models base their arguments on work taken out of context (Ong studied populations of people who did not read or write; Piaget studied children), they also reduce a complex human cognition to a process that is stable, uniform, and unchanging based on context or task (Rose, "Narrowing the Mind"; Berthoff). Both models also view literacy as a kind of "salvation" or "state of grace" (Scribner 13).

These theoretical framings of the basic writer as underdeveloped, and the language difference manifested in their writing as lacking or juvenile subscribe to a monolingualist stance toward language difference. In the United States, monolingualism

\footnotetext{
${ }^{25}$ It's worth mentioning here Min-Zhan Lu's chapter in Representing the Other in which she argues that Bernstein's work was taken up by basic writing scholars in ways that dismiss his attempts to find linkages between codes, meaning, and power, preferring instead to stretch his findings on linguistic codes into the realm of cognitive differences amongst students ("Importing 'Science'” 90-93).
} 
does not contest the existence of other named language varieties, but rather asserts that a singular, fixed ideal called "Standard English" is the default language against which alternatives compete. The monolingual approach aims to eradicate difference, seeing variance as working against the collective aim of universal linguistic understanding. U.S. policy still implicitly aligns with the monolingualist agenda, naming its educational courses on literacy "English" and teaching this language as if it were an unchanging globalized medium of communication (Yildiz, Beyond the Mother Tongue; Horner and Lu, "Resisting Monolingualism"; Horner and Trimbur, "English-Only”). The EnglishOnly movement is another manifestation of monolingualism; subscribers to this ideology imagine English as a reassuring, solid, unchanging force of American-ness. ${ }^{26}$ In her introduction to volume I of Language Ideologies: Critical Perspectives on the Official English Movement, Roseann Dueñas González asserts that language is the acceptable channel through which Americans who feel threatened by the dramatic increase in the non-white population in the U.S. can vent their racism (xxxii). To González, the quasirespectability of the English-Only movement legitimizes its demands: asking the entire population to speak some "correct" form of a single language "seemingly cultivates unity and integration" (xxxii).

In this way, monolingualism is a tool of colonization, and in our context, settler colonialism, erasing the other by asserting itself as always already existing and natural. Discourses of colonialism utilized in official language movements work to dominate and disempower social groups by making them subjects of a certain rule, rules that exert

\footnotetext{
${ }^{26}$ This misplaced sense of patriotism persists, despite 20 states in the continental U.S. having no policy on official language. Contrast this with the fact that English is the official, legally-mandated language of all territories with a history of U.S. colonization (Alaska, Hawaii, Samoa, Guam, Mariana Islands, Puerto Rico, and the Virgin Islands).
} 
control over daily lives, education, and community fabric, similar to the restrictions imposed by banning a religion (González xxx). Speaking and writing in "correct” English becomes a kind of "earned citizenship"; conversely, exposure of one's errors calls into question one's social identity, making us lose sense of who we claim to be (Lees, "The Exceptable Way" 144, "Proofreading" 223-6). Asserting an unchanging core of English turns the colonizing tool inward in order to assuage our fear of linguistic invasion by the other; we must separate the center from the periphery, the like from the unlike (Pennycook, Language as a Local Practice 82).

Like English, literacy was granted staggering stability, internal uniformity, and transformative power. Both cognitivism and the oral/literate divide represent examples of Street's theory of autonomous literacy: the idea that literacy is a monolith that, in and by itself, has effects on cognition and social practices (Literacy in Theory and Practice). To basic writing scholars of this time, the linguistic tools seemingly lay waiting, and the frustration felt by teachers stemmed from the question of why these students seemed incapable of grasping what was provided by their educational systems. The ideology of autonomous literacy similarly absolves its proponents from the charge that the claims they make about cultural differences are ideological in nature, ascribing the difference to the "neutral" technology of literacy itself and not to any group's superiority or inferiority (Street, Literacy in Theory and Practice 29). Both cognitivism and the oral/literate divide ignore dynamics of power but, more importantly, personify literacy, like they do English and standards, as transferable and transformative in and of itself. Rather than recognizing writing conventions as changeable and dynamic constructs contingent on the behavior of actants (Lu, "Metaphors" 290), this approach to basic writing held firm that students' 
deficiencies could be measured against a stable norm and remedied through alignment. Yet Shaughnessy's seminal text signaled a rift in this thinking even during the height of its prevalence, as the field broadened its view of how and why new language is taken up by individuals.

\section{Ryan: A Cognitivist Approach}

To highlight each approach's stance toward the basic writer as both individual and crafter of language, I include here an excerpt of a real writer's work, along with an overview of how each model would tackle such a submission. The sample comes from a student I will call Ryan, whom I taught in the spring of 2019. The course was the second of a two-semester mandatory writing sequence at a large, public, midwestern university. I had developed the course from a Writing in the Disciplines (WID) perspective; students spent the semester imagining and then learning about the writing, reading, and communication practices of the career fields they hoped to enter. Ryan was a preengineering major, but wrote in his daily class papers (akin to a free write journal) of his struggles with the writing and math required by his current course schedule. He was affable, funny, and had a charming southern drawl. He was also fresh from high school, white, and spoke with pride to the class about being the first in his family (who lived in a rural part of the state and farmed for a living) to go to college. He was one of the few students in the class to have perfect attendance, was punctual to a fault, but often had points deducted from his participation grade for chatting and texting openly in class.

Below is the first draft of an article annotation, part of the class' work toward a larger annotated bibliography that compiled findings in response to their individualized research questions. Ryan's research questions had to do with the written and verbal 
communication that happened on the job between engineers. He was particularly interested in how young, recently graduated engineers communicated with engineers below them in rank who might be older and more experienced, as well as how blueprints might be a unique form of communication for engineers. The assignment asked the class to "[b]egin by giving some brief context of the source, piece, and author. Summarize the information you learned from the source, and analyze it in relation to your research questions ... Include at least one direct quotation with an in-text citation ... End each annotation with a brief reflection on the usefulness of this source for your overall research." Here is Ryan's complete annotation:

"The article cited above was a well written piece on the communication in the field of construction. The author goes into great detail, on how important communication can be when working as a civil engineer. The article uses realwork examples to help explain the importance of communication, for an example "the customer must communicate their needs to the consultant engineers. The consultant engineers must understand the customer's needs and interpret them into a design. Then, once the plans have been developed and a bid has been taken, the contractor must understand the plans and communicate the plans to the subcontractors." This really shows how many people are involved and the importance of communication. The example above gives a clear understanding on how communication is key. It also does a great job on answering my question, on the form of communication that goes into building a blue print and then putting it into action."

There are larger-order issues with this annotation; namely, that Ryan describes the article as being "well written," using "great detail" and "clear understanding," and doing a "great job," making his annotation merely evaluative without actually providing a substantive summary or analysis of the source. The cognitivists would claim that Ryan's focus on lauding the article and his "inability to analyze and synthesize" it (Lunsford, "Cognitive Development" 41) in relation to his research questions is evidence of his inability to progress past Piaget's third stage of cognitive development: the concrete 
operational stage. Ryan cannot yet take what he read in the article and transfer it into the context of the annotation; he can only positively review the text. Analyzing Ryan's daily papers would provide further proof of the "connection between poorly developed writing skills and poor self-image, lack of confidence, and lower levels of cognitive development" (Lunsford, "The Content" 284).

However, the phrase I would like to center attention on is in the second sentence of the sample: "real-work examples." This is not the first time I encountered Ryan using the phrase "real-work." A few weeks earlier the daily in-class paper prompt asked students to free write about their excitement and hesitation concerning their upcoming interviews with experts in their field. Many of the students were new to the experience of conducting an interview with a professional, and I could tell most were nervous about logistics and potential awkwardness. Ryan wrote in that day's paper that he hoped the civil engineers he would interview would have "real-work experience" he could learn from. It was my habit to mark minimally on journals, leaving most grammar and spelling mistakes untouched in order to encourage a free flow of writing. However, in the margins of this paper of Ryan's, I wrote, "Do you mean 'real-world experience'?"

There is much of the cognitivist approach in my initial response to Ryan's phrasing. My default, almost instinctive reaction was to assume the phrase was a mistake: that Ryan misspelled "work" as "world" or was unknowingly mashing together "realworld" and "work experience." At the time, I thought perhaps Ryan had only heard the phrase "real-world" and heard it as "real-work," indicating my initial belief in the possibility that Ryan's orality trumped his literacy. Farrell would go further, claiming that although basic writers "mastered the rudiments of reading and writing, oral habits of 
thought and expression permeate and dominate their way of thinking” (Farrell, "Open Admissions" 248). Bernstein, whose 1962 study examined working-class young men only a few years younger than Ryan, would likely call this phrase an example of Ryan's unsuccessful attempt to take up the more elaborate codes of the middle-class, which his rural upbringing had so far denied him access to ("Social Class" 233). Rather than dig into the reasons behind the decisions Ryan made in his annotation, a cognitive approach would label him an underdeveloped, immature writer whose literacy history was found lacking when confronted with the demands of college writing. For the most part, the cognitive approach has gone out of favor, as the field of rhetoric and composition turned away from a psychological understanding of student development and toward a psychosocial approach.

\section{Part Two: Language Difference as Natural: The Basic Writer as Initiate}

Mina Shaughnessy's more holistic approach to basic writers' linguistic difference in Errors and Expectations was due in part to a frenzy of activity within the field of rhetoric and composition in the 1970s to define and address such difference; the decade saw the 1974 CCCC resolution on "Students' Right To Their Own Language” (STROL) championing students' "variant dialects" of English, Shaughnessy's book, and the 1975 founding of the Journal of Basic Writing. Part of this frenzy meant a change in nomenclature; as theory moved away from the deficit model, many institutions changed the name of their developmental writing class from "remedial" to "basic," as if heralding a break from an old paradigm. Unfortunately, as this "new" approach to basic writing tried to separate itself from past scholarship, it also inadvertently separated itself from 
past lessons (Horner, “"Birth”). This is a stage characterized by social constructivism, language rights, and celebrating diversity in all its forms. In this model, language difference is seen as naturally occurring and positive, just simply contextually inappropriate for academic settings. Students write differently from the "standard" because of a lack of exposure to the correct form, not because of cognitive deficiencies or oral home cultures. Basic writers, as initiates to academia, are constructed as seeking access to the dominant discourse and needing the help of expert guides (their teachers) to show them the ropes. Pedagogues attempt to fulfill a dual and tricky aim: applaud the diversity of their students' languages as well as the cultures they thought produced such languages, while at the same time teach the standard so as to enable their students to access its undeniable power.

This trend, which saw its chief popularity in the 1980s, turns away from what Bizzell calls "inner-directed" theories, and toward an "outer-directed" focus on development ("Cognition") which validates the mature minds of basic writers and aims to equip them with the tools needed to enter a new discourse, while acknowledging the utility of their existing toolkit. A key concept in this paradigm shift is that of the discourse community, which Bizzell defines as "conventions that bind [a] group ... at work together on some project of interaction with the material world" ("Cognition" 66). People who belong to a discourse community share literacy skills and practices, and individuals move between different discourse communities at different times in their lives (see Swales and Gee, and also Lees for her work on composition teachers as one of Fish's interpretive communities). In this framework, basic writers are conceptualized as struggling to join a discourse community they are unfamiliar with, while simultaneously 
being assessed on their performance (Bizzell, "Cognition"; Bartholomae, "Inventing the University"). "To help them, then," Bizzell writes, "we should be looking for ways to explain discourse conventions ... to ease the transition into the academic discourse community for students who come from discourse communities far removed from it" (“Cognition” 70). According to Bizzell, in order to challenge a discourse community’s conventions, one must speak from within the community "in terms the community already understands" ("Cognition" 76), sanctioning the teaching of Standard English in order to help position students as authorized challengers of language.

If the cognitive model aligns with Lea and Street's study skills perspective on literacy, this approach marks a similar parallel with Lea and Street's second model of literacy education: the academic socialisation model, in which the pedagogue sees him/herself as inducting students into the new culture of the academy (Lea and Street, "Student Writing"). This model assumes, as did the initiation basic writing theorists, that disciplinary discourses, conventions, and genres are both stable and unproblematically reproduced by novices (Lea and Street, “The 'Academic Literacies' Model” 369). Just as many basic writing courses still emphasize sentence-building and grammar drills à la cognition, the initiation model is still present in some of our programming today. We see the academic socialisation model in approaches to writing studies such as Writing Across the Curriculum/Writing in the Disciplines, which, some might argue, interpret disciplinary genre conventions as static, encouraging students to acquire these conventions in order to gain seamless access to that discipline (Mahala). ${ }^{27}$

\footnotetext{
${ }^{27}$ See Anis Bawarshi, Charles Bazerman, and Carolyn Miller for work on Rhetorical Genre Studies, upon which many WAC/WID models are based.
} 
According to the initiation theory of basic writing, student writing is evidence of idiosyncratic dialects at work, dialects that these theorists could interpret like diagnosticians. Taken from second language acquisition (SLA) theory, error analysis emerged as a popular methodology, quantifying errors into recognizable patterns, each with their own prescriptive remedy. In a way, these scholars apply a New Critical approach to basic writers' texts, close reading for logic and intention and "focusing on what they think the [student] text says, ... is trying to say, ... or believe it ought to say" (Lees, "The Exceptable Way” 152; Hull, “Acts”). Borrowing from SLA led scholars in this vein to consider academic discourse a true second language students are in the process of learning, and granted teachers the power to discern the precise moves basic writers are making during this interstitial phase in their initiation. This was called "Standard English as a Second Dialect" (Nattinger; Taylor, "Standard English”). For instance, Bartholomae's "The Study of Error" uses the SLA term "interlanguage" (256). To him, the identifiable errors in a writer's attempt to reproduce Standard English were not interference or noise, but glimpses into a developing process. While dabbling in sociolinguistics, this iteration of basic writing nevertheless begins to acknowledge the distinction between speech and writing, turning away from analyses of students' speech patterns as a key to understanding their writing. Writing is seen as having its own learning pathways, lexicon, grammar, and rhetoric, and therefore its own errors (Bartholomae, "The Study"). While nodding to the agency of basic writers, initiation theorists also stress the responsibility that compositionists take on when agreeing to teach the basic writer, unconsciously evoking a patronizing tone in taking on the toiling burden that is the remedial classroom. ${ }^{28}$ Comparing the work of students in basic writing

\footnotetext{
${ }^{28}$ This patronizing tone is apparent in the overt praise such scholars gave to their students' flawed attempts
} 
classrooms to that of English language learners perpetuates the belief that both populations veer away from a stable norm of correct "English," a norm toward which both classrooms are necessarily striving with the teacher as shepherd. Still, the initiation model encourages experimentation rather than lamenting errors, seeing students' "interlanguages" as active, purposeful approximations (however faulty) of the "second language" that is academic writing, not evidence of cognitive lack.

This approach to basic writing constructs the writer and her/his language difference in the same way as Street's academic socialisation model, and the bi/multi/plurilingualism turn in ideologies of language difference. These ideologies' acknowledgement of the existence of many named languages and named language varieties contributes to a newly desired diversity. This is a modern, neoliberal approach which permits yet contains linguistic difference in distinct realms of appropriateness, valuing it in certain designated contexts as a marketable skill for globalized workers, but without questioning the stable existence and necessity of mastering Standard English. Such ideologies also rely on the idea of linguistic codes: using terms such as "code switching" "code meshing" or "code mixing": concepts from linguistics that refer to a speaker or writer's ability to alternate back and forth between named languages in a single identifiable communicative episode, such as spoken Spanglish (for proponents of “code-meshing," see Young, "Nah, We Straight”, Young, Rivera and Lovejoy, and Canagarajah, "World Englishes"). Even within rhetoric and composition the distinction between terms like "code switching and "code meshing" is nebulous at best; despite our field's apparent preference for code meshing, Paul Kei Matsuda points out that the terms

to approximate academic discourse, indicating their quasi-scientific fascination by calling basic writers' errors "marvelous," "clever," and "ingenious" (Hull, "Acts" 199, 212). 
are interchangeable in linguistics, the field from which rhetoricians and compositionists “prospect" for new terminology ("It's the Wild West" 135). ${ }^{29}$ Despite differences in terms, the ideological assumptions inherent in both terms remains the same: language can be codified, "Spanish" and "English" are two discrete and recognizable language practices, and "switching" between them or "meshing" them, while a sign of dexterity, has varying degrees of consequence in academic settings (Lu, "Metaphors"). Moreover, as John Vance point out in "Code-Meshing Meshed Codes: Some Complications and Possibilities," satisfaction with the uncomplicated meshing of current, dominant codes “inhibit[s] our ability to consider more liberating, less marginalizing taxonomical possibilities" (284).

The move toward an embrace of bi/multi/plurilingualism goes by many other names, including zerolingualism, semilingualism, metrolingualism, polylingualism, trilingualism and transglossia (Pennycook, Language as a Local Practice). The bi/multi/plural model attempts to taxonomize language proficiency (for examples of this see Hornberger and the Common European Framework), maintaining a sense of hierarchy in language learning and command even while acknowledging language varieties (Street, Literacy in Theory and Practice 7). These efforts take up the question of how to handle students who straddle linguistic divides, an issue that has been at stake in the United States since the late 19th and early 20th centuries, with the Bureau of Indian Affairs boarding schools and government efforts to acculturate newly arrived immigrants (Spack, America's Second Tongue). Bi/multi/plurilingualism is inherently positive (unlike monolingualism's positioning of non-English as threat), seeing linguistic

\footnotetext{
${ }^{29}$ Matsuda himself at one point calls code-meshing "code-switching with attitude," calling the term "valuable insofar as it highlights the active and agentive use of language mixing" "It's the Wild West" $135)$.
} 
flexibility as essential for citizenship in a changing world. Still, what is outwardly multilingual may cling to the idea of languages as stable entities that one possesses, switches between, or is excluded from (Yildiz, Beyond the Mother Tongue 35).

An approach to basic writing that claims to be able to classify students neatly as either already capable of collegiate work or "outsiders" needing development is an example of what Tom Fox in Defending Access called the "social sorting" function of basic writing. To Fox, basic writing's role in (seemingly definitively) classifying its students dangerously portrays both academia and the students' home communities as stable, homogenous, and without any overlap (54). Even today, when we think of the kinds of students populating a basic writing classroom, we are apt to believe that the majority of these students must be second language speakers, or nontraditional students, or first-generation. This leaves little space for the traditional-aged, monolingual, middleclass, recent high school graduate, many of whom are assigned to basic writing. The risk in the initiation theory, as phrased by Kelly Ritter, is that "[i]f we continue to classify the whole of underprepared writers as 'strangers,' it is almost impossible for us to recognize and assist basic writers who emerge from other populations assumedly 'familiar' with academic discourse and intellectual conventions" (35). Ritter's project recognizes the basic writers of Harvard and Yale, and mine attempts the same of so-called monolingual students. While the initiation approach moved basic writing closer to an acceptance of alternative discourses, it nevertheless continues to rely on the inherent value of Standard English and the stability of academic writing and disciplinary writing conventions. The writing teacher can make error "count less" through tailored prescriptions but she still does not question why error counts or who it disadvantages (Hull, "Research" 181). 
Additionally, bi/multi/plurilingualism, which Ryuko Kubota calls the "multi/plural turn"

(475), risks "perpetuating color-blindness and racism" (474) in its overlap with neoliberal multiculturalism and subsequent uncritical embrace of diversity and hybridity.

\section{Ryan: An Initiation Approach}

Ryan's personality was cavalier, even overconfident in class discussions and peer reviews; he made friends with his tablemates easily, and while respecting authority by coming to class on time, the minutiae of classwork seemed to bore him. He often expressed that engineers in general, and he in particular, didn't need any English classes after high school, but his daily papers and reflections conveyed insecurities below the surface. For instance, in a daily paper written during one of the final classes of the semester, in which he was reflecting on his group's presentation compared to others in the class, Ryan wrote: "I probably was the worse [sic]. I wasn't very prepared and I should have B.S. more and added more to the group. I really let the whole team down. The last engineering group was good but I think we beat them." You can see here the interesting mix of Ryan's resignation at his own subpar skills with his competitive nature and characteristic bravado. While Ryan may have felt my class unnecessary, the B he earned as a final grade was the result of sheer grit and much revision.

A pedagogical response to Ryan in the vein of the initiation theorists would simultaneously acknowledge the external factors impacting his success in my course, (e.g. his high school education in a rural setting, his status as a first generation student, the importance of passing my class in order to stay on engineering's prescribed degree plan) while also honing in on the internal stylistic patterns of his writing in search of his idiosyncratic language. Rather than see his bland annotation or use of "real-work 
experience" as rooted in cognitive deficiency, initiation theorists interpret such deviation from the standard as evidence of a lack of exposure. The insecurities voiced in Ryan's daily papers illustrate his awareness of this lack; his writing expresses his desire for a teacher's expertise in realigning his language without revealing his outsider status to his peers, thereby compromising his initiation into the rites of academic discourse. He knew already that in order to succeed in college he, as Lees puts it, "must regard himself as already entitled to participate in the dialogue of the university - well before he has mastered the community's rule book” (“"The Exceptable Way' 152).

An initiation theorist might have responded to Ryan's second use of "real-work examples" with marginalia feedback in his annotation that attempted to explain the discourse conventions I was seeing at work: his "mix-up" of "real-world examples" and "real work examples." Ryan would need to know the difference, this model asserts, because he must first speak from within the sanctioned discourse of the community before being granted the authority to change this discourse. In other words, he must first belong to the club in order to try and enact change. This theory unproblematically bestows upon teacher/readers the ability to discern the true meaning of the text, even when the actual text itself belies that interpretation.

The structure of my class as a whole, being based on a Writing in the Disciplines (WID) model, lends itself well to an initiation approach, in that the goal of WID is to acculturate writers into the discursive practices of new communities through observation, deconstruction, and practice. WID assumes, as does the initiation approach to basic writing and Lea and Street's academic socialisation model, that disciplinary writing conventions are knowable, nameable, and stable. Otherwise, we could not "teach" them 
(Mahala 780). Although writing teachers of this bent acknowledge the discrete conventions of other disciplines, they themselves are still the bastions of grammatical truth, discipline notwithstanding. I did not grant Ryan the possibility that "real-work" could be a phrase deployed in engineering writing. I didn't even Google it to see. I assumed that I as teacher knew not only what Ryan meant to say, but what a vetted engineer would have said. While my noticing of the phrase and my inclusion of it in a class workshop (more on this later) indicate that I too stood "wistful and admiring" (Hull, "Acts" 223) of Ryan's crafting of language, my sense of the surety of the standard to which I was leading him, and my conviction in the "correct" way his annotation should have been written, would not waver from an initiation theory mindset. The chief aim for the initiation theorists, as was mine for the most part that spring, was to work to give students the language we know they need to access the power they want.

\section{Part Three: Language Difference as Opportunity: The Basic Writer as Conflicted}

In the 1990s, scholars of basic writing began to take issue with the initiation model, pointing out that initiation as a concept requires submission and a negation of one's self (Lu, "Conflict") and that communities by definition exclude and cannot be said to have clear internal consensus (Harris, "The Idea" 12-15). Elaine Lees even prefigured translingual descriptors, calling the rules of the academic discourse community "approximate, negotiable, revisable, [and] permeab[le]" ("The Exceptable Way" 156). Critiques surfaced that the initiation model failed to give significant attention to the ideological power structures shaping the basic writing classroom. This resulted in a paradigm I mark here as the conflict model. The conflict model expands upon the 
initiation model's idea that student errors are fault lines; to conflict theorists such errors are evidence of the jarring collision of students' personal language and the conventions of a foreign, academic discourse. Proponents of the conflict approach disagreed with the "appropriateness" of certain language varieties, arguing that our willingness to accept language diversity in some arenas but not others (in literary texts for example, and not student writing) condones linguistic injustice (Lu, "Professing Multiculturalism"). The issue, then, as Bartholomae writes, comes down to "not who misses the mark but whose misses matter and why" ("Writing on the Margins: The Concept of Literacy" 68).

Conflict scholars use student texts in classroom discussions of choice and effect, highlighting the unequal power relations made apparent when writers draw upon all available linguistic and rhetorical resources (Trimbur, "Translingualism"; Lu, "Professing Multiculturalism"). Min-Zhan Lu and Mike Rose both questioned the initiation model's mitigation of conflict, anxiety, and confusion in the basic writing environment (both that of students and of teachers), asserting that conflict should not be neutralized through classification, order, or de-escalation (Lu, "Conflict"; Rose, "The Language of Exclusion"). Pushing back against the traditional insistence that students write clear prose capable of being seamlessly transmitted to their reader's understanding, conflict theorists encourage negotiation of the reader/writer relationship, seeing moments of linguistic confusion in student writing as gateways into fruitful discussions about language conventions and redefinitions of meaning, thereby expanding what language makes possible. The conflict model challenges the initiation model's framing of discourse communities as static (Fox, "Basic Writing"), forwarding instead a model of cultural conflict that acknowledges the dynamic and polyvocal nature of discourse communities. 
Forced initiation into academic discourse is viewed as neither desirable nor possible (in that the idea of a single, stable and knowable "academic discourse community" is a fiction). The conflict model places the onus on teachers to show students that academic discourse itself is adaptable, and that students hold the keys to enact change upon the system rather than be subsumed by it (Fox, "Basic Writing"). This acknowledgement of students as caught in an institutional web turns away from what Rose calls the "myth of transience," false thinking of past ideologies that if education (especially the K-12 system) works harder to remediate basic writers, they won't exist in the future ("The Language of Exclusion"). While still sympathetic to the idiosyncrasies of student patterns of writing against the grain, basic writing teachers of this era imagined the feelings of conflict and anxiety in their students as useful experiences of dwelling in the space between discourses, which are themselves in flux, as student identities are in flux (Lu, "Conflict"; Fox, "Basic Writing”). Lu writes that language education, as a "process of repositioning" ("Conflict" 890), "is a source of pain but constructive as well: a new consciousness emerges from the creative motion of breaking down the rigid boundaries of social and linguistic paradigms" ("Conflict" 888; and "From Silence"). Conflict theorists hope to harness the power of this motion, encouraging students to leverage the dissonance amongst their discourses to both "resist and transform academic discourse in their writing" (Lu, "Writing as Repositioning" 19) as well as "problematize the domination of academic culture both within and outside the classroom" (20).

This paradigm, with its explicit emphasis on power and marginalization, corresponds with two of Street's theories of literacy: his ideological literacies model, and Lea and Street's third and final literacy model: the academic literacies approach. As 
opposed to the ideology of autonomous literacy, which grants literacy itself the power to change lives, Street's ideological model of literacy unveils the cultural and ideological assumptions that underpin any literacy campaign, insisting that literacy is neither neutral nor benign (Street, "What's 'New' in New Literacy Studies?"). In the context of higher education, the academic literacies model argues that literacy is a social practice, and its ideology is "transformation rather than normative" (Lillis and Scott, "Defining Academic Literacies Research" 12). Lillis and Scott link the "normative" model with an "identify and induct" approach which mirrors the initiation model described in this chapter; this approach constructs learning as "a journey with marked stages and the [teacher's] role as being to move or induct students into conventions and practices currently considered to be appropriate" (Lillis and Scott, "Defining Academic Literacies Research" 14), assuming the "homogeneity of the student population, the stability of disciplines, and the unidirectionality of the teacher-student relation" (14). In contrast, Lillis and Scott's academic literacy model of transformation considers, as does the conflict model of basic writing, academic conventions as contested, meaning making as a struggle, and explicit discussions of authority as the purview of the classroom. Forefronting the ideologies of teachers, students, and institutions of higher education is the work of both the academic literacy model and the conflict model of basic writing. An academic literacies model asks students to switch literacy practices frequently, deploying different aspects of their repertoire in ever-changing academic contexts; this potentially results in student resistance (Lea and Street, "Student Writing"). Rather than be deterred, proponents of the conflict approach to basic writing would welcome this resistance and make it a topic of study and class discussion, similar to critical pedagogy. 
Conflict theorists were progressive in their acknowledgement of academic discourse as "overlapping and conflicted" (Harris, "The Idea of Community" 19), even if that same slipperiness was not awarded to language in general. Conflict theorists weren't yet willing to go that far. Accordingly, the conflict approach to language difference maintains an ideology of multi/plurilingualism. While the multiplicity of conflicting discourses was problematized and galvanized for pedagogical purposes, languages themselves were still considered discrete entities, just entities in tension rather than submission. While the initiation model's multilingualism was a celebration and a compartmentalization, the conflict model's multilingualism was fraught and dissonant. For instance, in her 1987 piece "From Silence to Words," Lu's personal narrative of her adolescent struggles to reconcile the Marxism of Mao Tse-tung with her Western humanist education at home ultimately manifests as a seesaw in which "Chinese" as a bounded language is pitted against "English." There is friction between the two languages only in the personhood of Lu-as-speaker; they remain mostly solid outside of that context. Lu writes metaphorically that as a child she expected herself "to set down one discourse whenever I took up another just as I would take off or put on a particular set of clothes for school or home" ("From Silence" 445). Lu does begin to enclose the word "language" in quotation marks, indicating her growing "suspicion," in the final pages of the narrative ("From Silence" 443), yet at its conclusion, Chinese and English remain "conflicting voices," implying the coherence of each when separate entities ("From Silence" 444). Ultimately though, Lu's work, as well as that of Horner in pieces like "The Birth of Basic Writing," which explicitly sets out to examine and deconstruct binaries in the field of Basic Writing (such as the dual demand to teach grammar vs. draw 
on students' existing resources), is chiefly interested in deterioration of borders taken for granted as firm.

Eventually, proponents of the conflict model began to identify internal flaws. Embracing conflict is difficult to enact in practice for basic writing, since its formative moment in CUNY's open admissions was based on accommodation to the dominant discourse (that basic writers are illiterate people of color who could not be expected to achieve much) rather than resistance to power structures (Horner, "'The Birth"”). Basic writing has, by definition, never been able to push back against the pre-existing definition of academic excellence, or question why these students (many of whom are white, working class youths) have been barred from college. This accommodation won basic writing a place in academia, albeit a perpetually marginalized one, that faces intense scrutiny and the pressure to produce measurable results. The conflict model has also been accused of importing exotic cultural difference into the classroom, teaching what Joseph Harris called a "multicultural bazaar" rather than centering its focus on difference as it already existed in the unfamiliarity of basic writers' texts ("Negotiating the Contact Zone" 33). ${ }^{30}$ While nearing Street's ideological literacies model, pedagogues welcoming conflict in basic writing still struggled to surrender the authority long granted academic standards. Rather than questioning the validity of the standard (as current basic writing scholarship that takes up translingualism is beginning to do), scholars of the conflict approach tried to raise the value awarded to basic writers' text to meet that of the standard. For instance, in dissecting the essay "The Boy Who Saw the Light" by basic

\footnotetext{
${ }^{30}$ For example, Lu utilized Jewish and Black educator narratives by Leonard Kriegel, Irving Howe, W.E.B DuBois and James Baldwin as examples of how to creatively cope with double consciousness ("Conflict"), and Tom Fox centers "Basic Writing as Cultural Conflict" on the anxious experience of African American students in college.
} 
writer Leon in Tom Fox's "Basic Writing as Cultural Conflict," Fox asks readers to consider Leon's discursive ability "to do academic work" by focusing on his linguistic adaptability rather than the plethora of "misspellings or idiosyncratic punctuation" which "[n]o doubt and no argument, Leon needs to work on" (80). The "requirement to join" (Fox, "Basic Writing" 71) academic discourse did not dissolve in the conflict model; rather, students were newly seen as capable of consciously "accommodating, resisting, or reproducing" (note, not yet capable of changing) the "cultural forces" that shape them (Fox, "Basic Writing" 81).

Ryan: A Conflict Approach

Rather than assuage Ryan's insecurities by gently guiding him toward "correct" disciplinary writing conventions, the conflict approach to basic writing would harness Ryan's anxieties about the rigorous writing expected of him in college (he was certainly not alone in his stress) as class material. A conflict model would use the "pervasive, immediate" concern to "sound "right"” (Lu, "Professing Multiculturalism" 446) amongst the class ${ }^{31}$ as a springboard into the discussion of the "re-production, approximation, negotiating, and revising" of the "norms of academic discourse" (Lu, "Professing Multiculturalism" 446). Though most of my feedback was of the shepherdess sort, I did embrace the conflict model's focus on explicit class conversation on the discursive power of writing conventions in the way described by Lea and Scott's academic literacies model.

I chose Ryan's annotation to be included in the third class wide workshop of the semester. In these workshops, I select three or four sections of student work to be

\footnotetext{
${ }^{31}$ Another student in the same class, Leah, wrote in one of her journals "My only concern with [a class assignment] is that I sound stupid. Mine is just generic while everyone else's is more specific and sounds good."
} 
distributed and displayed for the class anonymously. The class reads and annotates the excerpts, and then I open up the floor for discussion. In previous workshops and rounds of peer review I had tried to steer students away from focusing too intently on sentencelevel issues, encouraging them rather to spend time talking with peers about larger issues like ideas, organization, and support of claims. It was therefore unsurprising to me that the class did not immediately call attention to the "real-work examples" phrasing I was interested in. During a lull in the conversation around Ryan's piece (he had up to this point chosen to remain anonymous during the workshop; some students liked to identify themselves as the writer to clarify a point or ask a direct question of the group) I asked, "What about the language of this piece?" and it was at this point that a student pointed out "real-work examples," saying that the writer had mistakenly added a dash and it needed to be deleted. At first this recommendation went unchallenged, but then Ryan stepped in to defend his phrasing. He outed himself as the writer and said the phrase meant that the examples in the article were real and not, for instance, hypothetical situations. With no further discussion, at this point the class was willing to accept Ryan's eclectic phrasing and another student switched gears to discuss Ryan's quotation integration.

To the conflict theorists, this workshop was a missed opportunity for students "to explore the full range of choices and options, including those excluded by the conventions of academic discourse" (Lu, "Professing Multiculturalism" 447). A conflict approach would have harnessed the energy of past class conversations about the gatekeeping power of discourse in students' various imagined disciplines and created a contact zone in this workshop. As Lu did with her student's phrase "can able to" in a 
similar scene, I could have asked the students to consider the position of "real-work examples" within the dynamics of the annotation's content. For instance, why did the writer find it important to highlight that the article provided authentic and not hypothetical examples? Why is the genuineness of the article's examples a key point in its valuation? Perhaps the writer, being a novice engineer, wanted to stress that the source was valuable to engineers, knowing I, as a non-engineer reader, might not be able to distinguish between "real-work examples" and fake ones. In this way, the writer was stressing the credibility of real engineers in discussing his topic, not English teachers. I could have broken down how I, as reader, saw "real-work examples" as a fruitful conflation of "real-world examples" and "real work examples," thereby "furthering the students' existing construction ... so it is not easily silenced" (Lu, "Professing Multiculturalism" 452). Rather than convince students that linguistic "rules" are easily ignored or forgotten, such a conversation would have "acknowledge[d] the writer's right and ability to experiment with innovative ways of deploying the codes taught in the classroom" (Lu, "Professing Multiculturalism" 457), thereby demonstrating that the discourse communities they seek to enter in a way already belong to them, and "will not work against their identity and their interests" (Fox, "Basic Writing" 75).

Ryan was, after all, openly interested in balances of power. His research questions hinted at this. He wanted to know how younger engineers, fresh out of college in positions of power, communicated with older, more experienced engineers. In other words, how do you talk to subordinates who are skeptical of your authority? If he was not alone in his writing anxieties, surely he too was not alone in feeling unsure about how to navigate authority in the workplace once vetted by the stamp of a collegiate education. 
Ryan was not the only student from a rural area, nor the only first-generation student in the class. The class was composed entirely of traditional-aged students. A third of the class was female. There were also non-native speakers of English, students of color, LGBTQ-identified students, and students with disabilities. While difficult, discussions about holding and exercising power in new discursive communities would likely have been engaging and practical for all involved. To conflict theorists, such conversations serve as steps in the painful "repositioning" that is education (Lu, "Conflict" 890).

\section{Part Four: Questioning Language "Difference": The Basic Writer as Agent of}

\section{Change}

In recent years, language theorists have turned away from the idea of discrete languages and linguistic codes, toward the fluidity and negotiability of language, termed "translingualism." Translingualism was brought to the attention of many in the field of rhetoric and composition by a 2011 College English opinion piece co-written by Horner, Lu, Royster, and Trimbur, with 50 teacher-scholars adding their names to the article in support. Since then, the term has been widely explored and taken up. ${ }^{32}$ It is worth noting that the term translingualism has been taken up in conflicting ways, some of which do not wholly break with past ideologies (Horner and Alvarez). Rather than actively working against the former language ideologies, translingualism decenters the imaginary essence of language in a postmodern move toward a reconfiguration of what language means,

\footnotetext{
${ }^{32}$ Translingualism's popularity is exemplified most recently by special issues in College English, L2 Journal, Language and Education, Translation Studies, and EuroAmerican Journal of Applied Linguistics and Language, edited collections including Crossing Divides: Exploring Translingual Writing Pedagogies and Programs (2017) and Literacy as Translingual Practice: Between Communities and Classrooms (2013), Translingual Practice: Global Englishes and Cosmopolitan Relations by sociolinguist Suresh Canagarajah, Translingual Identities and Transnational Realities in the U.S. College Classroom, a CompPile WPA bibliography on translingualism (2019), and the website www.translingualwriting.com.
} 
looks like, and does. Where monolingualism was the either/or, bi/multi/plurilingualism was the both/and, and translingualism is the neither/nor (Guerra, "Putting Literacy In Its Place"). To translingualism, languages are not unchanging systems that speakers draw upon to communicate, but rather constructs that change through users' repetition and relocalization (Pennycook, Language as a Local Practice). The "stable core" of English is open to question as an illusion created by our misrecognition of sedimented behavior as underlying rules (Pennycook, "Myth"). Translingualism is not an observable mixing or switching of languages, but a frame of mind in which language is not discrete and movement is not progressive. Rather than an outgrowth of monolingualism, bilingualism, or multilingualism, it is recognition of diverse practices that have persisted before and even during the reign of monolingual ideologies.

In the realm of basic writing, while recognizing the possibility that writers make mistakes, translingualism is wary of calling what may seem to deviate from "Standard English" an "error," when it may in fact be innovation. Even a decision to adhere to the norm and reproduce the so-called standard is in itself an act of agency when made consciously after deliberating one's linguistic options (Lu, "Metaphors Matter" 290). We are just now beginning to see publications that position translingualism and basic writing together: common pedagogies include the integration of reflective and multimodal storytelling or ethnographies of the self in the basic writing classroom (Mlynarczyk; Parmegiani, "Bridging Literacy Practices through Storytelling”; Corcoran; Wang), reconfiguring the purpose and practice of sentence-level class wide workshops (Stanley, "Noticing the Way"; Horner "Relocating Basic Writing"; Lu "Professing Multiculturalism"), and considering assessment practices that incorporate respect, 
listening, and negotiation (Inoue, "Writing Assessment"). There has been little theoretical work that joins translingualism and basic writing to find its harmonies and disjunctures. ${ }^{33}$ As previously alluded to, the boundary between the conflict model and translingualism is shifting and porous, and translingualism has received some of the same critiques, including an undue, touristic fascination with language difference that may lead students to believe they must bend language rules on the page to achieve self-expression (Matsuda, "The Lure").

This project offers translingualism as both example of and extension beyond Street's theory of ideological literacy, in that proponents of translingualism see literacy as a social practice, thereby divesting language and literacy from any intrinsic ability to empower students. Empowerment results from the same source as disempowerment: context-dependent, emergent language practices by human actants. In future chapters I will argue that nascent translinguality can be seen in previous iterations of basic writing pedagogy and programming, and that language ideologies like translingualism have informed, and should continue to inform, basic writing studies.

\section{Ryan: A Translingual Approach}

While the following chapters will provide an in-depth exploration of a translingual approach to error in the context of basic writing pedagogy, it is worth returning briefly to Ryan once more to see how a translingual approach to "real-work examples" may extend beyond and differ from that of the conflict model. Translingualism sees "real-work examples" as a successful negotiation of language. All readers, from myself to his workshopping peers, understood Ryan's meaning without

\footnotetext{
${ }^{33}$ Exceptions include Horner's "Relocating Basic Writing”, and Trimbur's "Translingualism and Close Reading."
} 
difficulty. As engineering is often about precise, concise languaging, "real-work examples" is a more effective way of saying "real-world work examples" without any loss of meaning. "Real-work" also opens up new realms of possibilities; by repeating and "relocalizing" this construct, Ryan has broken a chain of behavior and has made space for transverse movement (Pennycook, “The Myth"). What now stops us from saying "realschool experience," "real-home examples"? Translingualism acknowledges that "real[place/activity]" has "the potential to achieve status as the norm, at least for a time, through subsequent iteration" (Horner, "Relocating" 16).

Sanctioning Ryan's innovation, the class mirrored Ryan's belief in his own authority to exercise language in a way he sees fit; his decision to repeat the phrase in his annotation after my earlier, questioning marginalia in his daily paper demonstrates that no, he did not mean "real-world." Translingualism would "detrain" me, as reader, to focus on the reality of the text in front of me, not search for hidden meaning that I as expert can decipher better than the crafter himself (Krall-Lanoue 237). This does not mean I would read without noticing what I interpret as error; instead, I would stop to notice the "error," the "miss-communication between writer and reader" (Stanley 40), so as to grant Ryan's writing the greatest potential of meaning and create space for negotiation. Rather than decide what is correct, or even what is appropriate, translingualism advocates for practice that asks students "how they are doing English and why" (Lu and Horner, "Translingual Literacy" 32) in its assertion that students "write, and rewrite, English" as opposed to write in English (Horner, "Relocating" 16).

If students had been able to choose their own sentences for workshopping, as in Sarah Stanley's "Noticing the Way: Translingual Possibility and Basic Writers," they 
would have more ownership over the language chosen for discussion and would, by default, not have already "noticed" any errors highlighted by the group, thereby eliminating from the conversation any simple writing mistakes such as misspelled words the writer would notice and correct on his/her own (46). The workshop, for Ryan, would have become, instead of a contact zone, a "space to develop his misunderstanding" with the participation of the class (Stanley 52). For me, both reading Ryan's phrase in his daily paper and listening to him in the workshop would be opportunities to re-see his language (and language in general) as well as re-examine my own expectations. Translingualism permits the possibility that Ryan is playing with language to convey a complex idea. Even here I am presuming that I know what "real-work examples" is trying to say; that is how strong the grip of evaluative reading practices can be.

In practice, a translingual workshop might experiment with the aforementioned phrasings of "real-work" to consider the rhetorical change in meaning brought about by small linguistic changes. Moreover, a translingual approach steps back from a laser focus on this phrase into a discussion of whether and when such "play" with language might be permitted, or even encouraged, in students' academic, professional, or personal writing. Similar explicit discussion would question why college students are being asked to summarize or annotate at all; what ability does this type of writing demonstrate proof of, and why is this ability in demand in neoliberal workplaces? Continual zooming in, only to zoom out illustrates how, to translingualism, a single utterance of language can be representative of language in general and, vice versa, how conceptualizations about porous language borders may (or may not) manifest on the page. 
The intersection between translingualism and basic writing is in its infancy, and the introduction of Street's ideological literacy to this conversation, with its contestation of academic writing conventions, is new ground (Lillis and Scott, "Defining Academic Literacies"). Whereas basic writing was once much concerned with distinguishing itself from ESL/L2 writing (Friedrich; Matsuda, "Composition Studies"), more recently the presence of linguistic difference in the basic writing classroom is seen as enriching, rather than diluting the learning experience of so-called monolingual basic writers. Still, the links are tentative, and scholars often default to utilizing translinguality as a theoretical frame in which to situate specific and context-dependent pedagogies, rather than stepping back and asking how translingualism informs our conceptualization of basic writers and their role in our institutions. By demonstrating that since its inception, basic writing has been irrevocably linked with evolutions in ideological stances toward language and language difference, this chapter paves the way for the remainder of this work, which presents translingualism as an ideology that can open doors for agentive basic writing classrooms.

The next chapter narrows in on two manifestations of a language ideology in a writing classroom: belief in a "standard" and the treatment of "error." These are also the dual anxieties of both basic writing practitioners and skeptics of translingualism. Scholarship in this vein often takes the form of study on Standard American English, error analysis, linguistic varieties and dialects, and treatment of language difference in the writing classroom. ${ }^{34}$ In this way, the study of language difference is inherently part of the

\footnotetext{
${ }^{34}$ Standard American English, or SAE, is a term for the language of formal transactions and communications in American English. The term itself encompasses various registers (both the text of a newspaper article and an academic journal would be considered SAE, despite different valences). Standard English (SE) is a more general term for the lingua franca of international commerce.
} 
study of the concepts of standardization and error. Though widely considered social constructs, standards are nevertheless upheld and given much prominence in higher education and in the writing classroom. This tension is nowhere clearer than the basic writing classroom, where the power of the standard comes not from without but rather within. By definition, basic writing creates and maintains the primary space necessary for the idea of a universal, unchanging standard to thrive. Moreover, students often vehemently proclaim their desire to be corrected, and for their writing to be "correct." We know that realignment is impossible, given that the core itself is unstable and shifting. Chapter two asks the question: why do we continue to attempt to it, and what are the alternatives? 


\section{CHAPTER TWO:}

\section{QUESTIONING THE REIFICATION OF “ERROR” AND “STANDARDS” IN THE \\ BASIC WRITING CLASSROOM}

What constitutes an error, and what is the standard to which student writing should conform? Has the field always meant the same thing when deploying these terms, and for what purposes are they deployed? By enclosing both in quotation marks in my title, my skepticism concerning the ontology of these terms is likely self-evident. However, it is not enough to simply expand or blur the boundaries of meaning when defining error and standards. A translingual approach to basic writing, I argue here, must work backwards to understand the field's justification of its attitude toward writing that "deviates" from some central core of correctness. Understanding why so much labor has been expended over the years attempting to solidify these terms carves out space for retraining (or "de-training” as Aimee Krall-Lanoue writes in "A Translingual Approach to Error in a Multilingual Context") and re-envisioning what difference on the written page of basic writers looks like, does, and means. Relinquishing the notion of control, both the control basic writers need to obtain over their own script as well as the control teachers must exert in overseeing this effort, is a chief tenet of the translingual basic writing framework I propose. When controlled prose and controlled students are no longer goals of basic writing, the so-called "errors" of basic writers can exert new, positive pressure on not only basic writing teachers, but on language as a whole. 
Why devote a chapter to error when basic writing encompasses so much more than a pedagogical response to student texts that deviate from a reader's expectations of convention? In short, the field's stance toward error reflects its broader view of both student writing and students. In the words of Tracy Santa, author of Dead Letters: Error in Composition, 1873-2004, error can be read as "a synecdoche, a fragment revealing a larger design, a thread running through the history of composition, which . . offers insight into the nature and progress of the field as a whole" (viii). Tracing the evolution of the field's conception of and response to standards of writing conventions (and their violation in the form of error), therefore, sheds light on ongoing attempts to grapple with language difference as perceived in student texts. As early as 1940, Karl Dykema wrote in the first volume of College English that "often language serves as a shibboleth" (617), with correctness being "an easy - and often extremely unjust - means of forming a superficial estimate of an individual" (618). Error has customarily served as a red flag, invalidating the "reader's sense of linguistic propriety" (Dykema 618). However, correctness is notoriously slippery, being merely that "which is felt or believed to be correct" (Dykema 618); "mere rules of correctness cannot be relied upon" (618). The indefinability of both correctness and incorrectness, when juxtaposed with the high stakes for both, makes error a rich topic of study. The nature of these "red flags," their origins, crafting, and purposes must be examined, if their overabundance ultimately voids a student's right to a place in a college classroom. Basic writing as a field exists because of this perception of overabundant error, and higher education continues to relegate the perpetrators of error to basic writing classrooms. Mina Shaughnessy's 1977 Errors and Expectations is often called a seminal text for basic writing, and its centralization of error 
(paralleling the inaugural issue of The Journal of Basic Writing's theme of error, with Shaughnessy as editor) has made error the "sine qua non of basic writing and basic writers" (Santa 49). This is no accident. Basic writing, arguably the most visible site of language difference in college, exists not because a distinct population needed separation from traditional college writers; rather, traditional college writing can only define itself by naming and excising what it is not (Nordquist). First year composition thus separates itself from its own historical identification as a place of writing remediation, expelling that inferiority into the sphere of basic writing. The boundary between basic writing and first year composition, often drawn by quantifying error, is what gives FYC its shape and sense of self. Consequently, the field's understanding of error has not only called basic writing into being, but also maintained its viability.

Errors on the page by basic writers glitter and snag readers' attention, but my argument relies on the premise that the phenomenon of error resides not in words or punctuation marks (i.e., the page), but in the environment of the reading context. What is seen as a standard and what is defined as error, though teachers may navigate by their constancy, are always undergoing rapid change. ${ }^{35}$ Studies by Elaine Lees have demonstrated the arbitrariness of error; what some composition instructors mark as incorrect others think is acceptable ("The Exceptable Way," "Proofreading"). Drawing on Stanley Fish, Lees highlights how, despite the assumption that errors within student texts are available for discovery "in the way orchards contain apples and apples contain worms" ("The Exceptable Way" 145-6), in reality the "interpretive community" of writing teachers, while they may "perceive a good many errors about ... rarely agree on

\footnotetext{
${ }^{35}$ In their 1988 error-analysis study, Connors and Lunsford even note types of once-significant errors described in early 20th century scholarship on student writing that today cannot be easily understood, such as "stringy sentences" and "use of would for simple past tense forms" ("Frequency" 399).
} 
exactly where the errors appear" (150). Lees points out that the readers in her study have all been vetted by their survival of the trials of academia; they "are Insiders by definition" (151). Rather than throwing into question how accurate teachers are as proofreaders, Lees instead explores what it is readers are doing when they read for error. If each reader is conducting a different kind of assessment, it is no surprise that they obtain different results. Lees concludes that the interpretive community of composition instructors may be homogeneous in purpose, but is heterogeneous in practice. In other words, even if approaching the same student essay, each individual reader will construct, or "write," a different kind of text.

What the academic community deems "unacceptable" is both idiosyncratic and contextual, as demonstrated in Joseph Williams' 1981 “The Phenomenology of Error.” Williams writes ostensibly of the errors ironically present within grammar handbooks by authors like E.B. White and H.W. Fowler, errors that have gone unnoticed for decades by these texts' readership. Only at the article's conclusion do readers learn that Williams deliberately inserted a host of errors within the body of his essay, to highlight how few errors readers notice if they come to a text in search of content rather than mistakes; that is, if they automatically ascribe authority to the writer. Calling error "a variably experienced union of item and response" controlled by intention, Williams asks readers to shift their perspective to one where "we can talk about how we experience (or not) what we popularly call errors of usage as they occur in the ordinary course of our reading a text" (158-9). While the field did not take up Williams' now forty-year-old challenge, it is from that vantage point that I will construct a translingual view of error. 
Facing this new framing of error fills the seasoned pedagogue with understandable alarm, as it proposes to alter highly ingrained patterns of reading and assessment. For this reason, hollow notions of error and standards are the dual, yet intertwined forces preventing a consideration of the affordances of a translingual approach to basic writing. Thus, the following six sections offer a gradual, sequential "de-training." I begin by providing the traditional definitions of error and standards, highlighting their arbitrariness. Next I delve into understanding the vested interests stakeholders claim in upholding clear-cut standards and eliminating error, both for personal and national prestige. Then I critically examine this vested interest, finding that the purported aims to eliminate linguistic confusion and streamline the role of the reader do more damage than they do good. I conclude by outlining translingualism's stance, which, contrastingly, welcomes confusion and complicates the role of the reader. Overall, these pages seek to divest readers of an uncomplicated, value-free notion of error and standards and begin the redefinition of these ideas necessary for the later consideration of a translingual approach to basic writing pedagogy and programming.

\section{Defining Standards and Error}

A language pattern becomes and continues as a standard through an ongoing and never-ending process. Often, this process is initiated for nationalistic reasons, such as the formation of a new country. William Kretzschmar and Charles Meyer, in their "The Idea of Standard American English," give the example of John Adams, who in 1780 wrote in letters to Congress of his dream of establishing an academy that would concretize standards for American English as distinct from British English (139). Adams' goal 
exemplifies the desire to unite a fledgling America under a unique, yet consistent linguistic banner. The idiosyncratic American way of spelling, outlined in Noah Webster's 1783 American Spelling Book, is one such example of the ideological effort to distinguish nationhood through written linguistic forms (Kretzschmar and Meyer 140). As Suzanne Romaine writes in Language in Society, "American” English became a shared symbol of nationhood (88). The politicization of language is thus used as a tool by movements claiming to promote patriotism, such as English Only, but, as Kretzschmar and Meyer point out, nothing about standardization is inherently tied to a particular political point of view (155).

Language standards are never natural evolutions, but are rather "created by conscious and deliberate planning which may span centuries," whose processes "can never be regarded as complete" (Romaine 88). Brice Nordquist, drawing on Joseph Roach's concept of surrogate doubling, describes how nonstandard forms of English are invoked as "linguistic doubles or antitypes" of "correct" English, a repeated performance meant precisely to disavow that which was invoked (60). Such invocation, argues Nordquist, bolsters the fiction that standard English has a core that is fixed and pure, reinforcing the imaginary boundaries of standard English by constructing it in opposition to its lesser double, the nonstandard or deviant form (60-61). The boundaries that purport to define the standard are determined in part by influential people, who adopt the prestige variety and disseminate it geographically and socially (Milroy and Milroy 22). Some aspects of standardization are more clear-cut than others. Spelling, for instance, is strictly policed, whereas notational practices such as, say, comma usage, are considered by many to be more idiosyncratic and stylistic. Therefore, the consequences for violating a 
standard of spelling are much higher than those for disregarding conventional sentence boundaries. Still, even spelling is not static. As standards are updated, new rules are enforced and maintained in the ongoing practice of lexicography.

Essential to the maintenance process of standardization is codification, seen in the freezing of syntax rules into grammar handbooks or spelling rules into dictionaries. Codification outwardly legitimizes any given writing practice and makes this practice ostensibly available for uptake by any citizen with the means of accessing the code (Milroy and Milroy 50). In this way, the process of standardization is linked with the acquisition of literacy; such acquisition presupposes that a codified standard is available for learning (Lillis 7). Unlike speech, which is presumed to be acquired naturally, the learning of writing is positioned as requiring organized study, and a codified standard provides such content. Frequent public outcries of a literacy crisis, such as 1975's "Why Johnny Can't Write" in Newsweek, are attempts to appeal to the gatekeepers of language to reverse the perceived decline in language abilities. In these cases, authority, usually in the form of educational institutions, are tasked with increasing the stringency with which they align their teaching to what is imagined to be the current prestige language variety. The official aim of standardization in language, as in other forms of standardization such as coinage and machinery, is function, efficiency, and reliability. Consistency is imagined to increase the confidence in any medium of exchange, yet humans are not duplicates, and human communication cannot be likened to the mechanization of factory work or the transportation of goods. By fixing "correctness," standards ostensibly claim to prevent linguistic misunderstanding, therefore ensuring progress in a society fueled by the efficient production and distribution of capital. In this way, standardization is posed as a 
reliable known in the face of the opposite, often framed as a return to Babel. This portraiture of normal, regular language variation and negotiation as chaos, or incomprehensibility, furthers the agenda of the ideology of standardization.

Milroy and Milroy in Authority in Language write that standardization is "an idea in the mind rather than a reality - a set of abstract norms to which actual usage may conform to a greater or lesser extent" (19). Locating standardization as internal and idiosyncratic, rather than identifiable in the outside world as universally recognizable, aids in understanding how, rather than reflect a linguistic reality, standards dictate how people should write. While it might sound paradoxical, like asking whether the chicken or the egg came first, the stakes in this origin story are high. Considering that, as Kretzschmar and Meyer argue, academic conventions are the standards that shape academic writing, and not vice versa, then it makes sense that pure, pristine academic writing has no identifiable location; no discipline owns the rights to it. Instead, academic forms of language are revealed to be ideological ways of thinking that overlay all disciplines. Too often standard language can be portrayed as "refined and elemental, in the same way that raw ore can be refined and purified into 24-carat gold" (Kretzschmar and Meyer 143), fashioning the standard into a kind of ultimate repository out of which all language users draw. This model portrays language as existing in a vacuum apart from the contexts of time, space, and human agency. Dissecting this portrayal is essential for understanding how and for what aim forms of writing are pitted against each other and evaluated.

Standards, ostensibly neutral and value-free, are in fact a proxy way to discriminate against certain races, religions, genders, or social classes (Street, Literacy 
27), in that standards are a symbol available to elites for "displaying and embodying privilege" (Coupland 624). Despite the "artificiality" and "snobbishness" of a "dogmatic insistence on correctness" (Dykema 622), the invocation of language standards (or outcry at their violation) remains "a convenient, even an indispensable means of judging others" (Dykema 622-3). Sociolinguistic researchers whose findings hinge on the impartiality of language standards, writes Brian Street in Literacy in Theory and Practice, seek to be "absolve[d] from the charge that they are making ideological claims about cultural difference" (29) when they examine the "sub-par" language practices of a particular group. ${ }^{36}$ Calling upon language standards as if they are tangible, stable benchmarks justifies both the inculcation of a particular language variety as well as the denigration of people whose writing is marked as differing from that variety (Street, Literacy 39).

One such group often judged for their languaging is basic writers. In "Teaching Standard Written English," the first article in the first issue of The Journal of Basic Writing, Sarah D’Eloia writes that “teaching 'basic' writing is synonymous with teaching standard written English" (5). She goes on to outline what standard written English looks like to her in the context of basic writing, describing the teaching of syntax, punctuation, the now-abandoned "modes" of academic discourse, and, interestingly enough, "the conventionalized ways of presenting the answers to the questions asked in various disciplines" (5). More broadly, standard English in academia is understood to be unambiguous, explicit writing, a concept often attributed to David Olson's theory of "essayist technique," a method of writing taught in schools which aims to make "all the

\footnotetext{
${ }^{36}$ Or, more accurately, when, on the basis of some written feature, researchers or assessors mark a writer as belonging to a race, ethnicity, or class identity that invalidates the acceptability of their writing. These markings are often idiosyncratic, contextual, and damaging (Williams, "Phenomenology,"; Agnew and McLaughlin).
} 
information explicit in the text so that it relies neither on context nor on personal knowledge, such that we may say "the meaning is in the text"" "Oral and Written Language" 16). This explicitness, according to Olson, subjects written language to "reflection and control" to a degree unachievable in speech ("Oral Discourse" 140). Teasing out the origin of this belief in the necessary explicitness of formal, academic writing reveals how the "standard" came to be considered writing that is easily understood, eliminating the possibilities of multiple interpretations. John Trimbur in "Essayist Literacy and the Rhetoric of Deproduction" outlines a historical (not natural) movement in the 17th and 18th centuries that shifted the authority of a text away from the social status of the writer and toward the empirical rationality of the text itself (79). To Trimbur, today's students consider textbooks the vessels of truth and meaning, in turn learning to write in a way that minimizes their authorship and the context of their writing production. The resulting prose, theoretically, can stand alone in its transparent clarity for a future, unknown reader, the way a textbook is seen as a "self-contained vehicle" (Trimbur, "Essayist Literacy" 76) of "unimpeded and public communication, where meanings may pass from one rational mind, the writer's, to another, the reader's, without reference to the social standing of either" (79). The more explicit a text, the less latitude for interpretation, thus facilitating longevity and dissemination. The pedagogue's role, Trimbur writes, is to provide students with opportunities to critically examine this stance toward writing.

Yet many basic writing classrooms leave little room for pushback against the explicitness taken for granted as natural and necessary to logical, effective written communication. Some scholars, like D'Eloia, Lisa Delpit, and Jeff Smith, believe that 
teaching the standard promotes students' social mobility (9). To this set of scholars, the role of the basic writing teacher as enforcer of the standard is "obvious" (D'Eloia 5); the teacher delivers "the goods" (D'Eloia 9) that students need to succeed in the social order as it stands. This mindset portrays the standard as a kind of key which, once bestowed, grants the recipient new opportunity, similar to Street's description of autonomous literacy, which positions literacy as, in and of itself, capable of enlightening the newly literate. However, the "literacy as key" model has been widely contested, perhaps most famously by Harvey Graff. Graff, conducting a rich analysis of the effect of schooling on the social and material wealth of nineteenth-century Ontarians using empirical and numerical data from sources like censuses, tax rolls, employment contracts, and jail registers in his 1979 The Literacy Myth, found that literacy reinforced the systemic patterns of social inequality and stratification, rather than opened up possibilities for advancement (52). Ascription, not achievement, was the dominant predictor of social success (56); "the possession of literacy alone rarely entailed occupational and economic gains ... in sharp contrast to theory and assertions" (114).

Graff destabilized the connection between literacy and economic success, and, as recently as 2012, Dylan Dryer similarly destabilized the connection between the work of composition and the teaching of language standards. Dryer interviewed ten novice composition instructors, asking them to characterize the work being done by a freshman writer in a sample essay. He discovered that these new teachers felt considerable anxiety, ambivalence, cynicism, and even hostility toward academic writing conventions, despite believing it their mandate to teach standards to students and employ standards in their own academic writing as scholars (421). Remarkably, the instructors in Dryer's study did 
not grant the same ambivalence about academic writing conventions to their

undergraduate students; that is, students were perceived as having an uncomplicated desire to write more academically, effacing any sense of the inner conflict of the imagined undergraduate writer (432). There is a distinct disconnect between the lessons from Graff and the beliefs held by teachers like those from Dryer's project. Though the pathway from literacy to upward social mobility is uncertain, enough young pedagogues believe in the pathway with enough firmness to continue teaching academic conventions they themselves question.

The importance of standards in the conceptualization of error cannot be overstated. At its most stringent, any language that is perceived to fall outside of the standard becomes an error; error is recognized by its veering from an invisible line known as the standard. ${ }^{37}$ As Patricia Bizzell writes, basic writers are "defined by the seemingly obvious fact that they do not produce Standard English and traditional academic discourse ("Basic Writing" 5); teachers judge the inability to produce this discourse by the prevalence of errors in students' writing. As I have earlier argued, the definition of what constitutes an error, and what error signifies, has evolved over the history of the field of rhetoric and composition. For the field's cognitivists or, what Bizzell calls inner-directed theorists ("Cognition"), language is for the most part nameable, solid, and unchanging. Any difference in language use, like error, is a user's

\footnotetext{
${ }^{37}$ Still, a reader's decision to recognize language as "veering" from some more-desired alternative is dependent on many factors, a chief one being the dynamics of power between reader and writer, as MinZhan Lu has highlighted in her "Professing Multiculturalism." Lu compares the different experiences of fiction writers Gertrude Stein and Theodore Dreiser when sanctioned by their editors to modify their "idiosyncratic style" (444). Stein, cognizant of her American nationality and purebred education, feels the authority to be "indignant" (444) at the suggestion, while Dreiser, son of a humble German immigrant with little formal education, sought editorial help from others and accepted all their suggestions in an effort to erase any remnant of German in his English writing (444). In the context of higher education, this power differential is perhaps nowhere greater than in the context of the basic writing classroom.
} 
misstep when confronted with the complexity of language beyond their grasp. Bizzell describes these theorists as assured that "the basic structure of the language cannot change from location to location because [linguistic] structure is isomorphic with the innate mental structures that enabled one to learn a language, and hence presumably universal and independent of lexical choice" ("Cognition" 77). Therefore, these theorists justified their teaching of a standard form of language, since one's "innate mental structures" found truest expression in embodiment by a language form deemed intellectually superior to all other, more colloquial forms. Anis Bawarshi refers to a seemingly default preference for standardized English in the higher education classroom as a manifestation of linguistic elitism ("The Challenges" 198). A preference for writing that is believed to be inherently better than other, more deviant writing impacts pedagogical practice and valuation.

Compositionists differ even at the ground level: recognizing and defining error. While revolutionary in her consideration of the function of student errors as interpretable signs of learning, Shaughnessy, often considered to be the initiator of a new era in basic writing scholarship, defined error in the 1975 inaugural issue of The Journal of Basic Writing in what would be considered a traditional way: "the unintentional deviation from expected patterns ... that inhibit[s students] and their readers from concentrating on what is being said" ("Introduction" 3). In 1985, Mary Epes "define[d] error narrowly as any clear deviation from the norms of standard written English. This definition places error in the domain of right/wrong, not of better/worse" (6). Often, error goes undefined in scholarship explicitly on error, its meaning considered a given. The location of error traditionally is the physical text: Patricia Laurence writes in "Error's Endless Train" of 
"turning away from the actual error on the student's paper" (29 emphasis added) toward developing in students the perception needed to see what needs correction, emphasizing later that this revision would occur "on the written page" (31). Compositionists have labeled, classified, tallied, and ranked the errors of student writers ad nauseam; in the early decades of the 20th century over thirty studies of error frequency were conducted, ${ }^{38}$ and, in more recent memory, error-analysis studies like those by Barry Kroll and John Schafer (1978), Richard Haswell (1988), Robert Connors and Andrea Lunsford (1988), and Andrea Lunsford and Karen Lunsford (2008) dissected errors as signs of learning rather than evidence of failures. The reactions of teachers as well as businesspeople to common errors were surveyed in studies by Maxine Hairston (1981), Sidney Greenbaum and John Taylor (1981), Susan Wall and Glynda Hull (1989), Donald Leonard and Jeanette Gilsdorf (1990), and Larry Beason (2001). Epic attempts at quantification, while aiming to achieve a holistic sense of student error types and incidence, could easily become overwhelming. Andrea Lunsford recalls writing Mina Shaughnessy in 1976 for help, saying "I am awash in a sea of uncontrolled variables, error counts, and tests for statistical significance. Now that I've started counting things, I can't seem to stop" (“The Content" 278). Such analyses tapered off around the turn of the century. In 1998, Susan Marie Harrington and Linda Adler-Kassner issued a call for basic writing scholars to refocus their attention on more sophisticated ways of studying error. Their call went largely unheeded, as scholarship explored the blurring and complication of boundaries, defining error more rhetorically and less explicitly (17).

\footnotetext{
${ }^{38}$ For a list of these studies, see Henry Harap's 1930 essay in English Journal, "The Most Common Grammatical Errors."
} 
The move away from error-analysis was a turn toward flexibility and openness in considering what counts as an error and what (if anything) teachers should do about them. If errors aren't "real" apart from readers' investment in their interpretation, writes Glynda Hull, then taxonomies of error, even if scholars could agree on them, might only serve at best to wrongly inform pedagogy ("Research" 170). Yet there was no initiative to come to a consensus on the types of grave errors; rather, scholars suggested doing away with error counting altogether. In "The Language of Exclusion,” Mike Rose advocates basic writing's departure from a "scientific-atomistic approach to language, with its attendant tallies and charts" (346), favoring instead a curriculum that "encourages the full play of language activity" (358), similar to the creativity fostered by Lu's "multicultural approach to style, particularly those styles of student writing which appear to be ridden with 'errors"” ("Professing Multiculturalism" 442). In addition to widening a teacher's tolerance for error, this shift in thinking reminded teachers that error is negotiable, temporal, and a question of power relations (Horner, "Rethinking the Sociality"). While the above citations would imply the mid 1980s to mid 1990s as particularly defined by "vastly complex sets of questions about social identity and access" (Otte and Mlynarczyk 132) regarding the social nature of error, politicization has always been present in error studies, as students' errors are weapons used against them in decries of illiteracy and changes to admission standards.

Rejecting a bird's eye analysis of students' error patterns, scholarship had to contend with the resulting question fixed in the minds of basic writing teachers: how, then, do I address errors in my teaching practices? While the practical was often sidestepped, David Bartholomae and Glynda Hull suggested the individual student 
conference as the place to ask students open-ended questions about their meanings and employ talk-aloud protocols. ${ }^{39}$ Error could not even be safely identified, Bartholomae would argue, without the benefit of context and intention ("The Study of Error" 267). While individual conferences allow for rich understandings of student meaning, the demand on time and emotional energy was a difficult ask of already overworked and under trained basic writing teachers. As Otte and Mlynarczyk write in their 2010 book Basic Writing, this “was a tough trade-off” (127). As expansive as the new stance toward error was, it lost the textual element so fascinating about error-analysis, a method which, while flawed, satisfied the cravings of the basic writing teacher and WPA for prescribed steps and solutions.

Moving beyond error-analysis meant more than just revisions to pedagogical approaches to error; such a shift questions the very root of error itself. On its surface, the question of the source of error seems facetious, surely a writer's mistakes belong to the writer. Yet a translingual approach throws into doubt not only what error is, but who owns error. Traditionally, error is a breach of contract: a reader agrees to pay attention to the writer's text only if the writer agrees to be intelligible and conform to the reader's expectations of how writing should look (Santa 33). Writing assignments test students' understanding of this contract, and a decision on the part of a teacher to mark some written feature of language as an error is a communicative act designed to indicate to a writer that they are not conforming to expectations. Reading in this way, for error, not only focuses attention on a writer's form rather than their meaning, more importantly, it makes it challenging, if not impossible, to pause and notice language invention or

\footnotetext{
${ }^{39}$ Talk-aloud protocols are a method of gathering data in which participants describe the actions they took while completing a task, in this case, talking aloud about the drafting or revision process.
} 
language play in so-called "monolingual" student writing. ${ }^{40}$ Yet Williams" "The

Phenomenology of Error" (an article often referenced, if only briefly), unravels the

source of error, noting that error must first exist in a book somewhere in order for readers

to call it an error upon seeing it in a student essay, meaning that the error then resides in

the mind of the teacher/reader who, having once read such a handbook, approaches the

basic writers' text with a concretized ability to identify "errors" when s/he sees them

(155). While Williams' "hunt" for the origin of error is almost comical, like an opening

of Russian nesting dolls, his point is a salient one: error cannot be definitively located

because it is personal. Ultimately, errors become not textual features but rather "mental

events taking place outside the immediate text" (Beason 35).

Centering teachers, paradoxically "as both consumer and author of error" (Santa

6) shifts the source of error from entities frozen on the page to instead "at the very center of our consciousness" (Williams, "Phenomenology" 158-9). Error is not born in the moment the writer's fingers type on the keyboard but in the moment of reader

experience. This experience is not universal; the writing teacher reads for error in student texts, ${ }^{41}$ and would hardly notice the same error if reading under a different banner, say, as collegial reader of published scholarship, which is read "unreflexively" (Williams, "The

\footnotetext{
${ }^{40}$ My use of the term "notice" is particular. Sarah Stanley writes in her 2013 "Noticing the Way: Translingual Possibility and Basic Writers" that "noticing," derived from second language acquisition (SLA) scholarship "invites attention to a linguistic feature which may belie a writer's expressed purpose" (37). SLA advocates for pedagogies in which teachers notice errors and "bring them to a learner's attention in an interactive manner" (43), often in a social, class-wide context, as noticing error, when stripped of its punitive consequences, can become "opportunities for an entire class to notice and negotiate sentence-level writing" (39). When writing teachers fail to notice with their students, Stanley argues, and instead notice only for themselves as a vehicle toward correction, they "dismiss errors' relevance to the impact of writing" (39). As errors (unlike mistakes) are unnoticeable to the writer, errors are opportunities for learning and transformative change. Chapter three will explore how to create conditions for noticing to occur for both the student and the teacher.

${ }^{41}$ And are pleasantly surprised when this search for error is in vain. Williams puts it this way: "[m]any of us may be surprised when we get a paper with no mispelled [sic] words, but that pleasure does not derive from our noticing that each word in turn is correctly spelled, but rather in the absence of mispelled words ("Phenomenology" 162).
} 
Phenomenology" 159). Error, like truth, is negotiated between people in the act of communication and takes on a unique aspect depending on the actors and context. Yet even as Williams identifies an alternative to traditional views of error, he himself acknowledges that this novel approach is "a way we virtually never follow" ("Phenomenology" 159). It is this approach, I claim, that is nascent translingualism at work in Williams' prose, and which should be revived and reexamined in a modern light.

Teachers virtually never read student prose as if it were published prose because of their affective investment in the eradication of error. Student writing must be cleansed of error in order to make these students worthy of the larger task ahead: academic and professional writing in standard English. Basic writing teachers especially, guarding the gate to unfettered college access, are apt to consider standard English in need of protection against unqualified and unworthy students. It is not only error therefore, whose ownership must be questioned, but also the ownership and obtainability of standard English and academic writing conventions.

\section{The Efficient Arbitrariness of Language Standards}

When learning to drive in the United States for the first time, young people and adults alike must undergo driver's education. There, instructors teach a set of "rules of the road" that are positioned as solid, stable, and lasting. These "rules of the road," while related to the driving laws printed in manuals that vary by state, are more about a novice driver's smooth integration into a community of flowing traffic than about memorization of facts. The education is capped by assessment, whether multiple choice, in-person under staged conditions, or both. Students must pass all tests to earn a physical credential 
that can be verified at any time by police. Of course, the way driving is taught does not quite mirror the reality of traffic, but that knowledge is not enough to justify an end, or even serious revision, to driver's ed. Society collectively believes that the fictional driving world as portrayed in these courses is necessary for the safety and success of new initiates.

However sacrosanct the course, newcomers don't enter driver's ed devoid of all driving knowledge. Virtually all students have been passengers, most know the road from other perspectives like that of pedestrians or bicyclists, and some have been drivers in other contexts. Yet the credential earned in driver's ed is not only framed as a good idea, it is a legal necessity. Once on the road, novices discover that the skillset taught in driver's ed is not entirely the same as that needed to be a good driver. Being a "good driver" is in fact a very relative term that cannot be measured by, say, a lack of accidents. With hindsight, more experienced drivers can see what it would have behooved them to learn as beginners: flexibility (driving different types of vehicles), adaptability (driving in different weather conditions), and contextual decision making (quickly measuring distance and speed).

Language standards operate in much the same way. I am not the first to adopt a traffic metaphor in parsing out the learning and navigating of language. Bruce Horner ("Relocating") as well as Mary Louise Pratt ("The Traffic"), Alastair Pennycook ("English"), and Claire Kramsch have each taken up the idea of a "global traffic of meaning" in describing everyday language practices, translation between languages, and the learning of new languages. Horner prefers the fluidity and complexity of the traffic model, which, unlike other models he argues against, acknowledges the interdependent 
relationship between the language and literacy practices of users, as well as the temporal dimension of language ("Relocating" 13-14). Language difference is created even through repetition: even if the traffic looks continuous, participants and time continually change (Horner, "Relocating" 15). To Pennycook, entering the global traffic of meaning in the practice of translation is akin to a "passing to and fro of ideas, concepts, symbols, [and] discourses" ("English" 33); for him, translingual activism is a way "not only [of] entering the traffic, but of disrupting the traffic" ("English" 44). Claire Kramsch similarly embraces the cacophony of traffic; she believes evaluation of language competence should not be based on one's performance in a single context (e.g. a learner's permit test) but rather on one's ability to reflect on the meanings chosen and not chosen when translating, and the political reasons behind those choices (103). My argument here, while not about translation or language learning per se, embraces the traffic model's assumption that students (in this case basic writers) are already vested participants in an ongoing traffic of language; they "write, and rewrite, English with each writing" (Horner "Relocating" 16), shaping and reshaping what is called "English" both in and outside of the basic writing classroom.

Through schooling, specifically the writing and reading classroom, what a teacher delivers as a corpus of academic writing "rules" bears some resemblance to the writing of everyday life but differs, not only from the lived writing experiences of students, but also from the rules delivered by students' past teachers as well as the rules followed by academic texts held up as models. In other words, what remains consistent throughout a student's educational career is not definitive English rules, but rather the belief that agreed-upon rules exist. Some rules, like the grammatical distinction between "that" and 
"which," or "who" and "whom," no longer remain necessary knowledge, as the number of users who know the difference wanes. Education positions the teaching of standard language conventions as a kind of mantle superimposed over the language practices students come to the classroom with, the hope being that the "correct" language will permeate into students' subconscious. In his Language as a Local Practice, Pennycook teases out the difference between the false but pervasive notion of language as a "pregiven entity" applied contextually, versus his view of language as a product of repeated, local activities (46). The idea that language has a permanent, underlying structure held together by a system of grammar rules is taken for granted; upon closer inspection language becomes a collection of sedimented practices which are intended to fulfill the needs of social interaction, and which change as society changes.

This idea is encapsulated in Paul Hopper's concept of "Emergent Grammar," whereby a language's structure is a process undergoing continual flux (157). This is in contrast to A Priori Grammar, a familiar model that asserts that grammar exists as an essential inner core of constant meaning that speakers and writers draw upon for their communicative needs. Distinctly, Hopper's grammar is "emergent," that is, it is always becoming and never arriving; grammar is simply the name for the current repetitions observed in discourse, repetitions that are provisional and context-dependent (156). If language practices are "sedimented," Hopper argues, every occasion of individual language use "results in a constant erosion and replacement of the sediment of usage that is called grammar" (159). This difference produced (even through repetition) looks on the surface like stability, creating an "illusion of systematicity" (Pennycook, Language as a Local Practice 47). But suspicion of the emergent ephemerality of writing conventions, 
while likely shared by students and teachers alike, is not galvanized into an active dismantling of the standardized approach to teaching writing. The fear is that open skepticism, if acted upon, would strip the credential of a college education of much of its value, a value in which the writing teacher has a vested interest. Ostensibly it is this credential that is the tangible goal of collegiate writers, who, some compositionists claim, seek only to write with the grain of the standard, aligning themselves with the kinds of writing identities valued by those in power. Hence teachers find themselves in an ideological crux.

To assert that language conventions are social constructions that exist only in a certain, ever-changing time and space, and therefore must be unstable, is not the same as claiming that such conventions serve no purpose or are not designed exclusively for effective and efficient communication. Immersion in the neoliberal capitalist aims of streamlined, cost-saving efficiency results in scarcely stopping to question what valuing "efficient" communication erases, namely, the labor expended by every act of reading. The formation of rules, while often arbitrary, is hardly ever pointless. Consider again the metaphor of traffic. Regulations such as traffic lights direct road sharing, and result in fewer accidents. But it is safe to say that we have all been that driver at $2 \mathrm{am}$ in the darkened, empty streets, perhaps headed to the airport or the hospital, stopping dutifully at a red light with no other cars in sight. There is nothing inherent to the color "red" that means "stop"; similarly, nothing about "green" in other contexts tells us to "proceed." Yet to stop or go based on a flashing color seems second nature; the stoplights seem to have always been there, and natural to driving itself. It is difficult to imagine a past or a future without them. Some of what stops us at these red lights is fear: fear of traffic 
cameras, of police. But most of what stops us is the internalization of the rule: always stop at a red light. The sway of rules holds us fast even when we are removed from the context that reifies their intended purpose.

Many writers' approach to writing rules works in much the same way, directing how writing is imagined to be, outside of space and time. The process of internalization occludes the possibility that rules, if constructed, can be deconstructed. When internalized, language conventions verge dangerously toward assurance in the existence of writing rules outside of human agency. By contrast, externalization reveals the treatment of conventions as acontextual to be an ideological effort to govern writing uniformly, thereby making reading a transparent and smooth act. Some rules are not imposed by higher authorities, in the way that city or county officials determine speed limits on local roads, or how the Modern Language Association regulates citation. ${ }^{42}$ Plenty of rules with equal hold are formed based on idiosyncratic understandings or applications, shaping uniquely what one considers "polite" driving or "good" writing. This idiosyncrasy has, in composition scholarship, been identified in various places, including those guiding teachers in determining the location and severity of student error (Lees, "The Exceptable Way," "Proofreading"), readers in determining whether or not they notice an error at all (Williams, "Phenomenology"), and novice writers in their struggle to approximate a new discourse, what Bartholomae, borrowing a term from SLA error analysis, calls the "interlanguage" of basic writers ("The Study of Error").

If we think of language standards like traffic lights, and writing education like the teaching of the rules of the road, which vary by teacher, location, and student,

\footnotetext{
${ }^{42}$ In my experiences teaching citation, students are often very surprised to learn that the MLA and APA they are familiar with are "Associations," comprised of paying members, and that changes to citation rules are the effect of human discussion and negotiation.
} 
translingualism does not ignore language conventions or advocate students write wildly and rampantly for the sake of mere liberty. Communication with other speakers, like decorous sharing of the road, is still essential. Rather, translingualism looks at language rules with fresh eyes, noticing them as unusual and constructed artifices present and negotiated in everyday communicative acts, for better and for worse. Retraining the eye aids in recognizing situations in which standards are useful tools as well as situations in which they stifle. There are certainly scenarios in which disregarding the standard or purposefully breaking it allows a writer the freedom to communicate more effectively or authentically than otherwise. For instance, while a lone driver might instinctively stop at the witching hour red light, a community of drivers would not stop interminably at a broken stoplight in midday traffic. When exigency demands adaptation, any single driver may propose a new pattern that may veer outside of the (in this case literal) lines. Some proposals might fail, their instigator considered rogue, while others might be accepted and mimicked. Exigencies can also influence change from above, like accident-prone intersections that become roundabouts, which, despite an adjustment period, are adopted by the community. In comparison, any writer may experiment with and invent language that, while on the surface may seem to violate a writing standard, is in truth a novel way of conveying meaning. And the writer who chooses to align with the standard, like the driver who chooses to stop at the 2am red light, is nevertheless part of the ongoing flow of language traffic despite the appearance of conventionality.

Still, calling out language standards for what they are, that is, arbitrary and ever changing, would fly in the face of the expectations society has of writing teachers. A tradition of upholding conventions so as to protect disciplinary and professional prestige 
is evidence of the power of oppressive language ideologies over the work of composition. In Language and Symbolic Power, Bourdieu writes that "[i]deological production is all the more successful when it is able to put in the wrong anyone who attempts to reduce it to its objective truth ... uttering the hidden truth of a discourse is scandalous" (153, emphasis in original). One can imagine how scandalous driver's ed would be if it taught the real dangers of the road such as drug and human trafficking, police brutality against people of color, or road rage.

In driver's ed, as in other classrooms where students aim to learn in theory what they will then try to enact in practice, what is taught is not adaptability, but rather a blanket set of rules framed as applicable in any scenario. Anyone who has learned a new language through classroom or textbook training may have experienced the disjuncture between the promise of the delivered language rules and the lived reality of language that escapes containment. I began learning Spanish in 6th grade, and continued that practice, increasing in intensity and dedication, until graduating with Spanish as one of my undergraduate majors. During this span, I conversed with other novice speakers and writers of Spanish, received tutelage from professors and tutors of Spanish nationality, read Spanish novels, and watched Spanish cinema. Yet, when I traveled abroad to Spain for the first time, I was alarmed at my lack of preparedness. Spaniards could understand me well enough, but I could barely understand them. In fact, they smirked at my schoolgirl Spanish. Wildly different vocabulary, accent, and slang all factored in my inability to transfer language-in-theory to language-in-practice. The standard I had been taught bore little resemblance to the Spanish I had thought I was learning all along. Similarly, writers out of college are likely to discover that what constitutes "good 
academic writing" is exclusive not just to college, and not even to English teachers as a set, but to the idiosyncratic preferences of any particular professor or peer reader (Lees, “The Exceptable Way," "Proofreading”; Greenbaum and Taylor; Wall and Hull). Postgraduation, when tasked for the first time with writing a memo, a report, or a resignation email, many students discover that the conventions they had worked so hard to acquire were more slippery, transitory, diverse, and contested than higher education had portrayed them to be.

Even if the acknowledgement of writing standards as social constructs is widespread, as Lu points out in "Metaphors Matter: Transcultural Literacy," standards are nevertheless touted as granting power independent of human agency and are still seen as stable rather than formed by users (290). How is it that something can be both a social construct and be seen as powerful apart from its social construction? In the afterword to Reworking English in Rhetoric and Composition: Global Interrogations, Local Interventions, Karen Kopelson argues that there are "times and contexts wherein terms like 'standards' and 'the dominant' do not need to and in fact should not be attended by their ever-present scare quotes because they are literal, true, real, and utterly imposing" (215). Drawing on Halberstam, Kopelson asserts that even when certain sedimented systems are revealed as constructs, this revelation in and of itself does not relieve the effects of the construction, nor make it easier to manipulate the constructed systems (“Afterword" 215). Moreover, she writes, when teachers of writing feel that they have been "done right" by the construct of standard English (and Kopelson includes herself in this set to a large part), not only can they afford to not pay attention to a growing 
resistance against standard English, such a challenge to what some may consider their "home language" (“Afterword” 212) may even feel threatening.

Across the board, the felt sense is that standards carry social weight in the world and their clout has long-since been established. In this viewpoint, individuals have little authority to overturn standards, thereby justifying their inculcation. ${ }^{43}$ The credential of a college education becomes the shaky bridge between conformity to language standards and upward social mobility. Lisa Delpit asserts that the role of the language teacher is to reinforce the standard despite its arbitrariness, arguing that teaching students the "codes of power" (Delpit xvi) grants them access to the language of economic success, of which the teacher is an owner (Delpit 68). According to Delpit, to those who have been excluded from "the culture of power, being told explicitly the rules of that culture makes acquiring power easier" (24). Not only does Delpit's way of thinking assume that what constitutes standard English is agreed-upon universally, it also falsely equates "having" standard English with empowerment and economic success. In reality, language is merely the conduit for enactments of power dynamics based in race, class, gender, etc. Lu traces the exigency felt by educators to the sway of neoliberal, capitalist industries ("Metaphors"), and I would narrow that claim yet further: educational systems are the engines that construct the standard.

Ironically, teaching the so-called standard rules of writing intends to give students the capacity to manipulate the power relations of the world by enhancing their linguistic capital, while meanwhile said capital is fashioned and packaged by the very institution

\footnotetext{
${ }^{43}$ See John Fisher's The Emergence of Standard English and the collection edited by Laura Wright entitled The Development of Standard English, 1300-1800: Theories, Descriptions, Conflicts for historical perspectives on the development, codification, and maintenance of standard English.
} 
that claims the power to sell it: higher education. ${ }^{44}$ The simplistic, transactional view that "the standard" can be granted or transferred confuses academic writing as discrete and knowable vs. fluid and emergent. Thoroughly versed in (albeit idiosyncratic) understandings of the standard, writing instructors permit themselves considerable laxity in their own scholarly writing, and Bourdieu's analysis of the dynamics of linguistic power helps explain why. "One of the privileges of consecration" Bourdieu writes, is "an undeniable and indelible essence" which "authorizes transgressions which would otherwise be forbidden" (Language 125). Bourdieu calls these transgressions a breaking of the "rules of the cultural game" (Language 125), writing that only those confident in their identity and place can play such a game (let alone break its rules). Teaching students standardization's rules, and framing them as meaningful and lasting, hardly prepares students to navigate a world where the rules of the game are arbitrary and shifting. Such pedagogy, writes Mary Louise Pratt, assumes "that all participants are engaged in the same [linguistic] game and that the game is the same for all players" ("Linguistic Utopias" 51-2), a dangerous assumption to make of the diverse population of basic writers.

\section{Student Desire and the Lowering of the Bar}

The high stakes around eliminating error and maintaining adherence to the standard fuels societal fears of a perpetual literacy crisis in the United States, signaled to many by the ever lowering of the academic "bar" to college admissions. If basic writers

\footnotetext{
${ }^{44}$ Additionally, linguistic capital has a different exchange value depending on the receiver. Larry Beason's "Ethos and Error," a study of business people's ranking of how bothered they were by a variety of errors, or what Beason calls "error gravity" (38) revealed "a disconcerting amount of disagreement" in reader reaction (35), not just between readers but within an individual's reactions to different instances of the same kind of error.
} 
do not know the "simplest" of writing rules (e.g. sentence boundaries, verb conjugation, spelling) how is their presence in college justified at all? The lowering of the bar, a sports analogy, is the creation of a less challenging environment where high jumpers would need to exert less energy (implying a demonstration of less talent) to surpass a low-set goal. Reversely, "raising the bar," setting higher goals and jumping to new heights, weeds out weaker competitors. The prize for successfully clearing the bar is access to a college degree, rendering the student into a performer, and higher education into little more than a credentialing service.

In this section I trace in order to fracture the very consensus around the so-called "bar" defining proficient college writing. As access to college education widened in the years after World War I, the influx of students created a demand for mechanized, standardized approaches to the teaching of writing (Ritter 49). The urge to define what constituted "good writing," born of exigencies for equitable training across the board as well as relief of teacher workload, resulted in the supremacy of clarity and correctness in grammar, spelling, and mechanics. The short, frequent "themes" written by basic writers of Harvard and Yale, discussed in the work of Tracy Santa, Kelly Ritter, and David Jolliffe, assumed its reign as the ultimate, rapid judge of a student's writing progress. Ritter writes in Before Shaughnessy: Basic Writing at Yale and Harvard, 1920-1960 that "[i]n the university's eyes, only when such cleanliness had been achieved could students be trusted to undertake the complexities of literary work and other higher-order thinking tasks across the curriculum" (49). Reading hundreds if not thousands of such themes in a given academic school year, ${ }^{45}$ pedagogues sedimented slowly but surely their concept of

\footnotetext{
${ }^{45}$ In Dead Letters, Santa writes that Barrett Wendell, a practicing instructor at Harvard in the late 19th century, reported reading more than 20,000 student themes in a single academic year.
} 
a nebulous "bar" that students must surpass in remedial coursework before being deemed ready to tackle upper level collegiate writing. The bar, therefore, is an internal barometer, idiosyncratic to each reader's context and personal experience.

While the bar measuring "acceptable" student writing may vary by individual and with time, it is important to note that institutional standards for writing shift more perceptibly than any one given class of students from semester to semester. By this I mean that changing contexts impact admissions criteria, policies, and curriculum in ways that affect the types of students present in a basic writing class, affecting in turn the way a teacher perceives student writing "ability" more generally. In "Class Dismissed" and The Politics of Remediation, Mary Soliday historicizes institutional responses to social and fiscal crises such as privatization, downsizing, and enrollment surges. To maintain the delicate balance between external pressures to ever widen access and internal pressures to maintain exclusivity and vie for research funding, institutions respond in a variety of ways. Their responses may include creating basic writing programs to house an influx of students, redirecting remedial students to nearby lower-tiered schools to maintain prestige, or implementing internal barriers to "cool-off" remedial students already within the student body (such as raising tuition, mandating exit testing, setting limits on the number of times one may attempt a course, fining students who withdraw, or strict course sequencing) (“Class" 736, The Politics 12). Universities manipulate their writing programs to manage tides of growth and constriction, and must share some of the responsibility for deciding who "deserves" a college education.

When contextual forces, say, the intervention of a WPA, student evaluations or pass rates, or a faculty calibration session, force teachers to reexamine and readjust their 
understanding of where the "bar" should rest, the process is often a painful one.

Researchers conducting error-analysis, like those performed by Wall and Hull (1989) and Greenbaum and Taylor (1981) found that even just the artificial conditions of an experimental setting in which teachers were asked to identify error in a piece of writing were enough to cause teacher/subjects to feel both insecure (Greenbaum and Taylor 174) and threatened (Wall and Hull 286). The personal barometer for judging writing is a product of countless hours of reading and evaluation, tying this hard-won perspective into one's professional sense of self. It seems to go without saying that any credible writing teacher must excel at ranking the quality of student writing when $\mathrm{s} / \mathrm{he}$ sees it. When asked to lower one's standard to accommodate new kinds of students or new kinds of writing, the message can be received as a threat not only to one's arduous honing efforts, but also to one's identity as a writing expert and the status attached to that identity. Changing this, writes Trimbur in his "Literacy and the Discourse of Crisis," would require "imagination and political courage" from writing teachers, theorists, researchers, and program administrators; recognizing the implication in what Trimbur calls the privatization of literacy is vital: "[o]ur own academic positions are authorized by the hegemony of expertise that legitimizes a stratified and antidemocratic educational system" (294). Periods of readjustment are never more frequent than when admissions criteria result in new types of students in basic writing classrooms. If a bigger population of students means necessary adjustments to one's barometer, logic might erroneously dictate that the literacy level of society itself must be in a state of decline.

Difficult as it may be to accept, the chagrin felt at this perpetual lowering of the bar is, in actuality, a protest against "the greater inclusivity of U.S. society itself" 
(Fleming 7). Trimbur examined what he calls the "discourse of crisis" surrounding literacy in the United States, finding that instead of signaling a downward trend in student intellect, "the discourse that puts literacy in crisis ... [is] about the ongoing crisis of the middle class. Fear of downward mobility and a loss of status has repeatedly been displaced and refigured as a fear of the alien and the other" ("Literacy" 293). Richard Ohmann, writing in the 1970s, identified periods characterized by lament of the growing illiteracy of the American population each time the gates to college widened ("The Strange Case"). Ohmann gives a specific example of a dip in recorded ACT scores between 1965 and 1975, used as justification for yet another literacy crisis. What he found when he looked deeper was that the decline was disproportionately on the part of female test takers, who constituted $55 \%$ of test takers, an increase from $45 \%$ of testers before 1965 ("The Strange Case"). The female test scores were lower, true, but the number of female test takers increased, reflecting more socially just admissions practices. The decline in scores was indicative of not a general decline in ability, but rather an increase in equality.

Advances in social justice correspond with key eras of academic panic concerning the generalized reading and writing abilities of young people, resulting in popular publications condemning the newest literacy crisis. As early as 1897 Edwin Godkin, member of the Harvard Committee on Composition and Rhetoric, wrote to express his disdain for the concept of collegiate writing remediation, instituted when more middle class youths, educated without the benefit of years of private tutoring, were being admitted:

"We of this Harvard committee have been unwilling to admit that [the American boy's] growing illiteracy made his case hopeless until some further and a different 
kind of effort had been made to improve him. . . If you do not mend his English, he will be only too glad not to mend it himself. And let me say again emphatically that college is not the place to mend it ... It is not the place to acquire dexterity in the mere daily use of the mother tongue." ("The Illiteracy" 8-9)

Almost eighty years later, this same sentiment seeped into the popular imagination with the 1975 publication of "Why Johnny Can't Write" in Newsweek. Author of the piece Merrill Sheils cites a host of depressing statistics claiming a deteriorating literacy level since the early 1960s, and blames television along with academia's inconceivable claim that all languages are equally valid (she quotes CCCC's Students' Right to Their Own Language, adopted one year earlier) in her overall denunciation that "[w]illy-nilly, the U.S. educational system is spawning a generation of semiliterates" (58). Sheils' closing words encapsulate the dominant ideology of monolingualism's insistence on the necessity of maintaining academic standards: "[t]he point is that there have to be some fixed rules, however tedious, if the codes of human communication are to remain decipherable. If the written language is placed at the mercy of every new colloquialism .. then we will soon find ourselves back in Babel" (58). Rather than aiming to be "masters" of language, Sheils writes, we must be "willing to be its servants" (58). Stripped of context, one can hardly tell a difference in the fear mongering rhetoric of Godkin and Sheils, writing 78 years apart.

Eight years after the Newsweek article, the National Commission on Excellence in Education published "A Nation at Risk: The Imperative for Educational Reform.” The widely publicized report sang a similar tune, declaring famously that "the educational foundations of our society are presently being eroded by a rising tide of mediocrity that threatens our very future as a Nation and a people" (9). While the concern in "Why Johnny Can't Read" was the impact said semiliteracy would have on the workforce, "A 
Nation at Risk," raised the stakes, claiming that the U.S.'s "once unchallenged preeminence in commerce, industry, science, and technological innovation is being overtaken by competitors throughout the world," (9) in part because of subpar national writing skills. As recently as 2003, the College Board's report on the National Commission on Writing in America's Schools and Colleges' “The Neglected 'R': The Need for a Writing Revolution" stated that "[b]y grade 12, most students are producing relatively immature and unsophisticated writing" $(17) .{ }^{46}$ The commission was created, asserts the report, from "the growing concern within the education, business, and policymaking communities that the level of writing in the United States is not what it should be," but also, admittedly, because College Board had plans to implement a writing assessment into the SAT (7).

If one is to take these outcries as reflective of truths, then the literacy level of American youths has been on a steady decline for over a hundred years. Similar decries of waning literacy continue today with the widespread belief that texting technology has harmed not only writing skills but also attention spans and critical thinking capacities, despite reputable studies that have found otherwise (Purcell et al.). As Trimbur summarizes succinctly: "[i]t is not deteriorating educational standards or the needs of a new high-tech postindustrial economy that have put literacy in crisis but the appropriation of literacy by a stratified educational apparatus and the wider meritocratic order of a credentialed society" ("Literacy" 294). When these crises infiltrate the public imagination, the stakes are raised concerning the value of a college education. Basic

\footnotetext{
${ }^{46}$ Five years later, Andrea Lunsford and Karen Lunsford's 2008 follow-up to the Connors and Lunsford "Ma and Pa Kettle" major error study would find no such evidence, confirming instead a consistency in the frequency of student error between the 1986 sample and their 2006 sample, which, unsurprisingly, is close to the frequency recorded in a study from 1917.
} 
writing is one avenue where parents and other stakeholders like college administrators believe they can assess the value of literacy. Demands are made for quantifiable progress, and errors, in the way they are traditionally conceived, can be counted.

To those scholars who accept the proposition that students exiting college with writing "deficiencies" will be deemed incompetent in a globalized economy, the duty of the writing teacher necessarily becomes granting students access to the language patterns that will in turn presumably grant them access to the success they crave. ${ }^{47}$ This duty extends to the teaching of standard English to students whose "home language" is an underprivileged dialect, such as African American Vernacular English (AAVE) (Delpit). In this model, not only is the writing professor problematically positioned as keeper of all unquestionable writing truths, but "access" is only a matter of a semester or two of writing practice. In this short span of time not only will future academic writing be improved, but one's chances in the corporate market will equate with those of the children of privilege, because language alone has granted the student power. Students, Jeff Smith claims in his "Students' Goals, Gatekeeping, and Some Questions of Ethics," have bought into this customer-service model of writing instruction. In questioning his students about their reason for being in school, Smith found that "more than $80 \% \ldots$ volunteer college-related career goals" (303). To Smith, students enter into financial agreements with universities as adults; colleges in turn agree to either grant or deny them

\footnotetext{
${ }^{47}$ While scholars like Lisa Delpit and Jeff Smith unequivocally portray students' reasons for seeking a college education as social and economic success, the picture is more nuanced than this. A 2015 survey conducted by Harris Poll (commissioned by New America's Education Policy Program and sponsored by the Lumina Foundation) asked 1,011 recently enrolled and prospective college students what their top reasons were for going to college (Fishman 3). While financial gain ranked highest, ( "to improve my employment opportunities," "to make more money," and "to get a good job"), $85 \%$ of respondents cited the importance of going to college "to learn more about a favorite topic or area of interest," $81 \%$ said "to become a better person," $76 \%$ said "to improve my self confidence" and $74 \%$ said "to learn more about the world" (Fishman 4). Interestingly, $42 \%$ of respondents reported that their parents wanting them to go to college factored heavily in their decision to attend (Fishman 4).
} 
an earned credential, and teachers volunteer to be agents of this enterprise (312). While I agree with Smith and Delpit that the goals of educators should be ethically tied to those of their students, their viewpoint forecloses any possibility that different students have different goals, that students' goals change over time, or that students can have multiple, competing goals. The underlying assumption that teachers must adopt students' goals as their own and that such goals, as stated, should dictate a teacher's praxis is problematic territory. College professors have the boon of already having earned the credential they are now helping to bestow; such hindsight aids them in encouraging students to examine and question their varying expectations of a college writing course. Students may see the injustice of gates closed to them without realizing the gates are made by human hands, and are therefore movable, changeable, and temporary.

The ethical pull on pedagogical heartstrings makes the question of student desire to be absorbed into the standard all the more powerful. Students do not naturally seek out alignment of their languaging into a more socially accepted linguistic current; their language habits align through custom with those of the people around them. Only when exposed to settings fraught with power dynamics and the carrot of upward social mobility do they "declare themselves ready, even eager, to toe the line ... after having resisted just such instruction all their school lives" (Rouse 3). More than once, Mary Epes in her 1985 study of adult basic writers' linguistic patterns in relation to their written errors refers to her student subjects as "highly motivated to improve their writing skills both for their career advancement and for their [writing] course” (7). Similarly, Marilyn Sternglass' 1997 Time to Know Them, a longitudinal study of around 50 young college freshmen, most of whom were basic writers, features in-depth case studies of students 
like Joan, to whom "success in college meant everything . . it was her whole life" (xvii). This craving for the social success made possible by academic success raises the stakes of basic writers' educational pursuits, leading to "frustration" (Epes 7), "vague fear" (22), timid uncertainty (22), "tension" (28), and "linguistic insecurity" (22) when talking about their writing processes and struggles; when quoting one participant, Epes wrote that the student "mourned" the terror they felt when writing (22). Such heightened anxiety is not coming solely from within; for many younger students their parents' demand for "proof" of the effects of their expensive education sweeps students up with concern to fit into a world they have been told works, sounds, and writes a certain way. These parental pressures are present in Sternglass' other vignettes of her student participants: Ricardo once "had aspirations to become a physician" but "his father forced him to attend a vocational high school" (xvii) and Stanley "had been pushed into going to college by his mother, a beautician, who wanted him to have the opportunities she had not had" (123). External forces like parental pressure or educational histories have affected the self-perception of basic writers before they enter a college classroom, thus it makes sense that anxiety to be absorbed into the standard is nowhere deeper and more subconscious than in the basic writing classroom, where students (by nature of their very assignment as basic writers) have already been confirmed in their suspicions that their language is deficient, and have, quite literally, purchased a semester of education which claims to "remediate" them in preparation for "normal" college writing. One subject in Sternglass' study, Jacob, changed his major from architecture to physics, after receiving an unsatisfactory grade in his architecture course, reporting to Sternglass "that his performance in the math and physics course he was now taking would help determine 
how successful he could be in the field of physics" (xxi). Despite good grades in physics, Jacob too felt "thwarted by family pressures and required to pursue a 'practical' major," leading to eventual burn out (Sternglass xxi). To students like Jacob, their potential as people to succeed in certain careers can be gauged by their academic success or failure in undergraduate coursework like basic writing; these students define themselves by their grades. This equation is a tense one, laden as it is with the promise of purchasing knowledge and access with tuition dollars. Yet unlike physics or architecture, where the guaranteed return for a passing grade is at least college credit, in the basic writing classroom, sometimes the only takeaway besides permission to enroll in "regular" composition is an amorphous sense of "improved" writing.

\section{The Teaching of Linguistic Control}

Questioning the teaching of standard English feeds into concerns over what exactly is standard English, who owns it, who defines it, and who can distribute it to worthy novices. As we have seen, it is facile to call standard English a stable set of rules, however handy generations of writing handbooks have made this seem. Instead, the definition of standard English resides in the mind of the writer and reader. The writer and reader may have two different golden calves in mind, but both parties are there to pay tribute. Even if a basic writer doubts that some ideal language exists withheld from her view because of her own deficiencies, she must contend with societal forces that insist on the standard's solidity. Teachers devote many working hours honing their conception of standard English; Christopher Thaiss and Terry Zawacki's study as detailed in their book Engaged Writers, Dynamic Disciplines: Research on the Academic Writing Life found 
that teachers' "knowledge of standards accrued over time, through coursework, reading, attempts to write and reactions to that writing, through regular talk with fellow students and fellow researchers and teachers" (7). This labor in part aims to achieve fair and efficient assessment: the closer aligned a teacher/reader is to an unchanging, uniform standard, the easier and less partial grading must be, falsely equating command of the standard with expertise. Teachers are assumed capable of transmitting the clean, controlled prose they have spent years crafting to basic writers in the span of a single semester. The firmer a teacher's grasp on the standard, it is reasoned, the better and faster they surely are at bequeathing it to students. So inoculated, basic writers are imagined as being immune from the confusion or complexity of future writing tasks.

When asked what defines a student as successful in academic writing, the image called to mind is often one of a writer in control over their own prose. The implication is that controlled prose is clean prose. Basic writing, then, is a designated time and space for writers to learn this control, however bewildering of a prospect that seems to all parties. Thomas Farrell, in describing the success of "literate" students in contrast to less academically successful "oral" students, describes writing as "a developmental process of acquiring more conscious control over language and composing" ("Developing Literacy" 47). To him, basic writers were simply at an earlier stage in this process, gaining control over their language more slowly. Teachers are positioned as in complete control of these faculties, and control over one's writing is equated with control over one's thinking. In a different publication, Farrell continues in the same vein, urging teachers to "transmit a sense of the power of control literate patterns of thought can give the students, even though the road may be a vigorous one for them to travel" ("Open Admissions" 250). In 
this mode of thinking, writing is falsely conflated with a transcription of thought: the more logical and seamless the prose, the higher order the thinking behind it.

While finding remarkable discrepancy amongst teachers and students regarding what constitutes academic writing, two universal traits identified by Thaiss and Zawacki are writing characterized by "discipline" and "control by reason of emotion [sic]" (6). This idea of control is pervasive in composition, especially basic writing, and is the namesake for a technique called "controlled composition." Taken from ESL pedagogies, controlled composition asks students to first copy a short text, word for word, punctuation mark for punctuation mark. Once they can do this "error-free," they are then given explicit instructions on minute syntactic or lexical manipulations, such as replacing general pronouns with someone's name, or changing verbs from active to passive voice. Donna Gorrell recommends a "controlled progression of twenty-five to thirty-five steps or more" over the course of a semester in her CCC article from 1981, claiming that controlled composition allows students to "perform competently in writing for perhaps the first time in their lives" (309). Students then use the models they have diligently copied as templates for their own self-generated writing, which would somehow feature "increased syntactic maturity by means of [the practiced] artificial language manipulations" (Gorrell 310). Gorrell asserts strongly that controlled composition results in a "positive attitude toward writing" (312), saying students felt encouraged and more confident after producing error-free prose (315).

This, of course, is the lynchpin. Students of controlled composition are not producing error-free prose; they are copying words. Of course they would feel heartened at the good grade awarded to a beautifully written paragraph in their own handwriting. 
That the thoughts, phrasings, and ideas are not of their own crafting would only matter if it mattered to their instructor, and in the case of controlled composition, it does not.

Gorrell acknowledges freely that it is the "predetermined content which frees [students] from the demands of composing on paper," and that the lack of investment in the ideas of the paper means the essays are "no threat to the creative ego" (313). This is like saying that meticulous parroting of famous concertos subconsciously unlocks the creativity of a novice composer. What happens in this nebulous, liminal space between copying prose and generating prose is never made clear in Gorrell's text, but if students are using templates in the creation of their essays, then whatever "control" they are learning over their own writing is contextual to the isolated demands of the basic writing classroom, at best. ${ }^{48}$ Aiming thus low doesn't seem to concern Gorrell, who, like many other basic writing teachers, believes rote sentence manipulation to require "a degree of cognitive involvement that for basic, remedial writers, frequently reaches the upper limits of their capabilities" (314).

Belief in the inferior minds of basic writers aggrandizes the nature of the work of basic writing, whose teachers are then tasked not only with improving students' standard English, but also their implied "basic" cognition. This belief is rooted in the concept of the "cognitive egocentrism" of adult basic writers, a term taken from Piaget's studies of

\footnotetext{
${ }^{48}$ Lest the reader think that Gorrell's templates are a thing of the past, about five years ago I was encouraged to give templates to my basic writing students in order to aid them in drafting an Annotated Bibliography. The template I was provided with as a sample was fill-in-the-blank, with leading suggestions practically encouraging students to hunt for the "correct" answers in the primary source. To illustrate, part of that template read: "Based on [the author's] situation, she decided to . In the end it was clear to her that and that future people in her position should ." In a later department meeting, some faculty complained that the length of the blank lines were too short, and students were filling in the template with only one or two words. As a response, we were issued an updated template with longer lines.
} 
children's cognitive development. Rather than meaning selfishness or self-centeredness, Piaget's egocentrism is a term used to describe a cognitive state in which a person understands the world from only his or her point of view, that is, their unawareness of the existence of other perspectives or, in the context of writing, their "hypothetical readership" (Kroll 271). According to this theory, the basic writer crafts text without mentally constructing the figure of the reader and his/her unique contextual needs. The basic writer is then positioned as "embedded in their personal view of reality" (Kroll 279), or, as Trimbur puts it more forcefully in his critique of such a framing, "prisoners locked in the cell of inner speech ... struggling to free themselves and their ideas from the confines of the private verbal thought that goes on in their heads" ("Beyond Cognition" 212).

Both Trimbur and Rose have written against the hasty application of this theory to the cognition of adult, collegiate writers, arguing instead that basic writers are more acutely, if not painfully, aware of their audiences than any other set. Trimbur shows that closer examination of the tenets of Vygotsky, whose work on cognition is often unproblematically aligned with Piaget, demonstrates that "the outer world of public discourse has already entered as a constitutive element into the inner world of verbal thought" ("Beyond Cognition" 215). In other words the reader, the audience, the teacher, the fellow students, are all already present in the inner thought and language of every basic writer. The issue when writing, therefore, is not an inability to imagine one's audience, but the effort to "negotiate and resolve the conflicting claims of different inner voices speaking for different systems of authority" (Trimbur, "Beyond Cognition" 218). Rose shares a similar view, claiming that rather than being "cognitively locked out of 
other ... points of view, [basic writers] are more likely emotionally and politically barred from them" ("Narrowing the Mind" 293). Trimbur especially aligns with translingualism in his acknowledgement of the "multi-accented, shifting and unstable" as well as "irreducible [and] nonreiterative" nature of language ("Beyond Cognition" 219). If traditionally a basic writer's very cognitive development is at play in a writing course, then of course the stakes of basic writing are framed as high. In this framework, basic writers are uncontrolled writers of chaotic prose, determined so by the very existence of their names on basic writing rosters. As chapter one has shown, it is adherence to dominant and oppressive language ideologies that permits belief in the ability to master and bequeath linguistic control (let alone critical thinking) to basic writers.

Reexamination of the idea that the role of basic writing is to hold students accountable to a core of language correctness is needed, especially given that this "core" exists only idiosyncratically and as a result of external institutional pressures.

I do not wish to imply that basic writing teachers are not experts in their own right, but that their expertise needs reframing. Rather than possessors of a key which, when duplicated in miniature and gifted, can open literal doors for students, basic writing teachers who consider themselves navigators comfortable in a flexible world of words shift their mission accordingly. Suddenly the bounds of a semester are without a doubt incapable of containing any measurable "improvement" in students' writing. This altered perception is a struggle, perhaps because a writing teacher's status is derived in part from ability to master conventions. Yet the ever-changing terrain of language cannot be dominated or even mapped; the role of guide is to remain open to the unexpected, changing knowledge resources of those in their retinue. 


\section{The Damage of the Standard}

Even if it was possible to teach writing standards, what kinds of writers would such praxis produce? For one, teaching conventional forms of writing as correct would create readers who are unprepared to tackle complicated, nuanced texts and writing assignments. Patricia Donahue and Ellen Quandahl, writing in the introduction to Reclaiming Pedagogy: The Rhetoric of The Classroom, list the conventions of writing as traditionally including "moving ... from narration to exposition, reading for and writing thesis statements, emphasizing unity, and managing ambiguity" (14). Donahue and Quandahl critique these easy definitions, claiming that these conventions, clean and straightforward as they might feel to assess, "lead to prose that suppresses conflict and encourages the unconscious reproduction of social norms (self-control, for example)" (14). Students should come to complex texts, like those debating deeply rooted social justice issues, with a sense of the impossibility that any single essay can solve a systemic problem. Cleanly packaged argumentative and research assignments, like those that follow a model or template, too often portray the opposite.

Additionally, when standards are assumed by a pedagogue's praxis to be universal and stable, the effect upon students is a destabilization of their understanding of how to write in academic contexts at all, often resulting in students linking a professor's feedback not to the epistemology of a particular discipline but rather idiosyncratic preferences. In other words, students begin to write in order to please their professor instead of attempting to adopt the conventions of a new discourse. Interviewing both faculty and students at two universities in England, Mary Lea and Brian Street found in 
"Student Writing in Higher Education" that disciplinarity influenced individual faculty members' perception of "good writing." For example, though many faculty cited "structure" and "argument" as crucial to effective writing, "underlying, often disciplinary, assumptions about the nature of knowledge affected the meaning given to the terms" (157). In a similar vein, Thaiss and Zawacki observed in their 2006 book, another interview-based study of academic writing perceptions, "over and over almost all our informants - teachers and students - using the same short list of terms to describe good writing, but meaning, as we came to learn, very different things by them" (138). These teachers nevertheless work under the idea that writing standards are both uniform and transferable. Thus students feel understandably confused and misled as they moved from course to course, employing previously effective strategies in new contexts with unpredictable degrees of success. Thaiss and Zawacki witnessed students adopting a "radically relativistic view" of writing conventions after encountering teachers' differing methods and emphasis, asserting that all teachers want different things and thus are "unpredictable" (7).

Perhaps even more damaging, strict adherence to the standard may blind writing teachers to their own prejudiced assessment practices, which Agnew and McLaughlin in their 2008 "Those Crazy Gates and How They Swing: Tracking the System that Tracks African-American Students" proved "is often most damaging to African-American basic writers whose home speech is African American Vernacular English (AAVE)" (86). Agnew and McLaughlin, tracking 61 basic writers over the course of five years, found that it was not the content or quality of the basic writing course that determined a student's overall long-term retention and success, but rather the "inflexible assessment 
styles of some English instructors" (91), applied to speakers of AAVE in particular, that would predict whether a student would exit basic writing successfully or need to repeat or drop out. The authors highlight the case of student Shanda, whose final paper was "clearly a passing essay" (87) but who was failed by multiple assessors not due to a lack of thought or straying from the prompt but because of "inconsistent and petty" (86) objections to her mechanics, such as pronouns and comma splices. Agnew and McLaughlin, unable to locate most of these errors in Shanda's essay, attributed her failure to features in her writing that readers used to mark her as African-American, thereby flagging her as a poor writer despite the quality of her text.

While these harsh instructors might claim their dogmatic attention to grammatical and mechanical correctness preserved the sanctified standard, in the end their inflexibility did students like Shanda a disservice. Had it not been for the intervention of Agnew and McLaughlin, Shanda would have failed the course, as did many other students in their study whose writing triggered a suspicion of a racial identity other than white. The same written features unaccompanied by a readerly perception that the writer must belong to a racial minority would be glossed over or ignored. In other words, when the imagined writer's identity matches that of the reader, fewer errors are written into the reading of the text. In their purported attempts to uphold the "bar," instructors like those at Agnew and McLaughlin's institution instead sabotaged students' chances to even attempt a higher education.

Basic writers are by no means the only writers to deviate from the conventions of academic discourse. Such patterns appear in the work of freshmen, advanced undergraduates, graduate students, professional colleagues, published scholarship, and 
surely this dissertation. The difference, then, in the words of Bartholomae, "is not who misses the mark but whose misses matter and why... The errors that count in the work of basic writers have no clear and absolute value but gain value only in the ways they put pressure on what we take to be correct, in the way that these errors are different from acceptable errors. .." ("Writing on the Margins" 68, emphasis added). Bartholomae quickly ameliorates what is a revolutionary claim; a few lines down he writes that "[t]his is not to say that order, correctness, and convention should not be the goals of a literate education" ("Writing on the Margins" 68-9). Yet I would wish to explore the strength of Bartholomae's realization without the reassurance of a correct standard which helps identify writing that is "off the track" (Bartholomae, "Writing on the Margins" 68).

What might destabilizing correctness and shedding both the authority and impulse to recognize, judge, or remedy error accomplish? Bartholomae's statement implies that the "errors" in a basic writer's draft reveal less about students as writers and more about teachers as readers. If the assumed negative value of error is taken away, and error instead posited as a neutral difference from readerly expectations, then basic writers' errors put "pressure" on these expectations. The term "pressure," when used here by Bartholomae, has a negative connotation; the pressure exerted by basic writers' error is “different from acceptable errors." Basic writers' errors, then, are unacceptable; readers sense and immediately reject the pressure they exert, perhaps because it has always been the role of the writing teacher, and not that of the basic writer, to exert pressure, to influence, and to change.

However, given this idea of writerly pressure upon readerly convictions of correctness, could not basic writers' errors be pressure points on pedagogical bodies? 
Pressure points, vital, tenders spots all over the body, are used to both inflict and relieve pain. Manipulating pressure points is a form of offense in martial arts, but in traditional Chinese and Indian Ayurveda medicine, slighter pressure to the same points restores balance and brings relief. Error can be thought of in the same way: it is the receiver of the error who experiences the sensation of pressure, not the giver/writer. In this vein of thinking, the noticing of error in basic writing can be simultaneously an offensive, painful experience that puts one on the defensive, or an opportunity to refocus reader and writer attention. The same error, when appearing in the work of an article or monograph, produces a comparatively weaker response in academic readers. That is because readers are not receptive to the negative or positive potential pressure of error in these contexts; in other words, readers don't see what they're not looking for. While Williams in "Phenomenology of Error" may cheekily plant “about 100" (165) errors in order to prove a point about gracious readership, his errors exert less force (when even detected) because of their very facetiousness. The default response to the pressure of error is negative, but if the possibility is granted that the same pressure may produce a different response, as I will argue translingualism shows us how to do, then the same error can be an opportunity for mutual learning and negotiation rather than an affront to the senses.

\section{Translingualism's Relation to Error and Standards}

Translingualism has been called a pedagogical approach that may thwart students' desires for standardization and linguistic capital. In a 2014 piece in $C C C$, Todd Ruecker, in summarizing pedagogical takeaways of his longitudinal study of the difficulties faced by Latino/a students in transitioning from high school to college, specifically excludes a 
translingual approach from his recommendations for faculty and graduate student training, instead advocating for a model commonly implemented in elementary schools to build students' multiliteracies (114). Ruecker writes that the students in his study "enter college classrooms with a clear purpose: to learn a privileged standardized variety of English," that their "busy lives outside the classroom" coupled with the fact that they have "much to learn to increase their academic fluency" puts them at risk when taught a translingual approach, which, Ruecker argues, "may do [them] a disservice ... by possibly delaying [their] attempts to learn standardized language varieties" (116). Ruecker falls into the same line of thinking as Delpit and Smith: that students are better judges of what they need, linguistically, than the college professors employed to expose them to new ways of thinking and learning. The idea that translingualism would delay students' learning of standardized language varieties as well as the implication that this learning would happen elsewhere, later in a student's collegiate career, is a fundamental misinterpretation of what translingualism is and does. Translingualism does not ignore or teach against standardization or standards; rather, it reveals language conventions as thinly veiled attempts to marginalize, control, and suppress all variation in languaging, variation being language's natural state.

The 2011 Horner et al. piece "Language Difference in Writing: Toward a Translingual Approach" faces the question of if and how standards should be taught head-on. It is possible, the authors argue, to acknowledge the bankruptcy of "notions of the 'standard English speaker' and 'Standard Written English"” without denying "the ongoing, dominant political reality that posits and demands what is termed standard, 'unaccented' English in speech and 'standard' writing" (305). Survival and success, in a 
translingual approach, comes not from close alignment to the standard through mimicry and absorption of writing conventions, but rather an understanding of the contingency of such standards, and a recognition of any writer's role in “challenging and transforming language conventions to revise knowledge, ways of knowing, and social relations between specific writers and readers" (Horner et al. 306). Consequently, in order to demystify standards, standards must be taught, but taught "precisely as historical, variable, and negotiable" (Horner et al. 311), with Horner adding "mercurial" in his 2020 chapter in Reconciling Translingualism and Second Language Writing. Thus, students armed with a decentered view of standards can, in their writing practices, make choices about whether, when, and in what way to conform or to invent. ${ }^{49}$

Students in a writing classroom imbued with a translingual ideology may exit that classroom writing in a way that looks superficially to align with convention and contain less "error" than when they entered. Horner et al. articulate that a translingual approach "questions language practices more generally, even those that appear to conform to dominant standards. It asks what produces the appearance of conformity, as well as what that appearance might and might not do, for whom, and how" (304). This is a sentiment not born in 2011, just as translingualism as an ideology was not "invented" with Horner et al.'s publication. Take Lu's “Professing Multiculturalism: Politics of Style in the Contact Zone," published almost twenty years before Horner et al. Lu's oft-cited "can able to" student ultimately revised her phrasing to "may be able to" because "as [the student] put it, it was clearly 'grammatically correct' and 'says what [she] want[s] to say"

\footnotetext{
${ }^{49}$ I want to again conscientiously distinguish my use of the term "choice" from the neoliberal connotation of free choice. Neoliberalism positions an individual's unrestrained free choice in the market system as a necessary driver of competition. Equally, markers of failure (such as poverty or unemployment) are framed as a matter of personal decision-making.
} 
(454) ${ }^{50}$ Yet, this student's decision to conform to the standard was still made from a translingual frame of mind, since, as Lu puts it, "decisions on how to revise the "can able to' structure depend on who is present, the particular ways in which the discussion unfolds, and who is doing the revision" ("Professing Multiculturalism" 454). The writer had to negotiate with the various ways readers might interpret her phrase and review her original intended meaning, making the ultimate outcome unpredictable. If language is a negotiation, then one of the places that negotiation happens is between a professor and a student, and a negotiation takes the vested interests of both parties into account as part of deliberations. The point, however, is that students are made aware of their decisions as just that, decisions, made in a particular time and space for a particular exigency. With each new writing situation, those contextual conditions may change, as a student's decision may change.

Horner et al.'s article ends with a list of anticipated questions from its readership, the second question being: "Does translingualism mean there's no such thing as error in writing?" (310). This question acknowledges a pervasive pedagogical concern. Horner et al.'s response was to distinguish between mistakes and errors, an important point I will tease out below, also noting that a translingual approach demands a responsible and humble readerly stance toward writing that does not match expectations. Why is it that this same fear of unalignment appears in both basic writing and translingualism? It is because, at their roots, basic writing and translingualism deal with the same central questions: What do we do with language difference? What is our responsibility? While

\footnotetext{
${ }^{50}$ For those unfamiliar with this article, Lu describes a novel phrasing she encountered in a student's writing, which she chose to workshop as a class, so that the unique linguistic construction could be explored and appreciated. Using the word "can" In a traditionally "correct" sense in other parts of the excerpt, the student at one point wrote: "As a Hawaiian native historian, Trask can able to argue for her people" (450).
} 
the answer in the realm of basic writing has too often been to chip away at language difference through unequivocal correction, or to cordon off difference, the answer from translingual scholars is more curious and exploratory. The two subfields have more in common than most may realize, and basic writers have more to gain from a translingualminded professor than any other collegiate writer.

A translingual approach to error will be outlined in greater detail in the next chapter. Going forward, however, it is key to note the shift in the rhetorical positioning of error from a translingual approach. As I have earlier alluded to, translingualism separates the term "mistake" from "error." A mistake, as Sarah Stanley writes in "Noticing the Way: Translingual Possibility and Basic Writers," "is readily noticed [by the writer] and resolved when pointed out," while error is "a miss-communication between writer and reader" (40). Stanley extends both miscommunication as "miss-communication" and mistake as "miss-take" (40) in her piece, an elaboration I find useful. Rather than errors as deficiencies or markers of ignorance, translingualism positions noticed errors as opportunities - perhaps opportunities missed by the writer to write what they mean, but perhaps opportunities missed by the teacher to leave space for students' agentive reinterpretation and refashioning of language itself, a right of all writers. The difference between an error and mistake, Stanley outlines, “rests in the error-maker's relationship to forms and a meta-knowledge of a given form's meaning-making possibility, knowledge of which makes a difference" (42). Serious writers, she claims, want to learn about error, "so that the ideas themselves are clearer and have a chance for wider impact" (42). Yet the separation between "mistake" and "error" is not work done by the professor, but by the student. Teachers cannot claim to assess students' meta-knowledge about the 
potential of the language forms they choose on the page. Indeed, to claim access and authority to evaluate this would be unethical.

As a concluding example, let us return to Ryan's phrasing from chapter one, when he wrote in his annotation that an article he read "uses real-work examples to help explain the importance of communication." A standard approach to this sentence would be to swiftly mark "real-work" - assuming, as may be the case, that the writer meant "real-world." This marking might be an underline, a circle, or, more likely, the "correct" form written next to or over the writer's words, such as a line slashing through ' $k$ " and adding "ld." A translingual approach doesn’t gloss over this so-called “deviation”; so sedimented is reading practice in favor of standardization that re-training to not see this "error" might be near impossible. Neither is the decision whether to leave the error unmarked or mark it, as leaving it unmarked assumes "real-work" is a mistake that Ryan could correct with a thorough re-reading, or, conversely, signals to him that it is "correct" as written. It is, especially in the basic writing classroom, quite possible that Ryan doesn't know the difference between "real-world" and "real work," or is typing a phrase he has only ever heard spoken aloud. A translingual-minded professor would notice the unexpected pattern and point it out, in a way that is non-judgmental, non-punitive, and non-corrective, thus leaving open the space for meaning to be negotiated between writer and reader. Ryan may choose to engage in this negotiation or not, depending on whether "real-work" is simply a mis-type. You might think this overkill, but could it not be possible that "real-work" is doing in a shorter space what "real-world" and "real work" do separately? Wouldn't it be more awkward to write, correctly, that the article "uses real-world work examples to explain the importance of communication"? 
bell hooks leaves her name in lower case "to emphasize the importance of the substance of her writing as opposed to who she is" ("Biography"). Yet Wilson, the basic writer from my introduction, left his name in lowercase, and his move was first automatically rejected by autocorrect on a word processor, and was again rejected automatically by me, his teacher. Assuming to know a writer's intention even more than the writer themselves is a dangerous proposition, one translingualism works to unveil and examine. What this looks like in the classroom and in writing programs will be examined in the remainder of this project. Error destabilizes language itself, "disrupt[ing] the illusion that a reader can maintain control of a text" (Santa 38), and in this way is a fundamental question of translingualism, which disputes the transparency and reliability of all language. 


\section{CHAPTER THREE:}

\section{TRANSLINGUAL BASIC WRITING PEDAGOGY}

In evaluating the degree to which basic writing has explored or adopted principles of translingualism, and identifying ways in which this scholarship sometimes veers away from translingualism's tenets, it is first important to give a sense of what happens in a traditional basic writing classroom. It goes without saying that there is vast variety in what this "traditional" classroom looks like, basic writing being the subject of significantly less oversight than FYC. The reasons for this variation include a lack of prestige, a lack of departmental or divisional scrutiny, the hiring and under preparation of adjuncts and graduate students whose educational backgrounds are not necessarily in writing studies, less funding, and fewer opportunities for basic writing teachers to maintain professionalization through conferencing or publishing. Thus, basic writing courses receive even less attention than the already-marginalized teaching of composition as a field (see Friend; Horner and Lu "Working Rhetoric"). Moreover, basic writing courses tend to be highly contextual, tying coursework and objectives closely to the needs of the institution's FYC. The variation extends even to the course setup; while most basic writing courses are semester-long, some are shorter (such as boot camps or supplemental lab hours) and some are longer sequences of several basic writing courses to be completed before FYC. Some basic writing courses carry credit hours and count toward progress to degree, but many do not. 
When we think of the basic writing classroom, the image that comes to mind may be of the depiction (and critique) by authors like Mike Rose in Lives on the Boundary or Mina Shaughnessy in Errors and Expectations, whose now-dated accounts feature descriptions of activities such as vocabulary expansion, grammar workbooks or worksheets that ask students to circle the right answer or fill in the blank, sentence work on the board, and short readings followed by checks of comprehension. Key to these activities is repetition; the hope is that drilling students in a familiar pattern will lead to better uptake. When students would be asked to write, they would write in sentences or paragraphs during class, instead of being assigned long essays or responses to write independently at home. Traditionally, basic writers first must be vetted as sentence writers before they are granted the right to draft paragraphs, and paragraphs before essays, passing through a series of gateways in a gateway course (Bartholomae, “Teaching Basic Writing” 87). ${ }^{51}$ Such pedagogy rarely utilizes scholarly sources, individual research, or book-length texts. While it might be convenient to imagine all basic writing classrooms as having progressed past this kind of pedagogy, this is not always the case. ${ }^{52}$ Describing the basic writing course at her institution before her intervention, Mellinee Lesley wrote in 2001 that "little emphasis was placed on reading 'real' texts or the interconnectedness of reading and writing, and certainly no attempt was

\footnotetext{
${ }^{51}$ Writing of this traditional model as he witnessed it, Bartholomae writes: "Before students can be let loose to write, the argument goes, they need a semester to 'work on' sentences or paragraphs, as if writing a sentence in a workbook or paragraph in isolation were somehow equivalent to producing those units in the midst of some extended act of writing, or as if the difficulties of writing sentences or paragraphs are concepts rather than intrinsic to the writer and his struggle to juggle the demands of a language, a rhetoric, and a task. These basic skills are defined in terms of sequences - 'words, sentences, paragraphs, essays' or 'description, narration, exposition, persuasion' - that, in turn, stand for a pedagogy" (87).

${ }^{52}$ This is not to say that basic writing has not in many places pushed past the traditional skills and drills model, as evinced by ongoing scholarship on basic writing practices and online collections of resources in places like CompFAQ from CompPile and CBWShare blog. Nevertheless, among these shared materials one finds many of the kinds of worksheets, templates, and grammar handouts that demonstrate the lasting endurance of the traditional model.
} 
made at reflexive practice or evoking a pedagogy of critical literacy" (182). In the traditional model, the false idea of concrete, knowable writing standards is clearly upheld, and the goal of the semester is to slowly, excruciatingly, raise the basic writer's ability in the direction of the bar.

Basic writing has embraced various ideologies over the decades, adapting pedagogical approaches to suit trends in writing studies such as the study of basic writers' cognition as underdeveloped, ${ }^{53}$ a consideration of the basic writer as a novice in search of initiation in the rites of academic discourse,${ }^{54}$ or an embrace of the conflicted discourses at work in the basic writer's mind and language practices. ${ }^{55}$ The culmination of my argument here, however, is to assess the degree to which basic writing has taken up translingualism as a disposition toward language. In order to perform this assessment, it is first necessary to outline a framework of translingual principles for basic writing, principles derived from the theoretical body of work on translingualism. This serves as an ideal against which to compare scholarship that touches on translingual work in the basic writing classroom. I see this scholarship as trifold: firstly, the scant scholarship on translingual basic writing, secondly, work on translingual FYC pedagogies that may be applied in the context of basic writing, and finally, canonical basic writing scholarship published before the term "translingualism" was coined. Holding these corpuses up to a translingual theory exposes patterns in scholarship, specifically, in how basic writers are treated, who basic writers are assumed to be, and who translingualism is assumed to serve. Acknowledging both promising and harmful patterns in the current literature is

\footnotetext{
${ }^{53}$ D'Angelo; Flower and Hayes; Lunsford, "Cognitive Development"; Odell; Troyka, "Perspectives"

${ }^{54}$ Bartholomae, "Inventing the University"; Bizzell, "College Composition", "Cognition," "What Happens", "Review"; Shaughnessy, Errors

${ }^{55}$ Fox, "Basic Writing"; Lu, "Conflict," "Professing Multiculturalism," "Redefining the Legacy"; Gilyard; Rose, "Narrowing the Mind," Lives; Shor; Villanueva
} 
essential for any teacher or administrator considering the adoption of a translingual approach to the teaching of basic writing. I also go beyond merely evaluating scholarship, pointing out missed translingual opportunities, expanding translingual ideas others may gloss over briefly in their work, and surfacing translingual tenets in canonical basic writing scholarship that can and should be revisited. I continue with my practice of integrating real student writing, in illustration of both the promise and the difficulty of enacting the translingual approach I forward.

As a final note before introducing my framework, I must assert that I am not inventing a translingual basic writing pedagogy, as exciting as that may sound. The translingual principles outlined here have been taken up in the past (albeit under different banners), are being used right now, and can be used in the future. It is important to distinguish between translingual practices as novel discoveries and as already existing in composition classrooms for decades, perhaps under different guises, perhaps disparately implemented, but which nevertheless have served basic writers successfully in the past. Bruce Horner in "Discoursing Basic Writing" describes the illogical gap created in the 1970s when the field separated itself from the term "remedial," embracing instead "basic" in "claims to "newness" (211). Though the students in question and their place in the university remained the same, the move's intention of breaking ties with the damaging deficit model caused an "erasure of the sort of critical insights that first propelled practices and projects in basic writing," necessitating Horner's injunction that lessons of the past be "'relearned,' in order that they not be 're-lost"' ("Discoursing" 200). The field of rhetoric and composition, like language itself, is always in transition and always shifting; consequently, a translingual basic writing pedagogy necessarily 
draws upon the history of past practices, if leveraged for new purposes. Claiming that a translingual basic writing pedagogy is altogether new and thus requires wiping the slate clean would fall into this same trap, securing within the patina of novelty its status as an experimental project, one that is temporary, and worthy of only provisional experimentation.

\section{Principles of a Translingual Basic Writing Pedagogy}

The following framework will be used to evaluate the extent to which extant relevant scholarship aligns with the core principles of a translingual view of language. Such assessment necessarily identifies gaps, gaps that reveal where basic writing pedagogy has not yet fully explored a translingual disposition toward language, as well as gaps in translingual scholarship that do not account for the unique context of basic writing. I argue here that a translingual basic writing pedagogy is defined by the following four assertions:

1. Basic writers are agentive users, (re)producers, and changers of language. The texts of basic writers are no more incomplete than any other text. Dissonance between any writer (whether published or "basic")'s meaning as materialized on the text and any reader's understanding is a productive space of negotiation and not an opportunity for writerly or readerly realignment. A translingual basic writing pedagogy notices and galvanizes these productive spaces of negotiation. 
2. The process of writing is recursive and emergent; texts are instantiations that are themselves the product of a process of negotiation, and continue to be negotiated post-production. These processes are acknowledged as acts requiring labor.

3. Named languages are in reality capacious and shifting, and the borders between them porous. Language users are also capacious and shifting. Thus, it is not only the basic writer whose understanding of language undergoes change, but also that of the teacher.

4. Standard academic writing conventions, while identifiable and teachable, are also constructed, contextual, and always undergoing transformation. Thus they can continue to be taught, but as constructed, contextual, and undergoing transformation. Writing that differs from the conventional does not deviate from some central, stable norm of correctness. Rather, every iteration of language use, including conventional usage, is different because it is new. Language difference is therefore to be expected, because it is inevitable and a part of all language use. $^{56}$

A translingual approach to basic writing would be the result of a praxis that is aligned with these principles, with the ultimate goal of instilling in basic writers and basic writing

\footnotetext{
${ }^{56}$ The term "translingualism" is itself contested, as discussed by Horner and Alvarez, Matsuda, Atkinson et al. and contributors to the 2021 edited collection Reconciling Translingualism and Second Language Writing, amongst others. Therefore I provide here some origins of my uptake of the term and of my pedagogical principles. My understanding of the basic writer's agency is informed by Shaughnessy's 1979 Errors and Expectations, David Bartholomae's essays as compiled in the 2005 Writing on the Margins, and multiple works by Min-Zhan Lu, especially her 1994 "Professing Multiculturalism: The Politics of Style in the Contact Zone." Ongoing negotiation as a central tenet of translingual pedagogy I attribute to Bruce Horner's 1992 "Rethinking the 'Sociality' of Error: Teaching Editing as Negotiation." My perception of the nature of language, its usage, and its difference, is informed by scholars such as Alastair Pennycook (Language as a Local Practice), Louis-Jean Calvet (Towards an Ecology of World Languages) and Suresh Canagarajah (Translingual Practice). For the idiosyncratic, contextual, and changing nature of "correct" and "academic" writing, see studies of error by scholars such as Elaine Lees, David Bartholomae, Maxine Hairston, and Joseph Williams. My touchstone text for the defining principles of a translingual pedagogy is Horner et al.’s "Language Difference in Writing: Toward a Translingual Approach."
} 
teachers a translingual disposition toward language. This framework is distinct from the principles that would define a translingual FYC or advanced writing classroom. In this way, my framework does not claim to represent the "essence" of translingualism, but is tailored to the unique needs of the basic writer and the unique context of the basic writing classroom.

The tailoring of my framework consists of a fundamental prioritization of the agency of basic writers, and the equality of basic writers as authors of texts and published scholars as authors of texts. The right granted to an "advanced" writer to affect and shape the ongoing discourse in the Burkean parlor is one often denied to basic writers. Therefore, granting to the basic writer an automatic authority to participate in language negotiation, with the basic writing teacher as equal participant instead of judge, is the chief element that distinguishes a translingual basic writing pedagogy from other approaches to translingual writing pedagogy.

Additionally, this framework focuses on destabilizing the hypostatization of standard academic writing conventions, even if such destabilization nevertheless results in continuing to teach these conventions in the basic writing classroom (a likely result). The grip of the standard is much tighter in basic writing than in other writing classrooms, and the basic writing teacher may feel herself beholden to uphold the standard with a degree of pressure that is lessened in places such as FYC. When my fourth principle claims that "language difference" is to be expected in all writing, one should note that I am not using the term "language difference" in order to dodge declaring my allegiance with regards to the code-switching vs. code-meshing debate (see Vershawn Ashanti Young's “"Nah We Straight"”). Neither do I mean the integration of named languages 
other than English in the texts of the basic writer. Too often, as we shall see, basic writing scholarship that purports to stem from a translingual mindset celebrates as "translingual" the novelty of multilingual writers' code-meshing. To me, however, a so-called "monolingual" basic writer has just as much potential as a multilingual writer to write from a translingual mindset. Both types of students (though typifying students is problematic in and of itself) have as much of a chance of producing texts that reproduce academic conventions as they have of producing texts that feature linguistic innovation. Key to this framework is the acknowledgement that both of these productions can be equally translingual, insofar as all language production, whether sedimenting convention or deviating from convention, recreates language in a unique spatiotemporal context and is therefore, by default, both new and different.

\section{Scholarship on Translingual Basic Writing}

The first, and arguably most salient, type of scholarship that I will evaluate against my framework is scholarship that already claims to be advancing a basic writing translingual pedagogy. There are only a handful of such texts; therefore, I will analyze here all of the scholarship I have encountered that puts basic writing and translingualism in conversation. ${ }^{57}$ This includes articles by Andrea Parmegiani, Rebecca Williams Mlynarczyk, Lucas Corcoran, Xiqiao Wang, Michael T. MacDonald and William DeGenaro, Sarah Stanley, and Bruce Horner, published between 2011 and 2019 chiefly

\footnotetext{
${ }^{57}$ As my focus is the basic writing teacher in American institutions of higher education, I exclude from my scope scholarship that portrays translingual uptakes in other reading/writing classrooms that may or may not carry credit weight, such as ESL classrooms, language institutes, or English language schools in other countries.
} 
in the Journal of Basic Writing. ${ }^{58}$ True to a core value of basic writing as a field, most of this scholarship acknowledges the basic writer as a capable and fully formed individual knowledgeable on the language practices of their lives and local cultures. Equally, these scholars' uptake of translingualism aims for a pedagogy of negotiation between the teacher and the student when language difference manifests on the page of the basic writer. However, the terms of this negotiation are unclear, with basic writing teachers favoring visible code-meshing that commodifies the basic writer's language repertoire as a novelty to be admired (see Matsuda's "The Lure" 482). This visible code-meshing is most obvious in the writing of multilingual students, who receive the vast majority of attention in the scholarship of this set, with the monolingual basic writer barely receiving any mention. When they are mentioned, they are depicted as not well positioned to perform translinguality. A focus on multilingual, international, and L2 basic writers inhibits this scholarship from conceiving of the boundaries between named languages (English, Chinese, Arabic, etc.) as shifting and porous; "language difference" becomes the difference between different languages as seen on the page. Ultimately, the evidence of a "successful" translingual basic writing pedagogy is given in the form of unconventional language by multilingual students.

To its credit, scholarship forwarding a translingual basic writing agenda universally posits the basic writer as an authoritative agent who in many ways is an expert in language practices unbeknownst to the teacher. There is scarcely any echo of the deficit model thinking rife in earlier approaches to basic writing: students are

\footnotetext{
${ }^{58}$ In addition to a piece in $J B W$, Andrea Parmegiani published a book entitled Using ESL Students' First Language to Promote College Success: Sneaking the Mother Tongue through the Backdoor in 2019 out of Routledge. Outside of $J B W$, the only scholarly journal dedicated to the study of basic writing is The Basic Writing E-Journal, which, as far as I am aware, has not published anything expressly on translingualism.
} 
positioned as "active language investigators instead of passive language learners" (Corcoran 61), "agents who draw on their multilingual repertoire to navigate . . rhetorical situations" (Wang 58), and a source of extra-textual knowledge about language, power, and genre (MacDonald and DeGenaro 31). As proof of this, the primary site of inquiry in these classrooms was the students' own linguistic knowledge; recurring assignments were the literacy narrative and other autoethnographic research, often putting students' own texts in conversation with scholarly articles from writing studies or linguistics, positioning both texts as equal in their expertise (Corcoran 55, MacDonald and DeGenaro 31).

The literacy narrative and the role of storytelling as central in a translingual basic writing pedagogy appears across the board, most notably in pieces by Andrea Parmegiani and Rebecca Williams Mlynarczyk. In his $2014 J B W$ article "Bridging Literacy Practices through Storytelling, Translanguaging, and an Ethnographic Partnership: A Case Study of Dominican Students at Bronx Community College," Andrea Parmegiani describes an effort to use storytelling as a way for ESL recent immigrants to enter into American academic discourse. To Parmegiani, storytelling in the basic writing classroom serves as an "ethnographic tool for instructors to understand the 'cultural knowledge' and 'prior experiences' upon which learning must be built” (34). Similarly, Rebecca Williams Mlynarczyk’s “Storytelling and Academic Discourse: Including More Voices in the Conversation," which is in itself part personal narrative, argues for a more central place for personal writing and storytelling in all composition courses, but especially basic writing and ESL courses, arguing that encouraging students to tell stories is a way of "supporting and enlarging the scope of academic discourse" (19). 
While I see the literacy narrative as only one way of engaging students in reflective practice with their own language and writing histories, I do applaud the overarching commitment to the use of texts about everyday reading and writing practices, both as assigned reading and assigned writing. Indeed, the texts most capable of facilitating a level of engagement that allows the basic writer to see the negotiability of all language are those in which the student-as-reader can call the authority of the author into question, interrogating an author's ethos and logos because the content stems from a place where the basic writer can consider themselves to be experienced. Since a translingual approach is one in which the student comes to see language as negotiable, and themselves as worthy negotiators, learning about the terms of these negotiations is facilitated by teaching texts of everyday language practices. Texts about everyday language practices create a more equal playing field between author and reader, in that the basic writer-as-reader feels expertly situated (since they are an everyday language user themselves). Thus reading becomes for the basic writer not a matter of receiving the mysterious knowledge imparted by the author, but a matter of being persuaded. When the basic writer learns to recognize him/herself as a collaborator in the making of textual meaning, rather than the communicator of a fully-formed meaning, then the ultimate authority of any text is rightly questioned and destabilized, making space for a larger understanding of the permeability of all language practices. Suddenly it is not just published scholars or famous authors who can challenge and transform language, but ordinary language users.

Yet, while scholars publishing on translingual basic writing may see the basic writer as an expert user of language, few extend to the basic writer the power to reshape 
language itself. This right seems to remain in the purview of more established writers. For instance, while Mlynarczyk advocates for a wider acceptance of storytelling as an academic genre, she admits that this acceptance may begin and end in the writing classroom, writing that "[w]hile we certainly cannot change the academy's longstanding preference for the more distanced approach to language commonly known as academic discourse, we, as professors . . . can set a different tone and control the expectations for language use within our classrooms" (12). According to Mlynarczyk, since for basic writers, academic discourse "can feel like a foreign language" (10), trusting in the language style of their own expressive writing is one building block toward the acquisition of standard discourse (9). Students' home discourses, she writes, can 'help the students in their quest to acquire a further education and to become contributors to the making of knowledge within the academy" (12 emphasis added). To Mlynarczyk, it is the credential that grants the basic writer the ability to contribute, rather than this ability being an automatic right.

In contrast, Bruce Horner's 2011 “Relocating Basic Writing” claims from the start a stake for basic writers in reshaping and reproducing language. Horner writes that, as participants in the traffic of meaning, "basic writing students rewrite these [language and literacy practices] through their work with and on them. In terms of language, we can say that our students, like all writers, do not so much write 'in' English, or any other language, but rather write, and rewrite, English with each writing" ("Relocating” 16). While the distinction between Mlynarczyk and Horner's framing may seem subtle, it is an important one. When basic writers are positioned as only using language, in their quest to become part of an academic community, then language in the basic writing classroom 
is reified, and the aim of acquisition is upheld. If, however, the basic writer is positioned as not just already in possession of language but capable of changing it, power is stripped from a language-as-monolith model and invested in students instead.

Part of the issue that may explain the difficulty these scholars have recognizing the basic writer's ability to remake language may lie in the murkiness concerning how exactly translingual negotiation with basic writers is supposed to work. The idea that teachers should consider the dissonance or difficulty they encounter when reading basic writing texts (and that basic writers encounter when reading assigned texts) as an opportunity for negotiation is an accepted one. The answer to how to negotiate and what happens when teachers try to negotiate is most visible in two texts from this corpus: Michael MacDonald and William DeGenaro's 2017 description of a two-year study at their institution designed to cultivate what they call a "transcultural ethos" in their basic writing program, and Sarah Stanley's 2014 “Noticing the Way," in which Stanley outlines her method of in-class sentence-level workshops that foster mutual noticing between basic writers, their peers, and the teacher.

MacDonald and DeGenaro prioritized negotiation of "global-local language shifts" (28) in fostering a transcultural ethos in their basic writing program. Their project codes the comments basic writing teachers at their institution made on portfolios at the culmination of a semester's pilot pedagogy encouraging code-meshing as a way of "making acts of negotiation more deliberate" (25). What MacDonald and DeGenaro found when they analyzed the faculty comments was that portfolio readers "often hesitated when praising or criticizing student writing, and [MacDonald and DeGenaro] saw such hesitations as evidence of BW instructors negotiating between the student 
writing and their own assumptions about language" (41). This hesitation they read as instantiations of negotiation in that the teachers" comments were "measured" or "undercut" with a qualifier like "but" or "however" (43). They give an example of a comment along these lines: "Could be somewhat long-winded at times_-but, wow, what an interesting perspective!” (43). MacDonald and DeGenaro counted 182 instances of these qualified comments, making it "one of the most observable characteristics across all reader responses" (43). They surmised several reasons for this extensive mediation, including teachers' desire to praise visible code-meshing but still express a desire for deeper critical engagement with the themes of the course, as well as a teachers' struggle "to make sense of evolving dynamics in student writing while also holding true to various standard language ideologies" (44). ${ }^{59}$ The portfolio readers thought students were too apt to code-mesh without engaging in deeper critical reflection, just as MacDonald and DeGenaro thought the portfolio readers too apt to value code-meshing without engaging in reflection as to why they valued it so highly. As MacDonald and DeGenaro phrased it, both parties "thought it was enough to point to instances of code-meshing" (44). MacDonald and DeGenaro admitted that they found even more qualification on basic writers' texts that, while describing language, did not illustrate it with visible codemeshing, implying that the source of the qualification lies in a lingering desire for

\footnotetext{
${ }^{59}$ This kind of qualification calls to mind the work of Mary Lea and Brian Street, who, in analyzing instructor feedback on student essays, found that some teacher feedback solidified for students the boundaries between what is incorrect and what is correct, even if a teacher meant feedback to be taken as exploratory engagement. For instance, the exclamation mark was read by students as a sign that the teacher doubted the veracity of their statement and not that the teacher was excited, and the question mark, rather than indicating a genuine question, "rather is used as a kind of expletive, or as a categorical assertion that the point is "not correct"' ("Student Writing"). While MacDonald and DeGenaro's teachers' qualified praise would likely have been interpreted by students as kindly meant requests for deletion or revision, the teachers in this study assessed the portfolios as if writing to students, all the while knowing their real audience was the researchers studying their response. Perhaps hedging in this research context is indicative of the teachers' desire to straddle the line between celebrating the success of the "transcultural ethos" initiative while also making known their reservations about students' lack of adherence to convention.
} 
evidence of translingual-thinking-as-visible-code-meshing. Only when the code-meshing was absent did the teachers, through their qualified feedback, seem aware of their struggle to negotiate basic writers' texts from a translingual, or, as MacDonald and DeGenaro would say, a transcultural ethos.

Still, MacDonald and DeGenaro's efforts demonstrate a laudable engagement with the idea of negotiating texts with basic writers, even if negotiations were strained and artificial (in that the feedback was knowingly written for only the researchers' consumption, not the actual students). It remains unclear from reading MacDonald and DeGenaro's piece what kind of verbal or written negotiation took place in the basic writing classroom, but we do have access to such on-the-ground negotiation through the workshops described by Sarah Stanley. Stanley's approach to sentence-level workshopping from a translingual perspective centers on the term "noticing," a term she takes from second language acquisition (SLA). The concept of noticing is worth more elaboration than Stanley allots in her article, as I believe it to be more capacious than even she allows.

According to SLA, teachers (in this case mostly ESL teachers) should work to "notice" error patterns in the writing of second language learners, and then call attention to these patterns in an interactive manner so that the student can then "notice" that which had been invisible to him/her about their idiosyncratic interlanguage. SLA has primarily associated noticing with task-based instruction - asking ESL students to "notice" grammatical features by underlining them in texts or reproduce them in their own writing after looking at a model. ${ }^{60}$ These tasks are meant to help learners notice the gap, or, as

\footnotetext{
${ }^{60}$ To give an example, in one study linguists Shinichi Izumi and Martha Bigelow organized two groups of ESL students, providing one group with sample paragraphs to read aloud together that included many
} 
linguist Scott Thornbury writes, "make comparisons between the current state of their developing linguistic system, as realized in their output, and the target language system, available as input" (Thornbury 326). Such comparison, argues Thornbury, provides students "with positive evidence of yet-to-be-acquired language features" (330), or, in other words, proves to students that they do not yet know what they need to know. The goal of noticing, to SLA scholars, is for the language learner to be able in the future to identify their own errors and correct them without intervention by the teacher, to, as linguist Rob Batstone puts it, "internalize the underlying rule" (273). Successful noticing, therefore, eliminates itself. As defined by SLA, noticing is not a way of shedding light on the changeability of language itself, but a way of aligning multilingual students to the standard, and this definition is where Stanley's uptake of the term in a translingual context differs from its usage in SLA. When applied from a translingual frame, noticing acknowledges the need for negotiation, carving out space (both temporal, in pausing and taking time to call attention, as well as spatial, in its location on the page) for negotiation to happen.

In her article, Stanley outlines her workshop method for making agentive space for the basic writer to negotiate meaning aloud and decide, with help from others, on the revision that best conveys their meaning. Stanley's definition of noticing is an act that "invites attention to a linguistic feature which may belie a writer's expressed purpose" (37). I would take up and extend Stanley's usage, qualifying the latter half of her definition in arguing that noticing the distinct in student writing is not to assume the

examples of the past hypothetical conditional in English (e.g. "If Andy had gone to Greece, he would have seen the Olympics."), while the other group had control paragraphs. Izumi and Bigelow compared the two groups' ability to write sentences in the past hypothetical conditional in a post-test, and, unsurprisingly, those who had read the targeted paragraphs performed better. 
writer's original intention but rather to recognize an opportunity to engage with an instance of language difference that has the potential to change language itself. This opportunity is available for both students and teachers, but can only be galvanized through intention, the time and space for which can be achieved with conscious attention. Noticing is more important in a basic writing classroom than in, say, a FYC classroom, because when a basic writing teacher does notice linguistic difference on the page, she is less likely to assume that it is evidence of a student's cognizant re-working of English for their own purposes. A translingual-minded professor of a more advanced writing course may immediately give students the benefit of the doubt when encountering novel phrasing or strange syntax. The same cannot be said for the basic writing teacher, which is why "noticing" error, without assuming either that the error is a mistake that needs correcting or that it is purposeful language play, is a key translingual strategy. Of course, instances of language difference cannot be easily sorted into categories of "mistake" or "translanguaging," but a basic writer can, with help, reflect on their meaning and choose their path forward. The basic writing teacher, on the other hand, neither can nor should decide on the student's meaning or choose the best path for them.

The particular need for conscious noticing in basic writing is described in Xiqiao Wang's "Developing Translingual Disposition through a Writing Theory Cartoon," an article that stresses the importance of making visible that which both teachers and students too often gloss over, with Wang writing that "the subtle and invisible acts of composing across differences often evade our attention because they function as such a routine part of our language work that they often recede into the background of our 
consciousness. If untabbed [sic], ${ }^{61}$ such cultural and linguistic knowledge that shapes basic writer's language practices may very well remain invisible and never turn into transferrable meta-knowledge of writing" (60). Stanley's answer to making visible these often invisible linguistic features of students' working English is to reclaim the study of the sentence from grammar drills, emphasizing instead the translingual potential of the individual sentence (Stanley 56). The reclamation of the sentence is vital for not only the translingual development of the student but also for the writer; as a teacher trains herself to notice more features of student writing, she in turn expands the number of options available to herself and to the student for potential negotiation of meaning (Stanley 55).

While the previous pages outline an expanded perception of the role of noticing in the translingual basic writing classroom, it is important to recognize that the current scholarship in this cross-field does already feature a type of noticing, albeit a damaging type. As I alluded to earlier, the extant scholarship forwarding their conceptions of a translingual basic writing pedagogy is eager to concentrate on the textual product of the basic writer. What is lost, however, in this emphasis is the recognition of writing as a recursive, emergent process, one in which texts result, yes, but texts that are themselves products of a negotiated process that is ongoing even after publication/submission.

Readers who privilege the exoticization of visible language difference concentrate on the performance of the basic writer, rather than recognizing the labor involved in the writing of any text. For instance, when the teachers in MacDonald and DeGenaro's study were "prompted to shift focus from the students to the textual performances" (35), this shift

\footnotetext{
${ }^{61}$ There are several moments in each of the articles on translingual basic writing that feature unconventional languaging. While none of the writers explicitly discusses their own translanguaging, it is nevertheless interesting to note my urge (as per academic conventions) to highlight this language as belonging to the writer and not myself.
} 
resulted in teachers hunting for how well basic writers performed the language strategies, namely code-meshing, that the pedagogues had introduced to them. MacDonald and DeGenaro write that over half of the 88 portfolios analyzed showed no evidence of codemeshing (34), highlighting that even the researchers, in their pushback against mandating code-meshing, quantified "translingual writing" in this way. Instead of focusing on the composing processes and practices of the students, MacDonald and DeGenaro's "transcultural ethos" gets lost in this latent idea that evidence of a writer's translingualmindedness can be identified on the page as language difference, which ignores the emergent and ongoing nature of writing.

In a similar vein, Lucas Corcoran's “'Languaging 101': Translingual Practices for the Translingual Realities of the SEEK Composition Classroom," while otherwise brilliantly depicting a translingual disposition toward writing he hoped to foster in his students, yet contains evidence that students seemingly on-board with his theoretical framework nevertheless focused on their final writing product as entirely determining their success or failure. The student whose work Corcoran excerpts at length, Genesis, researches her mother's bilingual background and its link to economic success. The content of Genesis' essay demonstrates clearly her engagement with questions of ideologies at play in the production and reproduction of language. Yet, buried in the description of Corcoran's work with Genesis is a description of her concentration on the product and its correctness: "Genesis called me over to ask for direct feedback on her work; she wanted to be sure that she was getting it right. So we would sit there in the cramped rows of aging desktops, with wall-mounted rotating fans whirling in the background, going over of her [sic] paragraphs, sentence by sentence" (67). Corcoran 
discusses revision and drafting as part of his pedagogical approach, but this image of painstaking one-on-one correction is a telling reminder of the lasting force of the isolated writing product when assessment is based on standalone papers and their "rightness."

Another overarching issue in the scholarship purporting to present a translingual basic writing pedagogy is the assumption that translingualism is an approach aimed chiefly at multilingual students. With the exception of Horner's 2011 piece, every scholar centers on a basic writing classroom occupied primarily by multilingual students, whether international students, immigrants, or heritage speakers. ${ }^{62}$ This is not necessarily a failing of the scholars in question; after all, they are representing their own classrooms, which, due to institutional contexts, are composed of mostly multilingual speakers. Yet these articles are published in the Journal of Basic Writing, not a journal in linguistics or SLA. For there to be only a single article that positions translingualism as an approach to teaching so-called "monolingual" basic writers signals a significant and worrying uptake of translingualism as belonging only to speakers of more than one named language.

Even in these basic writing classrooms that are somehow comprised of mostly multilingual students, there are monolingual students present on the fringes of the scholarship: Corcoran says "19 of out 22" students in his class reported speaking a language other than English (58), Wang describes a demographic mainstream of Chinese international students at her university, but also mentions international students from other countries, "as well as a few domestic African American students from a nearby metropolis that had suffered from steady economic decline and population loss" (63), and MacDonald and DeGenaro cite "growing linguistic diversity" (27) in the form of

\footnotetext{
${ }^{62}$ As others have already argued (Friedrich; Matsuda, "Basic Writing"), the populations of ESL writers and basic writers are often erroneously conflated, and the former's distinct needs are underserved in basic writing courses that have as an unstated side objective the learning of the English language.
} 
multilingual students as the exigency for their cultivation of a transcultural ethos. Thus we can deduce that the placement measures at these universities did not funnel only multilingual students into basic writing, but we hear nothing about these monolingual students or how they approached assignments that were obviously geared for their multilingual peers. All student samples featured but one are from multilingual students, and the one monolingual we do see, MacDonald and DeGenaro's "Phil," wrote of his experience hearing Arabic in his neighborhood, thus proving that Phil's understanding of translingualism is rooted in the differences between distinct languages. Scholars from this set often lackadaisically extend their findings to monolinguals, assured in a vague way that their pedagogies would transfer easily into seemingly less diverse classrooms (Parmegiani 25; Corcoran 57), but the assignments they provide in the pages of their articles are ones that the basic writing teacher of so-called monolinguals would be harderpressed to adapt. Assignments range from "reporting on the language practices of their communities" (Corcoran 62), to a "translation narrative," a "culture shock assignment," and the request to "draw a set of two pictures to represent your experiences with and relationships to multiple languages" (Wang 63, 66). These assignments ask students to focus on the differences and similarities between languages rather than ask them to question and challenge their ideas of language boundaries in general.

The dissonance between a pedagogue convinced of their investment in a translingual disposition toward language and a pedagogy that asks students to draw upon their languages in a visible, explicit way results (in this body of scholarship, at least) in a misinterpretation of student examples as performing a kind of translinguality that, upon further inspection, is more akin to a celebrated multilingualism. One stark example is in 
Wang's Chinese student Fan. Adapted from Paul Prior and Jodi Shipka's work on writing theory cartoons, Wang's article introduces a multimodal drawing assignment in which students design visual metaphors of their writing processes, spaces, or experiences, with the goal of expanding the possibilities for negotiated meaning-making outside of a textual mode. Fan's two "translingual" drawings depict how Chinese as a language "works" distinctly from English. In the first drawing, a red dot is poised at the entrance of a complex, light gray maze, its exit unclear. In the second, the same red dot is poised at the upper left corner of the light gray outline in the shape of an empty square, with a single "exit" clearly marked on the opposite diagonal (Wang 72).

The images clearly illustrate Fan's conception of each language as operating differently and working upon him as a user in a fixed, static way. Each cartoon has a lengthy caption, but the first sentences of each are tellingly parallel: "Chinese language is mealy-mouthed and profound" vs. "English language is direct and specific" (Wang 72). The second sentence in the English caption directly contrasts the two images even further, with Fan writing, "[i]f you regard the Chinese language as they maze, you may think the English language is the road which has only one way to go" (72). It seems impossible to read Fan's cartoons as interpreting the borders of Chinese and English as porous or changing in any way; they seem timeless and frozen, with him the observer and not the changer of their conventions.

Yet Wang confidently sees translinguality in Fan's cartoons, as well as cartoons by other basic writers in her article. When analyzing Fan's drawings, Wang writes that "while his analysis seems to essentialize the two languages as operating with distinct rhetorical conventions, such analysis points to how rhetorical demands are contingent and 
negotiable when one crosses genre, linguistic, and cultural boundaries" (74). Later, Wang writes that "[f]or Fan, thinking about English compels him to examine his home language, which often leads to recognition of languages as historically fluctuating and language differences as a norm" (79). Wang's connections, while ostensibly translingual in their intention, fail to connect these assertions satisfactorily to the actual cartoons readers see on the page. Wang acknowledges what the cartoons appear to be, but then provides her truth of what they really are (in her estimation), but the logic between these claims is occluded, likely because the reader has no access to the revision or discussion that must have taken place as these cartoons were formulated and redrawn. Rather than a negotiation between writer and reader, negotiation in Wang's students' cartoons is between different languages, as if the languages themselves were in conflict within the mind of the basic writer instead of being negotiable in and of themselves. Ultimately, Wang's claim that her cartoon assignment helps "basic writers learn to challenge binaries that separate languages as sealed and isolated entities" (79) is not substantiated in the drawings themselves. The widespread emphasis on translingualism as a multilingual opportunity, manifested on the page in literacy narratives that leave the teacher wanting more and cartoons that place languages in conflict with each other, stems from a larger, conceptual problem in this literature of coming to terms with the porousness of language and language conventions.

It makes sense that in the field of rhetoric and composition, basic writing would be a stronghold upholding the solidity of writing conventions, even as their nature as contextual and dynamic is being acknowledged in other subfields. After all, if first year composition is where the collegiate writer earns the mantle of alignment with the 
standard, then basic writing is the place where the writer who has been deemed as-yet unworthy of even attempting to earn the credential has been placed for a period of linguistic incubation. Yet Horner in his 2011 "Relocating Basic Writing" asserts that basic writing is the ideal place to challenge the seeming fixity of language conventions, as basic writing has always been about seeing language difference in a new light. Notably, Horner keys in on "what might seem to be highly conventional language" ("Relocating" 16-17) as equally worthy of translingual notice as the visible difference that is so often associated with the term. Rather than seeing language that reproduces convention as "mechanical, or being condescended to as the crude flailings of remedial students who need to learn 'the basics' before advancing to 'real,' thoughtful writing ... [basic writers who choose conventional language] are producing something with different meaning through necessarily re-locating a given practice ... and they can be expected, and asked, to account for their iteration of the seeming same: what ends, given this context and their desires and needs, this iteration might serve" (17).

Other than Horner's "Relocating," there is little critical attention being paid to the conventional language of basic writers in the scholarship on translingual basic writing. The boundaries of the standard are rarely questioned, and an emphasis on code-meshed language obscures the possibility that conventional language can be translingual too. For instance, the stated goal in Parmegiani's teaching of the literacy narrative is an entrance through the gate into "Academic Discourse" (24). Parmegiani uses the terms "translingual" and "translanguaging" to mean simply encouraging students to see their linguistic resources as tools for moving through this gate; students' literacy narratives are never positioned as exerting pressure upon the standards of the discourse they are 
ostensibly aiming to acquire. While Parmegiani stresses that welcoming the linguistic repertoires of ESL basic writers allows the learning process between teacher and student to be bidirectional, he, like other scholars of this set, does not extend the same bidirectionality to the boundaries of language or writing conventions. Unfortunately, the dearth of attention to the potential translinguality of conventional language is noticeable across all scholarship reviewed here, and is not exclusive to scholarship on translingual basic writing, indicating an area for potential future study.

\section{Scholarship on Translingual Pedagogy in FYC}

While the quantity of scholarship that forwards a translingual pedagogy in the mainstream writing classroom is much more voluminous than that which focuses more narrowly on basic writing, it nevertheless falls into some of the same pitfalls as have been already outlined. Still, scholars of translingual FYC pedagogies grapple more openly with the struggle to implement translingualism without looking for evident language difference on the page. Additionally, this body of scholarship, while still concentrating more on multilingual and L2 writers as the intended target audience of a translingual pedagogy, has begun to make space for the translingual-minded so-called "monolingual" writer, and the translingual potential of these writers' texts. Although the basic writer is not the primary focus of this scholarship, basic writing teacher-researchers rarely limit their scope to such a degree that would exclude this research from their purview. In that vein, I include writing by FYC student Ryan in this section, in order to provide a more direct example than is currently available in scholarship of how teachers can approach the writing of monolingual novices from a translingual perspective. 
The corpus of scholarship on translingual FYC pedagogy I cite here is only a fraction of the scholarship published widely on translingual theory in writing, reading, and literacy studies, both in rhetoric and composition and in sociolinguistics/L2 journals. I hone in on specific attempts to articulate pedagogies that enact and illustrate translingual tenets, such as special issues of the peer-reviewed journals College English (2016) and Composition Studies (2016), a group-authored forum on pedagogizing translingual practice in Research on the Teaching of English (2017), and chapters in edited collections, including Literacy as Translingual Practice: Between Communities and Classrooms (2013, edited by A. Suresh Canagarajah) and Crossing Divides: Exploring Translingual Writing Pedagogies and Programs (2017, edited by Bruce Horner and Laura Tetreault).

The tendency to see languages as discrete and bounded units that are markedly different from each other persists in much of this corpus. For instance, the six scholars in De Costa et al.'s forum on pedagogical applications of translinguality in $R T E$ are hindered by a fundamental understanding of languages as bounded and static; goals include aims like "heritage language appreciation" (465) rather than the exploration and explosion of the concept of languages altogether. One contributor to the forum, Esther Milu, cites the writing of a student she calls Patrick, who is of Angolan descent but who speaks Portuguese and English (not any Angolan languages). In his final reflection, Patrick wrote: "I am ashamed to admit that I cannot speak any Angolan language ... I want to appreciate my culture, exploring its beauty and singularity. I wanted to talk to my people using our own language" (467), and Milu argues that Patrick, through the benefit of her translingual-oriented pedagogy, is thus on the road to "cultural and ethnic 
decolonization" (467). However, Patrick leaves Milu's course with fixed notions of Portuguese vs. Angola vs. English, thinking that his deficiency in one named language somehow makes him less culturally authentic. His excerpted quote demonstrates his belief in the solidity of these languages and their obtainability as objects. An interpretation of translingualism that relies on discrete languages and their differences is also evident in scholarship that asks students to translate between their known languages as a kind of performative balancing act (Wang; Kiernan et al.). Such activities fall into what Rebecca Lorimer Leonard calls the "methodological nationalism" (127) of translingual pedagogies that reduce down to little more than comparative analysis. By treating languages as singular units of analysis, rather than as "socially significant but historically odd, as only meaningful in relation to phenomena diffusing across them" (Lorimer Leonard 128), such pedagogies rely on the sway of the term "translingualism" rather than on the questions such a term might lead one to ask.

Another enduring pitfall is that of exigency: translingual approaches being adopted because of changes in student demographics. The guest editors of the 2016 Composition Studies special issue reiterate the false assumption that translingualism is experiencing a kairotic moment due to a global turn that "seems inevitable for us to engage" (Ray and Theado 10). Earlier I demonstrated that perceptions of "new" waves of students suddenly invading the writing classroom are historically frequent and often unsubstantiated. In contrast, translingualism is a recognition of language practices that are already and have always been in all college writing classrooms, whether occupied by citizens, immigrants, international students, etc. ad nauseum. In the Composition Studies special issue, editor Brian Ray writes of teaching "college writing courses comprised of 
international and residential multilingual writers" (10), implying subtly, as is common in translingual scholarship, that placement practices at many universities funnel all multilingual speakers into cordoned off sections of FYC or basic writing, and that translingualism is an approach meant for these sections, and not college writing in general.

Yet this same body of scholarship has strengths in other avenues, including an expansive view of what "agency" means when it is acknowledged as belonging to the novice writer. Anis Bawarshi, in "Beyond the Genre Fixation," reconfigures how agency should be imagined from a translingual perspective, arguing against vertical imagery (in which students struggle upwards to reach greater power through education) in favor of a horizontal imagery, in which "agency is in play in all language use across the spectrum" (245). This shifts focus away from the idea that certain language acts involve the use of more agency than others, concentrating on the asymmetrical power relations in all linguistic transactions (247). However, sometimes the language used to describe the agency of the college writer remains hedged; for instance, in Shapiro et al., students are agents "with a degree of control over their own acts related to writing" (33; emphasis added).

The agency of the student writer in a translingual course is nowhere more evident than in Asao Inoue's labor-based, or contract grading model as described in his Crossing Divides chapter entitled "Writing Assessment as the Conditions for Translingual Approaches: An Argument for Fairer Assessments." Inoue advocates for student-led control of the conditions of assessment through negotiated labor-contracts. Anticipating that some readers might question if his method decreases student motivation or inflates 
grades, Inoue responds with the opposite: in his experience, labor-based grading contracts redirect students' motivation away from grades and toward "dimensions of student learning like metacognition, persistence, grit, and engagement" (130). In other words, students feel safe that their labor will ensure them the grade they want, and this safety leaves cognitive room for investments in other aspects of their writing besides its correctness.

Much of translingual scholarship on FYC draws its understanding from foundational scholars such as A. Suresh Canagarajah, whose theory of translingualism asserts the linguistic competence of all speakers and writers, monolinguals and multilinguals alike (Translingual Practice 8), language's ontological existence as dependent entirely on people's use of them (16), the role of the translingual teacher as creating an environment in which students may explore, investigate, perform, and innovate with language (133-135), and assessment as a readerly judgment of performative success or failure, not on the upholding of standard writing conventions (153). Still, even Canagarajah's carefully articulated theory is somewhat contradicted by his own student examples, with the last third of his 2012 book Translingual Practice: Global Englishes and Cosmopolitan Relations devoted to the writing of an advanced undergraduate Saudi Arabian student Buthainah, a speaker of Arabic, English, and French, whose writing he chose to excerpt "because she displayed some of the most creative and controversial codemeshing in the class" (134). To Canagarajah, explicit code-meshing in writing is a way of satisfying the demands of the standard while still staying true to one's unique voice, or, as he puts it, "a strategy of resisting from within" (113). Thus he cites the writing of Buthainah as well as code-meshing scholars such as 
Vershawn Ashanti Young and Geneva Smitherman, since "with codemeshing we find translinguals already exercising their agency to initiate changes [in language]" (113). The implication is that a writer's agency is latent if their texts feature no such code-meshing. The change these "conventional" texts make to language are indiscernible, and therefore, unworthy of study. Thus, subscribers to Canagarajah's brand of translingualism are apt to solicit from their students code-meshing visible on the page, and apt to consider this code-meshing evidence of their translingual disposition, even if the two are not necessarily correlated.

The scholars publishing on translingualism pedagogies for mainstream and advanced writing courses grapple openly, as part of their thinking, with the consequences of attempting to engage writers in code-meshing practices. This is in contrast to the previously reviewed scholarship from basic writing teacher-researchers, who often seem to see code-meshing as the ultimate goal of taking up translingualism as a theoretical frame. For an example of the kinds of frank struggles occurring in mainstream FYC translingual scholarship, Juan Guerra, in his "Cultivating a Rhetorical Sensibility in the Translingual Writing Classroom," when describing the idiosyncratic language of his student Mina and her brother (a mixture of words in French, Lao/Thai, Hebrew, Russian, Spanish, and Arabic, as well as timed humming sounds), considers Mina's denigrative stance toward her language practices as a failure on his part to acknowledge the vastly different rhetorical contexts of Mina's home life and Mina's academic writing, a false assumption on his part that Mina would be able to "easily transfer [her] language practices from one site to another" (231). Guerra sees his own effort to encourage "writing that mimics what we call code meshing" as a misguided attempt to achieve his 
true goal: having students call on their "rhetorical sensibilities" (“Cultivating” 231). Horner's chapter in Crossing Divides “Teaching Translingual Agency in Iteration” similarly emphasizes that encouraging students to experiment with language mixing "risks leading [them] to accept and experiment with producing writing the dominant has already defined for us as language difference rather than calling those definitions into question" (89). Thus, Horner points out, the "translinguality" of any assignment is never evident superficially; an assignment that results in seemingly conventional student writing may still have asked them to call upon translingual questions of language and power, just as assignments written to be "translingual" may ultimately reinforce monolingual ideologies (89). Speaking to the same idea, Brooke Ricker Schreiber and Missy Watson, in a piece largely defending code-meshing, nevertheless acknowledge the dangers of unilateral support for visible code meshing, in that it "can actually reinforce monolingualism, by drawing attention to combinations of fixed 'languages' rather than subtler variation, boundary pushing, or the fuzzy, complex histories in which words themselves cross borders and are repurposed" $(95) .{ }^{63}$

Despite the ongoing debate regarding visible code-meshing's place in a translingual pedagogy, scholars of translingual FYC and beyond are advancing in one arena that basic writing scholars have not yet broached: inviting the so-called monolingual writer in. My emphasis on the importance of including monolingual writers in any translingual pedagogy, as if they are a marginalized population, might seem counterintuitive; after all, as Lisa Arnold writes in her "“This is a Field That's Open, not

\footnotetext{
${ }^{63}$ It is worth noting that Schreiber and Watson's article (as well as the article they are responding to by Gevers called "Translingualism Revisited") is published in the Journal of Second Language Writing, an L2 journal not central to the field of writing studies, demonstrating that arguments against code-meshing in translingual student texts are happening in our peripheral vision.
} 
Closed," "much composition scholarship tends to speak to an audience that is assumed to be monolingual and assumed to teach primarily monolingual, native speakers of English" (73) ${ }^{64}$ Yet, if Arnold's claim is generally true, it is untrue in the scholarship that attempts to forward a translingual approach to the teaching of writing, which unfortunately assumes as a given that multilingual students stand to benefit most. Perhaps this is due to a field-wide assumption that Arnold herself touches on: that multilingual students (when represented at all), represent "a population with needs that are 'different' from the norm" (73), hence explaining why translingualism, a seemingly "different" approach to language in the classroom, is chiefly applied to these students. A different language pedagogy for students with different language needs.

This overwhelming focus on multilingual students is made all the more intriguing when we remember that Horner et al.'s 2011 College English opinion piece "Language Difference in Writing: Toward a Translingual Approach," a touchstone and ubiquitously cited article that was writing studies' first introduction to translingualism, was written just as Arnold claimed: for an anticipated readership of mostly monolingual teachers who believe their students to also be monolingual; Horner et al. preemptively ask and answer questions about how translinguality might apply to monolingual teachers and monolingual students (310-12). It is remarkable then that this question was not only not asked by readers (in that, readers continued to assume that a translingual approach applies only to multilinguals) but also that most later scholarship fails to even touch on the possibility that translingual work can be done by students whose linguistic repertoires don't include multiple named languages. This gap is all the more alarming when one

\footnotetext{
${ }^{64}$ Arnold's article recounts a semester-long study of 17 multilingual writing faculty at the American University of Beirut in their efforts to locate their own transnational work within composition scholarship.
} 
considers that writing studies is the only field where translingual teaching to so-called monolingual students is likely to ever be explored (since disciplines devoted to the teaching of L2 students have already taken up translingualism). While the majority of scholarship forgoes this exploration, some authors do attempt it, and these attempts are worth examining.

Some scholarship that references monolingual writers reverses the assumed deficit of multilinguals on its head: considering instead the monolingual student at a linguistic disadvantage in a translingual classroom, such as a chapter by Joleen Hanson in the 2013 edited collection Literacy as Translingual Practice in which she describes a Google Translate activity for her monolingual students geared to help them approach and learn from online texts written in languages other than English. This activity, Hanson argues, helps students "learn strategies for moving out of their monolingual comfort zone and into negotiating language difference in a multilingual world" (207). The implied dichotomy between the familiar monolingual home and the unfamiliar multilingual global reality positions monolingual writers as by default not as capable of negotiation as multilingual writers. In Hanson's estimation, then, a monolingual basic writer would face double the disadvantage. William Lalicker's chapter in Crossing Divides acknowledges that "native English speakers" are necessary "ingredients" in a translingual course (51), though the tandem "transnational variant" (58) classes in the U.S. and China Lalicker describes seems to pit the Chinese and American cultures and languages against each other, tying each language closely to the identity of its users (56-7). Still, mentioning monolingual students in the context of a translingual writing classroom at all is better than assuming all teachers interested in translingualism have only multilingual students. 
Works by Vanessa Kraemer Sohan and Aimee Krall-Lanoue go the furthest in demonstrating the translingual potential of monolingual writers' texts. Sohan's coined "relocalized listening," a way of "reading-writing-thinking that highlight[s] the need of language users to relocalize established conventions in light of users' spatiotemporal contexts" (193), makes room "for the meshing already at work in our everyday languaging practices" (194), and in this sense includes the so-called monolingual speaker. Sohan, channeling Lu, Ratcliffe and Royster in her chapter in Reworking English in Rhetoric and Composition, features the response of FYC student Kathy to Gloria Anzaldúa's "How to Tame a Wild Tongue." Sohan hones in on certain aspects of Kathy's prose, including the phrasings "Who am I to be confused" (196) and "natives who are not from this country" (198) as well as Kathy's ambiguous use of pronouns (201). By listening more carefully to the texts of monolingual students and exploring diverse ways of making sense of their words, Sohan argues, teachers can "begin to recognize the constantly dynamic and shifting nature of the Englishes our students use in our classrooms" (202).

Aimee Krall-Lanoue similarly advocates for the complexity at work in the journals of four monolingual basic writers in her chapter contribution to Literacy as Translingual Practice.$^{65}$ Concentrating on their use of verb tense, word choice, and sentence boundaries, Krall-Lanoue argues that if teachers can "defer understanding and resist editing [the student's] sentences, we might see a more complex way [they] feel"

\footnotetext{
${ }^{65}$ While Krall-Lanoue's article features the work of basic writers, I do not classify it under the heading of scholarship that puts translingualism in conversation with basic writing. Krall-Lanoue mentions and then dismisses the designation of these students, saying their writing is still "representative of much of what composition instructors see, regardless of the distinction between basic or mainstream writing courses" (229). Interestingly, Krall-Lanoue's exclusive use of monolingual students' text, what I see as the chapter's central strength, is something the author herself glosses over (229).
} 
(229). Krall-Lanoue proposes teachers assume the text on the page was intended to be written as such, deferring negotiation to an in-person conference to give students the opportunity to engage in real-time language revision. For example, Krall-Lanoue's student Josh used the present tense when reflecting back on his semester, writing: "I learn a lot this year about my writing. I gain the experience I need to be able to write a paper, but I make the small mistakes" (229). Josh wrote in another journal that "[ $\mathrm{t}]$ his hole week over all stunk, I never had the hang to hang with my family nor with any of my true friends" (230). In her piece, Krall-Lanoue considers what using present tense verbs to consider past experiences does to meaning, and allows the possibility that Josh meant "the hang to hang" to be play on words between having "the hang of something" and getting "to hang" with friends (231). In this way, Krall-Lanoue explores the translingual potential in reading such moments in student writing as opportunities to reconsider multiple meanings while also continuing to affirm the agency of the basic writer.

A key missing piece of Sohan's and Krall-Lanoue's nevertheless important contributions is an illustration of how negotiation transpired with students. Sohan mentions briefly that Kathy's writing was workshopped by the class, but only says that she aims to create a classroom space "where misunderstandings, unfamiliarity, and unpredictability are the norm" (204). Krall-Lanoue defers linguistic negotiation to oneon-one conferences with her basic writers, and since the texts being discussed were journals, it remains uncertain whether students revisited or revised these texts after their conference. To Krall-Lanoue, it is the discussion itself that "offers the possibility of becoming a shared resource for thinking and writing" (230), but readers are left wondering how to engage monolingual writers in translingual negotiation outside of the 
time-consuming conference. I hope to help fill this gap by including samples of my own monolingual students' writing, as well as my response to this writing.

Translingualism changes the way teachers read student writing and react to that writing, thereby changing how students engage in substantive revision. Below I provide examples from my own students, in an effort to frame student writing as material for critical inquiry in the classroom, as opposed to material by which teachers can assess adherence to a linguistic standard. What I mean by this is that when approaching a student draft, if a teacher considers the draft itself not as evidence for or against a certain grade, but rather a demonstration of the way the student is using language and imagining their relationship to the language they're using, then a pedagogical response will follow in which teachers do not reshape student language but rather highlight how language is working (or not working) from a readerly perspective. Initially awarding intention to all writing choices, whether or not it seems obvious that a given orthographic mark is a mistake, helps students consider the difference between intended language difference and accidental language difference, both of which have potential. In turn, the teacher must be cognizant of how their own orthographic marks are taken up by students. Even if a mark is meant to signal curiosity or interrogation, if it is taken up in a different way, then the mark should not be used.

Students in a translingual basic writing class may well be faced with confusinglooking feedback, much less directive than the x's and strikethroughs and circled words they have come to expect. ${ }^{66}$ Overly directive feedback signals to students that they are wrong and the teacher is right; they must follow the teacher's commands no matter how

\footnotetext{
${ }^{66}$ Although students may have come to expect strikethroughs and circled words, this does not necessarily mean they know what to do with such markings.
} 
faulty the teacher's interpretation of their intended meaning. If the teacher's revision warps the meaning they had intended, students are likely to assume that the teacher's thoughts and interpretations are more valid than their own, and this is verging into dangerous territory. As Mariolina Salvatori writes in "Pedagogy: From the Periphery to the Center," a classroom in which the reader of any text is positioned as the producer of subjective meaning, not the revealer of truth, permits radical change in students' relationships to texts (including their own) "as long as this calling into question, this interrogation, is not just a game through which a teacher ultimately appropriates, assumes, the authority and authorship" (27). ${ }^{67}$ In order to avoid this game of bait and switch, teachers must, as Krall-Lanoue writes, "focus on the text, not what a student "meant to do"' (237). It is with this intention and mindset in place that I present excerpts from two of my own students.

Ryan (whose work you have already encountered) and Leah ${ }^{68}$ were both selfidentified monolingual freshmen in the University of Louisville's notoriously rigorous Speed School pre-engineering program. Through various channels, both Ryan and Leah told me of their struggles with English and their dislike of my course. ${ }^{69}$ Although they did not disclose their racial identities or ages to me, both students were ostensibly Caucasian and traditional aged freshmen. Ryan was a first-generation student, and Leah had engineers in her family, and felt pressured to continue that legacy. Both were talkative in class, and ruminated openly about the very real possibility of failing out of this, their

\footnotetext{
${ }^{67}$ Positioning the teacher as the producer of subjective meaning from a student's text, and not the revealer of the truth the student meant to write, is an equally radical change.

${ }^{68}$ Student names used are pseudonyms; I have the written consent to use featured students' writing in my research.

${ }^{69}$ When asked to write about the most enjoyable part of our class, Leah wrote "none of it. nothing against you. I just hate english classes in general." When asked next to write about the least enjoyable part, she wrote "all of it. for the same reason."
} 
second semester of college. Leah had been in my class the previous fall (the institution has a two-semester FYC sequence), but it was Ryan's first time encountering me as a teacher. As previously mentioned, my course asked them to investigate over the course of the semester the reading, writing, and communication practices of their future anticipated disciplines or careers. My efforts to enact a translingual approach to written feedback manifested in two ways: attention to students' self-editing and revision practices as an inroad to negotiation, and noticing and admiring phrasings that, while differing from standard language conventions, were indicative to me of their attempts to experiment with language.

Paying attention to students' writing processes helps to respond to them effectively, and maximizes negotiative potential. My students write "daily papers": short, reflective, handwritten pieces that help me learn about them and track their thinking. ${ }^{70}$ In an early daily paper of Leah's that clocks in at 67 words written in pen, Leah has four sections that feature a single line strikethrough. ${ }^{71}$ Two of her strikethroughs appear to be her beginning a word, anticipating a misspelling, and crossing out the first attempt before writing the correct spelling. Another misspelling she catches post-facto, changing "grammer" to "grammar." The last instance is a change of heart concerning diction: "I like the way he writes his sentences" becomes "I like the way he structures his sentences." At the time, part of me wondered if Leah wanted me to see these strikethroughs; they were always a single line across the word and not a scratch out, as is

\footnotetext{
${ }^{70}$ Many students use the daily paper as a space to stress about college in general, run ideas for assignments by me, or ask questions, since I would read, briefly respond to, and return daily papers the following class period. They can also be used as attendance tickets. I use them as a way to take the class pulse.

${ }^{71}$ Leah's entire daily paper reads as follows: "My only eө concern with my case study is that I sound stu stupid. Mine is just generic while everyone else's is more specific and sounds good. I would like my peers to give me feedback on my grammer grammar and if it flows right. I look at [peer]'s paper as a model paper because I like the way he writes and structures his sentences. It is very smooth and flows well."
} 
more common. By changing "grammer" to "grammar" and refining "writing" to "structuring," I felt Leah was showing me that she is attentive and committed to the task, despite knowing she would not be penalized for misspelling (language in "daily papers" is not marked).

Later in the semester, I was humorously validated in my suspicion that Leah's strikethroughs were purposeful when she seemingly thought better of adopting an über casual tone. In another daily paper, when asked what I should consider changing about the course next time I taught it, Leah wrote: "nothing :) continue doing what your doing and don't take shit nothing from anyone." By paying attention to her low-stakes writing early in the semester, I knew that when looking at Leah's formal essays, I could probably assume misspelled words were mistakes and not errors; that is, that Leah could likely catch them with a second read and wouldn't need my correction. I also knew I could help her refine her phrasings by offering at times possible vocabulary words tailored to her ideas without risking insulting her. Perhaps most importantly, I learned that Leah felt stupid compared to her peers and hated English classes, and reading her drafts with this knowledge in mind certainly framed the way I responded to her.

Translingual scholarship often cites students' unique phrasings, such as Min-Zhan Lu's "can able to" student and the Arabic script and elongated words of Canagarajah's Buthainah, but, as Sohan and Krall-Lanoue have begun to show, such phrasings also exist in the writing of monolingual students. ${ }^{72}$ I have three such examples in Ryan and Leah's work, two of which I commented on positively, and one which I left alone. The first, Ryan's, reads: “Using correct body language and maintaining proper eye contact are all

\footnotetext{
${ }^{72}$ Horner's 2011 "Relocating Basic Writing" also provides two unique phrasings by basic writers not labeled in terms like "monolingual" or "multilingual": "she spills out her heritage and upbringing" (16) and "use language as a stepping stool" (16).
} 
important on how to communicate effectively in general, but then the author dives in deeper to explain that listening skills are just as important as being able to give presentation or filling out repots." There are several moments in this sentence where the reader might notice that Ryan's writing deviates from the conventional ("important on how to communicate," "able to give presentation," "filling out repots") but in the act of giving him feedback I chose to ignore all these, instead highlighting his beautiful phrase: "the author dives in deeper to explain." I wrote in the margin: "What a lovely way to express a section of the article that got more detailed." While "dives in deeper" is not an invented phrase, it is lyrical and at odds with the rest of Ryan's rather pedestrian prose. I wanted to show Ryan that I valued this uncharacteristic moment of imagery in his text. To me, it is worthwhile to ignore some seeming errors, especially on essays that are confusing or frustrating to read, in order to focus on the positive.

Leah often phrased things in ways that, while initially confusing, became poignant with deeper scrutiny. The opening line from one of her essays reads: "In mechanical engineering, we construct knowledge from having previous knowledge of how the item works and runs so that we have the ability to fix back to the way it is supposed to be." My readerly eye caught on "fix back to the way it is supposed to be," but here I paused. Admittedly I knew (and still know) next to nothing about mechanical engineering; in this case, Leah was the expert teaching me. Did mechanical engineers reverse engineer products? Did they deconstruct items in the reverse order from which they were built, in order to understand a defect? These are questions I didn't have the answer to, but, it being the first line of her essay, I wanted to signal to Leah that I enjoyed her phrasing and was ready to learn more. I wrote: "Interesting - I can see the gears 
turning in your mind here as you figure out how to phrase complex engineering ideas." Had I written something less celebratory, such as: "What do you mean by 'fix back'?", Leah, particularly self-conscious of her languaging, would likely have read my commentary as a signal that her phrasing was, as she feared, "stupid," and that she should delete it, even though that would have been in opposition to my intended message.

Later in the same essay Leah also wrote: "One way we learn is by communicating with ... a mechanic with a lot of experience over the topic you are learning about." Instinctively the writing teacher might like to suggest "experience with" or "experience about" instead of "experience over," but, with a moment's pause to consider, I found the preposition "over," with its conveyance of a bird's eye view, to be more indicative of the broad scope of engineering experience Leah was getting at. Unfortunately, while I remember her writing this phrase, I did not address it in my feedback. Sometimes my decision whether to comment depends less on the particular phrase in question and more on context; looking at Leah's draft as a whole I can see that I had already commented several times in this paragraph and perhaps was trying not to overwhelm Leah or make her believe this paragraph was especially weak. Still, I consider Leah's "experience over" a missed opportunity for me to notice for Leah a novel phrasing that made me think differently about how experience functions.

At the conclusion of this chapter, I will return to Ryan's writing as I discuss how to call attention to unclear moments in student writing in a way that engages students in re-thinking about their meaning rather than us re-shaping it for them. For now though, I will conclude this section on translingual FYC scholarship by saying that while some inroads are being made in including monolingual students in translingual teaching, the 
how of this inclusion is still under construction. The existing attempts, my own included, rely heavily on teachers pointing out phrasings that differ from their idiosyncratic expectations. Yet translingual theory rightly asserts that even writing that reproduces the standard can be translingual. Lu and Horner, drawing on Bourdieu, Butler, Giddens, and Pennycook in their "Translingual Literacy, Language Difference, and Matters of Agency," remind us that any utterance in a new temporal and spatial context is different from any utterance that has ever come before or will ever come again $(587) \cdot{ }^{73}$ Novel and quirky phrasings, while inventive and interesting, are not the foundation of translingual writing, and more work remains to be done articulating activities and feedback practices that can emphasize the translinguality of the seemingly conventional. One in-road is featuring the writing of so-called monolingual students, but this is not enough. The question uppermost in students' minds as they write should not be how to make their language look different on the page, but rather, as Lu and Horner write, "what kinds of difference to make through their writing, how, and why" ("Translingual Literacy" 585).

\section{Basic Writing Scholarship Before "Translingualism” was Coined}

It may seem counterintuitive to include basic writing scholarship before the coinage of the term "translingualism" when considering a translingual basic writing pedagogy,${ }^{74}$ but, as I stated at the chapter's opening, basic writing's tendency to

\footnotetext{
${ }^{73}$ This idea is reiterated by Horner in his Crossing Divides chapter "Teaching Translingual Agency in Iteration."

${ }^{74}$ I mark the coinage of the term for the field of writing studies as 2011, with the publication of Horner et al.'s "Language Difference in Writing: Toward a Translingual Approach." However, one can see the early stirring of the term "translingualism" in Lu's 2006 "Living English Work," when she writes of her burgeoning interest in "scholarship that approaches the transrelations of nations, cultures, peoples, and language(s) in terms of transactions that transform, transfuse, translate, transport, traverse, transubstantiate, transvalue, transpose, and transplant established ways of doing things and in terms of multidirectional transactions - not merely top-down but also bottom-up and sideways" (611).
} 
wholeheartedly embrace each "turn" as they come sometimes results in what Horner calls an "erasure of the sort of critical insights that first propelled practices and projects in basic writing" ("Discoursing Basic Writing" 200). By looking closely at these early propulsions in basic writing, many of which were penned by the same scholars now writing about translingualism, we can see nascent translingual principles emerging. Why is this important? Again, my answer echoes my opening: translingualism is not new, and to consider it new would be foolhardy. Seeing translingualism only for its lustre would be its downfall. If we can keep open the gate between the lessons of the past and the pedagogies of the future, then teacher-scholars of basic writing can travel easily to and fro and, like their basic writing students, can acknowledge that they come to the study of language with a bountiful fund of knowledge that has informed what translingualism is and which translingualism can speak back to. I examine "pre-translingual" basic writing scholarship using the same framework of principles provided at the beginning of this chapter. ${ }^{75}$ This examination reveals translingualism, as it is known in rhetoric and composition, to be an outgrowth of a progression of thought by a handful of scholars working with language ideologies, most of whom, interestingly enough, wrote at the cutting edge of basic writing scholarship.

In the same vein, I should note that I am not the first to discern prefigurations of translingualism in early basic writing scholarship. In his 2016 "Translingualism and Close Reading," John Trimbur traces what he calls a "genealogy of close reading” (223) from the 1970s through the 1990s in scholarship by Shaughnessy, Bartholomae, Horner, and $\mathrm{Lu}$. Trimbur presents each scholar as increasingly destabilizing traditional ideas of error in a trajectory toward the adoption of a translingual approach to language

\footnotetext{
${ }^{75}$ If the reader needs a refresher, that framework appears on page 126-7.
} 
difference. As Trimbur sees it, Shaughnessy utilized her training in New Criticism to "apprehend the ordered patterns in basic writers' individual styles of making mistakes" (221). In response, Trimbur writes, Bartholomae concentrated on the writer's intention rather than their mistakes, seeing error as "an interlanguage, in its wrongness a valuable but ephemeral step on the way from L1 to L2" (224). Trimbur moves the reader instead towards a politics of style in the manner described by $\mathrm{Lu}$, one in which, in Trimbur's words, language differences are "permanent features of the linguistic landscape" ("Translingualism" 224). Trimbur himself likewise destabilizes the assumed fixedness of writing conventions, asking writing instructors to "read student writing closely not just for its errors but for the possible rhetorical effects of its language differences" (“Translingualism" 224). While I agree with Trimbur's argument, my analysis of "pretranslingual" basic writing scholarship extends beyond his recognition of the porousness of academic conventions to include this era's acknowledgement of student agency and embrace of generous, negotiative reading practices.

Much of basic writing scholarship of the 1980s and 1990s aims to counter the portrayal of basic writers as deficient. Those scholars who advocate for the greatest amount of agency for basic writers go so far as to argue, quite revolutionarily, that basic writers can change and shape language in the same way that published, "expert" writers can. Lu writes early and often of this power of basic writers: in her 1987 "From Silence to Words" she argues that teaching students about the complexity of all language, both inside and outside the classroom, shows them that they are actors in a dynamic linguistic world, which in turn encourages them "to see themselves as responsible for forming or transforming as well as preserving the discourse they are learning" (447). Four years later 
she goes a step further, highlighting for teachers the benefit they too incur when students' agency is affirmed, writing: "[i]f the teacher acknowledges that all practitioners of academic discourse, including those who are learning to master it as well as those who have already mastered it, can participate in this process of reshaping, then students might be less passive in coping with the constraints that academic discourse puts on their alignments with their home discourses" ("Redefining the Legacy" 35). And in her oftcited "Professing Multiculturalism" (1994), Lu blurs the distinction between "basic" writers and "real" writers, arguing that all writers have the right to innovative style, no matter how close they can come to "error-free" prose (446). Proving she practices what she preaches, Lu writes of assigning readings by "real" writers who refused to reproduce writing conventions they saw as hegemonic, such as Haunani-Kay Trask's 'From a Native Daughter," and emphasizes her commitment to treating the languaging of her basic writers with the same respect and curiosity she affords to Trask.

Basic writing scholars of this time also explores two ideas that would become central questions of translingualism: firstly, that conventions of writing are arbitrary constructs, invested with power but not powerful in and of themselves (that is, apart from human investment), and secondly, that the borders between languages are not static or solid but rather porous and always in flux. In responding to Mina Shaughnessy's Errors and Expectations (while also crediting Shaughnessy for her landmark role in furthering basic writing as a study and in championing the intelligence of basic writers), Lu points out that in tailoring pedagogy to students' idiosyncratic error patterns, Shaughnessy sidestepped the opportunity to question the legitimacy of the standard by which such errors were recognized, equally sidestepping the opportunity to allow for the legitimacy 
of these same "errors" as potential linguistic innovations ("Redefining the Legacy"). Three years later, Lu argues in "Professing Multiculturalism" that even the work of replicating academic discourse necessarily involves "the re-production - approximating, negotiating, and revising - of these norms" (447). Similarly, Bruce Horner and John Trimbur in their 2002 "English Only and U.S. College Composition" call writing standards "contingent, local, and negotiable" (620). The idea that standards are a predetermined given, handed down to writing teachers who then feel compelled to teach them as if they are set in stone, is part of a larger problem identified by David Bartholomae in his 1987 "Writing on the Margins," when he defines (with heavy irony) basic writers as those students whose names appear on basic writing rosters, as if rosters, conjured out of thin air, could be trusted implicitly. "We begin," Bartholomae writes, "with what we have been given, and our definition is predetermined by a prior distinction" ("Writing on the Margins" 67).

When scholars began to question what they had been given, one result was an examination of what exactly English was, often drawing on a growing body of work in linguistics that did the same. Pushing back against what she called "an essentialist view of language" ("Redefining the Legacy" 26) in which "the essence of meaning precedes and is independent of language, which serves merely as a vehicle to communicate that essence" (26), Lu defines English instead as "living," "kept alive by many and by many different ways of using it, each of which is itself a living process in-the-forming: informing and informed by the specific, different and dynamic, historical and social contexts of individual acts" ("Living English Work" 608). Later drawing on the work of James Baldwin, who distinguishes between imitating language and using it, Lu concludes 
that using language, "making it do things it has not been historically geared to do, puts the formation of English in the hands of all its users" (610), including, importantly, the basic writer.

It is Horner and Trimbur's 2002 "English Only and U.S. College Composition" that most thoroughly dismantles what they term a "chain of reifications" (596) that has sedimented the unidirectional English monolingualism impacting the beliefs and practices of writing teachers. Links in this chain include conflating identity with language, reifying language as unchanging, and investing in a sequential trajectory that moves the basic writer toward literacy (596). Prefiguring later critiques of so-called "translingual" assignments that nevertheless advance the ideology of monolingualism in their aims, Horner and Trimbur demonstrate how reifications unsurprisingly used in arguments in favor of English Only are also operating in arguments in opposition to English Only (614). For example, the hypostatization of English is woven within claims that immigrants to the U.S. are eager to learn English, know its value, and are learning it at faster rates than ever before (614). Notably, in order to make their claims about the arbitrary, shifting nature of language, Horner and Trimbur must rely on the works of sociolinguistics and L2 scholars such as Constant Leung, Roxy Harris, Ben Rampton, Suresh Canagarajah, Judith Rodby, and Ruth Spack, drawing from fields in which such assertions had already gained traction. The abundance of phrases in their article such as "the linguistic territory known as English," (616) "what people think of as English" (616), and "what is called English" (616) are evidence of their efforts to situate their questioning of the borders of English within the field of rhetoric and composition. 
Yet the greatest strength of "pre-translingual" basic writing scholarship is its thorough engagement with the emergent, recursive, and negotiative processes of writing and reading, processes that both basic writing teachers and students participate in with each act of writing and reading. Examples of classroom activities published then, if republished now, could be easily classified as translingual. ${ }^{76}$ In his 1992 "Rethinking the ‘Sociality’ of Error: Teaching Editing as Negotiation,” Horner breaks down error as a matter of relationships. Horner claims that readers approach the negotiation of "real" writing willing to surrender more ground. Thus, when readers encounter stylistic deviations in, say, scholarly or literary writing, they do not mark such deviations as errors. In other words, readers are more apt to negotiate with the texts of vested writers. By contrast, Horner writes, too often the basic writing teacher approaches the basic writer's text already foreclosing negotiation; yet, this relationship "is a matter renegotiated at each writing and at each reading" ("Rethinking the 'Sociality' of Error" 174). A teacher who allows him/herself to be inevitably changed by the act of reading will give feedback that encourages the basic writer to take authority and responsibility over their writing, thereby making revision a matter of negotiation, not submission ("Rethinking the 'Sociality' of Error" 175). As a negotiator, writes Horner, his role is to "raise questions that occur to [him] ... but without authority to alter the writing" ("Rethinking the 'Sociality' of Error"192), or in other words, notice, and wait.

The translingual teacher's goal is to invite the student into a negotiation of meaning, but in a way that encourages the student to linger again on their sentence, re-

\footnotetext{
${ }^{76}$ Such pedagogical activities include comparing different editions or translations of the same text (Lu "Living English" 613; Horner "Rethinking the 'Sociality' of Error" 190), asking students to respond to the queries of real-life translators on international online forums (Lu, "Living English" 615), examining conflicting grammar rules as laid out in style handbooks (Horner "Rethinking the "Sociality' of Error" 190 ), and peer editing groups (Horner "Rethinking the 'Sociality' of Error" 193).
} 
reading it and re-considering both their original intention and their current intention (since beliefs change as drafts evolve). This evokes a relationship between the teacher and student in which power is divided (if still unequally) between the teacher/reader and the student/writer. By taking up their agency, the student surrenders a measure of their identity as an "outsider" who revises merely in accordance with their teacher's will. Thus the written marginalia feedback given to writers in a translingual model usually consists of purposefully nebulous, nondirective, and mitigated questions and comments, in an effort to force the student's noticing and substantive engagement.

This kind of feedback is best applied when a writer's phrasings are ambiguous to the point that the teacher should ethically step back and not assume a writer's meaning or intention. I noticed many of these kinds of phrasings in the writing of my student Ryan, including:

"When a problem arises, an engineer is responsible to be able to fix the problem and be able to communicate it to the client, the laborers, and the boss."

"The lab report genre often interacts with many other genres one of the main genres being progress reports."

"Prior to this assignment I never really thought of each discipline having its own form of literacy that which you communicate through."

In cases such as these, I would ask for clarification or expansion, sometimes beginning with an encouraging word or phrase to signal my positive (not punitive) interest. To Ryan's “is responsible to be able to fix the problem," I wrote: "Could you say more about this, the idea of engineers being both responsible and capable?" In his final draft, his wording became: "is responsible for fixing." To the interaction of lab reports and progress reports, I commented: "Interesting - what does it mean for two genres to 'interact' with each other?' In the next draft Ryan elaborated, adding a sentence afterwards: "By genres interacting I mean that an engineer will write a lab report then 
refer it in his progress report." To his "literacy that which you communicate through," I asked: "Are you providing a definition here of literacy or is this second part of the sentence connected to the first?" This phrasing remained the same in Ryan's revision. What I want to point out is that none of my questions could be answered by a "yes" or "no" answer, and neither do they nudge Ryan toward a revision of my own. The questions ask him to think, and the result of his thinking sometimes manifested in a revision or addition, and sometimes did not. ${ }^{77}$ Without having interviewed him, it is unknowable whether the persistence of a phrase in subsequent revisions is a result of internal negotiation or a decision not to engage. But a decision not to revise, or even a decision not to fully consider whether or not to revise, is a writer's choice. Keep in mind that simply reading teacher feedback is an act of engagement, and a sign that students are willing to come to the negotiation table. Sometimes proof of engagement comes in roundabout ways, like when students contemplate their revisions in their daily papers, or talk about it in workshops. ${ }^{78}$

Substantive examples of what negotiative reading practices look like in practice can be found in David Bartholomae and Anthony Petrosky’s 1986 Facts, Artifacts, and Counterfacts: Theory and Method for a Reading and Writing Course. The first half of the text is an in-depth look at the logistics and assignments of a basic writing course that carried six credits and met for six hours a week (29). ${ }^{79}$ The latter half is a compilation of

\footnotetext{
${ }^{77}$ I can imagine a reader anticipating the labor involved in feedback practices of this kind, and that is labor I must acknowledge as real. Mindful and careful noticing of student language takes an attentive reading eye. However, I would ask this reader to consider how much time they expend, cumulatively, in the studious identification and correction of error. The feedback strategy I advocate here asks that the majority (if not all) of this time be redirected to inquiry.

${ }^{78}$ In a daily paper, Leah once wrote: “I love your feedback. Isn't all just corrections on grammar or things like that. Sometimes you would respond to it or tell us parts that you liked."

${ }^{79}$ Other aspects of the Bartholomae and Petrosky course are equally fantastic, including its course cap of 15 students and its being co-taught by two tenure-track faculty.
} 
articles by teachers of the course. Nicholas Coles's chapter "Empowering Revision" includes an image of a typed student page with Coles's handwritten marginalia, each comment numbered and discussed. Of the six comments readers see, four are entirely made up of questions, such as "Can you say more?" "Why not?" How?" and "Can you explain?" Such feedback, writes Coles, "can invite the writer to question and explore the language of his paper in such a way that rewriting becomes a deliberate method of rethinking his subject" (190). Coles sees his own role as "suggesting the implications of particular choices and opening up important questions and possibilities which are implicit in [the student's] writing ... enacting in our comments how we take what they do there seriously" (196). In her chapter "Writing, Reading, and Authority: A Case Study," Susan Wall interviews basic writer John, who reflects on his teacher (who is not Wall)'s ambiguous but engaged response to his use in an essay of two terms: "internal" and "external." John reported that his teacher did not tell him what these terms meant, but that he himself "had to explain" (117). In this way, Wall writes, the teacher's response "focused on the language John had already created in order to suggest what else it might become" (118). This kind of approach to student texts, writes Mariolina Salvatori in her chapter "The Dialogical Nature of Basic Reading and Writing," models for students how to converse about their knowledge "in ways that open up rather than close off understanding" (138), thereby making it possible for students to learn to dialogue with their own writing.

One of the most fascinating aspects of Facts, Artifacts, and Counterfacts is its repeated portrayals of the basic writing classrooms of the University of Pittsburgh in the 1980s, providing prompts, images of student writing, as well as transcripts of class 
discussions, workshops, and one-on-one conferences. ${ }^{80}$ Workshops emerge in the book as essential for encapsulating the recursive and emergent nature of writing-as-labor; ${ }^{81}$ to Bartholomae and Petrosky, "all the students become vital participants, as both readers and writers, in a discussion which has as its focus reading-and-writing-in-progress. By continuously noting how meaning and intention change as reading and writing change, students are able to address the question of what reading and writing are good for" (93). Moreover, writes Mariolina Salvatori, workshops are "practice by which we implicitly and explicitly argue that [student] writing is worth reading and their reading is worth response" (144). In my own classes, I aim for at least two class periods devoted to class examination of anonymous student writing for every major assignment, usually timing a workshop before I review a new set of student drafts, so that I can leave these excerpts alone when providing feedback. To open a workshop, I ask a volunteer to read the excerpt aloud to the class, and open the floor for discussion, asking questions such as, "What did you notice here?" "What interested you?" "What confused you?" "Why do you think the writer made this choice?" and "What other choices might the writer have made?" Students come to expect no fixed resolution at the end of a workshop discussion. When Ryan's writing was workshopped, the class was working on draft research questions for a project composed of 16 sequenced assignments. When selecting excerpts, I noticed that in each of his three draft research questions, Ryan began with mediated

\footnotetext{
${ }^{80} \mathrm{~A}$ preference for negotiating via the teacher/student conference is common in scholarship forwarding translingual principles (Corcoran; Krall-Lanoue; Horner, "Rethinking the "Sociality"; Bartholomae and Petrosky). But I refrain in these pages from talking at length about the benefits of conferencing. When I conferenced as a basic writing teacher, even if I canceled a week of class (often without approval from my administrators), conferencing would easily require triple the time commitment of teaching. Once experienced, the physical and emotional toll on basic writing teachers, often graduate students or adjuncts, of multiple rounds of individual conferences is undeniable. Therefore I limit my discussion to activities that would not require additional labor from faculty who already often face exploitation.

${ }^{81}$ For more examples of translingual writing workshops, see Lu's "Professing Multiculturalism," Bruce Horner's "Relocating Basic Writing," and Sarah Stanley's "Noticing the Way."
} 
context before providing the central question. His mediation usually came in the form of the phrase: "a lot of the times." For example, his first question reads: "As a civil engineer, a lot of the times you will have people who work under you and a lot of the times you are much younger than the work crew. What forms of writing or verbal communication do you use to communicate with them to be the most effective?" Ryan also used either "a lot of the times" or "most of the time" in each of his two other questions. During the workshop, I asked the class what work they thought the writer was doing with this phrasing. The discussion began with a debate over whether the correct saying was "a lot of the time" or "a lot of the times." While the majority of class argued that the former was correct, someone pointed out that the latter made more sense, saying, "You would never say 'a lot of the life,' you would say 'a lot of the lives." Discussion devolved into a philosophical debate about what "time" actually meant in this colloquialism, ${ }^{82}$ but after a while I looped students back in, by again asking about the work the phrase was doing. One student remarked that "A lot of the times" was another way of saying "not all the time," and so the phrase was a way of avoiding blanket statements, characteristic, they thought, of academic writing. I validated this idea, that "mediation" could be a feature of academic writing, and someone else offered that it "sounded too much like the writer is just talking." With some prompting, this student explained they thought it sounded too informal.

Briefly, the class was at a crossroads: did the anonymous writer (Ryan) come across as nuanced, or colloquial? As you might predict, I myself veered toward the latter, but I stayed quiet. One student noted that the writer was researching how to be more

\footnotetext{
${ }^{82}$ This debate was confusing on all accounts; we were all whispering the sayings under our breath to hear how they sounded. I was confused myself, which is why I pivoted. Doing some research post-workshop, both "A lot of the time" and "lots of times" are "correct" sayings, but Ryan's is a combination of the two.
} 
confident in the workplace as a young engineer, and so the informality of the phrase made them sound young and inexperienced, so in this instance, they would suggest eliminating it, and the class seemed to like this idea. If Ryan had been an experienced engineer already, it seems, the phrase could have been read in a different way, but in our workshop, knowing as we did that the writer was a novice, the need for assertion trumped nuance. While the class was not able to agree on whether "a lot of the times" was even the "correct" saying, they were able to read contextual exigencies, leading us to talk about how the phrase changed in its appropriateness when we considered outside factors.

The workshop's response to Ryan's “a lot of the times” was more translingual than my own reading, which I will be the first to admit is a good example of poor negotiation. Before, I had sometimes returned drafts to students with feedback before the workshop, but this experience taught me to withdraw my own voice on student writing that had been workshopped by the class. On his question about age dynamics, I wrote to Ryan that it was "interesting" but that "I think you need to rephrase this question to sound more formal and academic though. Phrases like 'a lot of the times' should be eliminated . ..”Because I suggest eliminating the phrase, I myself don't even play with his combination of "a lot of the time" and "lots of times," a missed opportunity. I then go on in my feedback to take control of Ryan's question, rephrase it, and enclose my suggested version in quotation marks to offset it. Looking back, this was a power move that signaled to Ryan, both unintentionally and falsely, that his attempt to articulate $m y$ meaning had been unsuccessful.

Knowing now that Ryan came to the class workshop with a decision likely already formed as to revision (a decision to submit), I wonder if he was able to hear the 
interest with which his peers engaged in his writing, or did he hear only my own appropriation? Did my hijacking of his meaning divest him of his control, or did he consider the workshop feedback as balancing the scale against my own? Without having interviewed him, I have no sure way of knowing. But even without an interview, had I allowed Ryan to engage more deeply in negotiating his own meaning, I would have known that even his ultimate decision to omit "a lot of the times" (which is what he chose to do) would have stemmed from a translingual perspective, even if it looked like an acquiescence to convention. Lu's "can able to" student ultimately revised her phrase to "may be able to," a decision that both Lu and Horner point out as still agentive, because it was a choice made after consideration. Horner writes that it was the decision to revise that "relocates that practice, and in so doing, produces a difference in meaning by virtue of who is engaging that practice, when, where, and why" ("Relocating Basic Writing" 1718). But a student who yields to the implied demands of the teacher is being denied the opportunity to revise as a result of choice. Reflecting on why and how I took over, unlike other instances in which I did negotiate with Ryan ${ }^{83}$ while a somewhat painful experience, is nevertheless useful for noticing moments in my own teaching where I would have liked to have responded differently.

Ultimately, early basic writing scholarship granted to writers the logic of their words. Unlike Shaughnessy, who aimed to decode students' unconventional logic so as to more effectively realign them to the standard (Errors and Expectations, after all, was

\footnotetext{
${ }^{83}$ For instance, Ryan also had a habit of dividing words usually connected into two: in words like "blue print," "straight forward," "work place," "with out," "with in," "down fall," and "un able." I remember being surprised at these frequent splits, since a word processor would likely have called them to his attention. Sometimes I would simply ask, "Did you mean 'unable'?" But sometimes I would write longer comments on splits like "blue print" and "work place" since these would be important for Ryan to consider in his future engineering work. Most of these splits remained in Ryan's final drafts.
} 
originally titled "The Logic of Error"), scholars who came after her considered the possibility that students' logic can be the kind of ongoing work that changes language. Teaching, as Lu writes, "which neither overlooks the students' potential lack of knowledge and experience in reproducing the dominant codes of academic discourse nor dismisses the writer's potential social, political and linguistic interest in modifying these codes" ("Professing Multiculturalism" 449), strips the teacher of the burden of determining which potential is at work; that is, teachers can see both an opportunity to align and an opportunity to be changed. For instance, in their 1989 piece in Written Communication entitled "Rethinking Remediation: Toward a Social-Cognitive Understanding of Problematic Reading and Writing," Glynda Hull and Mike Rose feature a case study of basic writer and nurse-hopeful Tanya, whom they asked to summarize an article by a nurse about a particularly tough day at work. Hull and Rose provide Tanya's summary, which on the surface "suggest[s] to some people that this writer is somehow cognitively and linguistically deficient, that she is incoherent, or cannot think straight," but they ask readers to suspend their immediate reaction and "assume a coherence... assume that a learner's performance at any time has a history and ... a logic - then we will think about this text and the student who wrote it quite differently" (147). What initially looked like "bizarre word salad" (151) made a new kind of sense after Hull and Rose's talk with Tanya, in which they learned that she had purposefully lifted words and phrases from the original article in order to try on the nurse's identity (151). This knowledge informed their approach to help Tanya move forward, and forced Hull and Rose to "scrutinize [their] own reactions, to question [their] received assumptions about literacy and pedagogy ...” (151). 
Scholarship from before the coinage of "translingualism" is full of such moments when teachers begin negotiation with students from a place of initial acceptance of what they see on the page. Approaching negotiation with good faith is not the same as saying basic writers shouldn't revise or have nothing to learn, but means the teacher should read the text and not attempt to read the student. Interestingly, several scholars, including MinZhan Lu and John Rouse, revisit from this perspective the phrasings of the basic writers quoted in Mina Shaughnessy's Errors and Expectations. Lu cites one of Shaughnessy's students who wrote: "In my opinion I believe that you there is no field that cannot be effected some sort of advancement that one maybe need a college degree to make it" (Shaughnessy 62). Whereas Shaughnessy advocates for the deletion of what she calls the "fillers," in promotion of a more confident sentence, Lu asks readers to consider if the student's hedging may be indicative of their uncertainty as to whether education really does result in advancement ("Redefining the Legacy" 30). ${ }^{84}$ Noticing this hedging with the student, and acknowledging that revising might reflect a change in thinking and not just language, would make space for the student's next negotiative move.

In the same vein, John Rouse, in his 1979 "The Politics of Composition," cites student passages where Shaughnessy meant to highlight the basic writer's tendency to substitute phonetically similar words when in search of a word they are less familiar with:

"Coming to writing class stifle not only our will to write but your drive to think." "Students must also make an effort to make the necessary transgressions to fulfill their needs."

"School increases the childrens ability to withhold meaning." (Shaughnessy 191)

It wasn't Shaughnessy's intention to include these excerpts to allow for the possibility that her students were defying expectations and using unconventional words in order to

\footnotetext{
${ }^{84}$ One can say I advocated for the same deletion with Ryan's “a lot of the times.” Had I considered Ryan's hedging as signaling his uncertainty, I likely would have followed a different course.
} 
convey unconventional meaning, but Rouse argues in passing that "[p]erhaps what these students have written is the truth" (10). Some forty years later, translingualism erases the caveat, seeing a real possibility that Shaughnessy's students meant what they wrote. At least, it is not the teacher's role to decide. Students should be given the opportunity to explore the possibilities of meaning, an opportunity that only exists when a translingualminded teacher notices a difference and engages the student in negotiation. Such negotiation, when authentic, makes space for the so-called error of the basic writer to exert positive pressure on the teacher's conception of language itself. 


\section{CHAPTER FOUR:}

\section{TRANSLINGUAL BASIC WRITING PLACEMENT AND PROGRAMMING}

This chapter considers a translingual approach to the placement of incoming college students into composition courses, and also considers how a translingual-minded basic writing course might be structured within a given institution's curriculum. One must keep in mind that basic writing is nowhere less coherent as an academic project than when considering questions of placement and programming. How the label of "basic writer" comes to be applied to a student, and what is then deemed necessary to remediate them, are incredibly institution-specific. Basic writing also encompasses every kind of student, and is undergoing continual, emergent change. To put it succinctly, basic writing is an unstable construct. In fact, George Otte and Rebecca Williams Mlynarczyk open the final chapter of their 2010 book Basic Writing by acknowledging that the longer basic writing has existed, the less unity it seems to have. "What research has disclosed about basic writing - whether as a teaching project, a population of students taught, or a context for such teaching and learning — is that its incarnations differ from one site and time to the next" (162). With its reinventions, renamings, theoretical evolutions, and recent disappearances in the form of mainstreaming and outsourcing (more on these later), basic writing looks unique at every school where it persists. 
Basic writers can be online students or face to face. ${ }^{85}$ They can be freshmen or upper-classmen, incoming or transfer. Basic writers can be students of elite 4-year institutions as well as community colleges. And, as we have seen, they may be multilingual or monolingual, any race, and any age. Just as there is no quintessential "basic writer," neither is there a standard "basic writing" course setup that can serve as a template from which a translingual approach should diverge. Basic writing has often been a standalone course, but can be multiple courses; sometimes these courses are creditbearing, but often they are not. ${ }^{86}$ Students sometimes stay together as a cohort through multiple courses; sometimes they skip courses or test out. More recently, the term "basic writing" is being used to describe a host of writing options for students, options which bear little resemblance to these "traditional" semester-long courses where basic writers are sequestered from their mainstream FYC peers. These alternatives include accelerated courses, concurrent courses, or stretched courses, all of which will be reviewed here. But the point is that we must consider basic writing as a shifting construct, not a stable entity.

Acknowledging the dynamic nature of basic writing may seem to make the project of pinning down an ideal "translingual basic writing" course model a futile one. And that project, were it my aim, would likely be of little assistance. But if we come to see instability as a defining feature not only of basic writing, but of college writing as a whole (Sullivan and Tinberg), and language globally (Canagarajah, Translingual Practice), then the chimerical dream of a "perfect" translingual basic writing model

\footnotetext{
${ }^{85}$ For a review of the scant scholarship on online basic writing, see Linda Stine's "Teaching Basic Writing in a Web-Enhanced Environment." For hybrid basic writing, see Stine (2004) and Malcolm.

${ }^{86}$ In her chapter "Disrupting Monolingual Ideologies in a Community College: A Translingual Studio Approach," Katie Malcolm describes the former basic writing program at her institution, in which students testing into the lowest rung of basic writing were required to take five sequential courses before FYC.
} 
becomes an impossibility. After all, if basic writing as an idea is meant to fill the knowledge gaps required for "college writing," then a destabilization of the latter throws the former into question. As Kelly Ritter writes in Before Shaughnessy: Basic Writing at Yale and Harvard 1920-1960, the pressing question remains: "[i]f we cannot decide what 'college-level' work is, then is it not impossible to further demarcate what so-called precollege or basic work is?" (128). What defines basic work is different at each institution, with its unique demographic, financial, and political contexts. Yet, an inability to, as Ritter writes, "demarcate" basic writing, should not inhibit teacher-scholars and WPAs from theorizing how to place students into basic writing courses and craft said courses from a standpoint that recognizes the inability of demarcating college writing or even language itself. In any case, an institution may decide that there are admitted students who need instruction prior to or in tandem with FYC in order to succeed in FYC (and I write this "may" genuinely, for the discussion below of mainstreaming will question whether the designation of "basic writers" need exist at all). In such cases, designing basic writing placement and course formats from a translingual approach is one way of keeping at the fore the emerging, negotiable, shifting nature of language conventions, while at the same time acknowledging the role of all language users, including potential basic writers, in contributing to and changing language itself.

As I have argued before, a translingual approach to basic writing is more than pedagogy. It is an attitude towards language, error, standards, and the students who are labeled basic writers. In this sense, a translingual approach is an institutional mindset toward basic writers as they enter college and progress to their degree. In that the exigencies and effects of basic writing extend far beyond the isolated basic writing 
classroom, writing program administrators interested in the affordances of a translingual approach to basic writing should consider the multitude of factors that impact the basic writer's student experience. This chapter examines two central factors influencing how the basic writer understands their positioning and their agency (or lack thereof) within an institutional setting: the placement practices determining their freshman writing courses, and the setup and design of the courses labeled "basic."

Although this chapter focuses on decisions that prioritize the wellbeing and success of students, it should be noted that there are other factors in play besides student needs when it comes to admissions and placement decisions. To an institution, remediation as an ongoing initiative serves demands beyond those of the individual student, and even beyond those of the institution itself. Mary Soliday's 2002 The Politics of Remediation: Institutional and Student Needs in Higher Education explores the role of remediation in political, social, and ideological discourses, arguing that remediation as a construct exists and adapts to meet changing institutional and ideological needs. When national discourse on access results in wider admissions, remediation helps "solve crises in growth - in enrollment, curriculum, mission, and admissions standards" (2). By contrast, when national discourse foments a literacy crisis, a class consensus agrees to downsize public higher education, resulting in the constriction of remedial education in order to preserve "standards" (Soliday 15). In this way, remediation's chief function is in "managing the competing claims of access and excellence" (Soliday 105), and its shifting nature reflects the continual morphing of these competing claims. 


\section{The Mainstreaming Debate}

I have already written at length about the injustices of basic writing as a concept. In its less than ideal form, basic writing segregates a percentage of admitted students from the general population and prevents them from taking certain courses, charging them full tuition (and sometimes additional fees) while denying them graduation credit. Unsurprisingly, students of color and students from low socioeconomic backgrounds face this segregation at higher rates. When basic writing is a series of hoops a student must jump through, hoops too often having little to do with the ongoing practices and processes of writing itself, students may lose heart or fail to persist through sequences of sometimes several semesters of remedial coursework. For all these reasons, basic writing has a history of considering its own self-destruction. The largest wave of internal advocacy for the dissolution of basic writing came in the 1990s. During this time, the question was not how best to teach basic writing, but whether it should be taught at all. The most famous pieces of scholarship on this debate are David Bartholomae's "The Tidy House" and Ira Shor's "Our Apartheid."

Bartholomae's piece in the 1993 Journal of Basic Writing stemmed from his 1992 keynote address at the Conference of Basic Writing. Ironically, this was the last CBW, as after 1992 the conference downsized into annual all-day pre-CCCC workshops, which continue today (Uehling). Bartholomae, at first seemingly extolling his basic writing course at the University of Pittsburgh as described in Facts, Artifacts, and Counterfacts, instead steps back, questioning the narrative of both the course's success and of basic writing as an overarching humanitarian project. Basic writing, Bartholomae asserts, was guilty of "confirming existing patterns of power and authority, reproducing the 
hierarchies we had meant to question and overthrow" ("The Tidy House" 18). The field of basic writing studies, he argues, had lost sight of the name "basic writing" as just that, an arbitrary label that was once provisional and contested; the field now sees its work as "something naturally, inevitably, transparently there in the curriculum" ("The Tidy House" 8). A skewed self-perception inhibited scholars from seeing basic writing as anything other than stable and inevitable, reducing the work of basic writing teachers and administrators to "designing a curriculum to both insure [basic writers] and erase them in 14 weeks" ("The Tidy House" 12). Bartholomae challenged his listeners/readers to think beyond the current conceptualizations of basic writing placement and programming, proposing, in a prefiguration of directed self-placement, "an exam that looked for willingness to work, for a commitment to language and its uses" ("The Tidy House" 14) and an abandonment of tracking in favor of "offer[ing] classes with a variety of supports for those who need them" (14). ${ }^{87}$

The heated discussion after Bartholomae's keynote centered on whether basic writing should be entirely dissolved, an idea some listeners understood Bartholomae to be advocating. Karen Greenberg, whom Bartholomae recalls sparring with in the debate, published her response in the same issue of $J B W$ as "Tidy House," titled "The Politics of Basic Writing.” To Bartholomae's critique of placement tests and tracking, Greenberg asserts that without such assessment measures to demonstrate the efficacy of basic writing, "administrators, legislators, and accrediting agencies are ready and willing to step in and take over" ("The Politics" 65). Greenberg saw Bartholomae's speech as a

\footnotetext{
${ }^{87}$ Tracking refers to the practice of placing students into a certain "track" upon admittance, which students then must see to completion before progressing to "normal" coursework. The term is also used in the K-12 setting to describe a student's prescribed coursework as belonging to a "vocational/career" track versus a "college" track.
} 
wholesale attack on all basic writing programs, one that threatened the future of those doing good work. Bartholomae explicitly addresses Greenberg's charge in "The Tidy House." He agrees with her on the essential purpose basic writing serves when he writes: "I fear what would happen to the students who are protected, served in its name [if basic writing were to be dismantled]. I don't, in other words, trust the institution to take this as an intellectual exercise, a challenge to rethink old ways" (20). What Bartholomae insists was necessary was for institutions to question as suspect the status of basic writing as a programmatic endeavor, not slash programs indiscriminately.

Four years later, Ira Shor published a more vitriolic attack on basic writing in his “Our Apartheid: Writing Instruction and Inequality.” By calling basic writing composition's “apartheid," Shor highlights the structural inequalities that cemented the dismal educational futures of students from low socioeconomic and minority backgrounds, calling the basic writing models currently in place "undemocratic and immoral" (98). The often insurmountable obstacles basic writers face, Shor argues, were not accidental: by purposefully "cooling out" students (taking the term from sociologist Burton Clark), basic writing lowers the aspirations of a subset of college students while delaying their progress toward a degree (94). In other words, Shor believed basic writing convinces students that the problem lies within themselves, and charges them for the time it takes them to come to this realization, releasing them back into society sans degree and sans a significant amount of money while preserving the institution's facade of an openarmed welcome. By employing primarily adjuncts and graduate students to teach basic writing, Shor points out, the institution spends (and risks) little while gaining plenty ("Our Apartheid" 99). Like Bartholomae, Shor flagged testing as a primary problem, 
calling attention to the prevalence of short-answer, multiple-choice tests like SAT or ACT (which did not include essays at the time) as well as timed, impromptu essays as the artifacts being used to label a student "remedial" or "normal" (97). Shor accuses these assessment practices of being “invalid," (97) “bogus," (97) “cheap,” (98) “control[ling]," (98) and "punitive" (98), going so far as to call testing and tracking "the Twin Towers of Unequal City wherein BW resides" (97). Shor ultimately questions whether basic writing can exist without its flawed mechanisms. To him, a basic writing program wherein power resides in the classrooms, teachers, and students (rather than in administrators) may be impossible. Unlike Bartholomae's ultimate optimism, Shor ends his essay with the faintest hope for basic writing, forwarding only briefly a model emphasizing "critical literacy mobilized by the students' natural language competencies" (100), predicting, as did Bartholomae, the translingual approach examined here.

Advocates of basic writing were quick to critique Shor's position, and the Journal of Basic Writing published several responses, including two by Terence Collins and Karen Greenberg in the Fall 1997 volume. Collins and Greenberg went on the defensive and shared two key rejoinders, taking issue with both Shor's generalization and the similarity of his argument to that of politicians advocating the wholesale dismantling of basic writing programs. Both Collins and Greenberg pointed out Shor's use of sweeping statements regarding basic writing programs and basic writing teachers, generalization that was unfair and even impossible considering the wide variation in practices. Collins calls the homogenization of Shor's depiction of basic writing a straw man (98), insisting instead that there is no overarching "basic writing," only a multitude "of situated 
iterations" (98). ${ }^{88}$ Greenberg charges Shor with "oversimplifying the term [BW] and demonizing it" (“A Response" 90), writing that "there is no lumpen mass of 'basic writers' who conform to the stereotypes in [Shor's] essay" (“A Response” 92).

But the larger issue taken with Shor's call to dismantle basic writing was its dangerous similarity to institutional and state efforts to dissolve basic writing programs altogether, a similarity Bartholomae is careful to acknowledge and separate himself from. While Shor might have wanted a fundamental overhaul of basic writing, his prose is perfect fodder for the "reactionary political forces currently trying to achieve precisely this barring of access and precisely this reduction in size in colleges across the country" (Greenberg, "A Response” 94). These "pressing forces of exclusionism," writes Collins, would result not in equality for basic writers, but rather their rejection from colleges that had once admitted them (100). The students who would have traditionally entered basic writing would, under Shor's imagining, be faced with two perilous alternatives: "either fail admissions standards or . . . fail college-level courses because of inadequate writing skills" (Greenberg 94). ${ }^{89}$ Collins, drawing on Deborah Mutnick’s Writing in an Alien World, reminds basic writing scholars that they must "be careful in how we mount educational critique from the left, that in impolitic critique of Basic Writing we risk crawling into bed with the very elements of right wing elitism which access programs and many Basic Writing programs were founded to counteract" (99).

This is where, for all parties, things get complicated. Those who want to abolish basic writing want to do so for two very different reasons, but often couch their proposed

\footnotetext{
${ }^{88}$ Collins also accused Bartholomae of fallaciously generalizing in "The Tidy House," despite Bartholomae's efforts at a more nuanced reading of the dangers of basic writing when assumed to be a naturalized, permanent fixture.

${ }^{89}$ In Greenberg's article and elsewhere, this is referred to as a "sink or swim" approach, a model that automatically absorbs all basic writers into mainstream FYC without additional support.
} 
changes under the same header: mainstreaming. One camp consists of higher education administrators, local, state, and national politicians, and some of the general populace, all of whom want to erase basic writing programs from the landscape of higher education so that the "basic writers" who would have been enrolled in these programs are also erased. When the term "mainstreaming" is used by this camp, the goals in mind are other than student success; instead, the aim is to improve the data markers of an institution, state, or nation's "success" in churning out degree earners, data markers such as retention and completion rates.

The other camp, populated by teachers and often administrators of another bent, wants to erase only the stigma of basic writing, keeping all the same students enrolled, but giving would-be remedial students more equitable access to credit-bearing, collegelevel work. This version of mainstreaming offers basic writers some version of FYC with additional supports, supports that vary widely and may be offered to all students. One version restricts the stream of access, while the other widens it. So to defend basic writing, as advocates like Karen Greenberg and Deborah Mutnick do, puts scholars in the difficult argumentative position of having to contend, as Mutnick puts it, "both with conservatives who condemn us for allowing underprepared students through the doors of higher education in the first place and those in our own discipline who want to abolish remedial instruction because it stereotypes students and segregates them from the mainstream" ("The Strategic Value" 71). The two "mainstream" camps, despite their diametrically opposite exigencies, are often conflated even in today's scholarship.

Skeptics of "mainstreaming" like Greenberg and Collins are cautious with good reason, if when they hear the term they imagine anything other than mainstreaming in its 
legitimate form (efforts to provide would-be basic writers with credit-bearing FYC content). While marketed as a benevolent doing-away with an obstacle to student success, the reductionist, illegitimate form of mainstreaming in the form of abrupt, decisive programmatic elimination often coincides with a raising of the admissions bar. In an effort to improve retention rates, degree achievement, and national ranking, schools across the United States identify basic writers as lowering an institution's overall standards and taking longer to graduate (Otte and Mlynarczyk 167). Students who would at one time have been admitted under the flag of basic writing are then redirected to community colleges or even adult education programs; they must improve their scores or prove completion of a prerequisite before being admitted into the 4-year baccalaureate program they had initially applied to. ${ }^{90}$ This redirection may come from a singular institution, or may be a state-wide mandate.

Such tightening of admissions standards and outsourcing is antithetical to the aims of translingualism. Students whose language practices differ from the imagined standard, as well as students whose race or class positions them as nonstandard, are those most likely to be excluded. Eliminating basic writing full stop is also a thinly veiled effort to undo the affirmative action advancement of open admissions policies that made education available to working-class people of color and is, as Mutnick writes, akin to a resegregation of higher education ("The Strategic Value" 72-78). The link between affirmative action and developmental education (also the topic of Stygall's 1999 article in $J B W$ ) was confirmed by National Association of Developmental Education political liaison Gerald Corkran, who in 1995 wrote that national leaders believed "that because

\footnotetext{
${ }^{90}$ For case studies of this redirection, see Nicole Pepinster Greene and Patricia Alexander's 2008 Basic Writing in America: The History of Nine College Programs.
} 
there was no longer a need for affirmative action, there was therefore no need for developmental education" (qtd. in McNenny 1). The linguistic discrimination of the downsizing of basic writing is also illustrated by institutional practices that distinguish between "levels" of language difference, such as Hunter College's practice of exempting international ESL students from remedial coursework while dismissing domestic ESL students from the college altogether if they fail the writing assessment used for admission, as described by Trudy Smoke (196-8). Policies such as these reinforce to the students who are admitted that their writing has been deemed in alignment of the acceptable standard, negating the idea that students may, at some point, need or even want supplementary assistance in writing practice. If this were the case, writing centers would not need to exist. By falsely asserting to students that their language has met the "bar," and that below the bar there is only failure, students learn that language difference has no place in the university and should be excised as soon as possible. ${ }^{91}$

Unfortunately, basic writing programmatic elimination since the turn of the century has been widespread. Greenberg's 1997 response to Shor was eerie foreshadowing. She wrote in 1997 that should Shor's vision come to pass, "at least half of the students now entering the university where Shor and I teach (CUNY) would be barred. The University, far trimmed down in size, would probably return to the elite institution it was before 1970, when open admissions began” (94). Only two years later, CUNY's Board of Trustees ruled to end the open admissions policy of its twelve fouryear schools, sending students who failed any one of three "Freshman Skills Assessment

\footnotetext{
${ }^{91}$ In her chapter in Mainstreaming Basic Writers, Smoke describes a loophole course created at Hunter College that enrolled 500-800 (ESL and native speaker) students who nearly passed the writing assessment, students who would have been ejected due to their entry scores. However, in a footnote, Smoke writes that as of publishing the book, the course had been abolished (199).
} 
Tests" (in reading, writing, and math) instead to community colleges (Otte and Mlynarczyk 167; Gleason 488-89). ${ }^{92}$ Barbara Gleason reported that CUNY's Office of Institutional Research estimated the ruling affected one-fifth of the would-be freshman class of 2000 (489). Similar decisions occurred at the California State University system, where in the late 1990s the Board of Trustees ruled that students would only have one year to complete all remedial education and that schools should aim to decrease the number of students needing remedial courses by $10 \%$ every year until the need was eliminated altogether (Goen-Salter 83). At the University of Cincinnati, a 2003 decision dissolved the open admissions branch of its main campus (Gibson and Meem), and Terrence Collins's University of Minnesota in 2005 moved to eliminate the University's General College (which offered basic writing and other support services), initiatives again fueled by these institutions' desire to improve their ranking amongst research universities and in the U.S. News \& World Report (Otte and Mlynarczyk 167-8).

The practice of "vetting" potential students by requiring them to complete their writing prerequisites elsewhere before granting them admittance belies the contextual nature of basic writing; by sending students to a different institution, with different values and outcomes, there is no linkage between what students learn at the outsourced school and the institution they hope to attend. The implication in this practice is that all basic writers are the same at all times, that FYC expectations are the same everywhere and always, and that writing skills are pesky and tiresome tasks to be easily and quickly

\footnotetext{
${ }^{92}$ In the 1999 report An Institution Adrift issued by Mayor Giuliani's Task Force on CUNY, written by chair Benno Schmidt, remediation is described as "a distraction from the main business of the University" (38). CUNY's mandate, writes Schmidt, is to serve students "who are prepared to succeed" (39). For those students squeezed out, the report suggests purchasing educational services from for-profit companies such as Kaplan and Sylvan Learning. Mutnick writes of the report that it "does not take much to read between the lines ... to see the goals of privatization, corporatization, outsourcing, and downsizing" (76).
} 
obtained elsewhere before the "real" work of writing begins in the FYC classroom. To put it more bluntly, outsourcing reaffirms the ideology of monolingualism, in that as a practice, outsourcing assumes that literacy skills are obtainable as a discrete set of accomplishments that are identical at every institution of higher education, and that simply acquiring this literacy will transform the inadequate student into one worthy of higher level thinking and writing (see Brian Street's theory of autonomous literacy). Positioning "standard English" as neutral absolves institutions from the claim that their rejection of basic writers has a basis in these writers' race or class. Equally, positioning standard English as easily transferable means all institutions can teach it, some are just too elite to do so by choice. Outsourcing places the onus on the student to earn the badge of "correct English" in order to then claim the social identity of "college writer" (Lees, "The Exceptable Way"). Moreover, by funneling students elsewhere, the more selective institution is falling prey to Rose's myth of transience: the false thinking that once high schools more adequately prepare graduates for the demands of college writing, students will not need to attend this "gap" institution, but will, one utopian day, seamlessly transfer to college fully prepared. Kelly Ritter calls the outsourcing of basic writers "unconscionable" in her Before Shaughnessy (143) and I agree; basic writers should be visible participants of a college's community, not a source of embarrassment to be remediated elsewhere.

Outsourcing should not be confused with the legitimate forms of mainstreaming currently embraced by basic writing teacher-scholars, which share a common goal of giving all students access to FYC, even if other forms of support are required for a subset. The rationale behind traditional basic writing is to give students more time to practice; 
whereas, most legitimate mainstreaming models (with the exception of stretch) suggest that time is not the main or only factor helping students develop their writing acumen. In fact, Adams et al., writing of the ALP program, would argue that giving basic writers more time increases the likelihood that they will drop out. As Adams et al. write, "the longer the pipeline, the more likely there will be 'leakage'" (53). Other factors, such as the influence of advanced writers as classmates, a teacher invested in their success, explicit discussions of academic writing conventions as constructs, or access to tutors, conferencing, or computers may provide equal, if not greater, improvement in writing than a standalone basic writing course. This chapter will consider the translingual potential of legitimate mainstreaming approaches; every approach analyzed attempts to provide all students access to FYC in some form without changing institutional admissions criteria. The questions this chapter asks are: How should schools place students whose writing ability appears to fall below the arbitrary standard set as 'college ready'? And once placed, what kind of basic writing course structure gives students adequate support without delaying their progress to a degree?

If it is not already abundantly clear, let me state outright that I see no translingual potential in eliminating basic writing programs or in outsourcing, since, for me, the existence of basic writing is a question of ethics. As Gibson and Meem write, "how we choose to educate our non-elite and minority citizens is representative of our moral barometer as a nation" (50). Translingualism argues for the infusion of knowledge and even expertise that basic writers bring to colleges. Institutions of higher education, symbolic centers of language teaching as well as language innovation and creativity, set the national tone for what kind of language practices and ideologies the country's future 
leaders should subscribe to. What colleges fail to see is that excluding basic writers has consequences more far-reaching than economic; Otte and Mlynarczyk argue that schools "contract [their] own chances by curtailing educational opportunity" to so-called remedial students (188). The "chance" Otte and Mlynarczyk refer to is the chance to educate the full spectrum of America's students, and a chance, translingualism would assert, to be changed as an institution by the diverse knowledges and language labor of basic writers. But basic writing serves a role even beyond the institution: it serves a role in our democracy. As Mike Rose put it in his 2009 Why School: Reclaiming Education for All of Us, basic writing, when done well, is "a key mechanism in a democratic model of human development" (137) and is a place for students to "change, retool, [and] grow" (137).

\section{Principles of a Translingual Approach to Basic Writing Placement and Programming}

Principles similar in sensibility to those outlined in chapter three would characterize a translingual approach to the placement of basic writers and the programmatic shaping of a basic writing course or sequence of courses. I see these principles as follows:

1. Respect for the agency of every student writer. The student should be a vested and validated stakeholder, and their collegiate work should carry credit wherever state regulations allow.

2. Authentic negotiations between all stakeholders, including students, teachers, advisors, and administrators. Such negotiations necessitate deep listening. 
3. Student texts, as well as student perceptions of their texts and writing practices, serve as the basis for placement decisions. Placement practices should acknowledge that interpretation of student texts is an active state of negotiation in which the reader produces meaning through the act of reading itself. A single text cannot be ranked in terms of skill, as skill is a dynamic marker constantly under construction and negotiation. In the same way, a writer's proficiency is dynamic, contextual, emergent, and negotiated.

4. An assumption of heterogeneity as a feature of all language. As language is endlessly fluctuating, language learning is endless, making language proficiency a moving target. Programmatic models that rely on achieving language fluency or on aligning students to a mythical, monolithic standard are therefore working counter to translingual aims.

5. Flexible practices that recognize basic writing as well as basic writers as emergent and always becoming, allowing institutional practices to adapt in kind. ${ }^{93}$

\footnotetext{
${ }^{93}$ Although these principles are akin to those outlined in chapter three on a translingual approach to basic writing pedagogy, they differ enough to justify a re-establishment of the textual basis for my assertions regarding translinguality. My understanding of the agency of the basic writer as vested stakeholder and shaper of language comes from Shaughnessy's Errors and Expectations, David Bartholomae's essays as compiled in Writing on the Margins, and the work of Min-Zhan Lu and Bruce Horner, especially Lu's "Professing Multiculturalism," Lu and Horner's "Translingual Literacy, Language Difference, and Matters of Agency" and Horner's "Relocating Basic Writing." The importance of negotiation and deep listening in translingual approaches I take from Horner's "Rethinking the 'Sociality' of Error" and Asao Inoue's "Writing Assessment as the Conditions for Translingual Approaches." Specifically, negotiative reading practices that reflect the instability of meaning in any one text and the instability of skill as assigned to any one individual come from Lu, Elaine Lees's "'The Exceptable Way,"' Joseph Williams's "The Phenomenology of Error," and Sarah Stanley's "Noticing the Way." I attribute the heterogeneous, unstable, permeable, and emergent nature of language and standards to the work of Alastair Pennycook (Language as a Local Practice and "The Myth of English as an International Language"), Suresh Canagarajah (Translingual Practice), Nancy Hornberger ("Continua of Biliteracy") and Horner et al. ("Language Difference in Writing).
} 


\section{Placing Incoming Students}

The root of placement, like error, is often misattributed. It is taken for granted that the source of placement is a test (or a teacher reading an essay, or an advisor reading a high school transcript). But the source of placement resides in institutional desires to cheaply and efficiently sort students into categories, categories which easily funnel into tracks and courses that make the process of assessing writing ability (and writers) appear natural. This institutional desire highlights the deep-seatedness of ideologies of monolingualism in higher education, ideologies that insist on the stability of student identities and writing ability. Just because testing is the de facto standard for placing incoming students into writing classes does not mean that it is a valid or reliable way of measuring a student's likelihood of succeeding in a given course. The widespread skepticism about this standard practice is attested to in multiple position statements from both CCCC and NCTE regarding writing assessments (see "Writing Assessment: A Position Statement" and "All Position Statements"). What testing-as-placement does is falsely reassure stakeholders that there is a "true" placement against which all other potential placement methods must measure (Royer and Gilles "Introduction" 12), thus explaining the anxiety surrounding how alternatives might "improperly" place students, or, in other words, place them differently from how testing would have placed them. Yet if the notion of a "true" placement is set aside, and placement is regarded as a social, rhetorical act, then alternatives to the traditional testing model for placing basic writers can be explored. ${ }^{94}$

\footnotetext{
${ }^{94}$ For more on the sociality of placement, see Cynthia Lewiecki-Wilson, Jeff Sommers, and John Paul Tassoni's "Rhetoric and the Writer's Profile," David Blakesley's "Directed Self Placement in the University," Christie Toth's "Directed Self-Placement at 'Democracy's Open Door," and Peter Dow
} 
Unsurprisingly, "traditional" basic writing placement procedures do not fare well when evaluated against the translingual principles I have outlined here. ${ }^{95}$ In my view, "traditional" mechanisms channel students into basic writing or mainstream writing courses without student input and often without student awareness, denying the agency of incoming students and denying students any say in their academic trajectory. ${ }^{96}$ In a traditional placement model, students, in applying to an institution, submit with their application a slew of data: SAT/ACT scores, high school transcripts and GPA, English language proficiency scores, and in some cases, auto-generated writing scores from same-day timed placement tests such as Accuplacer, Compass, or ASSET. At best, advisors use this data alongside institutional placement parameters to inform students during course scheduling of their placement in basic writing and discuss with students what this means. Even so, the conversation is not a negotiation but rather a debriefing; the student's reaction to their placement cannot effect any change. At worst, computerized placement limits students' options for enrollment and provides no explanation; students may be unaware that they have even been marked as "basic" until after the course begins. The traditional model of basic writing is a semester-long course; students exit via either a passing grade or some kind of exit "crunch point," as Peter Elbow terms it ("Directed Self-Placement" 16), such as an in-class written exam or portfolio review. After passing basic writing, students' choices for enrollment in other

\footnotetext{
Adam's opening talk at the 1992 Conference on Basic Writing (CBW) as recounted in "Basic Writing Reconsidered."

${ }^{95}$ For a defense of placement testing as increasing students' likelihood of persisting through college, see Edward M. White's "The Importance of Placement and Basic Studies."

${ }^{96}$ The appropriation of students' futures is all the more difficult to stomach when we see the immense effort students expend when attempting the appropriate the specialized discourse of the university in the impromptu essays often used for such placement, even going so far as to lose themselves in the discourse they believe their readers want, as described in the "Clay Model" essay of Bartholomae "Inventing the University" (63).
} 
courses widen, and they leave the label of "basic writer" behind, though the mark stays on their transcript permanently. When these courses carry credit, they usually fall in a transcript as electives, not satisfying any degree requirements. If students fail this course, they repeat it, until they reach a limit of attempts, if one has been designated by the institution.

Even though the ACT and SAT tests now feature timed essays that are graded by human readers (this change occurred in 2005 for both exams), there are too many degrees of separation between the act of writing and the placement of the student to argue that these essays are valid artifacts for informed placement. ${ }^{97}$ The same argument could be made for high school transcripts; grades received on essays written about literature or quizzes on grammar are not likely to be predictive of a student's aptitude for persuasive, evidence-based prose. Still, a student's GPA is the cumulative, balanced result of years of labor and dozens, if not hundreds, of writing assignments. In this sense, GPA is more adaptive than a single assessment, since GPA changes as the student changes. Placement by test score is only adaptive as far as tests change over time and institutional brackets designating cut off scores change. As tests measure "ability" in a single instantiated moment, they do not acknowledge the emergent and contextual nature of writing skill. Students have agency in both of these placement models only as far as their agency is represented in the documents and numbers that serve as proxies for their identity. In that multiple choice questions about grammar and vocabulary have ostensibly "right" or "wrong" answers, language heterogeneity is certainly not valued.

\footnotetext{
${ }^{97}$ Although this is a view widely held in writing studies, it is not unanimous. Edward M. White's "An Apologia for the Timed Impromptu Essay Test" is a counter view, asserting that timed essays can spark "focus and concentration" (34) and can serve as an adequate middle ground for administrators leery of multiple choice placement tests but without the resources to implement a full-scale portfolio placement procedure (37).
} 
Some institutions have adapted a placement practice dubbed "multiple measures," in which advisors can use any one of multiple potential avenues for exempting a student out of basic writing and into FYC. ${ }^{98}$ These measures might include high school GPA, state-specific high school exit tests, SAT/ACT, courses appearing on a high school transcript, institution-specific writing assessments, and even noncognitive assessments. ${ }^{99}$ In the sense that multiple measures placement gives both students and advisors a broader and deeper picture of a student's writing past and present, multiple measures aligns with a translingual approach. Students are allowed to experience dips in writing proficiency without penalization; a poor same-day timed writing assessment would not trump four years of diligent effort in high school. In a multiple measures model, student writing, defined holistically, serves as the basis for decision making to the degree that a compendium of past writing (as assessed by others) is provided as a kind of pseudoportfolio. When multiple measures leads to a conversation between student and advisor, and a placement recommendation is given that a student may then agree with or push back against, translingual negotiation is taking place. Yet this is not the most common approach to multiple measures; in its standard expression, students simply have more quantitative "chances" to be exempted from basic writing, chances they themselves are unaware of as advisors crosscheck the various measures independently.

The current placement initiative with the most translingual potential is "directed self-placement," otherwise known as DSP, and sometimes referred to as "guided self-

\footnotetext{
${ }^{98}$ For a broad overview of multiple measures as a national initiative widespread in higher education, consult the 2019 report by Elizabeth Ganga and Amy Mazzariello of the Education Commission of the States' Center for the Analysis of Postsecondary Readiness entitled "Modernizing College Course Placement by Using Multiple Measures." For a recent example of local implementation in composition, see David Reinheimer's "Validating Placement: Local Means, Multiple Measures" in Assessing Writing.

${ }^{99}$ See the Community College Research Center's 2016 "A List of Non-Cognitive Assessment Instruments" by Tina Kafka for a compiled list of noncognitive assessment instruments that measure factors like resilience, emotional intelligence, and mindset.
} 
placement" or "informed self-placement." The term was developed by Daniel Royer and Roger Gilles in their 1998 article entitled "Directed Self-Placement: An Attitude of Orientation," but, as Inoue et al. write in their WPA-CompPile Research Bibliography on DSP, the practice of allowing students a say in their freshman English placement has some history in Judith D. Hackman and Paula Johnson’s 1981 “Using Standardized Test Scores for Placement in College English Courses: A New Look at an Old Problem" (Inoue et al. 1). Though DSP varies by institution, at its heart students are given information about the various introductory college English courses (at least one of which is usually a basic writing course). Then they are given time, and usually a self-assessment instrument to consider, before tentatively self-placing. When students meet with advisors to enroll in classes, they discuss their self-placement choice, and advisors offer additional context and answer questions. Though advisors may suggest a different placement than the one students have chosen for themselves, the decision is left ultimately up to students. Unlike placement tests, which signal to students that they cannot even be trusted to know whether their writing needs help, DSP says to students that they are the most qualified individuals to decide their aptitude and their needs. Inoue et al. write that schools usually implement DSP when unhappy with their long-standing placement practices, either because the test scores aren't predictive of pass rates, because teachers complain of a high number of "misplaced" students in their courses (whether over prepared for basic writing or underprepared for mainstream), or because of the costs involved in purchasing placement test software or paying teachers to read student portfolios (1).

A key translingual strength of DSP is its programmatic flexibility and adaptability. As student and institutional needs change, so too can DSP change with less 
overhaul than, say, computer-graded testing. Scholarship assessing the effectiveness of a DSP program usually cites student evaluations in addition to conventional pass or retention rates, which acknowledges that the "success" of placement depends more on student satisfaction than anything else, and in turn acknowledges the students as valid stakeholders. For instance, a student who might traditionally have been placed into basic writing but who chooses to self-place in mainstream FYC and then fails would traditionally be counted as a placement failure. The standard logic dictates that a student should be placed in the course they have the best chance of passing. However, if a student reports that they felt accurately placed, and were happily challenged by the course despite their failure, then is this placement still a failure? By asking students their perceptions of the placement process, DSP places the student at the center and values their opinion over the narrative data might otherwise tell. In the chapter they contributed to their 2003 edited collection Directed Self-Placement: Principles and Practices, Royer and Gilles describe DSP as a "design-feedback loop" ("The Pragmatist Foundations" 53) in which the "self" a student puts forward is valued by the institution, and consulted again at the end of a course in order to inform the next cohort of incoming students. Ongoing feedback shifts DSP processes in small ways, from the way courses are described to students, to the materials they are given, to the self-assessments they take in order to inform their placement decision, and the emergent process is shaped and reshaped by the students themselves. In turn, honoring the validity of student feedback equally transforms the writing class. Enacting curriculum and programmatic change based on the evolving student experience highlights composition classrooms as dynamic and emergent. To put it 
another way, if writers are changing and so is language, then no writing course can remain static.

Relinquishing the power of placement to the student is the ultimate affirmation of their agency, and this acknowledgement has widespread ramifications. Royer and Gilles argue that DSP encourages students to feel connected to the institution and part of a broader community of learners, and signals to incoming students "that their college education will be an active one; they will be in charge" ("The Pragmatist Foundation" 61, 69). From course evaluations and completion data, DSP scholars argue that students are happier with their classes and perform better. David Blakesley, Erin Harvey, and Erica Reynolds write in their Directed Self-Placement chapter that $93 \%$ of the students at Southern Illinois University Carbondale valued the right to choose their own placement (222), and Cynthia Cornell and Robert Newton, in their chapter on DePauw, discovered that students who would have been placed automatically in basic writing but who selfplaced into mainstream FYC succeeded in the mainstream course at an even higher rate than students in the basic writing course (168), suggesting student motivation and disposition play a greater role in predicting success than traditional placement measures like tests. In general, DSP acknowledges the impact of mindset toward writing, making space for students who feel themselves already capable of collegiate-level writing to press onward, despite what their data says. In this way, DSP validates the diverse and fluctuating nature of writing that may or may not be expressed in any given artifact a student is able to produce. By not presuming to be able to predict ability, DSP places the power to decide in the hands of the writers themselves. 
When students feel their language is respected from the onset of enrollment, before they even enter the classroom, they are provided with evidence of institutional commitment to diversity. When then this respect and commitment is mirrored in a translingual approach to writing (whether basic or FYC), students are more likely to embrace a reflective, agentive, and negotiative stance toward their own writing. Students are more apt to consider their language difference an asset when the institution did not position their difference as a deficit from the beginning. Asao Inoue writes astutely of the reverse in his Crossing Divides chapter:

If a student doesn't have much choice in what writing course she will take - if she's placed by a test - it is harder for a writing teacher to expect the same student to make conscious choices in class and in her writing, harder for the student and teacher to interrogate those choices as anything other than signs of deficit. In short, it is harder for the class to honor the student's language decisions in her writing since they could be seen by the student as the very things held against her in her placement in the very course that asks her to see her language choices as choices and not error, as textual markers of practices that can be interrogated and negotiated. (26)

In other words, placement by traditional testing means a translingual-oriented teacher must work backwards from day one to undo the sedimented, monolingual ideology of clear-cut tiers of ability reinforced by the testing that determined the makeup of her classroom.

Still, DSP is not flawless. Rachel Lewis Ketai points out DSP's reliance on individualism, arguing in her "Race, Remediation, and Readiness for College Writing: Reassessing the 'Self' in Directed Self-Placement" that individualism often expresses racist tendencies (146). Asking students to look inward, she writes, may result in students of color giving stronger weight to their own internal biases than traditional placement would have done, resulting in students of color self-placing lower than their aptitude as 
judged by others. While DSP honors a student's choice to self-place lower (though it is less common than self-placing higher than recommended), WPAs and directors of writing programs implementing DSP should be aware of this potential consequence, and should pay attention to the links between race, ethnicity, and self-placement.

Another weakness in the DSP model is that, usually, no actual student texts are examined by either the student in question or the advisors/teachers in coming to a decision re: writing ability. ${ }^{100}$ When a student is only remembering writing anecdotally, they may have difficulty evaluating their high school writing experiences against a collegiate backdrop. Similarly, negotiation on the part of the advisor/teacher remains theoretical when the advisor/teacher has no writing artifact to refer to when advocating for a placement different from the student's preference. One potential workaround is the approach described by Cynthia Lewiecki-Wilson, Jeff Sommers, and John Paul Tassoni in their 2000 article, "Rhetoric and the Writer's Profile: Problematizing Directed SelfPlacement." In this approach that combines the writing-centeredness of portfolio placement with the negotiative dialogue of DSP, incoming students assemble "lists, process notes, drafts, and revision," (170) into what is called a "writer's profile," and two writing teachers read each student's profile in preparation for a placement dialogue. The students select which writing pieces they feel best represent their ability, increasing the likelihood they would be able to effectively self-advocate, while also giving teachers an artifact to confirm or push back against the student's assertions. However, as Patrick Tompkins' critique points out, the costs of a DSP model are amplified when teachers and

\footnotetext{
${ }^{100}$ Some DSP models ask students to draft responses to open-ended questions about their writing history, but these responses are used to prompt reflection and are not examined. However, many DSP models implement diagnostic essays in the first week of class, which facilitates student movement as needed (Royer and Gilles Directed Self-Placement).
} 
advisors must be paid in advance of each enrollment period to read such portfolios and meet to discuss with students. As Tompkins writes in "Directed Self-Placement in a Community College Context," the costs would be most difficult to bear at the community college level, which sees the largest percentage of basic writers and at which such a portfolio intervention would be most transformative (195).

Given that I argue the translingual potential of DSP, I would be remiss in omitting the irony of arguments that DSP positions multilingual students, especially international students, at a disadvantage, in that these students are assumed to be less cognizant of the literacy expectations of writing courses in the U.S. (Gallagher and Noonan 167). Gita DasBender found in her 2011 study at Seton Hall University that domestic multilingual speakers tend to identify strongly with their domestic monolingual counterparts, leading multilingual students to self-place in mainstream composition sometimes at odds with their own understanding of their linguistic needs (382-3). Additionally, teachers and advisors tasked with guiding students may be more likely to push a developmental recommendation on multilingual students during the negotiations that determine course placement. Gallagher and Noonan in their Crossing Divides chapter “Becoming Global: Learning to 'Do' Translingualism” write that instructors at Northeastern were unequipped to read for meaning in texts by multilingual writers, and were quick to think that multilingual writers (whether their writing featured significant error or not) should be bumped down into developmental courses (166-7). These flaws, especially those concerning the uptake of DSP by students of color and multilingual students, are important for administrators considering implementing DSP to consider. Nevertheless, DSP is fundamentally a practice that gives all writers, especially those 
whom testing would have marked as veering from acceptable discourse, more control and more responsibility over their education.

\section{Designing the Basic Writing Course Model}

My use of the term "model" here serves as a catch-all for a number of factors describing a basic writing course: the duration of a course, the pace at which a course is taught compared to a traditional 15 week semester, the makeup of students in a course, the number of writing courses a basic writing student might be concurrently enrolled in, as well as each course's purpose. In 1999, William Lalicker devised 5 categories encompassing the majority of types of basic writing programs self-reported by schools: mainstreaming, directed self-placement, intensive, writing studio, and stretch ("A Basic Introduction"). As I consider DSP a placement model and not a course type, and mainstreaming (in the sense of dissolving basic writing entirely) has already been discussed, the following pages discuss the translingual potential of intensive basic writing and the studio and stretch models. The only category I would add to Lalicker's now 20year old list would be "accelerated," such as the Accelerated Learning Program or ALP of the Community College of Baltimore, or the California Acceleration Project (CAP). Other models not mentioned by Lalicker and less frequently occurring today include the service learning approach (Kraemer; Pine), and learning communities (Wiley; Gabelnick et al.; Darabi) such as "linked" courses. ${ }^{101}$

I consider the model with the least attention to the agency of the writer and the fluidity of their (and all) language to be intensive basic writing, sometimes referred to as

\footnotetext{
${ }^{101}$ Linked courses link a specific section of basic writing with a specific section of an introductory "content" course, such as history, communication, or psychology. The cohort of students takes both classes, and the teachers communicate to ensure transfer and cross-course learning.
} 
"fast-track" or "turbo" (Stygall 6). In my understanding, the intensive approach aims to "fit" the content of a one-semester basic writing course into a smaller period than a single semester. ${ }^{102}$ This can take the form of summer bridge courses for enrolled students before the start of their freshman year, 6-week courses, winter term courses, or any other "boot camp" type effort to cram learning into a hurried timeframe. Students in intensive basic writing courses are usually there due to failed test scores, and after the intervention, they are retested, with the hopes that aggressive and prolonged exposure to writing elements such as grammar, spelling, and the general conventions of brief essays (topic sentence, thesis, transition, etc.) will improve the post-intervention test score. The aim here is not to give students a multitude of opportunities to practice writing, nor to aid them in careful consideration of the possibilities and constraints of revision. Instead, the goal in this model is efficient and speedy alignment to the standard, which in this case takes the form of whatever exit crunch is required by the institution to "prove" preparedness for FYC. Little to no recognition of linguistic heterogeneity or the fluidity of language, writers, or skill is acknowledged. Due to these elements, intensive basic writing teaches students, as Katie Malcolm writes in "Disrupting Monolingual Ideologies in a Community College," to "hide or eradicate language differences more effectively ... and learn to omit or switch from fixed 'problems' into equally fixed 'standards' instead of learning to see both of these as negotiable and in flux" (104).

\footnotetext{
${ }^{102}$ As aforementioned, terminology can get confusing here. In some circles, the term "intensive" refers to a form of mainstreaming in which basic writers enroll in special sections of FYC that meet for more hours every week than a traditional FYC (Lalicker "A Basic Introduction”). For more on this approach, see Youga et al.'s program at Illinois State University and Mary Segall's model at Quinnipiac University. For the purposes of this chapter, I consider FYC courses that meet additional hours per week to be a form of stretch, since the underlying assumption is that basic writers simply need additional time to complete mainstream FYC work.
} 
Other models for basic writing hold greater translingual potential as defined by the principles I have outlined, including stretch, accelerated, and studio. With origins at Arizona State University, the "stretch" model of basic writing, as its name indicates, stretches the one-semester FYC into two semesters, in order to "give beginning writers more time to move into the university community" (Glau, "The Stretch Program" 79). ${ }^{103}$ Placement is determined by ACT/SAT scores, and international students are enrolled in their own sections (Glau, "The Stretch Program" 82). Students stay with the same teacher and same classmates for both semesters, giving this a learning community flavor; upon completion, students enter the traditional second-sequence FYC course as mainstreamed writers ("The Stretch Program" 81). At ASU, stretch resulted in higher retention rates and pass rates $(23 \%$ increase in pass rates after 1 year, 28\% after 10 years) (83-87; Glau, "Stretch at 10" 38). Stretch is a particularly crafty model when implemented in states that have begun to dismantle or curtail access to remedial education at four-year institutions. ${ }^{104}$ By avoiding the creation and justification of a new course, maintaining FYC content, and awarding credit to both classes, administrators are often able to argue that these courses are not truly remedial, and can thus be exempted from harsh legislation.

\footnotetext{
${ }^{103}$ As ASU's stretch program expanded, different forms were experimented with, including a summer bridge program that condensed the first "semester" of FYC into a 5-week summer term before freshman fall. Glau reports being dissatisfied with the retention numbers from this format, since only about half of those who completed the first semester enrolled in the second semester that fall. This is an example of "intensive" basic writing, often ultimately less successful even than traditional basic writing models (Glau, "The Stretch Program" 83-85).

${ }^{104}$ According to a 2016 National Center for Education Statistics report by Xianglei Chen and Sean Simone, Arkansas, California, Louisiana, Massachusetts, New York, Oklahoma, Tennessee, and Virginia all had (as of 5 years ago) policies in place that reduced the number of remedial course offerings (3). Illinois, Montana, South Carolina, Tennessee and Texas are directing remediation requirements to community colleges instead of 4-year schools (Chen and Simone 3; Grego and Thompson, Teaching/Writing 2). Other states have implemented drastic changes: Georgia denies admission to students testing below college-level in their placement test, Ohio no longer subsidizes remedial courses, and Connecticut has limited remedial instruction at community colleges to one semester (Grego and Thompson, Teaching/Writing 3).
} 
Stretch is translingual in its commitment to reimagining basic writers, not as cognitively impaired but as beginners who need time to develop their skill. ${ }^{105}$ In using the same textbook and completing the same assignments as all other first year composition students, stretch also reinforces to basic writers that they are fully vested college students who are capable of doing collegiate level work (Glau, "The Stretch Program" 80). Stretch is also somewhat adaptive, in that Glau cites anonymous student satisfaction surveys, the results of which changed the class from a pass/fail model to a graded model and informed changes to the way information about stretch is offered to qualifying incoming freshmen. Glau's 1996 article lists four "concepts" that underlie stretch, which bear some resemblance to the translingual principles I've outlined earlier, including "a view of basic writing students as capable and intelligent," an emphasis on writing practice, and a commitment to receiving college credit for college work. The fourth principle outlined by Glau is "the notion that beginning writers, since they lack experience in writing, need more time to learn to work with and to develop appropriate writing strategies" (80).

This is where I believe translinguality diverges from Glau's principles. With the phrase "lack experience in writing," it can be assumed Glau is referring to experience with the contextual, changing demands of collegiate, academic writing specific to ASU. It cannot be assumed that all basic writers write with less frequency than mainstream writers. I will outline below in my discussion of the studio model my belief that there is value in designated additional time (and ideally, space) for basic writers. However, the fundamental assumption in stretch is that basic writers can meet FYC curriculum

\footnotetext{
${ }^{105}$ Actually, Glau quotes Shaughnessy, who wrote that basic writers "are beginners and must, like all beginners, learn by making mistakes" (Errors 5). Shaughnessy's sentiment is not translingual, in that she portrays the language of basic writers as inherently flawed but capable of being slowly realigned. However, Glau's uptake of Shaughnessy is used to put basic writers in a positive light.
} 
demands only at a slower, more painstaking pace. But is time the magic formula? Glau asserts that the students in stretch needed "more time to work on and revise and think about their writing" (81). Indeed, $43 \%$ of surveyed students reported that having "more time to spend on their papers" was their favorite part of the stretch program (87), even if readers remain uncertain exactly what "time to work on writing" and "time to spend on papers" means. At the same time, $16 \%$ of students felt the pace of the class was too slow and they felt they lagged behind their peers (88).

For me, the question lies in what this time is being used for, an aspect of stretch not detailed in either Glau's 1996 or 2007 articles. One gets the feeling that the literal pace of class is slower - students have more minutes to do the same activities, such as more in-class writing time, longer peer review sessions, more rounds of revision. ${ }^{106}$ Slowing the pace of class sediments the idea that basic writers are cognitively slower, less adept, less flexible. Basic writers are positioned as needing more time to produce the same results as their FYC peers. If this is the case, then stretch falls short of its translingual possibility. What basic writers need time for is not just the writing process, but more importantly, time to talk about and understand what it is they are being asked to do, and why they are being asked to do it, time to lay the conventions bare as constructs and dissect them in the company of like-minded peers. This is what happens instead, in models like ALP and studio.

The model currently experiencing the biggest uptake in basic writing conversations is ALP, which stands for Accelerated Learning Program, from the

\footnotetext{
${ }^{106}$ I will note again the limitations of textual analysis as my chief methodology. My understandings of course setups and day-to-day logistics are, unfortunately, limited to just their description in scholarship. One can assume this picture would be complicated in speaking to basic writing teachers and administrators enacting these programmatic models.
} 
Community College of Baltimore County's Peter Adams, Sarah Gearhart, Robert Miller, and Anne Roberts. In their 2009 article, they describe ALP as having "borrowed the best features of existing mainstreaming approaches, added some features from studios and learning communities, and developed several new features of our own" (56). In this model, all students who test into basic writing (CCBC used Accuplacer in 2009) are given the option to choose ALP, in which they concurrently enroll in basic writing and FYC. These students enroll in specific sections of FYC, composed of twelve "regular" students and eight "basic writers." The eight developmental students stay behind after class, for a second "companion" class taught by the same teacher, which meets three hours a week for two credits and is, in essence, a workshop (58). This "companion class" in many ways resembles the studio model, described in a moment. The unique composition of students in the FYC course is purposeful. Adams et al. write that "[w]e think the fact that basic writers are in a class with twelve students who are stronger writers, and perhaps more accomplished students, is an important feature of ALP because these 101-level students frequently serve as role models for the basic writers" (57). ALP's claims to success are high; it purports to "double the number of basic writers who succeed in passing first-year composition ... cut the attrition rate for these students in half ... allowed them to accomplish this in half the time, and has done this at slightly less cost per successful student than traditional basic writing" (Adams et al. 50). Examining data from the late 1980s and early 1990s at then Essex Community College, Adams found that the original institutional problem was not that basic writers were failing their attempts at FYC, it was that students who enrolled in basic writing were giving up before 
ever reaching FYC (52). In fact, he cites that as many as two-thirds of basic writers dropped out (52).

ALP centers on the idea that the less time spent labeled a "basic writer," the more likely a student will stay in school and progress toward a degree. By giving basic writers immediate access to FYC in the company of "stronger" peers, but also providing additional time to process, practice, and discuss, ALP respects the basic writer as deserving of access to college. Adams et al. are right in arguing that basic writers seated in mainstream FYC classrooms feel included, and feel as if the institution believes them ready for college-level work (60). Adams et al. claim further that the stigma of being labeled a basic writer goes away with ALP because of the demographic mix of class, but this may not always be the case. If the companion course meets directly after class, then it is evident who is a basic writer. Equally, if a teacher, say, defers a basic writer's question to companion course time, then they are "outed" to the class. Adams et al. call the mainstream FYC students unwitting "role models," and this verges into dangerous territory. If some students come to see themselves as linguistically superior, and if a teacher sees and works within the imagined divide in the classroom, then the respect given to the basic writers is greatly reduced. If some students are "role models," then the others are there to watch and learn, and this framing does not make space easily for authentic negotiations in which both parties (whether peer pairs or teacher/students) are willing to be changed by the language of another.

Like Glau's stretch, the ALP model also keeps the same teacher for the FYC course and the companion course, giving the teacher a close relationship with the basic writers. Adams et al. call this setup satisfying, in that the small companion course of eight 
becomes a space of true mentorship and one-on-one teaching (58). ${ }^{107}$ This companion course does provide ALP with some programmatic flexibility; since it serves as a kind of ad-hoc workshop, teachers likely hear basic writers' confusions and questions in a way that then impacts their pedagogy in the next FYC class session. Still, this companion course is non-credit bearing (57), and keeping the same instructor for both classes may cause problems such as biased assessment as well as students' difficulty thinking outside of the contexts of their specific writing classroom into writing conventions more broadly.

When the ALP model is taken up only partially, it can lose its potential for translingual-minded learning. Lucas Corcoran and Caroline Wilkinson give such an example in "Translingualism and ALP: A Rhetorical Model for Bordered Latinx Writers." Corcoran and Wilkinson describe New Jersey City University's adaptation of ALP at length in order to critique it, specifically honing their critique on the translingual opportunities lost by NJCU's modified adaptation of Adams et al.'s program. Using SAT scores for placement, the majority of students at NJCU are categorized as developmental, and the authors report over one-third of the population identifying as Hispanic or Latinx (22). If you recall, ALP as conceived by Adams et al. is comprised of two distinct sections: an FYC section of twelve mainstream writers and eight basic writers, and a "companion" class just for the basic writers. Corcoran and Wilkinson write of NJCU's adaptation, in which both of these sections are composed entirely of basic writers. In other words, a group of basic writers takes FYC together, and then they all stay after for the companion studio (23). In essence, this single change transforms ALP into a kind of stretch, since basic writers are simply given more time per week to complete the FYC

\footnotetext{
${ }^{107}$ Glau similarly cites the benefit of maintaining the same teacher over both semesters of stretch, writing that "[e]leven percent of Stretch Program students report that being with the same instructor over two semesters is the "best thing" about the program" ("The Stretch Program" 83).
} 
curriculum. The stretch is just vertical, in the sense of a student's weekly calendar, instead of the horizontal timeline stretch of Glau's program. Corcoran and Wilkinson argue that cordoning off basic writers from the other FYC students, despite the content of both sections being the same, nevertheless gives ALP students at NJCU only partial access to academia.

Additionally, NJCU's ALP adaptation retains the portfolio grading rubric from NJCU's now-dissolved basic writing course, a rubric which grants $25 \%$ weight to grammar, shifting assessors' attention 'toward writers' adherence to or deviance from institutionalized stylistic norms ... reinforc[ing] a norm that writing comprises the decontextualized deployment of a singular language variety that does not need to be rhetorically situated" (Corcoran and Wilkinson 23). Corcoran and Wilkinson claim that the retention of this portfolio grading criteria is NJCU's way of continuing to subtly deploy the deficit model of remediation, effectively preventing "multilingual writers from accessing their full linguistic potential in their written work" (26). Even if NJCU is ALP on paper, the details are key, especially details of placement and the exit crunch that continue to prioritize a standard, stable form of English as available for mastery.

The final model analyzed here is the studio model, described first in Rhonda Grego and Nancy Thompson's 1995 article “The Writing Studio Program: Reconfiguring Basic Writing/Freshman Composition," and taken up more recently in their 2008 Teaching/Writing in Thirdspaces: The Studio Approach. The studio model channels all students into FYC; after a week of class, FYC teachers identify students in need of additional help. These students are then concurrently enrolled in an additional, supplementary class called a Writer's Studio, in which students spend one credited hour a 
week in small groups of four or five workshopping papers and getting tailored feedback. Students may also self select to add the studio to their schedule, as it is advertised to everyone taking mainstream FYC. The thinking behind the latter option is that students themselves are unaware, when attending either class, who is "basic" and who is "mainstream."

The above paragraph likely sounds similar to the ALP model described earlier. Although scholarship has so far not explicitly connected ALP as a form of studio, the similarity between the two models cannot be denied. The differences, however slight, are as follows: studio is a one hour/week course, while ALP is three. Studios are taught not by the teacher but by a "staff group facilitator," purposefully not the same instructor as students' FYC, but in ALP the same instructor teaches both FYC and the companion course. Studios are held in a separate location from the FYC classrooms, whereas, ALP is framed as occurring directly after FYC ends, in the same classroom. Studios are small, described as four to five students, and ALP is slightly larger at eight. ${ }^{108}$ In a studio model, the "staff group facilitator" is in contact with students' FYC teachers through what is called a Dialogue Sheet that gets passed between the two, a step not necessary in ALP. A studio is composed of students from various sections of FYC, while an ALP companion course is a subset of students all from the same FYC section. The content of both the studio and the ALP companion class seem relatively similar: student-centered workshopping, peer review, and conversation.

Studio retains all the translingual benefits of ALP, but its distinctness lends it even more translingual potential. The first translingual aspect unique to studio is the

\footnotetext{
${ }^{108}$ Although these are the course caps listed in Grego and Thompson and Adams et al., the actual number of students in a basic writing studio or ALP companion course varies by institution.
} 
theoretical framing of its purpose and goals. Drawing on theorists Homi Bhabha, Edward Soja, Doreen Massey, and Kris Gutierrez, Grego and Thompson call the studio space a "thirdspace," both a physical and a metaphysical space that disrupts the usual teacher "script" and student "script," in that the teacher-student power relationship is interrupted when students come from various FYC sections and the studio teacher is not the FYC teacher (Teaching/Writing 23). This interruption of the power dynamic creates a new space, the thirdspace, and the discourse of the thirdspace takes on the quality of being "outside but alongside" (Teaching/Writing 69) the discourse of mainstream FYC. In a typical studio class, students lead, presenting work to their classmates and asking for specific feedback (Teaching/Writing 12). In presenting their work, students rephrase teacher instructions, discuss their misunderstandings, concerns, and worries, but since their peers are in different FYC sections, the ensuing discussion is characterized by "questions, observations, and speculations" (Teaching/Writing 74). Discussion in the studio naturally gravitates toward broader, more explicit discussion of language conventions: assignments are negotiated and collaboratively read, and peer review is investigative and exploratory rather than corrective. Grego and Thompson write that students "are encouraged to compare, contrast, define, question, and otherwise collect, as it were, the patterns to be found in the 'moments' represented by each student writer ... over time, lessons are thus generated about the everyday work of student writing" (Teaching/Writing 13). In becoming a space of reflective communication where students "draw generalizations about what the assignments are leading [them] to do and think" (Teaching/Writing 11), studios refine not only students' writing but also their processes and their attitudes, developing what Grego and Thompson call students' "metarhetorical 
awareness" (Teaching/Writing 71). The tentativeness and contextual nature of these discussions aligns with a pedagogy that stresses the emergence of all language conventions; studio students experience how language heterogeneity might be valued by some teachers, in some contexts, but not in others.

Moreover, studios are explicitly described as being more adaptive than ALP. As studio time is spent grappling with the idiosyncratic preferences of various English teachers, studio acknowledges language proficiency as a moving target, with no "one right answer" to suit all student inquiries. Grego and Thompson mention the details of their institutions but insist studio is "an institutionally aware methodology" and "a configuration of relationships" rather than a prescribed pedagogy (Teaching/Writing 7, 21). Schools interested in studios, they write, should think in terms of adaptation rather than adoption. As the programs they themselves developed were dissolved with institutional policy changes, Grego and Thompson are quick to point out that studios are designed "to take advantage of gaps and fissures in institutional landscapes that inevitably shift and change" (Teaching/Writing 25), meaning even a dissolved program served a unique and necessary purpose at the time of its existence. ${ }^{109}$

To my understanding, the key benefit of a studio is in having a teacher distinct from the mainstream FYC teacher. While maintaining the same teacher provides a stable relationship, having a different teacher allows students to step back from their particular classroom context and question writing conventions and language ideologies more broadly. Students can compare their experiences with peers and witness the studio teacher interpret (but not decide) the expectations of assignments which they did not

\footnotetext{
${ }^{109}$ See page 84 of Teaching/Writing in Thirdspaces as well as the 2008 book The Writing Studio Sampler: Stories about Change edited by Mary Sutton and Sally Chandler for specific institutional adaptations of the studio model.
} 
design and will not be evaluating, an act akin to a writing center consultant's interpretation of an instructor's prompt. The teacher can offer a broader perspective, modeling for students how to think about language globally and not as it functions only within an isolated class. Since the studio is not graded but pass/fail based on effort and attendance, the stakes for impressing the teacher are lower and students can express emotions and frustrations that they may otherwise be unwilling to share. Grego and Thompson noted anger and frustration as the chief two emotions experienced by students at having been made to enroll in a studio, but instructors use this conflict as a starting place, employing deep listening to get students talking about their writing lives, repositioning them as agentive users and shapers of language ("The Writing Studio" 7273). Teachers also engage in a "cycle of reflective inquiry" ("The Writing Studio" 73), meeting regularly to converse with other studio teachers in identifying "the larger patterns, possibilities, and needs that arise in the course of Studio work" (Teaching/Writing 13-14).

There is only one aspect of studios that I feel veers from a translingual approach, and that is the element of continued dialogue between the studio teacher and the FYC teacher. Grego and Thompson discuss the use of "Dialogue Sheets," weekly written reports on each student, including information "about the students' life circumstances, writing/learning processes, and written products ... that can help an instructor understand the difficulties a student might be having" ("The Writing Studio" 74). They call these sheets "mediators," in that the process is meant to aid in mutual transfer of knowledge, context, and progress, but it is unclear whether students see or even know about these dialogue sheets. The secrecy of two teachers discussing a student's writing 
without his/her awareness or input thwarts the agency that studio otherwise affords the would-be basic writer and negates the opportunity for authentic negotiation. If constantly monitored, then this subset of students is being more closely observed than the mainstream FYC students. From here, it is only a small step to more intentional and persistent efforts to align these students to a monolingual, monolithic standard, erasing their linguistic difference in the process. Yet, as we have seen, iterations of models at different institutions can both weaken and strengthen the original, and this particular facet of studio is acknowledged and reversed at Katie Malcolm's community college.

Malcolm, in her contribution to Crossing Divides entitled "Disrupting Monolingual Ideologies in a Community College: A Translingual Studio Approach,” points out that despite the translingual potential of studio (which she calls a form of acceleration), it seems to be within a scholarly crossroads. Translingualism, Malcolm writes, is of interest primarily in the four-year institution, and acceleration is celebrated chiefly at the two-year college; the two approaches to basic writing have not yet put in conjunction (102). Her chapter articulates a studio approach in which basic writers from three distinct tracks (one for international students, one for resident ESL students, and one for adult basic education) were given the opportunity to concurrently enroll in FYC and a translingual studio, which was composed of writers from all three remedial tracks, each enrolled in various sections of FYC. Malcolm's institutional data painted a similar portrait to Adams, in that only $48 \%$ of students who had tested into a course only 2 rungs below FYC had enrolled in FYC within two years of beginning their basic writing course (106). Malcolm's solution channels the potential of the studio as a translingual thirdspace, even when students' various FYC courses may reinforce monolingual 
ideologies (108). Malcolm's model addresses the communication between studio teacher and FYC teacher; in her iteration students in the studio could "choose whether or not their 101 instructor would know they were in the acceleration program and thus potentially treat them differently from other English 101 students" (116). Although Malcolm does seem to focus on the international and resident ESL basic writers as ideal recipients of a translingual studio approach, her description of the studio signals the broader potential of translingual approaches to the studio model of basic writing.

\section{Looking Ahead}

When analyzing current scholarship attempting to put into conversation translingualism and basic writing placement practices and course design, a trend similar to one identified in chapter three emerges: the pervasive focus on the multilingual student. As in chapter three, scholarship at this nexus centers attention on translingualism as an applied adaptation to contextual, institutional changes, namely, increasing numbers of international and domestic multilingual students (for instance: Corcoran and Wilkinson, Dryer and Mitchell, Gallagher and Noonan, and Malcolm). To give an example, Gallagher and Noonan argue that Northeastern's globalization initiatives should not have been read by their faculty senate as a lowering of standards but rather an effort to "rethink those standards in light of the fact that our classrooms and university are now polyglot sites of global contact" (164). While shifting demographics may be one reason WPAs are prompted to rethink their programmatic approaches to language, the overrepresentation of ESL students as a reason for considering translingual approaches falsely links translingualism as a way of thinking meant for speakers of multiple 
languages. Moreover, readers whose institutions are not undergoing seismic shifts in demographics might inaccurately believe that translingualism would not apply to their context. Translingualism does not focus on visible, named languages; equally, it does not target students who write and speak in languages other than English as more qualified to benefit from its ideology. Therefore, more scholarship is needed that positions translingualism as suitable and applicable for "monolingual" students, scholarship that addresses how even seemingly conventional, sedimented uses of language may prompt a programmatic restructuring. I think here of the student writer of Bartholomae's "White Shoes" placement essay, whose "tidy, pat discourse allows him to dispose of the question of creativity in such a quick and efficient manner" ("Inventing the University" 20), and whom Bartholomae asserts is less prepared for his education than writers of placement essays containing much more error (20). Could not a preponderance of essays like this spark a conversation about how a translingual approach to placement might shift student energies? $?^{110}$

Another conclusion that emerges in this body of scholarship is that the odds are slim that any given institution will have in place both a placement method and a course structure that honors student agency, values linguistic diversity, and permits a degree of negotiation (whether in reading practices or between actual stakeholders). As Inoue points out, working diligently to implement a translingual-minded approach in one aspect of a student's experience with English/writing courses may have less impact than anticipated if other experiences negate translingual tenets entirely. For instance, a student

\footnotetext{
${ }^{110}$ Lu and Horner's 2013 "Translingual Literacy, Language Difference, and Matters of Agency" takes up a similar question, arguing that the conventionality of the "White Shoes" essay gives it translingual potential. To Lu and Horner, focusing on the impact of the author's recontextualization of the conventional allows one to consider the possibilities enacted by the essay's conventionality.
} 
placed into basic writing by a multiple choice test might understandably push back against a basic writing course that strives to demonstrate to her the validity and power of her language choices that go "against the grain." Certainly this seems like trickery from a student perspective. Why highlight and play with languaging that the very same institution has already used as a basis to punish? I do acknowledge, though, that WPAs only have control over certain aspects of a student experience, and my argument is not meant to assert that any effort toward translinguality is wasted unless an institution is holistically transformed. There are a few examples of programs that $d o$ combine translingual approaches to placement, course design, and pedagogy, such as Southern Illinois Carbondale, detailed by Blakesley, Harvey, and Reynolds, that combines DSP with Stretch, and Inoue at University of Washington Tacoma who combines DSP with labor-based grading assessment. While Adams et al.'s 2009 article on ALP describes using Accuplacer placement, current faculty there have recently posted on WPA-L listserv about pilot efforts to implement DSP.

Looking forward to future translingual possibilities for basic writing placement and programming, WPAs need to stay open minded and creative, as such invention is what birthed the innovative alternatives in place today. A relatively easy (all alternatives considered) opening move for any WPA might be advocating for renaming all writing courses to remove the stigma from basic writing, even if credit cannot be awarded. Kelly Ritter calls such a move "not only a humane and communally responsible act but a practical and efficient one as well, a means by which we might preserve the diversity and dignity of the first-year students ... some [of whom] require [preparation] in different configurations than others" (140). Ritter describes a "menu of course options . . .each 
with equal course credit, each with a small course capacity ... and each with a simple, objective name," (140) such as "Writing 1," "Writing 2," etc. Without the labels remedial, basic, or precollege, Ritter imagines a system in which students may self-place with guidance into any course, repeating, skipping, or even moving backwards as needed, thus exemplifying the programmatic fluidity and flexibility necessary in a translingual approach.

Similarly, Peter Elbow introduced what he calls a "yogurt model" for FYC in his 1997 "Writing Assessment in the Twenty-first Century: A Utopian View," and which he later applies to basic writing in his Directed Self-Placement chapter. A "yogurt model" allows students to "exit the course when they have met the necessary standard or criteria," bringing in new students at an equal pace to contribute to the "ongoing living writing culture" of class ("Directed Self-Placement" 28). Rather than mainstreamed FYC peers serving as role models to basic writers, as is the case in the ALP model, why not allow more advanced basic writers to model skills for new peers? What's to stop programs with multiple, semester-long basic writing courses to consider a multitude of "crunch" exit points? A student may consider themselves proficient before the official end of a course, and could demonstrate this belief through a portfolio process or conference with their teacher or WPA. Expanding the crunch points would prove to students that basic writing is not a waiting game or a cooling-out trap. What would it say to students if they could, with guidance, not only place themselves in basic writing, but place themselves out as well?

At the end of the day, even programs that on paper or in theory subscribe to translingual principles may still reinforce monolingualism, as seen in some of the 
pedagogies described in chapter three. As Corcoran and Wilkinson wrote of the ALP program at New Jersey City University, even if programmatic structures change to allow space for translingual negotiation, monolingualism may still reign. When courses are primarily taught by adjuncts who have no access to professionalization and no compensated time to reconfigure their courses, the lack of "top-down controls mandating a certain way of treating language and literacy" will result in the endurance of a monolingual ideology, since it "is an embedded belief system that keeps perpetuating itself" (34). Every pedagogy, even the teaching of grammar, has translingual potential, because translingualism is an attitude and a mindset. In the same way, every basic writing course structure can be approached from a translingual perspective. Those already designed from the onset to allow such a perspective to thrive, however, create the most space for ongoing negotiation and student agency. 


\section{CONCLUSION}

This dissertation aimed to make space for translingual basic writing, while at the same time emphasizing that translingual principles have long been a subcurrent in basic writing's past. While the term itself may be novel, the tenets of a translingual ideology have been in many ways fundamental to the development of basic writing theory. For instance, Shaughnessy's Errors and Expectations, likely the most quintessential basic writing text, was revolutionary to the field precisely because of its transferal of power (however small) away from the teacher and toward the basic writer. Shaughnessy acknowledged that the strange, almost unapproachable texts she and her colleagues encountered were not evidence of an underdeveloped mind, but rather evidence of effort and of idiosyncratic logic. Her fundamental claim is, in essence, translingual: that the goal of writing education should not be to denigrate language that differs from "standard English," but to study the breadth of a basic writer's repertoire, and help students study themselves in turn.

Basic writing has always been a study of language, and the field's approach to the teaching of basic writers hinges on the language ideology subscribed to by its practitioners at any given time. While basic writing may see its evolutions as par for the course, from an emphasis on cognitive psychology to a sociocultural approach, to then a postmodern fracture of consensus, in truth these evolutions are not so much a reflection

of field-specific turns of thought but rather changes in the way language itself is theorized 
and mobilized in American society. My project begins by tracing these evolutions, linking shifts in basic writing theory to shifts in language ideologies over time.

By separating the study of basic writing from the pedagogical imperative, chapter one asserted the study of both theory and ideology as essential for the practice of basic writing professionals. If a pedagogue wants to embrace a translingual understanding of language, then requisite to that understanding is grasping how translingualism challenges a standard language ideology in the basic writing classroom. Chapter one mapped the historical progression of the field's conception of who basic writers are, how they are designated, what abilities they have, and what their so-called differences mean and do. To accomplish this, I identified parallels between language ideologies and approaches to basic writing, using Brian Street and Mary Lea's models of literacy to forge the connections. Thus chapter one, while centering on the exigencies of the basic writing classroom, was also a conversation about literacy studies, sociolinguistics, and rhetoric and composition at large.

Lea and Street's literacy models articulate how the educational approach to literacy has shifted over time, as the monolithic concept of literacy has slowly chipped away in favor of acknowledging the agency of students themselves. Street described (in order to critique) the model of autonomous literacy, which reifies literacy as a uniform, discrete, obtainable skill that can be grasped by students under the right conditions (Literacy in Theory and Practice). The idea of autonomous literacy aligns with monolingualism's claim to languages as internally uniform, discrete, and obtainable, and that ideology's belief that the standard is the key to individual and social success. Autonomous literacy also aligns with the early cognitivists of basic writing, who saw the 
minds of basic writers as yet incapable of understanding the linguistic tools at their disposal. In contrast, Street's ideological literacy (the theory he himself forwards) points toward a diametrically opposite approach, and focuses on the power imbalances and marginalization inherent in any literacy campaign ("What's 'New' in New Literacy Studies?"). In the ideological model of literacy, language ideologies are highlighted and examined, and literacy is viewed as a social practice. My project begins to forge the link between translingualism as an example of and extension beyond Street's ideological literacy, an effort that would benefit from deeper analysis in a separate project.

Street had begun to imagine the future of ideological literacy as examining closely a writer's linguistic habitus. Similarly, a translingual disposition is the subject of increasing interest in translingual scholarship, as evidenced by the 2020 Translingual Dispositions: Globalized Approaches to the Teaching of Writing edited by Alanna Frost, Julia Kiernan, and Suzanne Blum Malley, as well as other work in the same vein (see Sohan's "Relocalized Listening," Guerra's “Cultivating a Rhetorical Sensibility," Hanson's "Moving Out of the Monolingual Comfort Zone," and Lorimer Leonard, "Multilingual Writing"). I had hoped to integrate this scholarship as well as the 2011 Framework for Success in Postsecondary Writing (created and endorsed by NCTE, CWPA, and NWP) in an exploration of the translingual "habits of mind" that would benefit the basic writer. Unfortunately, this initiative was cut from the final version, as I discovered this project could warrant a dissertation of its own.

The reader also met Ryan in my first chapter, a student whose writing I chose for inclusion not for any remarkable, cosmopolitan flair, but for its utilitarian and sparse style. The majority of student writing cited in work on translingualism is chosen because 
of its code-meshing, or otherwise unique linguistic constructions that purportedly highlight the interplay between named languages as a multilingual student writes. A major theme in this dissertation is the importance of widening the translingual conversation to include the so-called monolingual English speaker as every bit as capable of adopting a translingual mindset, and producing writing that reflects that mindset. This is why I chose Ryan and Leah. Their writing represents neither the bewildering and alien writing of the basic writers of Shaughnessy's open admissions of 1970s CUNY, nor the exotic and interesting code-meshed student writing of interest in scholarship by Canagarajah, Wang, or MacDonald and DeGenaro. Ryan and Leah are the everyman freshman, the bread and butter. They are the writers who fill the majority of seats in many basic writing classrooms, especially in less urban settings. Karen Kopelson writes in her afterword to Reworking English Rhetoric and Composition of classrooms in which the multilingual future seems to be "much slower arriving and further away" than it is for scholars who write of institutions inundated with international and multilingual speakers (210). Kopelson admits that even for herself, the privilege of such insularity makes resisting and even ignoring translingualism more permissible, as pedagogues can convince themselves that the multilingual reality is not yet the reality of their institution. Yet if one separates altogether the idea of translingualism from multilingualism, its affordances increase tenfold.

While I certainly do not discount the value of translingualism for ESL and multilingual basic writers, translingualism is more than capacious enough for broader adoption. As a theory, and not a teaching method, translingualism can impact any space where students are writing and reading. In chapter three, I highlighted the extant works 
that do begin to conceptualize the translingual potential of so-called monolingual basic writers, most successfully Vanessa Kraemer Sohan's “Relocalized Listening” and Aimee Krall-Lanoue's ““And Yea I’m Venting, But Hey I'm Writing Isn't I’: A Translingual Approach to Error in a Multilingual Context." Still, even Krall-Lanoue's work glosses over the fact that the students whose writing she featured are monolingual basic writers; it is not a central theme of her work. Moreover, works that address the monolingual student represent but a small fraction of the scholarship on translingualism. By including the writing of Ryan and Leah in chapter three, I demonstrated that students who are not obvious speakers of other languages nevertheless have vast and rich funds of linguistic knowledge that give them plenty to notice when writing from a translingual mindset. I hope this has contributed to the scant conversation on "monolingual" translingualism, but this is an avenue that warrants further development.

Of course, the "monolingual" basic writer has been, arguably, the subject of most basic writing scholarship since the discipline's infancy, namely, in the identification and eradication of common errors. The analysis of the logic of error in the pages of Errors and Expectations, as well as the error analyses of scholars like Robert Connors, Andrea Lunsford, Karen Lunsford, Barry Kroll, John Schafer, and Richard Haswell, has focused on the errors of (mostly monolingual) basic writers in order to devise more effective and appropriate ways of assisting students in correcting their error. In this body of work, the writing of Ryan and Leah feels like familiar territory. Yet my third chapter exposed the reader to more of Ryan and Leah's writing in order to ask a very different question: How can we call attention to language difference in a way that preserves student agency and maintains for students the possibility of choice? By reading from this frame of mind, the 
basic writing teacher is reminded that they play the starring role in the making of error; that is, in turning an utterance on the page into an error and giving it the consequences of being erroneous.

Chapter two worked to dislodge the source of error from the textual page and place it instead in the mind of the reader, equally dislodging the ownership of any error from the writer alone to a shared ownership between reader and writer. Thus, to understand how error works within basic writing, the reading environment must be scrutinized. This work is necessary to understand how errors come to be, and how teachers respond to them. Demonstrating, through the work of scholars such as Joseph Williams, Elaine Lees, and Min-Zhan Lu, that error is idiosyncratic, and therefore contextual, creates space for the imagining of error as a personal negotiation and not a cold, hard truth. Lees's ““The Exceptable Way of the Society': Stanley Fish's Theory of Reading and the Task of the Teacher" explores what pedagogues are doing when they read for error, finding that the interpretive community of teacher-readers is heterogeneous and rather unpredictable, leading Lees to conclude that each reader "writes" error into student texts in an individual way. Through their examples of moments in which readers do and do not "see" error on the page given vastly different contextual constraints, Williams, Lees, and Lu prove that it is the rhetorical situation of the reading environment, rather than the reality of any orthographic mark, that determines the existence and importance of error.

If the recognition of error depends in part on the ascribed social status of the writer (and by contrast, that of the reader), and if some error can be invention while other errors are evidence of ignorance, then the project of correcting student texts is thrown 
into question. Moreover, the act of zooming out from the page in consideration of error destabilizes basic writing as a concept, which was created, arguably, for the more efficient elimination of student error. If error does not exist outside of teachers' investment in their existence, then examining this pedagogical investment works further backwards to understand why teachers feel compelled to eradicate error with such vehemence. This investment in language difference persists even in scholarship aiming to take up translingualism, albeit in nontraditional ways. Understanding how language difference is taken up, and with what aims, was a chief goal of chapter three.

Chapter three contributed to the idea that translingualism, rather than a threat to the teaching of standards or correcting of error, offers a different and more nuanced way to do both. I began this chapter, as I did chapter four, by outlining translingual principles for a basic writing pedagogy, based on theoretical work on translingualism in rhetoric and composition and sociolinguistics. That is, I described the utopian translingual pedagogy as conceived theoretically. I then held up three bodies of scholarship to these principles: basic writing scholarship that already takes up translingualism, translingual scholarship on mainstream FYC that may still be applicable to the basic writer, and basic writing scholarship from before the coinage of the term translingualism. This process of holding up scholarship against translingual principles revealed avenues in which scholarship on pedagogy was breaking new ground, as well as avenues in which scholars continued to uphold a monolingual ideology even while striving for translingual ends.

While across the board scholarship re-evaluating language difference actively acknowledges the agency of all writers, including basic writers, translingual basic writing scholarship often falls back into multilingual, and even monolingual ideologies. By this I 
mean that scholars of this set often frame translingualism as needing to be implemented because of sudden waves of multilingual students, and therefore, as a pedagogy focused on multilingual recipients. The pedagogical activities that result from such a mindset treat languages as discrete and separate, often asking students to "perform" translinguality through visible code-meshing that can be noticed and admired by teachers. Translingual scholarship that more broadly considers FYC aligns more closely with translingual principles in its self-critique of the desire for code-meshing and its admittance of monolingual students into the translingual sphere of influence. The "how" of negotiating language difference, interestingly enough, is rarely explored in translingual FYC scholarship, but is a strength of basic writing scholarship before translingualism was a term taken up. Texts like Facts, Artifacts, and Counterfacts (1986) work diligently to show teachers what the process of negotiating language difference looks like, from images of page annotations to transcripts of student conferences and class workshops. Still, future scholarship on translingualism, especially in basic writing circles, would do well to start from a deep place of translingual reflection, as concrete pedagogical examples without a foundation in translingual tenets is food that will not sustain.

As I pointed out in chapter three, one area that has seen barely any attention is the translingual potential of conventional, standard English. With the exception of Bruce Horner's 2011 "Relocating Basic Writing," I cannot find that the idea (that the conventional language of basic writers can nevertheless be the product of translingual reflection and negotiation) has been explored anywhere. Even my own arguments rely heavily on the language "difference" of students like Ryan and Leah, sedimenting unwittingly the idea that language must stand out as unusual to merit attention in a 
translingual pedagogy. This is not the case, yet the task of describing the translingual potential of conventionality seems a difficult one not yet undertaken by many scholars. Even if scholars believe that sedimentation of the same is still a repetition with a difference, in that the utterance has occurred in a unique time, place, and context (as described by Lu and Horner in their "Translingual Literacy"), how to teach this process to students as translingual (or whether this should be undertaken at all) is a complex and valuable concept that merits future study.

Mirroring chapter three, chapter four extended the process of holding basic writing placement and programmatic approaches up to my conception of how such practices might look in a translingual expression. The findings in many ways were similar to chapter three, in that new initiatives in basic writing, such as directed self-placement and accelerated learning, do fundamentally aim to restore the agency to basic writers that earlier iterations (such as standardized testing and multi-semester basic writing course sequences) took away. In this sense, basic writing's effort to mainstream all students is a move that aligns the field closer to translingualism than to monolingualism. When mainstreaming is done right, the student is viewed as a decision-maker, whose language repertoire is not sub-par but rather in need of additional time and space to explore the expectations of academic discourse. Interestingly, the pitfalls of even the most current placement and programmatic efforts echo the cognitivism of old: the basic writer as needing more time to think than the average writer, and their language as in need of extra monitoring. As with translingual basic writing pedagogy, basic writing placement and program practices aimed at accommodating language difference overwhelmingly assume that the question of language difference is pertinent only to multilingual writers. 
While chapter four was about the possibilities of translingual basic writing placement and programming, it is important to note that almost none of the scholarship describing current initiatives actually claims to be translingual. I only encountered two works that take up the term: Lucas Corcoran and Caroline Wilkinson's "Translingualism and ALP: A Rhetorical Model for Bordered Latinx Writers," and Katie Malcolm's "Disrupting Monolingual Ideologies in a Community College: A Translingual Studio Approach." Herein lies a host of opportunities that the scope of my project did not allow adequate investigation into; for instance, there is no scholarship on directed selfplacement as an explicitly translingual practice, not only in its directives but in its servicing of exponentially more monolingual students than multilingual. As more and more institutions explore mainstreaming options that provide all admitted students with FYC content in some form, the need is clear for more scholarship on the benefits of adopting a translingual mindset when implementing programmatic change.

As a whole, my project has tried to bring together disparate conversations on the fringes of rhetoric and composition (often even, outside of it) in order to begin to amass an understanding of the possibilities of translingual basic writing. More specifically, my unique contribution lies in purposefully moving away from the notion of translingualism as meant for speakers of multiple languages, and which must always result in language on the page that evidences those languages. It is this small, unpopulated theoretical space that I hope this project has shed light on, in its argument that translingualism is much more capacious than many take it to be when they claim it as their theoretical framework. Taking up translingualism from a narrow-minded mindset does more damage than good, 
as practices that in truth reinforce monolingual ideologies are rebranded and repackaged as "translingual" for mere visibility.

Instead, I have asked the reader to consider the possibility, and even likelihood, that every basic writer and every teacher of basic writing is fully capable of adopting a translingual mindset and producing texts that reflect that mindset. They are all capable just as they are, with linguistic resources accumulated over years of communicating, writing, and reading on this planet. We all have repertoires much larger than we are aware of, and certainly larger than anything that appears on paper. When both the basic writing teacher and the basic writer can reflect on their languaging and the language difference they may notice in themselves, a kind of connection is forged in this mutual work that transcends the number of languages anyone can speak, just as it transcends the context of a single class or institution. Lessons of language, both given and received in the basic writing classroom, model the reflective negotiation that equips any writer to simultaneously draw down on and deepen their linguistic resources. Imagining the scope of language from this mindset expands what is possible for basic writing. 


\section{REFERENCES}

Adams, Peter Dow. "Basic Writing Reconsidered." Journal of Basic Writing, vol. 12, no. 1, 1993, pp. 22-36.

Adams, Peter Dow, Sarah Gearhart, Robert Miller, and Anne Roberts. "The Accelerated Learning Program: Throwing Open the Gates." Journal of Basic Writing, vol. 28, no. 2, 2009, pp. 50-69.

Agnew, Eleanor and Margaret McLaughlin. "Those Crazy Gates and How They Swing: Tracking the System that Tracks African-American Students.” Mainstreaming Basic Writers: Politics and Pedagogies of Access, edited by Gerri McNenny, Lawrence Erlbaum Associates, 2008, pp. 87-104.

“All Position Statements.” National Council of Teachers of English, https://ncte.org/resources/position-statements/all/ Accessed 6 Mar 2021.

Althusser, Louis. Lenin and Philosophy and Other Essays. Translated by Ben Brewster, Monthly Review Press, 1971.

Alvarez, Sara. “Composition Rhetoric Translingual Turn: Multilingual Approaches to Writing. International Journal of the Sociology of Language, vol. 2016, no. 241, 2016, pp. 155-161.

Anzaldúa, Gloria. Borderlands/La Frontera: The New Mestiza. Aunt Lute Books, 1987. 
Arendale, David. "Then and Now: The Early Years of Developmental Education." Research and Teaching in Developmental Education, vol. 27, no. 2, 2002, pp. 5876.

Arnold, Lisa R. “'This is a Field that's Open, not Closed': Multilingual and International Writing Faculty Respond to Composition Theory.” Composition Studies, vol. 44, no. 1,2016 , pp. $72-88$.

Atkinson et al., "Clarifying the Relationship between L2 Writing and Translingual Writing: An Open Letter to Writing Studies Editors and Organization Leaders.” College English, vol. 77, no. 4, 2015, pp. 383-86.

Baker-Bell, April, et al. “This Ain't Another Statement! This is a DEMAND for Black Linguistic Justice.” Conference on College Composition and Communication, hosted by National Council of Teachers of English. July 2020. https://cccc.ncte.org/cccc/demand-for-black-linguistic-justice

Bartholomae, David. "Inventing the University.” Journal of Basic Writing, vol. 5, no. 1, 1986, pp. 4-23.

---. "Teaching Basic Writing: An Alternative to Basic Skills." Journal of Basic Writing, vol. 2, no. 2, 1979, pp. 85-109.

---. "The Study of Error.” College Composition and Communication, vol. 31, no. 3, 1990, pp. 253-269.

---. "The Tidy House: Basic Writing in the American Curriculum.” Journal of Basic Writing, vol. 12, no. 3, 1993, pp. 4-21. 
---. Writing on the Margins: Essays on Composition and Teaching. Bedford/St. Martin's, 2005.

---. "Writing on the Margins: The Concept of Literacy in Higher Education." $A$ Sourcebook for Basic Writing Teachers, edited by Theresa Enos, Random House, 1987, pp. 66-83.

Bartholomae, David and Anthony Petrosky. Facts, Artifacts, and Counterfacts: Theory and Method for a Reading and Writing Course. Boynton/Cook Publishers, 1986.

Batstone, Rob. "Key Concepts in ELT: Noticing." ELT Journal, vol. 50, no. 3, 1996, pp. 273.

Bawarshi, Anis. "Beyond the Genre Fixation: A Translingual Perspective on Genre." College English, vol. 78, no. 3, 2016, pp. 243-249.

---. Genre and the Invention of the Writer. Utah State University Press, 2003.

---. "The Challenges and Possibilities of Taking Up Multiple Discursive Resources in U.S. Composition." Cross Language Relations, edited by Bruce Horner, MinZhan Lu and Paul Matsuda, Southern Illinois University Press, 2010, pp. 196-203.

Bazerman, Charles and Paul Prior. "Participating in Emergent Socio-Literate Worlds: Genre, Disciplinarity, and Interdisciplinarity." Multidisciplinary Perspectives on Literacy Research, 2nd ed, edited by Richard Beach, Hampton Press, 2005.

Beason, Larry. "Ethos and Error: How Business People React to Errors." College Composition and Communication, vol. 53, no. 1, 2001, pp. 33-64.

Berlin, James. "Rhetoric and Ideology in the Writing Class." College English, vol. 50, no. 5, 1988, pp. 477-94. 
Bernstein, Basil. "Social Class, Linguistic Codes and Grammatical Elements." Language and Speech, vol. 5, no. 4, 1962, pp. 221-40.

Bernstein, Basil and Dorothy Henderson. "Social Class Differences in the Relevance of Language to Socialization." Sociology, vol. 3, no. 1, 1969, pp. 1-20.

Berthoff, Ann. "Towards a Pedagogy of Knowing." Freshman English News, vol. 7, 1978, pp. 1- 4, 12-13.

Bhabha, Homi K. The Location of Culture. Routledge, 1994.

Bizzell, Patricia. "Basic Writing and the Issue of Correctness, or, What to Do with “Mixed” Forms of Academic Discourse.” Journal of Basic Writing, vol. 19, no. 1, 2000, pp. 4-12.

---. "Cognition, Convention, and Certainty: What We Need to Know About Writing." Pre/Text, vol. 3, no. 3, 1982, pp. 213-244.

---. "College Composition: Initiation into the Academic Discourse Community." Curriculum Inquiry, vol. 12, no. 2, 1982, pp. 191-207.

---. "What Happens When Basic Writers Come to College?" College Composition and Communication, vol. 37, 1986, pp. 294-301.

Blakesley, David. "Directed Self-Placement in the University." Writing Program Administration, vol. 25, no. 3, 2002, pp. 9-40.

Blakesley, David, Erin Harvey and Erica Reynolds. "Southern Illinois University Carbondale as an Institutional Model: The English 100/101 Stretch and Directed Self-Placement Program.” Directed Self-Placement: Principles and Practices, edited by Daniel Royer and Roger Gilles, Hampton Press, 2003, pp. 207-242. 
Bourdieu, Pierre. Language and Symbolic Power. Translated by Gino Raymond and Matthew Adamson, edited by John B. Thompson, Cambridge University Press, 1991.

---. Outline of a Theory of Practice. Cambridge University Press, 1977.

Boyd, John. Destruction and Creation, U.S. Army Command and General Staff College, 1976.

Britton, James, Tony Burgess, Nancy Martin, Alex McLeod, and Harold Rosen. The Development of Writing Abilities. Macmillan, 1975.

Brown, Danika. "Hegemony and the Discourse of the Land Grant Movement: Historicizing as a Point of Departure." JAC, vol. 23, 2003, pp. 319-49.

Butler, Judith. Excitable Speech: A Politics of the Performative. Routledge, 1997. Calvet, Louis-Jean. Towards an Ecology of World Languages. Translated by Andrew Brown. Polity, 2006.

Canagarajah, Suresh. Resisting Linguistic Imperialism in English Teaching. Oxford University Press, 1999.

---. Translingual Practice: Global Englishes and Cosmopolitan Relations. Routledge, 2013.

---. "World Englishes as Code-meshing." Code-meshing as World Englishes: Pedagogy, Policy, Performance, edited by Vershawn Ashanti Young and Aja Martines, National Council of Teachers of English, 2011, pp. 273-281.

Chen, Xianglei and Sean Simone. Remedial Coursetaking at U.S. Public 2- and 4-Year Institutions: Scope, Experiences, and Outcomes. U.S. Department of Education. 
Washington, DC: National Center for Education Statistics. 2016. Retrieved http://nces.ed.gov/pubsearch.

Clark, Burton. "The Cooling-Out Function in Higher Education." American Journal of Sociology, vol. 65, 1960, pp. 569-76.

Coles, Nicholas. "Empowering Revision." Facts, Artifacts, and Counterfacts: Theory and Method for a Reading and Writing Course, edited by David Bartholomae and Anthony Petrosky, Boynton/Cook Publishers, 1986, pp. 167-198.

Collins, Terence G. “A Response to Ira Shor's 'Our Apartheid: Writing Instruction and Inequality."' Journal of Basic Writing, vol. 16, no. 2, 1997, pp. 95-100.

Common European Framework of Reference for Languages: Learning, teaching, assessment. Council of Europe, Cambridge University Press, 2001.

Conference on College Composition and Communication. CCCC Guideline on the National Language Policy. National Council of Teachers of English. NCTE, 1988; updated 1992.

---. CCCC Statement on Second Language Writing and Writers. National Council of Teachers of English. NCTE, 2001; revised Nov. 2009.

---. Students' Right to Their Own Language. National Council of Teachers of English. NCTE, 1974.

Connors, Robert, and Andrea Lunsford. "Frequency of Formal Errors in Current College Writing, or Ma and Pa Kettle Do Research.” College Composition and Communication, vol. 39, no. 4, 1988, pp. 395-409. 
Corcoran, Lucas. “'Languaging 101': Translingual Practices for the Translingual Realities of the SEEK Composition Classroom." Journal of Basic Writing, vol. 36, no. 2, 2017, pp. 54-77.

Corcoran, Lucas and Caroline Wilkinson. "Translingualism and ALP: A Rhetorical Model for Bordered Latinx Writers.” Bordered Writers: Latinx Identities and Literacy Practices at Hispanic-Serving Institutions, edited by Isabel Baca, Yndalecio Isaac Hinojosa, and Susan Wolff Murphy, SUNY Press, 2019, pp. 1936.

Corkran, Gerald. "Report on the State of Politics in Developmental Education." 12 Nov 1995.

Cornell, Cynthia and Robert Newton. "The Case of a Small Liberal Arts University: Directed Self-Placement and DePauw." Directed Self-Placement: Principles and Practices, edited by Daniel Royer and Roger Gilles, Hampton Press, 2003, pp. $149-178$.

Council of Writing Program Administrators et al. "Framework for Success in Postsecondary Writing.”Jan. 2011, http://wpacouncil.org/files/framework-forsuccess-postsecondary-writing.pdf

Coupland, Nikolas. "Sociolinguistic Prevarication about 'Standard English." Journal of Sociolinguistics, vol. 4, no. 4, 2000, pp. 622-34.

Cummins, Jim. "Foreword." Language Ideologies: Critical Perspectives on the Official Language Movement. Volume I: Education and the Social Implications of Official Language, edited by Roseann Dueñas González and Ildikó Melis, National Council of Teachers of English, 2000, pp. ix-xxi. 
D’Angelo, Frank J. “Literacy and Cognition: A Developmental Perspective.” Literacy for Life: The Demand for Reading and Writing. Ed. Richard W. Bailey and Robin Melanie Fosheim, MLA, 1983.

Danzig, Arnold. "Applications and Distortions of Basil Bernstein's Code Theory." Knowledge and Pedagogy: The Sociology of Basil Bernstein, edited by Alan Sadovnik, Ablex, pp. 145-70.

Darabi, Rachelle. "Basic Writers and Learning Communities." Journal of Basic Writing, vol. 25 , no. 1,2006 , pp. 53-72.

DasBender, Gita. “Assessing Generation 1.5 Learners: The Revelations of Directed Self Placement." Writing Assessment in the 21st Century: Essays in Honor of Edward M. White, edited by Norbert Eliot and Les Perelman, Hampton Press, 2011, pp. $371-84$.

De Costa Peter et al. "Pedagogizing Translingual Practice: Prospects and Possibilities." Research in the Teaching of English, vol. 51, no. 4, 2017, pp. 464-72.

DeGenaro, William. "Class Consciousness and the Junior College Movement: Creating a Docile Workforce." JAC, vol. 21, 2001, pp. 499-520.

D'Eloia, Sarah. "Teaching Standard Written English.” Journal of Basic Writing, vol. 1, no. 1, 1975, pp. 5-13.

Delpit, Lisa. Other People's Children: Cultural Conflict in the Classroom. The New Press, 2006.

Derrida, Jacques. “Structure, Sign, and Play.” Macksey \& Donato, 1970. 
Dickler, Jessica. "Free college is now a reality in nearly 20 states." CNBC, 15 Dec 2018, https://www.cnbc.com/2018/12/14/free-college-is-now-a-reality-in-nearly-20states.html

Donahue, Patricia and Ellen Quandahl. "Reading the Classroom." Reclaiming Pedagogy: The Rhetoric of the Classroom, edited by Patricia Donahue and Ellen Quandahl, Southern Illinois University Press, 1989, pp. 1-16.

Dryer, Dylan. "At a Mirror, Darkly: The Imagined Undergraduate Writers of Ten Novice Composition Instructors." College Composition and Communication, vol. 63, no. 3, 2012, pp. 420-52.

Dryer, Dylan B. and Paige Mitchell. "Seizing an Opportunity for Translingual FYC at the University of Maine: Provocative Complexities, Unexpected Consequences.” Crossing Divides: Exploring Translingual Writing Pedagogies and Programs, edited by Bruce Horner and Laura Tetreault, Utah State University Press, 2017, pp. 135-60.

Duckworth, Angela. Grit: The Power of Passion and Perseverance. Simon and Schuster, 2016.

Dykema, Karl. "Criteria of Correctness." College English, vol. 1, no. 7, 1940, pp. 616-23. Elbow, Peter. "Directed Self-Placement in Relation to Assessment: Shifting the Crunch from Entrance to Exit.” Directed Self-Placement: Principles and Practices, edited by Daniel Royer and Roger Gilles, Hampton Press, 2003, pp. 15-30.

---. "Writing Assessment in the Twenty-first Century: A Utopian View." Composition in the $21^{\text {st }}$ Century: Crisis and Change, edited by William Lutz, Edward White, and Sandra Kamusikiri, Modern Language Association, 1997, pp. 120-34. 
"Enrollment." IEE: The Power of International Education. https://www.iie.org/Researchand-Insights/Open-Doors/Data/International-Students/Enrollment

Epes, Mary. "Tracing Errors to their Sources: A Study of the Encoding Processes of Adult Basic Writers." Journal of Basic Writing, vol. 4, no. 1, 1985, pp. 4-33.

Farrell, Thomas. "Developing Literacy: Walter J. Ong and Basic Writing." Journal of Basic Writing, vol. 2, no. 1, 1978, pp. 30-51.

---. "IQ and Standard English." College Composition and Communication, vol. 34, no. 4, 1983, pp. 470-484.

---. "Literacy, the Basics, and All That Jazz." College English, vol. 38, 1977, pp. 443-59.

---. "Open Admissions, Orality, and Literacy." Journal of Youth and Adolescence, vol. 3, 1974, pp. 247-60.

Fish, Stanley. Is There a Text in This Class? The Authority of Interpretive Communities. Harvard University Press, 1982.

Fisher, John. The Emergence of Standard English. University Press of Kentucky, 1996.

Fishman, Rachel. 2015 College Decisions Survey Part One: Deciding to Go to College. New America's Education Policy Program. May 2015. Retrieved from https://www.luminafoundation.org/files/resources/deciding-to-go-to-college.pdf

Fleming, David. From Form to Meaning: Freshman Composition and the Long Sixties. University of Pittsburgh Press, 2011.

Flower, Linda and John R. Hayes. "A Cognitive Process Theory of Writing.” College Composition and Communication, vol. 31, 1980, pp. 365-87.

Foucault, Michel. Language, Counter-Memory, Practice: Selected Essays and Interviews, Edited and translated by Donald Bouchard, Cornell University Press, 1977. 
Fox, Tom. "Basic Writing as Cultural Conflict." The Journal of Education, vol. 172, no. 1, 1990, pp. 65-83.

---. Defending Access: A Critique of Standards in Higher Education. Boynton/Cook, 1991.

Friedrich, Patricia. "Assessing the Needs of Linguistically Diverse First-Year Students: Bringing Together and Telling Apart International ESL, Resident ESL, and Monolingual Basic Writers.” Writing Program Administration, vol. 30, no. 1-2, 2006, pp. 15-36.

Friend, Christy. "The Excluded Conflict: The Marginalization of Composition and Rhetoric Studies in Graff's Professing Literature." College English, vol. 54, no. 3, 1992, pp. 276-86.

Frost, Alanna, Julia Kiernan, and Suzanne Blum Malley, editors. Translingual Dispositions: Globalized Approaches to the Teaching of Writing. University Press of Colorado, 2020.

Gabelnick, Faith et al. Learning Communities: Creating Connections Among Students, Faculty, and Disciplines. Jossey-Bass, 1990.

Gallagher, Chris and Matt Noonan. "Becoming Global: Learning to 'Do' Translingualism." Crossing Divides: Exploring Translingual Writing Pedagogies and Programs, edited by Bruce Horner and Laura Tetreault, Utah State University Press, 2017, pp. 161-77.

Ganga, Elizabeth and Amy Mazzariello. "Modernizing College Course Placement by Using Multiple Measures." Education Commission of the States' Center for the 
Analysis of Postsecondary Readiness, April 2009, https://files.eric.ed.gov/fulltext/ED594092.pdf

Gee, James. "Literacy, Discourse, and Linguistics: Introduction.” Journal of Education, vol. 171 , no. 1,1989 , pp. 5-17.

Gevers, Jeroen. "Translingualism Revisited: Language Difference and Hybridity in L2 Writing." Journal of Second Language Writing, vol. 40, 2018, pp. 73-83.

Gibson, Michelle, and Deborah T. Meem. "The Life and Death and Life of a College, a Department, \& a Basic Writing Program.” Basic Writing in America: The History of Nine College Programs, edited by Nicole Pepinster Greene and Patricia J. McAlexander, Hampton Press, 2008, pp. 49-70.

Giddens, Anthony. Central Problems in Social Theory: Action, Structure and Contradiction in Social Analysis. University of California Press, 1979.

Gilyard, Keith. "Basic Writing, Cost Effectiveness, and Ideology.” Journal of Basic Writing, vol. 19, no. 1, 2000, pp. 36-42.

Glau, Gregory. "Stretch at 10: A Progress Report on Arizona State University's Stretch Program." Journal of Basic Writing, vol. 26, no. 2, 2007, pp. 30-48.

---. “The 'Stretch Program': Arizona State University's New Model of University-level Basic Writing Instruction.” Writing Program Administration, vol. 20, no. 1-2, 1996, pp. 79-91.

Gleason, Barbara. "Remediation Phase-Out at CUNY: The 'Equity Versus Excellent' Controversy." College Composition and Communication, vol. 51, no. 3, 2000, pp. $488-91$. 
Godkin, Edwin Lawrence. “The Illiteracy of American Boys.” Educational Review, vol. 13, 1897, pp. 1-9.

Goen-Salter, Sugie. "Critiquing the Need to Eliminate Remediation: Lessons from San Francisco State.” Journal of Basic Writing, vol. 27, no. 2, 2008, pp. 81-105.

González, Roseann Dueñas. “Introduction.” Language Ideologies: Critical Perspectives on the Official Language Movement. Volume I: Education and the Social Implications of Official Language, edited by Roseann Dueñas González and Ildikó Melis, National Council of Teachers of English, 2000, pp. xxvii-1.

Gorrell, Donna. "Controlled Composition for Basic Writers." College Composition and Communication, vol. 32, no. 3, 1981, pp. 308-16.

Graff, Harvey. The Literacy Myth: Literacy and the Social Structure in the NineteenthCentury City. Academic Press, 1979.

Greenbaum, Sidney, and John Taylor. "The Recognition of Usage Errors by Instructors of Freshman Composition." College Composition and Communication, vol. 32, no. 2, 1981, pp. 169-74.

Greenberg, Karen. “A Response to Ira Shor’s 'Our Apartheid: Writing Instruction and Inequality." Journal of Basic Writing, vol. 16, no. 2, 1997, pp. 90-94.

---. “The Politics of Basic Writing.” Journal of Basic Writing, vol. 12, no. 1, 1993, pp. 64-71.

Greenberg, Karen, Patrick Hartwell, Margaret Himley and R.E. Stratton. "Responses to Thomas J. Farrell's 'IQ and Standard English."' College Composition and Communication, vol. 35 , no. 4, 1984, pp. 455-69. 
Greene, Nicole Pepinster, and Patricia J. McAlexander. Basic Writing in America: The History of Nine College Programs. Hampton Press, 2008.

Grego, Rhonda and Nancy Thompson. "The Writing Studio Program: Reconfiguring Basic Writing/Freshman Composition.” Writing Program Administration, vol. 19, no. $1-2,1995$, pp. 66-79.

---. Teaching/Writing in Thirdspaces: The Studio Approach. Southern Illinois University Press, 2007.

Guerra, Juan. "Cultivating a Rhetorical Sensibility in the Translingual Classroom." College English, vol. 78, no. 3, 2016, pp. 228-33.

---. "Putting Literacy In Its Place: Nomadic Consciousness and the Practice of Transcultural Repositioning." UC Santa Barbara: Chicano Studies Institutes, 2004, retrieved from https://escholarship.org/uc/item/52q817fq

Gutierrez, Kris, Betsy Rymes, and Joanne Larson. "Script, Counterscript, and Underlife in the Classroom: James Brown versus Brown v. Board of Education." Harvard Educational Review, vol. 65, 1995, pp. 452-53.

Hackman, Judith and Paula Johnson. "Using Standardized Test Scores for Placement in College English Courses: A New Look at an Old Problem." Research in the Teaching of English, vol. 15, no. 3, 1981, pp. 275-9.

Hairston, Maxine. "Not All Errors are Created Equal: Nonacademic Readers in the Profession Respond to Lapses in Usage." College English, vol. 43, no. 8, 1981, pp. 794-806.

Hall, Jonathan. "The Translingual Challenge: Boundary Work in Rhetoric \& Composition, Second Language Writing, and WAC/WID." Across the 
Disciplines: A Journal of Language, Learning, and Academic Writing, vol. 15, no. 3, 2018, pp. 28-47.

Hanson, Joleen. "Moving Out of the Monolingual Comfort Zone and Into the Multilingual World: An Exercise for the Writing Classroom." Literacy as Translingual Practice: Between Communities and Classrooms, edited by Suresh Canagarajah, Routledge, 2013, pp. 207-14.

Harap, Henry. "The Most Common Grammatical Errors.” English Journal, vol. 19, 1930, pp. 440-6.

Harrington, Susanmarie, and Linda Adler-Kassner. “"The Dilemma That Still Counts': Basic Writing at a Political Crossroads.” Journal of Basic Writing, vol. 17, no. 2, 1998, pp. 1-24.

Harris, Joseph. "The Idea of Community in the Study of Writing." College Composition and Communication, vol. 40, 1989, pp. 11-22.

--- "Negotiating the Contact Zone." Journal of Basic Writing, vol. 14, no. 1, 1995, pp. $27-42$.

Hartwell, Patrick. "Grammar, Grammars, and the Teaching of Grammar." College English, vol. 47, no. 2, 1985, pp. 105-27.

Haswell, Richard. "Error and Change in College Student Writing." Written Communication, vol. 5, no. 9, 1988, pp. 479-99.

Heller, Monica. Bilingualism: A Social Approach. Palgrave Macmillan, 2007. hooks, bell. "Biography." www. berea.edu, https://www.berea.edu/appalachiancenter/appalachian-center-home/faculty-and-staff/bell-hooks/. Accessed 15 June 2020. 
Hopper, Paul. "Emergent Grammar." The New Psychology of Language: Cognitive and Functional Approaches to Language Structure Volume 1, edited by Michael Tomasello, L. Erlbaum, 1998, pp. 155-75.

Hornberger, Nancy. "Continua of Biliteracy." Review of Educational Research, vol. 59, no. 3, 1989, pp. 271-96.

Horner, Bruce. "Discoursing Basic Writing." College Composition and Communication, vol. 47, no. 2, 1996, pp. 199-222.

---. "Language Difference, Translinguality, and L2 Writing: Conflations, Confusions, and the Work of Writing." Reconciling Translingualism and Second Language Writing, edited by Tony Silva and Zhaozhe Wang, Routledge, 2020, pp. 55-66.

---. "Relocating Basic Writing." Journal of Basic Writing, vol. 30, no. 2, 2011, pp. 5-23.

---. "Rethinking the 'Sociality' of Error: Teaching Editing as Negotiation." Rhetoric Review, vol. 11, no. 1, 1992, pp. 172-99.

---. “Teaching Translingual Agency in Iteration: Rewriting Difference.” Crossing Divides: Exploring Translingual Writing Pedagogies and Programs, edited by Bruce Horner and Laura Tetreault, Utah State University Press, 2017, pp. 87-97.

---. "The 'Birth' of 'Basic Writing'." Representing the 'Other': Basic Writers and the Teaching of Basic Writing, edited by Bruce Horner and Min-Zhan Lu, National Council of Teachers of English, 1999, pp. 3-29.

Horner, Bruce, and Sara Alvarez. "Defining Translinguality." Literacy in Composition Studies, vol. 7, no. 2, 2009, pp. 1-30.

Horner, Bruce, and Min-Zhan Lu. “Resisting Monolingualism in 'English': Reading and Writing the Politics of Language." Rethinking English in Schools: A New and 
Constructive Stage, edited by Viv Ellis, Carol Fox, and Brian Street, Continuum, 2007, pp. 141-57.

---. "Working Rhetoric and Composition." College English, vol. 72, no. 5, 2010, pp. 47094.

Horner, Bruce and Laura Tetreault, editors. Crossing Divides: Exploring Translingual Writing Pedagogies and Programs. Utah State University Press, 2017.

Horner, Bruce and John Trimbur. "English-Only and U.S. Composition." College Composition and Communication, vol. 53, no. 4, 2002, pp. 594-630.

Horner, Bruce et al., "Language Difference in Writing: Toward a Translingual Approach." College English, vol. 73, no. 3, 2011, pp. 303-21.

---. "Translingual Approaches to Writing and Its Instruction." WPA-CompPile Research Bibliography, no. 28, 2019.

Hull, Glynda. "Acts of Wonderment: Fixing Mistakes and Correcting Errors." Facts, Artifacts, and Counterfacts: Theory and Method for a Reading and Writing Course, edited by David Bartholomae and Anthony Petrosky, Boynton/Cook, 1986, pp. 199-226.

---. "Research on Error and Correction." Perspectives on Research and Scholarship in Composition, edited by Ben McClelland and Timothy Donovan, Modern Language Association, 1985, pp. 162-84.

Hull, Glynda and Mike Rose. "Rethinking Remediation: Toward a Social-Cognitive Understanding of Problematic Reading and Writing." Written Communication, vol. 6 , no. 2,1989 , pp. 139-154. 
Inoue, Asao. "How Do We Language So People Stop Killing Each Other, or, What Do We Do about White Language Supremacy?" Conference on College of Composition and Communication, 14 March 2019, David Lawrence Conference Center, Pittsburgh, PA, Chair's Address.

---. "Writing Assessment as the Conditions for Translingual Approaches: An Argument for Fairer Assessments.” Crossing Divides: Exploring Translingual Writing Pedagogies and Programs, edited by Bruce Horner and Laura Tetreault, Utah State University Press, 2017, pp. 119-134.

Inoue, Asao et al. "Directed Self-Placement." WPA-CompPile Research Bibliographies, no. 16. http://comppile.org/wpa/bibliographies/Bib16/DSP.pdf. May 2011.

Izumi, Shinichi and Martha Bigelow. "Does Output Promote Noticing and Second Language Acquisition?” TESOL Quarterly, vol. 34, no. 2, 2000, pp. 239-278.

Jackson, Rachel C. "The People Who Live Here: Localizing Transrhetorical Texts in G1/Oklahoma Classrooms." Reworking English in Rhetoric and Composition: Global Interrogations, Local Interventions, edited by Bruce Horner and Karen Kopelson, Southern Illinois University Press, 2014, pp. 90-102.

Jolliffe, David. “The Moral Subject in College Composition: A Conceptual Framework and the Case of Harvard, 1865-1900.” College English, vol. 51, 1989, pp. 163-73.

Kafka, Tina. “A List of Non-Cognitive Assessment Instruments.” Community College Research Center, Columbia University, January 2016. https://ccrc.tc.columbia.edu/images/a-list-of-non-cognitive-assessmentinstruments.pdf 
"KHEAA- Administered Programs: Work Ready Kentucky Scholarship Program.” Kentucky Higher Education Assistance Authority. 2019, https://www.kheaa.com/website/kheaa/work_ready?main=1

Kiernan, Julia et al. "Negotiating Languages and Cultures: Enacting Translingualism through a Translation Assignment." Composition Studies, vol. 44, no. 1, 2016, pp. 89-107.

Kopelson, Karen. “Afterword: On the Politics of Not Paying Attention (and the Resistance of Resistance)." Reworking English in Rhetoric and Composition: Global Interrogations, Local Interventions, edited by Bruce Horner and Karen Kopelson, Southern Illinois University Press, 2014, pp. 207-18.

---. "Sp(1)itting Images; or, Back to the Future of (Rhetoric and?) Composition." College Composition and Communication, vol. 59, no. 4, 2008, pp. 750-80.

Kraemer, Don. "Servant Class: Basic Writers and Service Learning." Journal of Basic Writing, vol. 24, no. 2, 2005, pp. 92-109.

Krall-Lanoue, Aimee. ““And Yea I'm Venting, But Hey I'm Writing Isn't I’: A Translingual Approach to Error in a Multilingual Context." Literacy as Translingual Practice: Between Communities and Classrooms, edited by Suresh Canagarajah, Routledge, 2013, pp. 228-34.

Kramsch, Claire. "The Traffic in Meaning." Asia Pacific Journal of Education, vol. 26, no. 1, 2006, pp. 99-104.

Kretzschmar, William and Charles Meyer. "The Idea of Standard American English." Standard English: Codified Varieties Around the World, edited by Raymond Hickey, Cambridge University Press, 2012, pp. 139-58. 
Kroll, Barry. "Cognitive Egocentrism and the Problem of Audience Awareness in Written Discourse." Research in the Teaching of English, vol. 12, 1978, pp. 26981.

Kroll, Barry and John Schafer. "Error-Analysis and the Teaching of Composition." College Composition and Communication, vol. 29, no. 3, 1978, pp. 242-48.

Kubota, Ryuko. "The Multi/Plural Turn, Postcolonial Theory, and Neoliberal Multiculturalism.” Applied Linguistics, vol. 37, no. 4, 2016, pp. 474-94.

Lalicker, William. “A Basic Introduction to Basic Writing Program Structures: A Baseline and Five Alternatives.” BWe: Basic Writing e-Journal, 1999. https://bwe.ccny.cuny.edu/Issue\%201.2.html\#bill

---. "Enacting Translingual Writing Pedagogy: Structures and Challenges for Two Courses in Two Countries." Crossing Divides: Exploring Translingual Writing Pedagogies and Programs, edited by Bruce Horner and Laura Tetreault, Utah State University Press, 2017, pp. 51-69.

Laurence, Patricia. “Error's Endless Train: Why Students Don't Perceive Errors.” Journal of Basic Writing, vol. 1, no. 1, 1975, pp. 23-42.

Lea, Mary R., and Brian V. Street. "Student Writing in Higher Education: An Academic Literacies Approach." Studies in Higher Education, vol. 23, 1998, pp. 157-72.

---. "The ‘Academic Literacies' Model: Theory and Applications." Theory into Practice, vol. 45 , no. 4 , 2006 , pp. $368-77$.

Lees, Elaine O. ““The Exceptable Way of the Society': Stanley Fish's Theory of Reading and the Task of the Teacher." Reclaiming Pedagogy: The Rhetoric of the 
Classroom, edited by Patricia Donahue and Ellen Quandahl, Southern Illinois University Press, 1989, pp. 144-63.

---. "Proofreading as Reader: Errors as Embarrassments." A Sourcebook for Basic Writing Teachers, edited by Theresa Enos. Random, 1987, pp. 216-30.

Leonard, Donald and Jeanette Gilsdorf. “Language in Change: Academics' and Executives' Perceptions of Usage Errors.” The Journal of Business Communication, vol. 27, no. 2, 1990, pp. 137-58.

Lesley, Mellinee. "Exploring the Links between Critical Literacy and Developmental Reading." Journal of Adolescent \& Adult Literacy, vol. 45, no. 3, 2001, pp. 1809.

Leung, Constant, Roxy Harris, and Ben Rampton. "The Idealised Native Speaker, Reified Ethnicities, and Classroom Realities." TESOL Quarterly, vol. 31, no. 3, 1997, pp. $543-75$.

Lewiecki-Wilson, Cynthia et al. "Rhetoric and the Writer's Profile: Problematizing Directed Self-Placement.” Assessing Writing, vol. 7, no. 2, 2000, pp. 165-83.

Lewis Ketai, Rachel. "Race, Remediation, and Readiness: Reassessing the 'Self' in Directed Self-Placement." Race and Writing Assessment, edited by Asao Inoue and Mya Poe, Peter Lang, 2012, pp. 141-54.

Lillis, Theresa. The Sociolinguistics of Writing. Edinburgh University Press, 2013. Lillis, Theresa and Mary Scott. "Defining Academic Literacies Research: Issues of Epistemology, Ideology and Strategy." Journal of Applied Linguistics, vol. 4, 2007, pp. 5-32. 
Lippi-Green, Rosina. “Accent, Standard Language Ideology, and Discriminatory Pretext in the Courts." Language in Society, vol. 23, no. 2, 1994, pp. 163-98.

Li Wei. “Translanguaging and Code-Switching: What's the Difference?” Oxford University Press blog post, 9 May 2018.

Lorimer Leonard, Rebecca. "Moving Beyond Methodological Nationalism." Composition Studies, vol. 44, no. 1, 2016, pp. 127-30.

---. "Multilingual Writing as Rhetorical Attunement." College English, vol. 76, no. 3, 2014, pp. 227-47.

Lu, Min-Zhan. "Conflict and Struggle: The Enemies or Preconditions of Basic Writing?" College English, vol. 54, no. 8, 1992, pp. 887-913.

---. "From Silence to Words: Writing as Struggle." College English, vol. 49, 1987, pp. $437-48$.

---. 'Importing 'Science': Neutralizing Basic Writing. Representing the Other: Basic Writers and the Teaching of Basic Writing, by Bruce Horner and Min-Zhan Lu. National Council of Teachers of English, 1999, pp. 56-104.

---. "Living-English Work.” College English, vol. 68, no. 6, 2006, pp. 605-618.

---. "Metaphors Matter: Transcultural Literacy.” JAC, vol. 29, no. 1, 2009, pp. 285-93.

---. "Professing Multiculturalism: The Politics of Style in the Contact Zone." College Composition and Communication, vol. 45, no. 4, 1994, pp. 442-58.

---. "Redefining the Legacy of Mina Shaughnessy: A Critique of the Politics of Linguistic Innocence." Journal of Basic Writing, vol. 10, no. 1, 1991, pp. 26-40.

---. "Writing as Repositioning." The Journal of Education, vol. 172, no. 1, 1990, pp. 1821. 
Lu, Min-Zhan, and Bruce Horner. "Translingual Literacy, Language Difference, and Matters of Agency." College English, vol. 75, no. 6, 2013, pp. 582-607.

Lunsford, Andrea A. "Cognitive Development and the Basic Writer." College English, vol. 41 , no. 1,1979 , pp. $38-46$.

---. "The Content of Basic Writers' Essays." College Composition and Communication, vol. 31, no. 3, 1980, pp. 278-90.

Lunsford, Andrea and Karen Lunsford. “'Mistakes are a Fact of Life': A National Comparative Study." College Composition and Communication, vol. 59, no. 4, 2008, pp. $781-806$.

Lynde, Samuel Adams. "A Plea for the Under-Educated Veteran.” The English Journal, vol. 34, no. 3, 1945, pp. 153-4.

MacDonald, Michael and Williams DeGenaro. "Negotiating a Transcultural Ethos from the Ground Up in a Basic Writing Program.” Journal of Basic Writing, vol. 36, no. 1, 2017, pp. 25-55.

Mahala, Daniel. "Writing Utopias: Writing Across the Curriculum and the Promise of Reform." College English, vol. 53, 1991, pp. 773-89.

Makoni, Sinfree and Alistair Pennycook. Disinventing and Reconstituting Languages. Multilingual Matters, 2010.

Malcolm, Katie. "Disrupting Monolingual Ideologies in a Community College: A Translingual Studio Approach.” Crossing Divides: Exploring Translingual Writing Pedagogies and Programs, edited by Bruce Horner and Laura Tetreault, Utah State University Press, 2017, pp. 101-18.

Marx, Karl and Friedrich Engels. The German Ideology. International Publishers, 1932. 
Massey, Doreen. Space, Place, and Gender. University of Minnesota Press, 1994.

Matsuda, Paul Kei. "Basic Writing and Second Language Writers: Toward an Inclusive Definition.” Journal of Basic Writing, vol. 22, no. 2, 2003, pp. 67-89.

---. "Composition Studies and ESL Writing: A Disciplinary Division of Labor." College Composition and Communication, vol. 50, no. 4, 1999, pp. 699-721.

---. "It's the Wild West Out There: A New Linguistic Frontier in U.S. College Composition." Literacy as Translingual Practice: Between Communities and Classrooms, edited by Suresh Canagarajah, Routledge, 2013, pp. 128-138.

---. "The Lure of Translingual Writing." PMLA, vol. 129, no. 3, 2014, pp. 478-83.

---. "The Myth of Linguistic Homogeneity in U.S. College Composition." College English, vol. 68, no. 6, 2006, pp. 637-51.

McNenny, Gerri. "Writing Instruction and the Post-Remedial University: Setting the Scene for the Mainstreaming Debate in Basic Writing." Mainstreaming Basic Writers: Politics and Pedagogies of Access, edited by Gerri McNenny, Lawrence Erlbaum Associates, 2001, pp. 1-18.

Miller, Carolyn. “Genre as Social Action.” Quarterly Journal of Speech, vol. 70, 1984, pp. 151-67.

Milroy, James. "Language Ideologies and the Consequences of Standardization." Journal of Sociolinguistics, vol. 5, no. 4, 2001, pp. 530-55.

Milroy, James and Leslie Milroy. Authority in Language: Investigating Language Prescription and Standardisation. Routledge, 1985. 
Mlynarczyk, Rebecca Williams. "Storytelling and Academic Discourse: Including More Voices in the Conversation.” Journal of Basic Writing, vol. 33, no. 1, 2014, pp. 422.

Mutnick, Deborah. "The Strategic Value of Basic Writing: An Analysis of the Current Moment.” Journal of Basic Writing, vol. 19, no. 1, 2000, pp. 69-83.

---. Writing in an Alien World: Basic Writing and the Struggle for Equality in Higher Education. Heinemann, 1995.

National Council of Teachers of English. Position Statement Prepared by the NCTE Committee on Issues in ESL and Bilingual Education. National Council of Teachers of English. NCTE, 1981; updated 2008.

---. Resolution on Developing and Maintaining Fluency in More Than One Language. National Council of Teachers of English. NCTE, 1997; updated 2008.

---. Resolution on English as a Second Language and Bilingual Education. National Council of Teachers of English. NCTE, 1982; updated 2008.

---. Resolution on English as the "Official Language." National Council of Teachers of English. NCTE, 1986; updated 2008.

Nattinger, James. "Second Dialect and Second Language in the Composition Classroom." TESOL Quarterly, vol. 12, 1978, pp. 77-84.

Nordquist, Brice. "English Only through Disavowal: Linguistic Violence in Politics and Pedagogy." Reworking English in Rhetoric and Composition: Global Interrogations, Local Interventions, edited by Bruce Horner and Karen Kopelson, Southern Illinois University Press, 2014, pp. 49-63. 
Odell, Lee. "Measuring Changes in Intellectual Processes as One Dimension of Growth in Writing." Evaluating Writing: Describing, Measuring, Judging, edited by Charles R. Cooper and Lee Odell, NCTE, 1977, pp. 107-34.

Ohmann, Richard. "The Strange Case of Our Vanishing Literacy.” Politics of Letters. Wesleyan, 1987, pp. 230-35.

Olson, David. "Oral and Written Language and the Cognitive Processes of Children." Journal of Communication, vol. 27, no. 3, 1977, pp. 10-26.

---. "Oral Discourse in a World of Literacy." Research in the Teaching of English, vol. 41, no. 2, 2006, pp. 136-43.

Ong, Walter. Orality and Literacy: The Technologizing of the Word. 2nd ed, Routledge, 2002.

Otte, George and Rebecca Williams Mlynarczyk. Basic Writing. Parlor Press, 2010.

Parmegiani, Andrea. "Bridging Literacy Practices through Storytelling, Translanguaging, and an Ethnographic Partnership: A Case Study of Dominican Students at Bronx Community College.” Journal of Basic Writing, vol. 33, no. 2, 2014, pp. 23-51.

---. Using ESL Students' First Language to Promote College Success: Sneaking the Mother Tongue through the Backdoor. Routledge, 2019.

Pennycook, Alastair. "English as a Language Always in Translation.” European Journal of English Studies, vol. 12, 2008, pp. 33-47.

---. Language as a Local Practice. Routledge, 2010.

---. "The Myth of English as an International Language." Disinventing and Reconstituting Languages, edited by Sinfree Makoni and Alastair Pennycook, Multilingual Matters, 2006, pp. 90-115. 
Piaget, Jean. The Language and Thought of the Child. Harcourt, Brace, 1926.

Pine, Nancy. "Service Learning in a Basic Writing Class: A Best Case Scenario." Journal of Basic Writing, vol. 27, no. 2, 2008, pp. 29-55.

Pratt, Mary Louise. "Linguistic Utopias." The Linguistics of Writing: Arguments between Language and Literature, edited by Nigel Fabb, Derek Attridge, Alan Durant, and Colin MacCabe, Methuen, 1987, pp. 48-66.

--- "The Traffic in Meaning: Translation, Contagion, and Infiltration." Profession, 2002, pp. 25-36.

Prior, Paul, and Jody Shipka. "Chronotopic Lamination: Tracing the Contours of Literate Activity." Writing Selves, Writing Societies: Research from Activity Perspectives, edited by Charles Bazerman and David Russell, Fort Collins, 2003, pp. 180-238.

Purcell, Kristen et al. "The Impact of Digital Tools on Student Writing and How Writing is Taught in Schools." National Writing Project and Pew Research Center, 2013. https://www.pewinternet.org/wpcontent/uploads/sites/9/media/Files/Reports/2013/PIP_NWP-Writing-andTech.pdf

Ratcliffe, Krista. Rhetorical Listening: Identification, Gender, Whiteness. Southern Illinois University Press, 2005.

Ray, Brain and Connie Kendall Theado. “Composition's 'Global Turn’: Writing Instruction in Multilingual/Translingual and Transnational Contexts." Composition Studies, vol. 44, no. 1, 2016, pp. 10-12.

Reinheimer, David. "Validating Placement: Local Means, Multiple Measures.” Assessing Writing, vol. 12, no. 3, 2007, pp. 170-79. 
Ritter, Kelly. Before Shaughnessy: Basic Writing at Yale and Harvard, 1920-1960. Southern Illinois University Press, 2009.

Robinson, Heather, Jonathan Hall, and Nela Navarro. Translingual Identities and Transnational Realities in the U.S. College Classroom. Routledge, 2020.

Rodby, Judith. Appropriating Literacy: Writing and Reading in English as a Second Language. Boynton/Cook, 1992.

Romaine, Suzanne. Language in Society: An Introduction to Sociolinguistics. Oxford University Press, 2000.

Rose, Mike. Lives on the Boundary: The Struggles and Achievements of America's Underprepared. Free Press, 1989.

---. "Narrowing the Mind and Page: Remedial Writers and Cognitive Reductionism." College Composition and Communication, vol. 39, no. 3, 1988, pp. 267-302.

---. "The Language of Exclusion: Writing Instruction at the University.” College English, vol. 47 , no. 4, 1985, pp. 341-59.

---. Why School: Reclaiming Education for All of Us. The New Press, 2009.

Rouse, John. "The Politics of Composition." College English, vol. 41, no. 1, 1979, pp. 112.

Royer, Daniel and Roger Gilles. "Directed Self-Placement: An Attitude of Orientation. College Composition and Communication, vol. 50, no. 1, 1998, pp. 54-70.

---. "Introduction." Directed Self-Placement: Principles and Practices. Hampton Press, 2003, pp. 1-12. 
---. "The Pragmatist Foundations of Directed Self-Placement." Directed Self-Placement: Principles and Practices. Hampton Press, 2003, pp. 49-72.

---, editors. Directed Self-Placement: Principles and Practices. Hampton Press, 2003.

Royster, Jacqueline Jones. "When the First Voice You Hear Is Not Your Own." College Composition and Communication, vol. 47, 1996, pp. 29-40.

Ruecker, Todd. "Here They Do This, There They Do That: Latinas/Latinos Writing Across Institutions." College Composition and Communication, vol. 66, no. 1, 2014, pp. 91-119.

Salvatori, Mariolina Rizzi, editor. Pedagogy: Disturbing History, 1819-1929. University of Pittsburgh Press, 1996.

---. "Pedagogy: From the Periphery to the Center." Reclaiming Pedagogy: The Rhetoric of the Classroom, edited by Patricia Donahue and Ellen Quandahl, Southern Illinois University Press, 1989, pp. 17-34.

---. "The Dialogical Nature of Basic Reading and Writing." Facts, Artifacts, and Counterfacts: Theory and Method for a Reading and Writing Course, edited by David Bartholomae and Anthony Petrosky, Boynton/Cook Publishers, 1986, pp. $137-66$.

Santa, Tracy. Dead Letters: Error in Composition 1873-2004. Hampton Press, 2008.

Schmidt. Benno. The City University of New York: An Institution Adrift. Report of the Mayor's Advisory Task Force on The City University of New York. June 7, 1999. https://cdha.cuny.edu/items/show/2421 
Schreiber, Brooke and Missy Watson. "Translingualism $\neq$ code-meshing: A response to Gevers' 'Translingualism Revisited'.” Journal of Second Language Writing, vol. 42, 2018, pp. 94-97.

Scribner, Sylvia. "Literacy in Three Metaphors." American Journal of Education, vol. 93, no. 1,1984 , pp. 6-21.

Segall, Mary T. “Embracing a Porcupine: Redesigning a Writing Program.” Journal of Basic Writing, vol. 14, no. 2, 1995, pp. 38-47.

Shapiro, Shawna et al. "Teaching for Agency: From Appreciating Linguistic Diversity to Empowering Student Writers.” Composition Studies, vol. 44, no. 1, 2016, pp. 3152.

Shaughnessy, Mina P. Errors and Expectations : A Guide for the Teacher of Basic Writing. Oxford University Press, 1977.

---. “Introduction.” Journal of Basic Writing, vol. 1, 1975, pp. 3.

Sheils, Merrill. “Why Johnny Can’t Write.” Newsweek, 8 Dec. 1975, pp. 58.

Shor, Ira. "Our Apartheid: Writing Instruction \& Inequality.” Journal of Basic Writing, vol. 16, no. 1, 1997, pp. 91-104.

Silva, Tony and Zhaozhe Wang, editors. Reconciling Translingualism and Second Language Writing. Routledge, 2021.

Slevin, James. Introducing English: Essays in the Intellectual Work of Composition. University of Pittsburgh Press, 2001.

Smith, Jeff. “Students' Goals, Gatekeeping, and Some Questions of Ethics.” College English, vol. 59, no. 3, 1997, pp. 299-320. 
Smoke, Trudy. "Mainstreaming Writing: What Does This Mean for ESL Students?" Mainstreaming Basic Writers: Politics and Pedagogies of Access, edited by Gerri McNenny, Lawrence Erlbaum Associates, 2001, pp. 193-214.

Sohan, Vanessa. "Relocalized Listening." Reworking English in Rhetoric and Composition: Global Interrogations, Local Interventions, edited by Bruce Horner and Karen Kopelson, Southern Illinois University Press, 2014, pp. 191-206.

Soja, Edward. Postmodern Geographies: The Reassertion of Space in Critical Social Theory. Verso, 1989.

Soliday, Mary. “Class Dismissed.” College English, vol. 61, no. 6, 1999, pp. 731-41.

---. The Politics of Remediation: Institutional and Student Needs in Higher Education. University of Pittsburgh Press, 2002.

Spack, Ruth. America's Second Tongue: American Indian Education and the Ownership of English 1860-1900. University of Nebraska Press, 2002.

---. "The Rhetorical Construction of Multilingual Students." TESOL Quarterly, vol. 31, 1997, pp. 765-74.

Stanley, Sarah. "Noticing the Way: Translingual Possibility and Basic Writers." Journal of Basic Writing, vol. 32, no. 1, 2013, pp. 37-61.

Sternglass, Marilyn. Time to Know Them: A Longitudinal Study of Writing and Learning at the College Level. Lawrence Erlbaum Associates, 1997.

Stine, Linda. "Teaching Basic Writing in a Web-Enhanced Environment." Journal of Basic Writing, vol. 29, no. 1, 2010, pp. 33-55.

---. “The Best of Both Worlds: Teaching Basic Writers in Class and Online.” Journal of Basic Writing, vol. 23, no. 2, 2004, pp. 49-69. 
Street, Brian. Literacy in Theory and Practice. Cambridge University Press, 1984.

---. "What's 'New' in New Literacy Studies?' Current Issues in Comparative Education, vol. 5, no. 2, 2003, pp. 77-91.

Stygall, Gail. "Unraveling at Both Ends: Anti-Undergraduate Education, AntiAffirmative Action, and Basic Writing at Research Schools." Journal of Basic Writing, vol. 18, no. 2, 1999, pp. 4-22.

Sullivan, Patrick and Howard Tinberg, editors. What is 'College-Level' Writing? National Council of Teachers of English, 2006.

Sutton, Mark and Sally Chandler, editors. The Writing Studio Sampler: Stories About Change. University Press of Colorado, 2018.

Swales, John. "The Concept of a Discourse Community." Genre Analysis: English in Academic and Research Settings. Cambridge University Press, 1990, pp. 21-32.

Taylor, Marcy and Jennifer Holberg. “'Tales of Neglect and Sadism': Disciplinarity and the Figuring of the Graduate Student in Composition." College Composition and Communication, vol. 50, no. 4, 1999, pp. 607-25.

Taylor, Orlando. "Standard English as a Second Dialect?" English Today, vol. 1, no. 2, 1985, pp. 9-12.

Thaiss, Chris, and Terry Zawacki. Engaged Writers, Dynamic Disciplines: Research on the Academic Writing Life. Boynton/Cook Heinemann, 2006.

"The Biden Plan for Education Beyond High School." Biden Harris: Battle for the Soul of the Nation. https://joebiden.com/beyondhs/ 
The College Board's Report of the National Commission on Writing in America's Schools and Colleges. The Neglected ' $R$ ': The Need for a Writing Revolution. 2003._https://archive.nwp.org/cs/public/print/resource/2523

The National Commission on Excellence in Education. A Nation at Risk: The Imperative for Educational Reform. A Report to the Nation and the Secretary of Education. United States Department of Education, 1983.

Therborn, Göran. The Ideology of Power and the Power of Ideology. Verso, 1999.

Thornbury, Scott. "Reformulation and Reconstruction: Tasks that Promote 'Noticing." ELT Journal, vol. 51, no. 4, 1997, 326-335.

Tompkins, Patrick. "Directed Self-Placement in a Community College Context." Directed Self-Placement: Principles and Practices, edited by Daniel Royer and Roger Gilles, Hampton Press, 2003, pp. 193-206.

Toth, Christie. “Directed Self-Placement at 'Democracy's Open Door': Writing Placement and Social Justice in Community Colleges." Writing Assessment, Social Justice, and the Advancement of Opportunity, edited by Mya Poe, Asao Inoue, and Norbert Elliot, WAC Clearinghouse, 2018, pp. 137-70.

Trask, Haunani-Kay. "From a Native Daughter." Rereading America: Cultural Contexts for Critical Thinking and Writing, 2nd edition, edited by Gary Colombo, Robert Cullen, and Bonnie Lisle, Bedford, 1989, pp. 118-27.

Trimbur, John. "Beyond Cognition: The Voices in Inner Speech.” Rhetoric Review, vol. 5, no. 2, 1987, pp. 211-21.

---. "Essayist Literacy and the Rhetoric of Deproduction." Rhetoric Review, vol. 9, no. 1, 1990, pp. $72-86$. 
---. "Literacy and the Discourse of Crisis." The Politics of Writing Instruction:

Postsecondary. Edited by Richard Bullock. Heinemann, 1991, pp. 277-95.

---. "Translingualism and Close Reading." College English, vol. 78, no. 3, 2016, pp. 21927.

Troyka, Lynn. "Defining Basic Writers in Context." A Sourcebook for Basic Writing Teachers, edited by Theresa Enos, Random House, 1987, pp. 2-15.

---."Perspectives on Legacies and Literacy in the 1980s." College Composition and Communication, vol. 30, 1982, pp. 252-62.

Uehling, Karen. “The Conference on Basic Writing: 1980-2001.” Histories of Developmental Education, edited by Dana Britt Lundell and Jeanne L. Higbee, University of Minnesota's Center for Research on Developmental Education and Urban Literacy, 2002, pp. 47-58.

Vance, John. "Code-Meshing Meshed Codes: Some Complications and Possibilities." $J A C$, vol. 29 , no. $1 / 2,2009$, pp. 281-84.

Villanueva, Victor, Jr. Bootstraps: From an American Academic of Color. NCTE, 1993. Vygotsky, L.S. Mind in Society: The Development of Higher Psychological Processes. Harvard University Press, 1978.

Wall, Susan. "Writing, Reading, and Authority: A Case Study." Facts, Artifacts, and Counterfacts: Theory and Method for a Reading and Writing Course, edited by David Bartholomae and Anthony Petrosky, Boynton/Cook Publishers, 1986, pp. 105-36. 
Wall, Susan and Glynda Hull. "The Semantics of Error: What Do Teachers Know?" Writing and Response: Theory, Practice, and Research, edited by Chris Anson, NCTE, 1989, pp. 261-92.

Wang, Xiqiao. "Developing Translingual Disposition through a Writing Theory Cartoon Assignment.” Journal of Basic Writing, vol. 36, no. 1, 2017, pp. 56-86.

White, Edward M. “An Apologia for the Timed Impromptu Essay Test.” College Composition and Communication, vol. 46, no. 1, 1995, pp. 30-45.

---. "The Importance of Placement and Basic Studies: Helping Students Succeed Under the New Elitism.” Journal of Basic Writing, vol. 14, no. 2, 1995, pp. 75-84.

Wiley, Mark. "Mainstreaming and Other Experiments in a Learning Community." Mainstreaming Basic Writers: Politics and Pedagogies of Access, edited by Gerri McNenny, Lawrence Erlbaum Associates, 2001, pp. 173-192.

Williams, Bronwyn. "Why Johnny Can Never, Ever Read: The Perpetual Literacy Crisis and Student Identity." Journal of Adolescent and Adult Literacy, vol. 51, no. 2, 2007, pp. 178-82.

Williams, Joseph M. “The Phenomenology of Error.” College Composition and Communication, vol. 32, no. 2, 1981, pp. 152-68.

Witty, Paul. "Teaching the 3 R's in the Army." The English Journal, vol. 34, no. 3, 1945, pp. 132-6.

Wright, Laura, editor. The Development of Standard English, 1300-1800: Theories, Descriptions, Conflicts. Cambridge University Press, 2000.

"Writing Assessment: A Position Statement." CCCC Committee on Assessment, College Composition and Communication, vol. 46, no. 3, 1995, pp. 430-437. 
Yildiz, Yasemin. Beyond the Mother Tongue: The Postmonolingual Condition. Fordham University Press, 2012.

Youga, Janet, et al. "Illinois State University Developmental Freshman Program.” New Methods in College Writing Programs, edited by Paul Connolly and Teresa Vilardi. MLA, 1986, pp. 57-64.

Young, Vershawn Ashanti. "Call for Program Proposals: Performance-Rhetoric, Performance-Composition." Conference on College Composition and Communication, hosted by National Council of Teachers of English. https://cccc.ncte.org/cccc/conv/call-2019

---. “Nah, We Straight': An Argument Against Code Switching.” JAC, vol. 29, no. 1-2, 2009, pp. 29-46.

Young, Vershawn Ashanti, Edward Barrett, Y'Shanda Young Rivera, and Kim Brian Lovejoy. Other People's English: Code Meshing, Code-Switching, and African American Literacy. Teachers College Press, 2014. 


\title{
CURRICULUM VITAE
}

\author{
Rachel Rodriguez \\ 125 Quiet Wood Ct Louisville KY \\ rachel.rodriguez@louisville.edu \\ 443.867.0483
}

\section{Education}

Ph.D. in Rhetoric and Composition, University of Louisville, May 2021

Dissertation: A Translingual Approach to the Theory and Practice of Basic Writing Committee: Bruce Horner, Karen Kopelson, John Trimbur, Frank Kelderman

M.A. in English, University of Maine, 2011

Concentration in Gender and Literature

B.A. in English and Spanish, McDaniel College, 2009

Universitat de València, Spain, Spring 2008

International School of Budapest, Hungary, Spring 2007

\section{Research and Teaching Interests}

Language Difference

Composition Pedagogy

Basic Writing
Translingualism

Writing Centers

Alterity/Otherness

\section{Academic Appointments}

Assistant Director of the University Writing Center, Univ. of Louisville, 2018-2020

Graduate Teaching Assistant, University of Louisville, 2018-2020

Academic and Career Advisor, Chesapeake College, 2015-2017

Academic Support Writing Specialist, Chesapeake College, 2014-2017

Graduate Teaching Assistant, University of Maine, 2009-2011

Adjunct Instructor, Eastern Maine Community College, Husson University, University of Maine, and Chesapeake College, 2011-2017

TRiO Scientific Writing Instructor, University of Maine, 2011

\section{Publications}

\section{Peer Reviewed Publications}

"Engaging the Quiet Student: Digital Back-Channeling in the Composition

Classroom." Teaching English in the Two-Year College, vol. 48, no. 3, 2021, pp. 354-362. 
"The Unique Affordances of Plainness in George Eliot's Silas Marner and Middlemarch.” George Eliot - George Henry Lewes Studies, vol. 72, no. 1, 2020, pp. 34-54.

"Translingual Approaches to Writing and Its Instruction." Co-authored with Bruce Horner, Emily Yuko Cousins, Jaclyn Hilberg, N. Claire Jackson, and Alex Way. WPA-CompPile Research Bibliography, No. 28, 2019.

\section{Short Pieces}

"Embracing the Unknown: Tutoring a Virtual Dissertation Writing Retreat during COVID-19." Connecting Writing Centers Across Borders: A Blog of WLN: A Journal of Writing Center Scholarship, 17 July 2020.

"(Literally) Meeting Writers where they are at Community Literacy Sites.” University of Louisville University Writing Center Blog, 15 April 2019.

“The Ultimate To-Do List!” University of Louisville University Writing Center Blog, 18 Nov. 2018.

\section{Conference Presentations}

\section{National Presentations}

"Questioning Our Reification of 'Standards' in the Writing Classroom." Conference on College Composition and Communication. Accepted for April 2021.

"Sustaining Community Literacy Efforts through a Rhetoric of Respect." National Conference on Peer Tutoring in Writing. Virtual, October 29, 2020.

"Rhetoric on Display: Playing Indian at the Speed Museum." Rhetoric Society of America. May 22, 2020. (Canceled due to COVID-19).

"The Impact of the 'Traveling Tutor' Program on Campus Outreach and Tutor Development." International Writing Centers Association. Columbus, OH, October 18, 2019.

"Watching Our Words: A Corpus Analysis of Translingual Metaphors." Conference on College Composition and Communication. Pittsburgh, PA, March 16th, 2019.

"Using the Framework for Success in Postsecondary Writing as a Tool to Inform First-Year Composition Pedagogy and Ensure College-Readiness in Secondary Schools." Conference on College Composition and Communication. St. Louis, MO, March 23, 2012.

\section{Regional Presentations}

"Sea Change Ahead: An Interdisciplinary Writing Center's Strategic Navigation of a College-Wide Reorganization.” Southeastern Writing Center Association Conference, February 24, 2018. 
"Meeting Students Where They Are (Literally)." Maryland College Learning Center Association, March 23, 2017.

“Tutoring Our Online Students Ourselves.” Maryland College Learning Center Association, April 7, 2015.

"Communal Justice and Preservation in Wabanaki Tribal Legends." University of Maine English Graduate Conference, April 30, 2011.

"The Sexless Bildungsroman: Initiation Through Storytelling in Alice Munro's Lives of Girls and Women." Boston College Biennial English Graduate Conference, March 19, 2011.

"The Maddening Pursuit of Release and Reform in Charlotte Perkins Gilman's The Yellow W allpaper.” Maine Women's Studies Conference, November 6, 2010.

"Colbrand the Swiss." University of Maine English Graduate Conference, May 1, 2010.

Invited Talks

"Communicating with your Professors" at Family Scholar House on October 30, 2019.

"Balancing Roles as Students and GTAs" at the New Graduate Teaching Assistantship Orientation at the University of Louisville on August 13, 2019.

“Setting and Achieving Goals for Fall” at Family Scholar House on July 31, 2019.

"Keys to Communicating in College" at the TRiO College Success Boot Camp at Chesapeake College on August 10, 2016.

\section{Academic and Administrative Experience}

Assistant Director of the University Writing Center, UofL, 2018-2020

- Coordinated community literacy partnerships staffed by recruited volunteers

- Tutored and developed workshops, including annual Dissertation Writing Retreat

- Taught sessions of graduate course on Writing Center Theory and Practice

- Directed undergraduate internships and consultant mentor groups

Graduate Teaching Assistant, University of Louisville, 2018-2020

- Completed 8-week certification on online pedagogies

- Advanced Teaching Academy for Graduate Teaching Assistants

- Faculty Learning Community on Student Response Systems

Academic and Career Advisor, Chesapeake College, 2015-2017

- Advised new students in placement, selecting a major, and course scheduling

- Advised current students in career planning, transfer, and academic probation 
Academic Support Writing Specialist, Chesapeake College, 2014-2017

- Hired, trained, and mentored staff of 10-15 peer and professional writing tutors

- Managed tutoring center's scheduling and data tracking system

- Developed interdisciplinary synchronous online tutoring service

- Created "Traveling Tutor" program to replace embedded English tutoring

- Managed and created content for library and tutoring center's Facebook and YouTube

Graduate Teaching Assistant, University of Maine, 2009-2011

- Created and implemented a topics course on 17th century Native American rhetoric

\section{Courses Taught}

First Year Composition

- ENGL101, Introduction to College Writing, University of Louisville, Fall 2018

- ENGL102, Intermediate College Writing, University of Louisville, Spring 2019

- ENG101, Hybrid Format, Composition, Chesapeake College, Fall 2016

- ENG101, College Composition, University of Maine, Fall 2009 through Fall 2011

\section{Basic Writing}

- ENG094, PASS English, Chesapeake College, Fall 2015

- ENG105, Included Supplemental Lab, Eastern Maine Community College, Fall 2011

\section{Business and Scientific Writing}

- ENGL306, Business Writing, University of Louisville, Fall 2020

- Scientific Writing, UMaine TRiO Upward Bound, Summer 2011

\section{Literature}

- EH200, Approaches to Literature, Husson University, Spring 2012

\section{Rhetoric}

- EH124, Rhetoric and Composition II, Husson University, Spring 2012

\section{SAT Prep}

- SAT PREP, Continuing Education course, Chesapeake College, Spring 2017

- SAT/ACT Prep, UMaine TRiO Upward Bound, Summer 2011

\section{Tutoring Experience}

University of Louisville, 2018-2020 
- Consulted with undergraduates, graduates, and faculty in writing across all disciplines via in-person as well as virtual asynchronous appointments (WCOnline)

\section{Chesapeake College, 2014-2017}

- Consulted with undergraduates in writing across all disciplines via in-person as well as virtual synchronous appointments (TutorTrac \& Zoom)

- Organized weekly basketball study hall for men and women's teams and tutored athletes as a generalist in all subjects

- Tutored Spanish to English speakers and English to Spanish speakers

\section{Service}

English Representative on Graduate Student Council, UofL, 2018-2020

Ph.D. Liaison for English Graduate Organization, UofL, 2019-2020

WPA-GO Accessibility Task Force, 2018-2019

Secretary for English Graduate Organization, University of Louisville, 2017-2018

Developmental Education Committee, Chesapeake College, 2015-2017

Staff Assembly Representative (Elected Position), Chesapeake College, 2015-2017

Search Committee, Dean for Students and Learning, Chesapeake College, 2016

Wellness Committee, Chesapeake College, 2015-2016

Search Committee, TRiO Academic Coordinator, Chesapeake College, 2015

Editor of Literary Magazine The Beacon, Chesapeake College, 2014-2015

President of English Graduate Student Association, University of Maine, 2010-2011

\section{Honors and Awards}

University Fellowship Award, University of Louisville, 2017-2018 and 2020-2021

Travel Grant from Graduate Student Council, UofL, \$350, 2017-2019

Rookie Staff Member of the Year, Chesapeake College, 2015

Outstanding Graduate Student Award, University of Maine, 2011

Albert Morton Turner Prize for Best Critical Essay, University of Maine, 2011

\section{Professional Memberships}

National Council of Teachers of English (NCTE)

College Composition and Communication (CCC)

International Writing Centers Association (IWCA)

Southeastern Writing Center Association (SWCA)

Online Writing Centers Association (OWCA)

Kentucky Academy of Science (KAS)

Council of Writing Program Administrators Graduate Organization (WPA-GO)

\section{Languages}

Spanish; fluency in speaking, reading, and writing 